The architecture of the primary plant cell wall: the role of pectin reconsidered

Suzanne E. Broxterman 


\section{Thesis committee}

\section{Promotor}

Prof. Dr H.A. Schols

Personal chair at the Laboratory of Food Chemistry

Wageningen University \& Research

\section{Other members:}

Prof. Dr M.E. Hendrickx, KU Leuven, Belgium

Dr M.-C. Ralet, INRA, Nantes, France

Prof. Dr R.G.F. Visser, Wageningen University \& Research

Prof. Dr R.P. de Vries, Westerdijk Fungal Biodiversity Institute, Utrecht/ Utrecht University

This research was conducted under the auspices of the Graduate School VLAG (Advanced Studies in Food Technology, Agrobiotechnology, Nutrition and Health sciences). 


\title{
The architecture of the primary plant cell wall: the role of pectin reconsidered
}

\author{
Suzanne E. Broxterman
}

Thesis

submitted in fulfilment of the requirements for the degree of doctor at Wageningen University

by the authority of the Rector Magnificus

Prof. Dr A.P.J. Mol, in the presence of the

Thesis Committee appointed by the Academic Board to be defended in public on Friday 7 September 2018 at 4 p.m. in the Aula 
Suzanne E. Broxterman

The architecture of the primary plant cell wall: the role of pectin reconsidered 164 pages

PhD thesis, Wageningen University, Wageningen, The Netherlands (2018)

With references, with summary in English

ISBN: 978-94-6343-781-3

DOI: https://doi.org/10.18174/451289 


\section{Abstract}

The primary plant cell wall is composed of the polysaccharide classes pectin, hemicellulose and cellulose, and together, all these polysaccharides form a complex network. However, it is still poorly understood how these polysaccharides together build up the complex primary plant cell wall network. This research aimed at a further understanding of the architecture of the plant cell wall, predominantly focussing on pectin and its potential interactions with (hemi)cellulose.

To overcome the insoluble nature of hemicellulose, cellulose and part of all pectin in muro, methods for targeted disruption of the cell wall were developed. The residue after sequential alkali-water extractions still contained $31 \%$ of all pectin in carrot. Half of this pectin was released by glucanase digestion of the alkali residue, and was proposed to be present in a covalently linked pectin-cellulose complex. The proposed pectin-cellulose complex was not found in tomato and strawberry, making this a unique characteristic of the carrot cell wall.

Planetary ball milling was introduced as a suitable tool to enhance extraction yields with limited depolymerisation of cell wall polysaccharides, allowing a more representative characterisation of cell wall polysaccharides including alkali-labile substituents. Milling followed by water extraction increased the extractability to $75 \%$ of all initially insoluble uronic acid and $60 \%$ of all initially insoluble xylose. It was proposed that a covalently linked pectin-xylan complex was released from the tomato cell wall, containing $18 \%$ of solubilised uronic acid, next to $48 \%$ of all xylose. For the sources studied in this research, the proposed pectin-xylan complex was a unique feature of the tomato cell wall.

Alternatively, planetary ball milling followed by LiCl-DMSO extraction also solubilised cellulose, next to an increased extractability of pectin and hemicellulose. Whereas $\mathrm{LiCl}-$ DMSO solubilised pectin with a low HG:RG-I ratio, the HG:RG-I ratio for the subsequent buffer extractions increased by a factor 2-7. Characterisation of both LiCl-DMSO soluble and insoluble fractions showed methyl-esterified and highly acetylated pectin, showing the potential of characterising methyl-esterification and acetylation of both soluble and insoluble pectin by using LiCl-DMSO. For both carrot and strawberry, pectin homogalacturonan regions were found to be highly acetylated. For carrot, also the additional part of water soluble pectin solubilised by heat processing contained highly methyl-esterified, acetylated $\mathrm{HG}$ regions.

More firmly associated pectin populations were relatively higher in RG-I, for all different extraction procedures used. This was observed for pectin extracted after heat processing, sequential water-alkaline extractions and milling followed by water or LiCl-DMSO extraction. Finally, the distribution of pectin over different pectin domains was discussed, and compared between sources. 



\section{Table of contents}

$\begin{array}{lll}\text { Chapter } 1 \text { General introduction } & 1\end{array}$

Chapter 2 Acetylated pectins in raw and heat processed carrots 29

Chapter 3 Interactions between pectin and cellulose in carrot primary 53 plant cell walls primary plant cell walls

Chapter 5 The solubility of primary plant cell wall polysaccharides in 105 LiCl-DMSO

$\begin{array}{lll}\text { Chapter } 6 \text { General discussion } & 129\end{array}$

$\begin{array}{ll}\text { Summary } & 150\end{array}$

$\begin{array}{ll}\text { Samenvatting } & 153\end{array}$

$\begin{array}{ll}\text { Acknowledgements } & 157\end{array}$

$\begin{array}{ll}\text { About the author } & 161\end{array}$ 



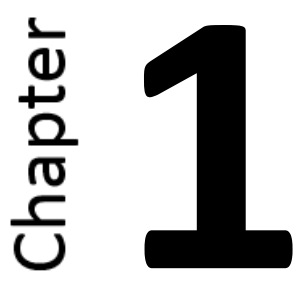




\subsection{Background}

The primary plant cell wall is essential for strength, growth and development of the plant $[1,2]$. Primary plant cell walls are generally composed of roughly $35 \%$ pectin, $30 \%$ cellulose, $30 \%$ hemicellulose, and $5 \%$ protein [3]. In some fruit cell walls, pectin levels might be even higher, with levels up to roughly half of the polymers present in the fruit cell wall [4]. Although macromolecular compositions of plant cell walls are quite well described, many questions remain unanswered on how these polysaccharides together form networks in the plant cell wall. Furthermore it is not fully understood yet which structural features of plant cell wall polysaccharides determine the precise architecture and potential interactions between cell wall polysaccharides. In this research, the cell wall architecture of carrot, tomato and strawberry was studied, more specifically focussed on the role of pectin in the cell wall.

In fruits and vegetables, pectin is of key importance for texture, and effects of (heat) processing on fruit and vegetable texture are therefore related to pectin structural changes. Part of this research was carried out within the EU-project OPTIFEL: Optimised food products for elderly people. The aim of the project was to develop protein- and fibre-enriched food products, and therefore understanding of fruit and vegetable texture and cell wall architecture in relation to processing was highly relevant.

\subsection{Plant cell wall polysaccharides}

The primary plant cell wall is composed of the polysaccharides pectin, hemicellulose and cellulose and these polysaccharides are schematically presented in Figure 1.1.

\subsubsection{Pectin}

\section{Role in plant functionality}

Pectin is present in both the middle lamella and the primary cell wall [1]. In contrast to the cell wall, the middle lamella are predominately composed of pectin. Related to its charged nature, pectin is involved in regulation of ion transport and porosity of walls, hereby controlling the permeability of cell walls and determining the water holding capacity [3]. Furthermore pectin is important for wall integrity signalling networks and cell-cell adhesion $[5,6]$. In fruits and vegetables, pectin levels are higher than in many other dicot tissues, and pectin properties determine important parameters such as texture and firmness [4, 7].

\section{Structural characteristics}

Pectin consists predominantly of the homogalacturonan (HG) and rhamnogalacturonan I (RG-I) structural elements, as depicted in Figure 1.1. In general, pectin is composed of 
roughly $65 \% \mathrm{HG}, 25 \% \mathrm{RG}-\mathrm{I}$, and the remaining $10 \%$ is found as rhamnogalacturonan II (RG-II) [8].

The HG backbone is solely composed of $\alpha$-(1 $\rightarrow 4)$-linked galacturonic acid (GalA) residues and generally has a length of 60-100 GalA residues $[9,10]$. The GalA residues in the HG backbone can be methyl-esterified and/or acetylated. GalA residues can be methyl-esterified at its 0-6 position. The degree of methyl-esterification (DM) and the distribution of methyl-esters depends on the source, location in the plant and the stage of ripening. Pectin is deposited in the plant cell wall with a very high DM (80-90\%), and the DM will decrease upon ripening in muro by endogenous pectin methyl esterases (PMEs) [4, 11]. Furthermore pectin is found in the middle lamella with a low DM $[12,13]$.

By lowering the DM, $\mathrm{Ca}^{2+}$-based cross-linking between pectin chains is enhanced within the egg-box model. It is proposed that 6-14 adjacent non methyl-esterified GalA residues are required for cross-linking, hereby leading to an increased viscosity [14, 15]. Next to methyl-esterification, galacturonic acid residues might also be acetylated. Whereas acetylation of galacturonic acid (GalA) residues in RG-I is common, acetylation of GalA residues in HG is less frequently observed. So far only pectins from specific origin, e.g. potato, sugar beet and chicory pulp are found to be substantially acetylated on the homogalacturonan region [16-18]. Acetylation can be found on both the 0-2 and 0-3 position of galacturonic acid [19, 20].

The RG-I backbone is composed of alternating [ $\rightarrow 4)-\alpha-G a l A-(1 \rightarrow 2)-\alpha-R h a-(1 \rightarrow]$ residues [1], and reported values for segments composed of this disaccharide are as high as 100 repeats [21]. High variation is observed in RG-I side chain length. Between $20 \%$ and $80 \%$ of all rhamnose residues in the RG-I backbone are substituted with side chains [21]. Side chains length vary from monomeric residues to much longer side chains. For soy galactan, the side chain length ranged from DP 1-47, with an average of approximately 29 residues [22, 23]. For potato, very long galactan side chains up to DP 40 were reported [24]. The GalA residues in RG-I segments are presumed not to be methyl-esterified [3, 25]. The rhamnose residues in RG-I can be substituted at the O-4 position with neutral sugar side chains, composed of arabinose (Ara) and galactose (Gal) [3]. Side chains are found with many variations, either composed of single or more residues, and can be divided in arabinans, galactans and arabinogalactans type I and II. Arabinans are composed of $\alpha-(1 \rightarrow 5)$-linked arabinose units, that can be substituted with $(1 \rightarrow 2)$-linked or $(1 \rightarrow 3)$-linked arabinose side chains. Galactans are composed of $\beta$-(1 $\rightarrow 4)$-linked Gal residues [8]. The arabinogalactans (AG) differ in their binding type with a $\beta$-(1 $\rightarrow 4)$-linked galactan backbone substituted by Ara and/or Gal residues at 0-3 and 0-6 of the galactose residue respectively, in Type I AG. Type II arabinogalactans are composed of a $\beta-(1 \rightarrow 3)$-linked backbone which might be branched with $\beta-(1 \rightarrow 6)$ Gal residues $[1,3]$. Type I arabinogalactans are associated with pectic 
polysaccharides. Type II arabinogalactans are part of arabinogalactan proteins (AGP's), although interactions between AGP and pectin by Type II AG have been suggested [26-28]. Next to HG and RG-I, pectin might be composed of RG-II and xylogalacturonan (XGA). Rhamnogalacturonan II (RG-II) is a structurally very complex element, composed of a GalA backbone and substituted with rare sugars such as 2-O-methyl xylose, 2-O-methyl fucose and aceric acid. RG-II is present in all plants and levels are typically low, although exceptions are found in pumpkin and grape-derived wine [29, 30]. Although RG-II is less frequently included in pectin studies than HG and RG-I, it seems of key importance to plant growth since decreased RG-II levels were shown to have major effects on inhibiting plant growth [31].

In XGA, GalA residues are substituted with $\beta$ - $(1 \rightarrow 3)$-xylose residues. The presence of xylogalacturonan does not seem to be universal but was reported in quite many sources such as apple, watermelon, onion, potato and pear [32, 33].

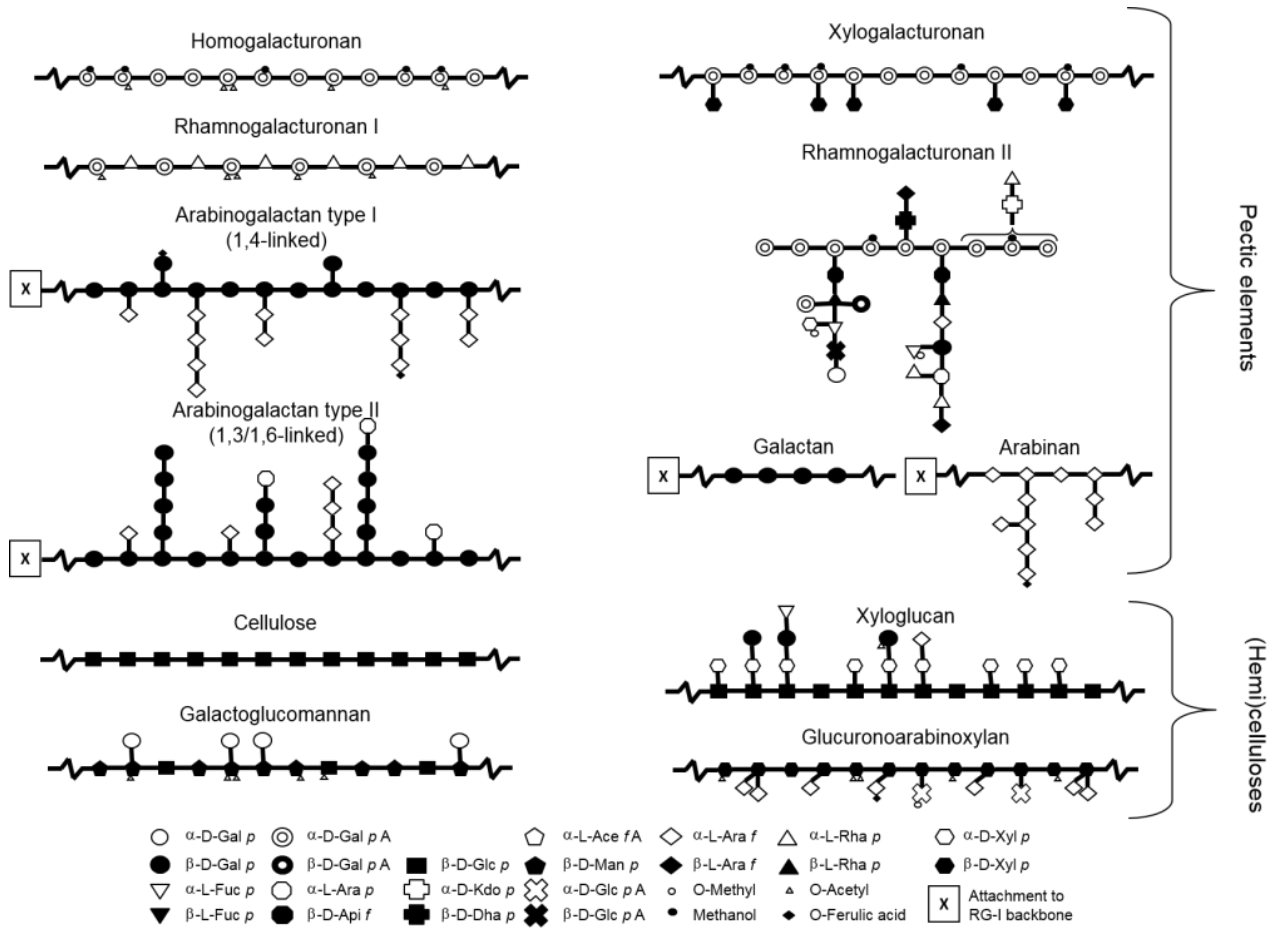

Figure 1.1 Schematic structures of plant cell wall polysaccharides [34]. 


\subsubsection{Hemicellulose}

The group of hemicelluloses are divided in xyloglucans, xylans and mannans.

Role in plant functionality

The functional role of hemicelluloses in the primary plant cell wall is less extensively characterised than the functional role of pectin. The most important role of hemicellulose is to strengthen primary plant cell walls, by their interactions with cellulose [35]. Both xyloglucan and xylan are prone to adsorb to cellulose by their similarities in backbone structures, since all are composed of $\beta(1 \rightarrow 4)$-linked glycopyranose rings [36, 37]. Furthermore also xyloglucan oligomers are reported to have signalling roles in plan defence, next to pectin oligosaccharides [35]

\section{Structural characteristics}

In dicot primary plant cell walls, xyloglucan (XG) is the major hemicellulosic polysaccharide [38]. XG is composed of a cellulose-like $\beta$ - $(1 \rightarrow 4)$-linked glucose (Glc) backbone branched at 0-6 by xylose residues. The xylose residues can be substituted at 0-2 with a Gal residue (L) or an Ara residue (S). Gal can be further substituted with a fucose residue (F), and Gal, Ara and Glc residues can be acetylated $[35,39,40]$. Whereas in xyloglucan typically 3 out of 4 glucose units are substituted to yield XXXG-type polymer substitution, xyloglucans from Solanaceous plants (e.g. tomato) are characterised by XXGG-type polymer substitution [41]. Less substituted xyloglucans are less soluble, and this might be related to functionality in the cell wall [35].

Xylans are build up from a backbone of $\beta$ - $(1 \rightarrow 4)$-linked xylose residues. The xylose residues of the backbone can be substituted at 0-2 or 0-3 with Ara, glucuronic acid (GlcA) (or its 4-O-methyl derivative) and acetyl groups [35]. Whereas xylans in monocotyledonous plant are primarily composed of arabinoxylans $(A X)$, glucuronoarabinoxylans (GAX) have been reported in dicotyledonous plants such as olive and tomato [35, 42, 43]. The group of mannans is divided in galacto- and glucomannans. Whereas galactomannans are entirely composed of a $\beta$ - $(1 \rightarrow 4)$-linked mannose backbones that can be substituted with galactose, glucomannans are composed of a backbone of both mannose and glucose. Mannans are often present as seed storage compounds, but mannans are also present in plant cell walls with highly variable levels between sources [35]. Mannans are often acetylated [35].

Cell walls can be divided in type I and type II walls. Type I walls are found in all dicots and about half of the monocots. In the other monocots, such as grasses, type II walls are found. The main difference between these types is found in the cellulose cross-linking glycans, which are xyloglucans in type I cell walls and arabinoxylans in type II walls $[35,44]$. The sources studied in our research belong to the dicots and therefore contain type I cell walls. 


\subsubsection{Cellulose}

\section{Role in plant functionality}

Roughly $30 \%$ of the primary plant cell wall is composed of cellulose, the most rigid and inaccessible polysaccharide in the cell wall. The cellulose microfibrils provide strength to the plant cell wall [45].

\section{Structural characteristics}

Cellulose is composed of a $\beta$ - $(1 \rightarrow 4)$-linked backbone composed of glucose residues. Glucan chains are organised into microfibrils: strong, insoluble structures held together by intra- and intermolecular hydrogen-bonds [45]. Microfibrils are partially amorphous and partially crystalline, and the crystallinity can be expressed by the crystallinity index ( $\mathrm{Cl})$. The $\mathrm{Cl}$ of primary cell wall cellulose was $42 \%$ for sugar beet, $38 \%$ for apple and $40 \%$ for Arabidopsis thaliana [46]. In contrast, the secondary cell wall has a more dense, organised packing of cellulose with a higher crystallinity $[47,48]$.

\subsubsection{Cell wall polysaccharides in carrot, tomato and strawberry}

The research presented in this thesis primarily aimed at characterising potential interactions in the primary plant cell wall of fruits and vegetables. As will be discussed in more detail in section 1.4, most of the primary plant cell models indicate a dominant role for hemicellulose. Therefore it was chosen to study the cell wall architecture of carrot, tomato and strawberry, 3 sources with a different hemicellulose content and composition $[49,50]$. The cell wall polysaccharides of carrot and tomato were previously fractionated and characterised according to classical fractionation schemes including water, chelating agent and sequential alkali extractions by Houben et al [49]. Water soluble, chelating agent soluble and mild alkali soluble populations were dominated by pectin, and taken together these fractions represented $83 \%$ and $65 \%$ of all uronic acid in the Alcohol Insoluble Solids (AIS) for carrot and tomato respectively. For carrot, RG-I levels were highest in mild alkali extracts while this trend was not so clear for tomato. The carrot $4 \mathrm{M} \mathrm{KOH}$ extract was composed of both pectin and hemicellulose whereas the tomato $4 \mathrm{M} \mathrm{KOH}$ extract was dominated by Glc and XYl, indicating that xyloglucan levels were higher in tomato than in carrot. Values of pectic and hemicellulosic monosaccharides remaining in the residue were not reported [49]. Rather similar extraction protocols showed that also for strawberry, water soluble, chelating agent soluble and mild alkali soluble populations were dominated by pectin. However, substantial GalA levels were found in the $1 \mathrm{M} \mathrm{KOH}$ extract ( $27 \mathrm{~mol} \%$ ) and the residue after $4 \mathrm{M} \mathrm{KOH}(23 \mathrm{~mol} \%)$, indicating that substantial part of pectin was not easily extractable [51]. 


\subsection{Plant cell wall proteins}

Next to polysaccharides, the plant cell wall is composed of $\sim 5-10 \%$ proteins $[3,52]$. Cell wall proteins are typically hydroxyproline-rich glycoproteins (HRGPs), a family of plant cell wall proteins that function in diverse aspects of plant growth and development. This family consists of at least three members: highly glycosylated, soluble arabinogalactan proteins (AGPs), moderately glycosylated, insoluble extensins (EXTs), and lightly glycosylated proline-rich proteins (PRPs) [53]. Next to structural proteins, many enzyme proteins involved in developmental and ripening-related processes are present in the cell wall [54].

\subsection{History and development of cell wall models}

It can be safely stated that the Keegstra/Albersheim model "everything is covalently linked" is the first widely-discussed model of the primary plant cell wall [55]. The model proposed a high level of cross-linking in the cell wall with proposed covalent linkages between pectin, hemicellulose and glycoproteins, and hydrogen bonding between xyloglucans and cellulose microfibrils, as depicted in Figure 1.2A. However, over time attempts to prove the validity of the Keegstra model failed, and a new model with a lower degree of cross-linking was proposed.

An alternative model proposed a load-bearing hemicellulose-cellulose network with a dominant role for xyloglucan, often referred to as the "tethered network model"(Figure 1.2B) [38]. Xyloglucan has a tethering role in connecting cellulose microfibrils. Despite its substitution, xyloglucan is prone to adsorb to cellulose microfibrils and act as a tether between these microfibrils due to the similarity with the cellulose backbone conformation. Although not frequently discussed for type I cell walls, also xylans are known to adsorb to cellulose microfibrils $[56,57]$. In the tethered network model, pectin is considered as a separate, co-existing network $[52,58]$. Cell wall proteins were believed to form the third, separate, co-existing network. Some speculations were made on interactions between the pectin and the hemicellulose-cellulose network, but those interactions were not so clearly specified and believed to be of non-covalent nature [38]. Up to now, this so-called tethered network model is a common depiction on the architecture of the primary plant cell wall.

Although less frequently discussed, also the multicoat model and the stratified wall model (Figure 1.2C, 1.2D) were introduced shortly after the tethered network model, and are considered worth mentioning. Both models propose a high degree of cross-linking between pectin, hemicellulose and cellulose, but in a different way than the Keegstra-model and the tethered network model. 


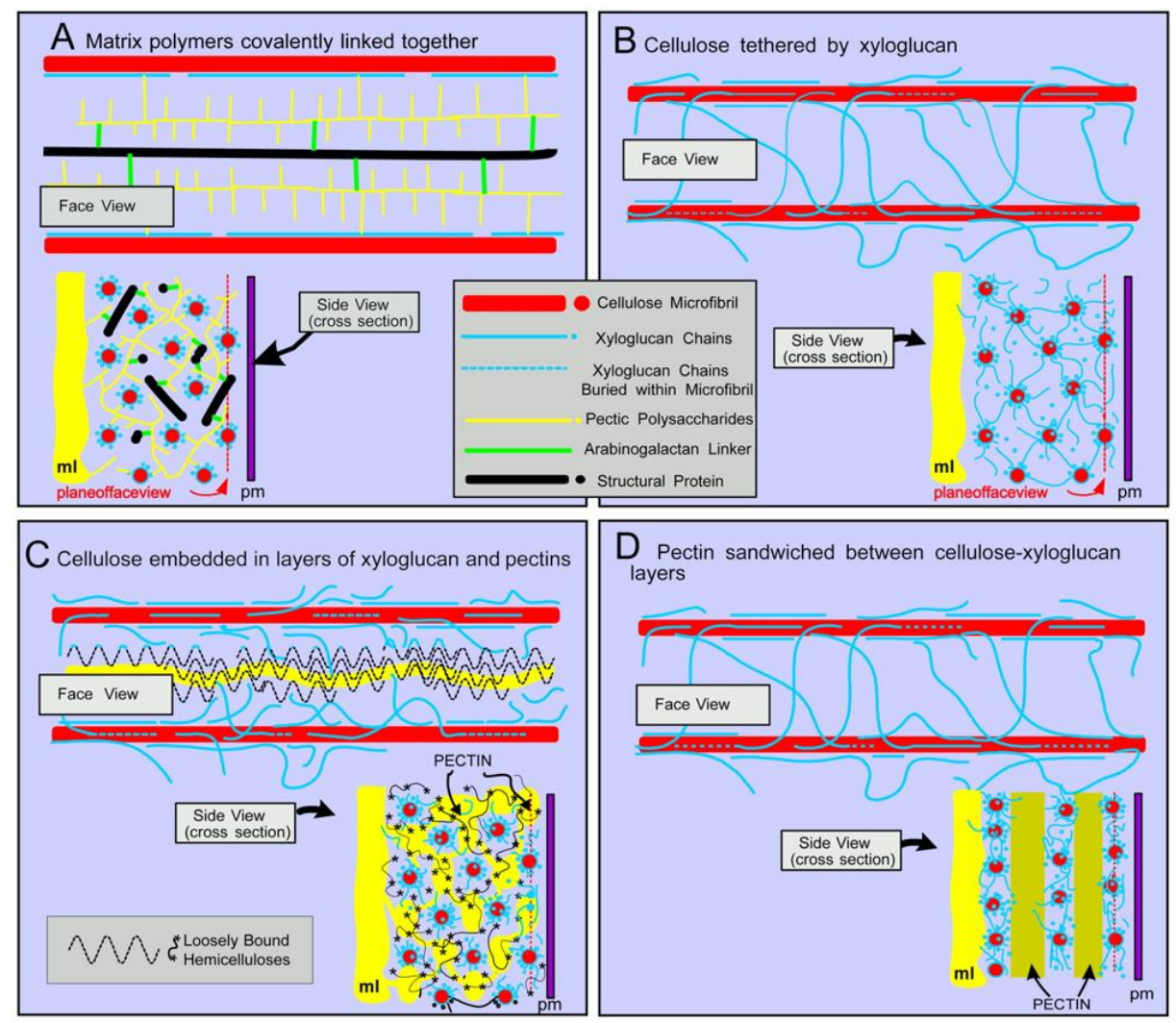

Figure 1.2 Structural representation of cell wall models [59]. (A) "All matrix polysaccharides are connected", according to Keegstra [55]; (B) Tethered network model, according to Fry [60], Hayashi [52] and McCann \& Roberts [61]; (C) The "multicoat" model according to Talbott and Ray [62]; (D) The "stratified" wall model according to Ha et al. [63]. Pm, plasma membrane; ml, middle lamella.

The "multicoat" model of Talbott and Ray [62] proposed that cellulose is coated with successively less tightly bound layers of matrix polysaccharides. XG is closest to the microfibrils followed by AG layers, and these layers might form non-covalent associations. The "stratified" wall model of $\mathrm{Ha}$ et al [63] proposed that pectic polysaccharides separate cellulose-xyloglucan lamella, based on differences of rigidity of the different cell wall polysaccharides.

Contrasting to the models presented above, the dominant role of xyloglucan in cell wall models was questioned in more recent years. Dick-Pérez et al showed by solid-state NMR that only a small portion of the cellulose surface is coated with xyloglucan [64]. Not only xyloglucan, but also pectin was present in the close vicinity of the cellulose microfibrils and perhaps interacting with these microfibrils. Another argument to question the dominant role of xyloglucan was found in the ability of pectins RG-I regions to adsorb to cellulose in 
vitro, showing that not only xyloglucan is able to adsorb to cellulose [65]. In yet another study, Arabidopsis mutants lacking xyloglucan showed only minor growth reduction, suggesting no requirement for XG [66]. These observations were addressed in the review from Höfte et al [67], where it was discussed that perhaps pectate cross-links have a more dominant role than often thought in plant growth.

\subsection{Cross-links involved in the primary plant cell wall}

\subsubsection{Experimental approaches to study polysaccharide interactions}

One of the major challenges in analysing cross-links between cell wall polysaccharides is the insoluble nature of hemicellulose, cellulose and part of the pectin in muro. Therefore, the most common experimental approach is using targeted disruption of hypothesized cross-links to solubilise specific populations. A major part of the literature on cross-linked polymers in plant cell walls uses co-extraction and/or co-chromatography [68].

Co-extraction typically includes extraction of pectin and other polymers under conditions that would be expected to solubilise only one of them. The co-solubilising polymer is expected to co-solubilise only by being linked with a solvent-stable linkage. Perhaps the most commonly used approach of co-extraction is using sequential alkaline extractions, due to the ability of alkaline solvents to dissolve pectin and subsequently hemicellulose by increasing the alkali strength, resulting in a cellulose-rich residue. Alkaline extractions are typically preceded by buffer, water or chelating agent extractions, since a substantial part of pectin is known to be extractable by these solvents [69]. Whereas mild alkaline extractions are hypothesized to solubilise ester-bound pectins, hemicelluloses are hypothesized to be solubilised by disruption of the $\mathrm{H}$-bonds between hemicellulose and cellulose. Furthermore strong alkaline conditions $(\geq 4 \mathrm{M})$ causes swelling of cellulose microfibrils [49, 69-71].

Co-chromatography is characterised by co-elution of solubilised pectins along with the other soluble polymers under conditions that ought to separate the two polymers if they were not covalently linked to each other. Anion exchange chromatography (AEC) is the most widely used technique, since it enables studies on cross-links between neutral and acidic polymers. Elution of neutral polymers in the part of the gradient where only acidic polymers are expected to elute is often one of the arguments for covalent cross-links between different polymer populations.

Additional to co-extraction and co-chromatography, disruption of proposed cross-links by enzymatic degradation has shown to be a suitable method to characterise interactions between polymers.

All approaches mentioned above require knowledge of the substrate: Co-extraction requires knowledge on solubility and stability of polymers in the chosen solvent, and 
co-chromatography requires structural knowledge on all elements determining elution behaviour. Relating the activity of purified glycosidases to cross-links also requires structural knowledge of the substrate, and the availability of purified, well-characterised enzymes.

Polysaccharide localisation

As an alternative approach, localisation of cell wall polysaccharides in plant cells was studied by using specific antibodies in combination with electron microscopy. An advantage of this technique is that it allows polymer allocation within a cell, and hereby also allows polymer differentiation between different types of tissues [72]. As an example, the LM7 pectic HG epitope can be used to localise HG regions, but many other epitopes towards other different pectin and hemicellulose structural elements have been described [73]. Studies using tomato extracts indeed showed the presence of the LM7 pectic HG epitope in specific regions as pectin is related to cell adhesion due to its presence in middle lamella [72].

\subsubsection{Overview of reported cross-links}

Although only a limited number of cell wall models exist that include all cell wall polymers, quite a number of cross-links between several cell wall elements were reported. An overview of frequently discussed cross-links between different classes of cell wall polymers is presented in Table 1.1. 
Table 1.1 Overview of most reported cross-links between cell wall polymers.

\begin{tabular}{|c|c|c|c|c|}
\hline & $\begin{array}{l}\text { Proposed cross- } \\
\text { linked polymers }\end{array}$ & Source & $\begin{array}{l}\text { (Suggested) nature of } \\
\text { the interaction }\end{array}$ & Reference \\
\hline & \multicolumn{4}{|c|}{ Interactions between different types of polysaccharides } \\
\hline 1 & $\begin{array}{l}\text { Xylan/xyloglucan- } \\
\text { cellulose }\end{array}$ & Generally present & Adsorption by $\mathrm{H}$-bonds & $\begin{array}{l}{[37,40,} \\
52,74]\end{array}$ \\
\hline 2 & Pectin-xyloglucan & $\begin{array}{l}\text { Arabidopsis, sycamore, } \\
\text { rose, tomato, spinach, } \\
\text { maize and barley }\end{array}$ & Covalent linkage & [75] \\
\hline 3 & Pectin-xylan & $\begin{array}{l}\text { Arabidopsis seed coat } \\
\text { mucilage }\end{array}$ & $\begin{array}{l}\text { Covalent: RG-I } \\
\text { backbone-xylan }\end{array}$ & [76] \\
\hline 4 & Pectin-cellulose & Arabidopsis & - & {$[64,77]$} \\
\hline 5 & $\begin{array}{l}\text { Xylan-xyloglucan- } \\
\text { pectin }\end{array}$ & Cauliflower stems & Covalent linkage & [78] \\
\hline 6 & Pectin-pectin, xylan & $\begin{array}{l}\text { Sugar beet pulp, } \\
\text { grasses, spinach, pine, } \\
\text { water chestnuts }\end{array}$ & $\begin{array}{l}\text { Covalent ferulic acid } \\
\text { dimer }\end{array}$ & [79-83] \\
\hline 7 & Pectin-cellulose & Sugar beet, potato & Adsorption by $\mathrm{H}$-bonds & [65] \\
\hline 8 & Pectin-cellulose & Plum, pear & $\begin{array}{l}\text { Covalent: Cellobiose- } \\
\text { GalA }\end{array}$ & [84] \\
\hline 9 & Pectin-xyloglucan & Pea & Covalent linkage & {$[85,86]$} \\
\hline 10 & Pectin-xyloglucan & $\begin{array}{l}\text { Arabidopsis root and } \\
\text { shoot extracts }\end{array}$ & Covalent linkage & [87] \\
\hline \multirow[t]{2}{*}{11} & Xylan-xyloglucan & Olive & Covalent linkage & {$[42]$} \\
\hline & \multicolumn{4}{|c|}{ Interactions between polysaccharides and proteins } \\
\hline 12 & $\begin{array}{l}\text { AGP-hemicellulose- } \\
\text { pectin }\end{array}$ & Arabidopsis & $\begin{array}{l}\text { Covalent linkage: } \\
\text { 1) AG Type II - Gal- } \\
\text { GlcA-Rha 2) AG Type II } \\
\text { - Arabinoxylan }\end{array}$ & {$[27]$} \\
\hline 13 & AGP-pectin & Carrot & Covalent linkage & {$[28]$} \\
\hline \multirow[t]{2}{*}{14} & Extensin-RG-I & $\begin{array}{l}\text { Cotton suspension } \\
\text { culture }\end{array}$ & Covalent linkage & {$[88]$} \\
\hline & \multicolumn{4}{|l|}{ Pectin only involved } \\
\hline 15 & HG-HG & Generally present & $\begin{array}{l}\text { Calcium-mediated ionic } \\
\text { cross-links }\end{array}$ & {$[15]$} \\
\hline \multirow[t]{2}{*}{16} & RG-II-RG-II & $\begin{array}{l}\text { Sugar beet, potato, } \\
\text { bamboo, red wine (in } \\
\text { vitro) }\end{array}$ & Borate-diol ester & [89] \\
\hline & \multicolumn{4}{|l|}{ Other factors involved } \\
\hline 17 & Molecular crowding & Arabidopsis & - & {$[47,77]$} \\
\hline
\end{tabular}


The cross-links reported in Table 1.1 will be discussed in more detail below.

1. Xyloglucan and xylan adsorb to cellulose microfibrils. Interactions are strong due to backbone similarities between xyloglucan, xylan and glucan (cellulose) backbones.. With respect to xyloglucan interactions, especially fucose substitution seems relevant, although contradictory results on the importance of fucosylation with respect to cellulose-adsorption affinity have been published [90-92]. For xylan, adsorption to cellulose is favoured by low substitution, with the drawback that especially arabinose substitution prevents aggregation and precipitation of xylan [74].

2. Co-elution of xyloglucan with anionic pectin fractions on AEC in cell-suspension cultures. The pectin-xyloglucan complex was proposed to be cross-linked by a covalent, non-ester connection since the anionic xyloglucan was extracted using $6 \mathrm{M} \mathrm{NaOH}$.

3. Interactions between RG-I backbones and xylan were described, based on in vitro adsorption experiments, enzymatic digestion studies and localisation of xylan epitopes. Due to its less complex polymer composition seed coat mucilage is considered as a suitable model system, even though RG-I side chains are absent.

4. Extensive interactions between pectin and cellulose were shown by solid-state NMR in 14-d Arabidopsis seedlings, in contrast to a limited number of cross-peaks between xyloglucan and cellulose [64]. Additional research showed that also in never-dried cell walls and partially depectinated cells [40\% HG removal], close pectin-cellulose interactions remained [77].

5. AEC and ethanol precipitation of insoluble immature and mature cauliflower stem tissues suggested the presence of closely associated, potentially covalently linked acidic xylan, xyloglucan and pectin.

6. Cross-linking of arabinan chains through ferulic acid dimers is described for sugar beet pectin [81, 82]. Arabinoxylan cross-linking through ferulic acid groups is reported as a cross-linking mechanism especially of relevance in sources high in arabinoxylan (monocots) [35].

7. Induced interactions between different pectin elements and cellulose in vitro show that RG-I side chains show affinity for adsorption of cellulose, albeit a substantially lower affinity than xyloglucan-cellulose adsorption. Adsorption affinity was higher for isolated plant cell wall cellulose compared to microcrystalline cellulose, and debranching of arabinans enhances adsorption compared to branched arabinan and galactan.

8. Polygalacturonase digestion of pectin fractions isolated from sequentially extracted alkali residues in plum and pear showed oligosacharides composed of GalA and hexose residues. Hexose residues were deduced to be cellobiose, indicating HG-cellodextrin linkages.

9. Pectin-xyloglucan complexes are described in 7-d old pea seedlings. Enzymatic digestion of the proposed pectin-xyloglucan complex, followed by AEC and paper chromatography led to the suggestion that the radioactively labelled galactan was integrated in this complex. 
10. AEC coupled to antibody detection by epitope detection chromatography showed the presence of co-eluting pectin-xyloglucan complexes. The majority, but not all, of the complexes were found in both $30-\mathrm{d}$ old root and shoot extracts. Furthermore differences in intensity were found between root and shoot extracts, indicating that the prevalence of pectin-xyloglucan is not constant throughout all tissues.

11. Graded ethanol precipitation followed by AEC and size-based fractionation showed xylan-xyloglucan complexes. Digestion with xylanases followed by linkage analysis led to the conclusion that glucuronoxylans and highly branched xyloglucans are covalently linked.

12. The presence of an arabinoxylan pectin arabinogalactan protein 1 complex (APAP1) in Arabidopsis cell cultures is characterised in detail [27]. Extensive isolation, purification and characterisation of the complex by NMR and amino acid sequencing showed a complex in which AG Type II links the protein part of AGP through a Gal-GICA-Rha element to RG-I. Furthermore arabinoxylan is shown to link to both AG type II and to rhamnose in the RG-I backbone.

13. AGP in carrot root was precipitated by Yariv reagent, the presence of AGP-pectin complexes as proposed. Subsequently, precipitation with copper led to different AGP fractions high and low in GalA.

14. Deglycosylation of 14-d old cultured cotton cell walls was followed by an extensive purification procedure including enzymatic digestion with trypsin, polygalacturonase, cellulase. Subsequent chemical purification with $\mathrm{HF}$ at various temperatures and extraction of ionically bound polymers led to a fraction containing an extensin-RG-I complex.

15. Cross-linking of $\mathrm{HG}$ chains by $\mathrm{Ca}^{2+}$ into the so-called egg-box is a well-known mechanism, leading to a higher viscosity. At least several adjacent non methyl-esterified GalA residues are required for cross-linking, and estimates for the number of required GalA residues alter in the range of 6-14 [14]. Formation of the egg-box is hindered by RG-I chains and substitution with methyl-esters and/or acetyl groups.

17. The concept molecular crowding addresses the presence of large polymers (plant cell wall polysaccharides and proteins) in a limited space (the cell wall). Polymers might behave differently in this crowded matrix, and effects in vitro might differ from in muro. This concept was included in describing the pectin-cellulose associations described Wang et al [77], to discriminate polysaccharides in close proximity from interacting polysaccharides.

\subsection{Biosynthesis of cell wall polysaccharides}

One of the major questions in understanding the cell wall architecture remains how all cell wall polysaccharides are synthesized and subsequently deposited in the cell wall. Hints for the architecture of the cell wall might be found in the biosynthesis pathways, and how these are adapted to different plant sources or tissues [93]. 
The pectic polysaccharides are synthesized and modified in the Golgi apparatus [94]. The large complexity of pectin with all its different monosaccharides and linkage types requires at least 67 different transferases, based on the assumption that each linkage is formed by a unique enzyme [8]. Different pectin synthetic events (e.g. esterification, branching) occur at different regions in the Golgi system and during transport in Golgi vesicles. Atmodjo et al [8] proposed two biosynthetic pathways for pectin synthesis in the Golgi system: one-by-one attachment of monosaccharides in the 'consecutive glycosyltransferase (GT) model', or blocks that are separately synthesized and subsequently fused together in the 'domain synthesis model'. After the biosynthesis, Golgi vesicles are transporting pectin to the plasma membrane and inserting pectin in the plant cell wall mostly as a highly methyl-esterified polymer [1, 2, 95]. Next to pectin, the hemicelluloses are also synthesized in the Golgi system by cellulose synthase-like (CSL) proteins [35]. As reviewed by Driouich et al [94], evidence on localisation of polysaccharide synthesis within the Golgi compartments is increasing but far from fully understood yet. Similarly, it is not characterised yet where all enzymes are located within the Golgi system, and whether proposed complexes of biosynthetic enzymes have a cooperative role [6].

In contrast to the matrix polysaccharides (pectin and hemicellulose), glucan chains are synthesized in the plasma membrane by cellulose synthase complexes, so-called rosettes [96]. Each rosette is composed of 6 rosette subunits each composed of 6 catalytic CesA proteins, leading to a total of 36 catalytic subunits. More recently, based on characterisation of plant cellulose synthases, these numbers were adjusted from 36 to $18-24$ chains $[47,97]$. The number of catalytic subunit equals the number of glucan chains synthesized by each complex. Subsequently all glucan chains formed by 1 rosette are believed to spontaneously crystallise together to a microfibril. Although only speculatively proposed, several microfibrils synthesized in close proximity might co-crystallise to larger aggregates [98].

After release of pectin, hemicellulose and cellulose into the cell wall, all polysaccharide associate to form networks (Figure 1.3). What exactly happens after the release of all polysaccharides in the cell wall is still poorly understood. It is therefore also poorly understood how interactions between cell wall polysaccharides are formed. Cross-linking is thought to be caused by both spontaneous interactions and activities of cross-linking enzymes. With respect to these enzymes, xyloglucan endotransglucosylase (XET) has perhaps received most attention, and has the ability to cut xyloglucan and subsequently form new xyloglucan chains [2]. However, knowledge is very limited on the presence of similar transferase enzymes active on other polysaccharides, and their promiscuity towards other substrates. 


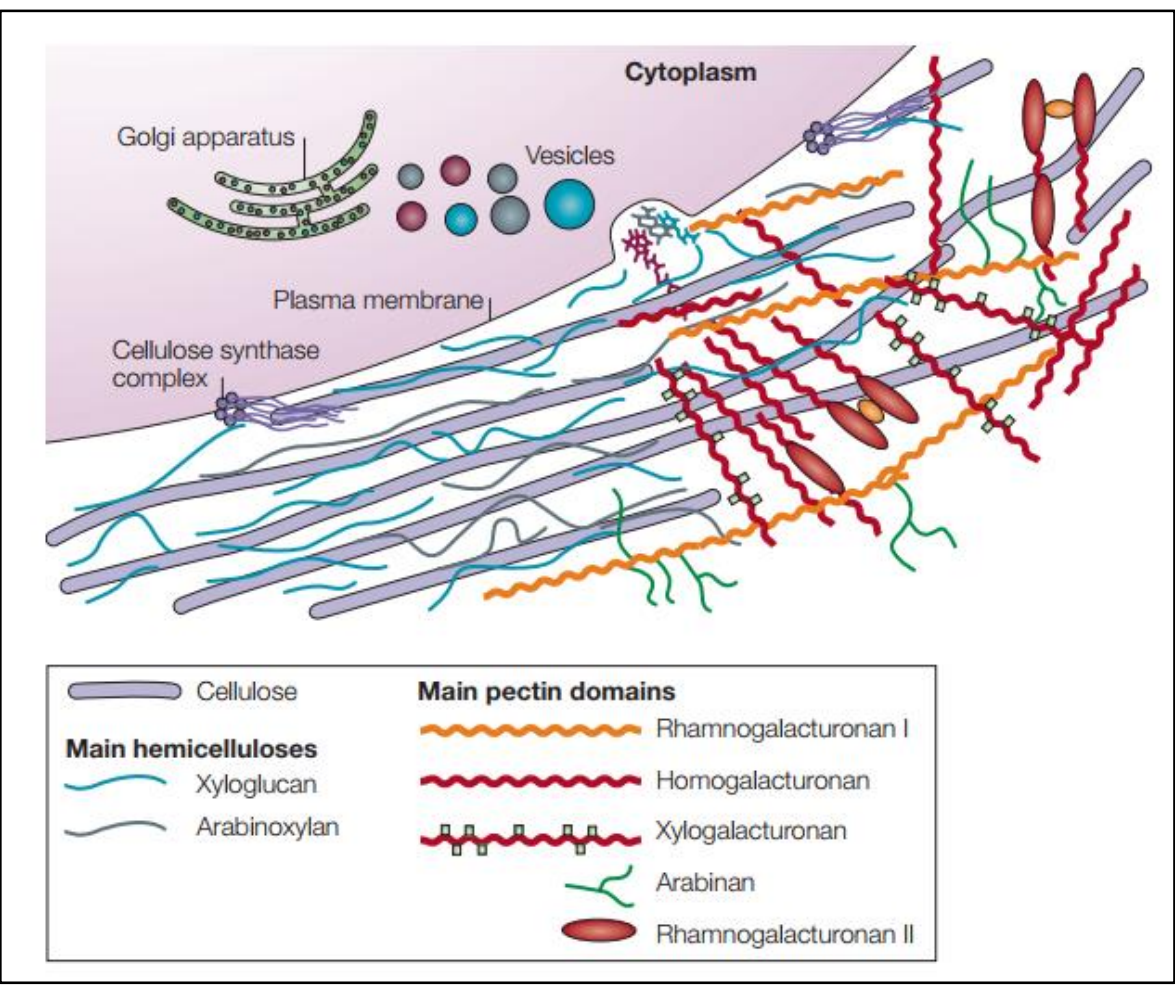

Figure 1.3 Release of matrix polysaccharides (pectin, hemicellulose) and cellulose from the plasma membrane into the cell wall [2].

\subsection{Growth and ripening}

The primary cell wall architecture is often represented as a static model. However, this is based on the incorrect assumption that the cell wall architecture remains unchanged during growth and ripening.

During growth, the cell volume and turgor pressure increase by water uptake. Subsequently plants extend their cell walls by addition of new polymers to prevent a too thin and weak cell wall that might collapse. Selective loosening of the cell wall is required for cellulose microfibrils to move through the wall during extension. This complicated process is believed to be controlled by several factors such as expansin activity, XET/XTH and glucanase activity, and finally hydroxyl radicals might play a role $[2,99]$. Furthermore the gel-forming ability of pectin is an important factor in growth control by enhancing or slowing down cellulose microfibrils [67]. In some sources, fruit growth and fruit ripening are distinctly separated, whereas in other sources (e.g. strawberry) softening starts before the fruits stop growing, so considerable overlap of growth and ripening process might occur [100]. 
Numerous amounts of carbohydrate-active enzymes are active during the ripening process in fruits and vegetables, active towards both pectin and hemicellulose. Understanding these activities might lead to an improved understanding of the cell wall architecture since endogenous enzyme activities might be related to interacting polysaccharides in the cell wall. With respect to pectin, polygalacturonase (PG) and pectin methyl-esterase (PME) are the most frequently studied pectinases since textural changes of fruits and vegetables are typically linked to HG regions. PME removes methyl-esters from HG regions, subsequently enabling PG to depolymerise HG. However, the ripening process typically starts with increased activity of galactanases acting on RG-I galactan side chains, next to depolymerisation of xyloglucans. Later on, arabinan side chains and pectin backbones are depolymerised and solubilised [4].

\subsubsection{Characteristics of carrot, tomato and strawberry ripening}

\section{Endogenous enzyme activities during growth and ripening}

For the three sources studied, endogenous enzyme activities were best described for carrot and tomato. Enzyme activity is obviously species-dependent, and some features of the different sources are reported below.

\section{Carrot}

Due to low xyloglucan levels in carrot [101], for carrot pectinases were more characterised than hemicellulases. The optimum for carrot PME was found to be $\mathrm{pH}$ 7.3-7.4, at a temperature of $48.5{ }^{\circ} \mathrm{C}$ [102]. With respect to stability during processing, the activity decreases substantially $>50^{\circ} \mathrm{C}$ and about $95 \%$ of all PME activity was lost $>60{ }^{\circ} \mathrm{C}$. With respect to pressure, substantial inactivation occurs around 600-700 MPa [102]. Similar hereto, purified carrot PME was found to contain a thermolabile and thermostable fraction. The thermolabile fraction was completely inactivated at $57{ }^{\circ} \mathrm{C}$ within $30 \mathrm{~min}$, whereas thermostable PME activity after thermal treatment at $64{ }^{\circ} \mathrm{C}$ for $15 \mathrm{~min}$ was reported, accounting for $5-6 \%$ of purified PME [103]. Carrot PG is rather heat-resistant, with inactivation reported only above $75^{\circ} \mathrm{C}[104]$

\section{Tomato}

For tomato, both pectinase and xyloglucanase activities were studied. For pectinases, the optimal tomato $P G$ activity is around $55^{\circ} \mathrm{C}-60^{\circ} \mathrm{C}$ [105]. With respect to the stability of tomato pectinases, PG is rather pressure-labile whereas PME is rather heat-labile [106]. Tomato PMEs are highly active and it was reported that upon ripening the DM of pectin in the cell wall reduces from $\sim 90 \%$ in the mature green stage to 35\% in the ripe stage [107]. Ripening-related changes in arabinan and galactan were mainly related to arabinans and galactans found in concentrated alkali extracts. This suggests that the softening process 
might be related to firmly-bound arabinans and galactans, rather than those attached to more loosely-bound pectins [4, 108].

Next to pectin, also hemicellulose and more specifically xyloglucan is thought to be involved in ripening processes. Xyloglucan depolymerisation upon ripening was reported in tomato [109]. Depolymerisation of xyloglucan might be governed by XET/XEH activity, and these enzymes have a double role in adding newly synthesized XG to existing $X G$, next to reorganisation and potential loosening of existing networks during expansion and growth of cell walls $[109,110]$. It has been attempted to study cellulose depolymerisation, and it was reported that cellulose depolymerisation was very limited or even absent [4].

\section{Strawberry}

For strawberry, it was reported that varieties with the highest PG and PME activities soften most during ripening [111]. The authors also provide an overview of PG and PME activities of 12 different strawberry varieties, indicating that both PG and PME activities differ substantially between species. Activities for PG and PME differed highly, from 20-77 g $\mathrm{Gal} / \mathrm{kg}$ fresh weight (per hour per mg protein) and 0.8-47 Units/kg fruit respectively. It was reported that during strawberry ripening, hemicelluloses depolymerise and pectins only solubilise rather than depolymerise [100].

Next to pectinases and hemicellulases, many other enzymes are active during growth and ripening. Perhaps one of the most important ones is expansin. Expansins are thought to act by weakening the links between xyloglucan and cellulose microfibrils, yet do not themselves act as hydrolases [112].

\subsection{Effects of fruit and vegetable processing on pectin}

Changes in fruit and vegetable texture as an effect of processing, are typically explained by alterations in pectin structure. The effects of processing fruits and vegetables on pectin structure and subsequent texture and viscosity are represented in Figure 1.4. As can be observed, heating at low $\mathrm{pH}(<3.0)$ will lead to acid hydrolysis, and relatively higher $\mathrm{pH}$ (>4.5) will lead to $\beta$-elimination. Whereas depolymerisation by either acid hydrolysis or $\beta$-elimination will lead to texture loss, pectin can also be modified in such a way that texture and viscosity increase. Endogenous PME activity might deesterify HG regions, leading to increased $\mathrm{Ca}^{2+}$ cross-linking and increased viscosity. These processes occur in muro, but enzymes such as PG or PME or modified pectins might also be added as functional food ingredients [113-115].

Whereas heat-based processing is the most commonly used processing method, high pressure based processing shows to be an interesting alternative due to differences in final texture. One of the main factors causing these differences is the different tolerance of endogenous enzymes towards heat and pressure. Typically, high pressure might enhance 
PME activity and decrease PG activity, and hereby induce $\mathrm{Ca}^{2+}$-gelation without degradation of the pectin backbone. This will result in a decreased loss of firmness compared to heat processing [116]. On industrial scale, high-pressure processing (HPP) is mainly applied for pasteurisation purposes $[117,118]$. By combining heat and high pressure processing, sterilisation might be reached as well [118].

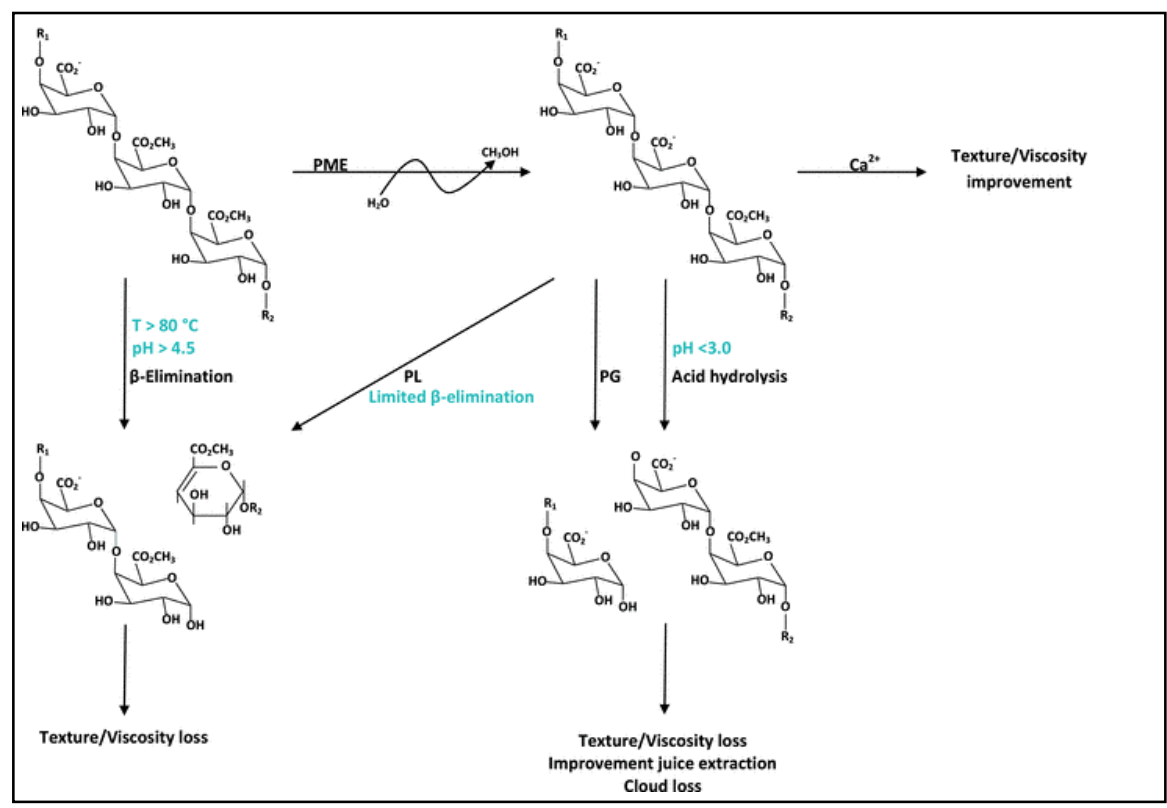

Figure 1.4 Effects of pectin modifications on texture and viscosity [119]. Effect of PME (pectin methyl esterase) on HG (homogalacturonan) regions in pectin. Different depolymerisation mechanisms by $\beta$ elimination, PL (pectin lyase) and PG (polygalacturonase) are indicated. 


\subsection{Thesis outline}

In this thesis, the cell wall architecture of carrot, tomato and strawberry was studied and these 3 sources were chosen based on differences in hemicellulose content and composition [49, 50].

In chapter 3, cell wall polysaccharides are extracted with sequential alkali extractions, targeted at co-extraction of potentially cross-linked cell wall polysaccharides. Solubilisation of pectin remaining in the final residue was targeted by digestion with pectinases and glucanases. Co-extraction was also used in chapter 5 , where the less frequently used solvent LiCl-DMSO was used. LiCl-DMSO solubilises (hemi)cellulose, making this a suitable solvent to extract cell wall polysaccharides that typically do not solubilise easily.

Co-chromatography of polysaccharides was used in chapter 4, where a pectin-xylan cross-link was proposed to be present based on the behaviour of polysaccharides on AEC. An example of the importance of structural knowledge on the substrate was given in chapter 2, which showed the difficulties of full enzymatic digestion of acetylated pectin, and the need for suitable enzymatic fingerprinting strategies.

In chapters 4 and 5 planetary ball milling for short time intervals was used as a mild pretreatment. Ball milling is known to decrease the crystallinity of cellulose by disrupting its $\mathrm{H}$-bonding [120]. Next to that, the extraction efficiency will increase by a better solvent accessibility due to a smaller particle size. Finally, in chapter 6 the results obtained in this work are discussed in relation to existing primary plant cell wall models. 


\section{References}

1. Caffall, K.H. and D. Mohnen, The structure, function, and biosynthesis of plant cell wall pectic polysaccharides. Carbohydrate Research, 2009. 344(14): p. 1879-1900.

2. Cosgrove, D.J., Growth of the plant cell wall. Nature Reviews Molecular Cell Biology, 2005. 6(11): p. 850-861.

3. Voragen, A.G., G.-J. Coenen, R.P. Verhoef and H.A. Schols, Pectin, a versatile polysaccharide present in plant cell walls. Structural Chemistry, 2009. 20(2): p. 263-275.

4. Brummell, D.A., Cell wall disassembly in ripening fruit. Functional Plant Biology, 2006. 33(2): p. 103-119.

5. Engelsdorf, T. and T. Hamann, An update on receptor-like kinase involvement in the maintenance of plant cell wall integrity. Annals of botany, 2014. 114(6): p. 1339-1347.

6. Anderson, C.T., We be jammin': an update on pectin biosynthesis, trafficking and dynamics. Journal of Experimental Botany, 2016. 67(2): p. 495-502.

7. Jarvis, M., S. Briggs and J. Knox, Intercellular adhesion and cell separation in plants. Plant, Cell \& Environment, 2003. 26(7): p. 977-989.

8. Atmodjo, M.A., Z. Hao and D. Mohnen, Evolving views of pectin biosynthesis. Annual Review of Plant Biology, 2013. 64: p. 747-779.

9. Thibault, J.-F., C.M.G.C. Renard, M.A.V. Axelos, P. Roger and M.-J. Crépeau, Studies of the length of homogalacturonic regions in pectins by acid hydrolysis. Carbohydrate Research, 1993. 238: p. 271-286.

10. Ralet, M. and J. Thibault, Hydrodynamic properties of isolated pectin domains: a way to figure out pectin macromolecular structure, in Pectins and pectinases, H.A. Schols, R.G.F. Visser, and A.G.J. Voragen, Eds. 2009, Wageningen Academic Publishers: Wageningen. p. 35-48.

11. Willats, W.G.T., C. Orfila, G. Limberg, H.C. Buchholt, G.J.W.M. van Alebeek, A.G.J. Voragen, S.E. Marcus, T.M.I.E. Christensen, J.D. Mikkelsen, B.S. Murray, and J.P. Knox, Modulation of the degree and pattern of methyl-esterification of pectic homogalacturonan in plant cell walls Implications for pectin methyl esterase action, matrix properties, and cell adhesion. Journal of Biological Chemistry, 2001. 276(22): p. 19404-19413.

12. Somerville, C., S. Bauer, G. Brininstool, M. Facette, T. Hamann, J. Milne, E. Osborne, A. Paredez, S. Persson, and T. Raab, Toward a systems approach to understanding plant cell walls. Science, 2004. 306(5705): p. 2206-2211.

13. Vincken, J.P., H.A. Schols, R.J.F.J. Oomen, M.C. McCann, P. Ulvskov, A.G.J. Voragen, and R.G.F. Visser, If homogalacturonan were a side chain of rhamnogalacturonan I. Implications for cell wall architecture. Plant Physiology, 2003. 132(4): p. 1781-1789.

14. Fraeye, I., T. Duvetter, E. Doungla, A. Van Loey and M. Hendrickx, Fine-tuning the properties of pectin-calcium gels by control of pectin fine structure, gel composition and environmental conditions. Trends in Food Science \& Technology, 2010. 21(5): p. 219-228.

15. Grant, G.T., E.R. Morris, D.A. Rees, P.J.C. Smith and D. Thom, Biological interactions between polysaccharides and divalent cations: The egg-box model. FEBS Letters, 1973. 32(1): p. 195-198.

16. Ramaswamy, U.R., M.A. Kabel, H.A. Schols and H. Gruppen, Structural features and water holding capacities of pressed potato fibre polysaccharides. Carbohydrate Polymers, 2013. 93(2): p. 589-596.

17. Ramasamy, U.S., H. Gruppen and H.A. Schols, Structural and water-holding characteristics of untreated and ensiled chicory root pulp. Journal of Agricultural and Food Chemistry, 2013. 61(25): p. 6077-6085.

18. Ralet, M.-C., J.C. Cabrera, E. Bonnin, B. Quéméner, P. Hellin, and J.-F. Thibault, Mapping sugar beet pectin acetylation pattern. Phytochemistry, 2005. 66(15): p. 1832-1843. 
19. Remoroza, C., S. Cord-Landwehr, A.G.M. Leijdekkers, B.M. Moerschbacher, H.A. Schols, and H. Gruppen, Combined HILIC-ELSD/ESI-MSn enables the separation, identification and quantification of sugar beet pectin derived oligomers. Carbohydrate Polymers, 2012. 90(1): p. 41-48.

20. Voragen, A.G.J., W. Pilnik, J.F. Thibault, M.A.V. Axelos and C.M.G.C. Renard, Pectins, in Food Polysaccharides and Their Applications. 1995, Marcel Dekker, New York. p. 287-339.

21. Albersheim, P., A.G. Darvill, M.A. O'Neill, H.A. Schols and A.G.J. Voragen, An hypothesis: The same six polysaccharides are components of the primary cell walls of all higher plants, in Progress in Biotechnology, J. Visser and A.G.J. Voragen, Eds. 1996, Elsevier. p. 47-55.

22. Mohnen, D., Pectin structure and biosynthesis. Current Opinion in Plant Biology, 2008. 11(3): $p$. 266-277.

23. Nakamura, A., H. Furuta, H. Maeda, T. TAKAO and Y. NAGAMATSU, Structural studies by stepwise enzymatic degradation of the main backbone of soybean soluble polysaccharides consisting of galacturonan and rhamnogalacturonan. Bioscience, Biotechnology, and Biochemistry, 2002. 66(6): p. 1301-1313.

24. Ha, M.-A., R.J. Viëtor, G.D. Jardine, D.C. Apperley and M.C. Jarvis, Conformation and mobility of the arabinan and galactan side-chains of pectin. Phytochemistry, 2005. 66(15): p. 1817-1824.

25. Kravtchenko, T.P., I. Arnould, A.G.J. Voragen and W. Pilnik, Improvement of the selective depolymerization of pectic substances by chemical Beta-elimination in aqueous-solution. Carbohydrate Polymers, 1992. 19(4): p. 237-242.

26. Serpe, M.D. and E.A. Nothnagel, Arabinogalactan-proteins in the Multiple Domains of the Plant Cell Surface, in Advances in Botanical Research, J.A. Callow, Editor. 1999, Academic Press. p. 207289.

27. Tan, L., S. Eberhard, S. Pattathil, C. Warder, J. Glushka, C.H. Yuan, Z.Y. Hao, X. Zhu, U. Avci, J.S. Miller, D. Baldwin, C. Pham, R. Orlando, A. Darvill, M.G. Hahn, M.J. Kieliszewski, and D. Mohnen, An Arabidopsis cell wall proteoglycan consists of pectin and arabinoxylan covalently linked to an arabinogalactan protein. Plant Cell, 2013. 25(1): p. 270-287.

28. Immerzeel, P., M.M. Eppink, S.C. de Vries, H.A. Schols and A.G.J. Voragen, Carrot arabinogalactan proteins are interlinked with pectins. Physiologia Plantarum, 2006. 128(1): p. 18-28.

29. Pellerin, P., T. Doco, S. Vida, P. Williams, J.-M. Brillouet, and M.A. O'Neill, Structural characterization of red wine rhamnogalacturonan II. Carbohydrate Research, 1996. 290(2): p. 183-197.

30. Ishii, T., T. Matsunaga and N. Hayashi, Formation of rhamnogalacturonan II-borate dimer in pectin determines cell wall thickness of pumpkin tissue. Plant Physiology, 2001. 126(4): p. 16981705.

31. O'Neill, M.A., S. Eberhard, P. Albersheim and A.G. Darvill, Requirement of borate cross-linking of cell wall rhamnogalacturonan II for Arabidopsis growth. Science, 2001. 294(5543): p. 846-849.

32. Zandleven, J., S.O. Sørensen, J. Harholt, G. Beldman, H.A. Schols, H.V. Scheller, and A.J. Voragen, Xylogalacturonan exists in cell walls from various tissues of Arabidopsis thaliana. Phytochemistry, 2007. 68(8): p. 1219-1226.

33. Schols, H.A., E.J. Bakx, D. Schipper and A.G.J. Voragen, $A$ xylogalacturonan subunit present in the modified hairy regions of apple pectin. Carbohydrate Research, 1995. 279(Supplement C): p. 265-279.

34. Hilz, H., PhD thesis: Characterisation of cell wall polysaccharides in bilberries and black currants. 2007: Wageningen University.

35. Scheller, H.V. and P. Ulvskov, Hemicelluloses. Plant Biology, 2010. 61(1): p. 263-289.

36. Mazeau, K. and L. Charlier, The molecular basis of the adsorption of xylans on cellulose surface. Cellulose, 2012. 19(2): p. 337-349. 
37. Kabel, M.A., H. van den Borne, J.-P. Vincken, A.G. Voragen and H.A. Schols, Structural differences of xylans affect their interaction with cellulose. Carbohydrate Polymers, 2007. 69(1): p. 94-105.

38. Carpita, N.C. and D.M. Gibeaut, Structural models of primary cell walls in flowering plants: consistency of molecular structure with the physical properties of the walls during growth. The Plant Journal, 1993. 3(1): p. 1-30.

39. Fry, S.C., W.S. York, P. Albersheim, A. Darvill, T. Hayashi, J.P. Joseleau, Y. Kato, E.P. Lorences, G.A. Maclachlan, and M. McNeil, An unambiguous nomenclature for xyloglucan - derived oligosaccharides. Physiologia Plantarum, 1993. 89(1): p. 1-3.

40. Vincken, J.-P., A. de Keizer, G. Beldman and A.G.J. Voragen, Fractionation of xyloglucan fragments and their interaction with cellulose. Plant Physiology, 1995. 108(4): p. 1579-1585.

41. Vincken, J.-P., W.S. York, G. Beldman and A. Voragen, Two general branching patterns of xyloglucan, XXXG and XXGG. Plant Physiology, 1997. 114(1): p. 9.

42. Coimbra, M.A., N.M. Rigby, R.R. Selvendran and K.W. Waldron, Investigation of the occurrence of xylan-xyloglucan complexes in the cell walls of olive pulp (Olea europaea). Carbohydrate Polymers, 1995. 27(4): p. 277-284.

43. Assor, C., B. Quemener, J. Vigouroux and M. Lahaye, Fractionation and structural characterization of LiCl-DMSO soluble hemicelluloses from tomato. Carbohydrate Polymers, 2013. 94(1): p. 46-55.

44. Carpita, N.C. and M.C. McCann, Maize and sorghum: genetic resources for bioenergy grasses. Trends in Plant Science, 2008. 13(8): p. 415-420.

45. Harris, P.J. and B.A. Stone, Chemistry and molecular organization of plant cell walls, in Biomass Recalcitrance: Deconstructing the Plant Cell Wall for Bioenergy, M.E. Himmel, Editor. 2008, Blackwell Publishing Ltd. p. 61-93.

46. Renard, C.M. and M.C. Jarvis, A cross-polarization, magic-angle-spinning, 13C-nuclear-magneticresonance study of polysaccharides in sugar beet cell walls. Plant Physiology, 1999. 119(4): p. 1315-1322.

47. Cosgrove, D.J., Re-constructing our models of cellulose and primary cell wall assembly. Current Opinion in Plant Biology, 2014. 22: p. 122-131.

48. Li, Y. and Z.R. Hardin, Enzymatic scouring of cotton: effects on structure and properties. Cellulose, 1997. 94(88.0): p. 96.0.

49. Houben, K., R.P. Jolie, I. Fraeye, A.M. Van Loey and M.E. Hendrickx, Comparative study of the cell wall composition of broccoli, carrot, and tomato: Structural characterization of the extractable pectins and hemicelluloses. Carbohydrate Research, 2011. 346(9): p. 1105-1111.

50. Voragen, F.G., J.P. Timmers, J.P. Linssen, H.A. Schols and W. Pilnik, Methods of analysis for cellwall polysaccharides of fruit and vegetables. Zeitschrift für Lebensmittel-Untersuchung und Forschung, 1983. 177(4): p. 251-256.

51. Heng Koh, T. and L.D. Melton, Ripening-related changes in cell wall polysaccharides of strawberry cortical and pith tissues. Postharvest Biology and Technology, 2002. 26(1): p. 23-33.

52. Hayashi, T., Xyloglucans in the primary cell wall. Annual Review of Plant Biology, 1989. 40(1): $p$. 139-168.

53. Showalter, A.M., B. Keppler, J. Lichtenberg, D. Gu and L.R. Welch, A Bioinformatics Approach to the Identification, Classification, and Analysis of Hydroxyproline-Rich Glycoproteins. Plant Physiology, 2010. 153(2): p. 485-513.

54. Showalter, A.M., Structure and function of plant cell wall proteins. The Plant Cell Online, 1993. 5(1): p. 9-23.

55. Keegstra, K., K.W. Talmadge, W.D. Bauer and P. Albersheim, The Structure of Plant Cell Walls: III. A Model of the Walls of Suspension-cultured Sycamore Cells Based on the Interconnections of the Macromolecular Components. Plant Physiology, 1973. 51(1): p. 188-197. 
56. Kerr, E.M. and S.C. Fry, Pre-formed xyloglucans and xylans increase in molecular weight in three distinct compartments of a maize cell-suspension culture. Planta, 2003. 217(2): p. 327-339.

57. Vierhuis, E., H. Schols, G. Beldman and A. Voragen, Structural characterisation of xyloglucan and xylans present in olive fruit (Olea europaea cv koroneiki). Carbohydrate Polymers, 2001. 44(1): p. 51-62.

58. Cosgrove, D.J., Enzymes and other agents that enhance cell wall extensibility. Annual Review of Plant Biology, 1999. 50(1): p. 391-417.

59. Cosgrove, D.J., Wall structure and wall loosening. A look backwards and forwards. Plant Physiology, 2001. 125(1): p. 131-134.

60. Fry, S.C., Cellulases, hemicelluloses and auxin - stimulated growth: a possible relationship. Physiologia Plantarum, 1989. 75(4): p. 532-536.

61. McCann, M.C. and K. Roberts, Architecture of the primary cell wall, in The Cytoskeletal Basis of Plant Growth and Form C.W. Lloyd, Editor. 1992, Academic Press: London. p. 109-129.

62. Talbott, L.D. and P.M. Ray, Molecular size and separability features of pea cell wall polysaccharides: implications for models of primary wall structure. Plant Physiology, 1992. 98(1): p. 357-368.

63. Ha, M.-A., D.C. Apperley and M.C. Jarvis, Molecular rigidity in dry and hydrated onion cell walls. Plant Physiology, 1997. 115(2): p. 593-598.

64. Dick-Pérez, M., Y. Zhang, J. Hayes, A. Salazar, O.A. Zabotina, and M. Hong, Structure and interactions of plant cell-wall polysaccharides by two-and three-dimensional magic-anglespinning solid-state NMR. Biochemistry, 2011. 50(6): p. 989-1000.

65. Zykwinska, A.W., M.C.J. Ralet, C.D. Garnier and J.F.J. Thibault, Evidence for in vitro binding of pectin side chains to cellulose. Plant Physiology, 2005. 139(1): p. 397-407.

66. Cavalier, D.M., O. Lerouxel, L. Neumetzler, K. Yamauchi, A. Reinecke, G. Freshour, O.A. Zabotina, M.G. Hahn, I. Burgert, and M. Pauly, Disrupting two Arabidopsis thaliana xylosyltransferase genes results in plants deficient in xyloglucan, a major primary cell wall component. The Plant Cell, 2008. 20(6): p. 1519-1537.

67. Höfte, H., A. Peaucelle and S. Braybrook, Cell wall mechanics and growth control in plants: the role of pectins revisited. Frontiers in Plant Science, 2012. 3(121): p. 1-6.

68. Mort, A.J., Interactions between pectins and other polymers, in Pectins and their manipulation, G.B. Seymour and J.P. Knox, Eds. 2002, Blackwell Publishing: Oxford, UK. p. 30-51.

69. Renard, C.M.G.C. and C. Ginies, Comparison of the cell wall composition for flesh and skin from five different plums. Food Chemistry, 2009. 114(3): p. 1042-1049.

70. Andersson, R., E. Westerlund and P. Aman, Cell-wall polysaccharides: Structural, chemical, and analytical aspects, in Food Science and Technology, A. Eliasson, Editor. 2006, CRC Press: Boca Raton. p. 129-166.

71. Zuluaga, R., J.L. Putaux, J. Cruz, J. Vélez, I. Mondragon, and P. Gañán, Cellulose microfibrils from banana rachis: Effect of alkaline treatments on structural and morphological features. Carbohydrate Polymers, 2009. 76(1): p. 51-59.

72. Ordaz-Ortiz, J.J., S.E. Marcus and P.J. Knox, Cell wall microstructure analysis implicates hemicellulose polysaccharides in cell adhesion in tomato fruit pericarp parenchyma. Molecular Plant, 2009. 2(5): p. 910-921.

73. Knox, J.P., Revealing the structural and functional diversity of plant cell walls. Current opinion in plant biology, 2008. 11(3): p. 308-313.

74. Köhnke, T., A. Östlund and H. Brelid, Adsorption of arabinoxylan on cellulosic surfaces: influence of degree of substitution and substitution pattern on adsorption characteristics. Biomacromolecules, 2011. 12(7): p. 2633-2641. 
75. Popper, Z.A. and S.C. Fry, Widespread occurrence of a covalent linkage between xyloglucan and acidic polysaccharides in suspension-cultured angiosperm cells. Annals of Botany, 2005. 96(1): p. 91-99.

76. Ralet, M.-C., M.-J. Crépeau, J. Vigouroux, J. Tran, A. Berger, C. Sallé, F. Granier, L. Botran, and H.M. North, Xylans provide the structural driving force for mucilage adhesion to the Arabidopsis seed coat. Plant Physiology, 2016. 171(1): p. 165-178.

77. Wang, T., Y. Park, D.J. Cosgrove and M. Hong, Cellulose-pectin spatial contacts are inherent to never-dried Arabidopsis thaliana primary cell walls: evidence from solid-state NMR. Plant Physiology, 2015. 168: p. 871-884.

78. Femenia, A., N. Rigby, R. Selvendran and K. Waldron, Investigation of the occurrence of pecticxylan-xyloglucan complexes in the cell walls of cauliflower stem tissues. Carbohydrate Polymers, 1999. 39(2): p. 151-164.

79. Kroon, P., M. Garcia - Conesa, I. Fillingham, G. Hazlewood and G. Williamson, Release of ferulic acid dehydrodimers from plant cell walls by feruloyl esterases. Journal of the Science of Food and Agriculture, 1999. 79(3): p. 428-434.

80. Hatfield, R.D., J. Ralph and J.H. Grabber, Cell wall cross-linking by ferulates and diferulates in grasses. Journal of the Science of Food and Agriculture, 1999. 79: p. 403-407.

81. Oosterveld, A., J.H. Grabber, G. Beldman, J. Ralph and A.G. Voragen, Formation of ferulic acid dehydrodimers through oxidative cross-linking of sugar beet pectin. Carbohydrate Research, 1997. 300(2): p. 179-181.

82. Ralet, M.-C., G. André-Leroux, B. Quéméner and J.-F. Thibault, Sugar beet (Beta vulgaris) pectins are covalently cross-linked through diferulic bridges in the cell wall. Phytochemistry, 2005. 66(24): p. 2800-2814.

83. Colquhoun, I.J., M.-C. Ralet, J.-F. Thibault, C.B. Faulds and G. Williamson, Structure identification of feruloylated oligosaccharides from sugar-beet pulp by NMR spectroscopy. Carbohydrate Research, 1994. 263(2): p. 243-256.

84. Nunes, C., L. Silva, A.P. Fernandes, R.P. Guiné, M.R.M. Domingues, and M.A. Coimbra, Occurrence of cellobiose residues directly linked to galacturonic acid in pectic polysaccharides. Carbohydrate Polymers, 2012. 87(1): p. 620-626.

85. Abdel-Massih, R.M., E.A.-H. Baydoun and C.T. Brett, In vitro biosynthesis of 1, 4- $\beta$-galactan attached to a pectin-xyloglucan complex in pea. Planta, 2003. 216(3): p. 502-511.

86. Cumming, C.M., H.D. Rizkallah, K.A. McKendrick, R.M. Abdel-Massih, E.A. Baydoun, and C.T. Brett, Biosynthesis and cell-wall deposition of a pectin-xyloglucan complex in pea. Planta, 2005. 222(3): p. 546-555.

87. Cornuault, V., I.W. Manfield, M.C. Ralet and J.P. Knox, Epitope detection chromatography: a method to dissect the structural heterogeneity and inter - connections of plant cell - wall matrix glycans. The Plant Journal, 2014. 78(4): p. 715-722.

88. Qi, X., B.X. Behrens, P.R. West and A.J. Mort, Solubilization and partial characterization of extensin fragments from cell walls of cotton suspension cultures (evidence for a covalent crosslink between extensin and pectin). Plant Physiology, 1995. 108(4): p. 1691-1701.

89. Ishii, T., T. Matsunaga, P. Pellerin, M.A. O'Neill, A. Darvill, and P. Albersheim, The plant cell wall polysaccharide rhamnogalacturonan II self-assembles into a covalently cross-linked dimer. Journal of Biological chemistry, 1999. 274(19): p. 13098-13104.

90. Lima, D.U., W. Loh and M.S. Buckeridge, Xyloglucan-cellulose interaction depends on the sidechains and molecular weight of xyloglucan. Plant Physiology and Biochemistry, 2004. 42(5): p. 389-394.

91. Hayashi, T., K. Ogawa and Y. Mitsuishi, Characterization of the adsorption of xyloglucan to cellulose. Plant and Cell Physiology, 1994. 35(8): p. 1199-1205. 
92. de Lima, D.U. and M.S. Buckeridge, Interaction between cellulose and storage xyloglucans: the influence of the degree of galactosylation. Carbohydrate Polymers, 2001. 46(2): p. 157-163.

93. Keegstra, K., Plant cell walls. Plant Physiology, 2010. 154(2): p. 483-486.

94. Driouich, A., L. Chevalier, M. Vicré and O. Lerouxel, Golgi-mediated synthesis and secretion of matrix polysaccharides of the primary cell wall of higher plants. Frontiers in Plant Science, 2012. 3 (79): p. 1-15.

95. Ridley, B.L., M.A. O'Neill and D.A. Mohnen, Pectins: structure, biosynthesis, and oligogalacturonide-related signaling. Phytochemistry, 2001. 57(6): p. 929-967.

96. Brett, C.T., Cellulose microfibrils in plants: biosynthesis, deposition, and integration into the cell wall. International Review of Cytology, 2000. 199: p. 161-199.

97. Thomas, L.H., V.T. Forsyth, A. Šturcová, C.J. Kennedy, R.P. May, C.M. Altaner, D.C. Apperley, T.J. Wess, and M.C. Jarvis, Structure of cellulose microfibrils in primary cell walls from collenchyma. Plant Physiology, 2013. 161(1): p. 465-476.

98. Guerriero, G., J. Fugelstad and V. Bulone, What do we really know about cellulose biosynthesis in higher plants? Journal of Integrative Plant Biology, 2010. 52(2): p. 161-175.

99. Wolf, S., K. Hématy and H. Höfte, Growth control and cell wall signaling in plants. Annual Review of Plant Biology, 2012. 63: p. 381-407.

100. Goulao, L.F. and C.M. Oliveira, Cell wall modifications during fruit ripening: when a fruit is not the fruit. Trends in Food Science \& Technology, 2008. 19(1): p. 4-25.

101. Zykwinska, A., J.-F. Thibault and M.-C. Ralet, Organization of pectic arabinan and galactan side chains in association with cellulose microfibrils in primary cell walls and related models envisaged. Journal of Experimental Botany, 2007. 58(7): p. 1795-1802.

102. Ly-Nguyen, B., A.M. Van Loey, D. Fachin, I. Verlent, Indrawati, and M.E. Hendrickx, Partial purification, characterization, and thermal and high-pressure inactivation of pectin methylesterase from carrots (Daucus carrota L.). Journal of Agricultural and Food Chemistry, 2002. 50(19): p. 5437-5444.

103. Ly-Nguyen, B., A.M. Van Loey, C. Smout, S.E. Ozcan, D. Fachin, I. Verlent, S.V. Truong, T. Duvetter, and M.E. Hendrickx, Mild-heat and high-pressure inactivation of carrot pectin methylesterase: A kinetic study. Journal of Food Science, 2003. 68(4): p. 1377-1383.

104. Anthon, G.E. and D.M. Barrett, Kinetic parameters for the thermal inactivation of quality-related enzymes in carrots and potatoes. Journal of Agricultural and Food Chemistry, 2002. 50(14): p. 4119-4125.

105. Verlent, I., A. Van Loey, C. Smout, T. Duvetter and M. Hendrickx, Purified tomato polygalacturonase activity during thermal and high - pressure treatment. Biotechnology and Bioengineering, 2004. 86(1): p. 63-71.

106. Rodrigo, D., C. Cortés, E. Clynen, L. Schoofs, A. Van Loey, and M. Hendrickx, Thermal and highpressure stability of purified polygalacturonase and pectinmethylesterase from four different tomato processing varieties. Food Research International, 2006. 39(4): p. 440-448.

107. Koch, J.L. and D.J. Nevins, Tomato fruit cell wall: I. Use of purified tomato polygalacturonase and pectinmethylesterase to identify developmental changes in pectins. Plant Physiology, 1989. 91(3): p. 816-822.

108. Redgwell, R.J., M. Fischer, E. Kendal and E.A. MacRae, Galactose loss and fruit ripening: highmolecular-weight arabinogalactans in the pectic polysaccharides of fruit cell walls. Planta, 1997. 203(2): p. 174-181.

109. Rose, J.K.C. and A.B. Bennett, Cooperative disassembly of the cellulose-xyloglucan network of plant cell walls: parallels between cell expansion and fruit ripening. Trends in Plant Science, 1999. 4(5): p. 176-183. 
110. Miedes, E. and E.P. Lorences, Xyloglucan endotransglucosylase/hydrolases (XTHs) during tomato fruit growth and ripening. Journal of Plant Physiology, 2009. 166(5): p. 489-498.

111. Lefever, G., M. Vieuille, N. Delage, J. Monteclerc and G. Bompeix, Characterization of cell wall enzyme activities, pectin composition, and technological criteria of strawberry cultivars (Fragariax ananassa Duch). Journal of Food Science, 2004. 69(4).

112. Cosgrove, D.J., Loosening of plant cell walls by expansins. Nature, 2000. 407(6802): p. 321-326.

113. Willats, W.G.T., P. Knox and J.D. Mikkelsen, Pectin: new insights into an old polymer are starting to gel. Trends in Food Science \& Technology, 2006. 17(3): p. 97-104.

114. Croak, S. and M. Corredig, The role of pectin in orange juice stabilization: Effect of pectin methylesterase and pectinase activity on the size of cloud particles. Food Hydrocolloids, 2006. 20(7): p. 961-965.

115. Kashyap, D., P. Vohra, S. Chopra and R. Tewari, Applications of pectinases in the commercial sector: a review. Bioresource Technology, 2001. 77(3): p. 215-227.

116. Oey, I., M. Lille, A. Van Loey and M. Hendrickx, Effect of high-pressure processing on colour, texture and flavour of fruit-and vegetable-based food products: a review. Trends in Food Science \& Technology, 2008. 19(6): p. 320-328.

117. Krebbers, B., A.M. Matser, S.W. Hoogerwerf, R. Moezelaar, M.M. Tomassen, and R.W. van den Berg, Combined high-pressure and thermal treatments for processing of tomato puree: evaluation of microbial inactivation and quality parameters. Innovative Food Science \& Emerging Technologies, 2003. 4(4): p. 377-385.

118. Mújica-Paz, H., A. Valdez-Fragoso, C.T. Samson, J. Welti-Chanes and J.A. Torres, High-pressure processing technologies for the pasteurization and sterilization of foods. Food and Bioprocess Technology, 2011. 4(6): p. 969-985.

119. Sila, D., S. Van Buggenhout, T. Duvetter, I. Fraeye, A. De Roeck, A. Van Loey, and M. Hendrickx, Pectins in processed fruits and vegetables: Part II-Structure-function relationships. Comprehensive Reviews in Food Science and Food Safety, 2009. 8(2): p. 86-104.

120. Paes, S., S. Sun, W. MacNaughtan, R. Ibbett, J. Ganster, T.J. Foster, and J.R. Mitchell, The glass transition and crystallization of ball milled cellulose. Cellulose, 2010. 17(4): p. 693-709. 




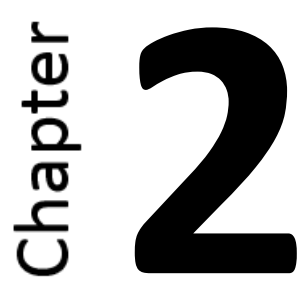

\section{Acetylated pectins in raw and heat processed carrots}

Published as: S.E. Broxterman, P. Picouet, H.A. Schols, Acetylated pectins in raw and heat processed carrots. Carbohydrate Polymers 2017, 177, 58-66 


\section{Abstract}

Heat processing results in softening of carrots, changing the pectin structure. The effect of heat processing on pectin was studied, showing that the amount of pectin in water soluble solids (WSS) and chelating agent soluble solids (ChSS) increased substantially upon heat processing of the carrots. Pectin in WSS from both unprocessed and heat processed carrot had a degree of methyl-esterification (DM) of $\approx 60 \%$ and a degree of acetylation (DA) of $\approx$ $20 \%$. Enzymatic degradation released methyl-esterified galacturonic acid oligomers of degree of polymerisation $\geq 6$ carrying acetyl groups. Mass spectrometry confirmed acetylation in highly methyl-esterified homogalacturonan (HG) regions, next to known rhamnogalacturonan (RG-I) acetylation. ChSS HGs were un-acetylated.

RG-I levels of both heat processed carrot WSS and ChSS increased. Digestion of WSS with RG-I degrading enzymes showed that WSS arabinan became more linear upon heat processing resulting in the release of oligosaccharides, while in ChSS galactan became more linear. 


\subsection{Introduction}

Vegetable-based products are often processed prior to consumption and the processing method used might have a big effect on the texture and firmness of the product It was shown before that the most common processing method, thermal treatment at elevated temperature, decreased the firmness of carrots [1]. The decreased firmness can be explained by alterations in pectin structure. Pectin is a complex mix of polysaccharides, building up the primary plant cell wall and middle lamella of vegetables. Pectin consists of galacturonic acid as the most prevailing building block, mostly present in homogalacturonan (HG) and in rhamnogalacturonan I (RG-I) structural elements. The HG backbone can be methyl-esterified at the C- 6 position, and acetylated at the 0-2 and/or 0-3 position. The rhamnose residues in RG-I can be substituted with neutral sugar side chains, composed of arabinose and galactose [2].

Softening of carrot tissue upon heat processing is mainly due to $\beta$-elimination of pectin, a $\mathrm{pH}$ - and temperature-dependent reaction which is highly relevant in carrots processing due to the $\mathrm{pH}$ of carrot tissue $(\approx 5-5.5)[3,4]$. The molecular weight of the pectin decreases and the amount of easily extractable, water soluble pectin increases by $\beta$-eliminative depolymerisation. Due to pectins ability to form $\mathrm{Ca}^{2+}$-mediated crosslinks, the degree of methyl-esterification and acetylation are also affecting firmness. It was shown that a decrease of the DM of pectins due to thermal processing promotes $\mathrm{Ca}^{2+}$-crosslinking between pectin chains and hereby improves firmness [3].

Pectins from many sources are highly methyl-esterified, while also acetylation of RG-I is common. In addition, pectins from some specific origin, e.g. potato, sugar beet and chicory pulp are found to be acetylated on the homogalacturonan region as well $[5,6]$. It is known that the functional properties of pectin depend on the distribution of methyl-esters and acetyl groups [7]. Enzymatic fingerprinting methods have been established to study the distribution pattern of methyl-esters and acetyl groups in sugar beet pectin $[7,8]$.

In the current study, the effect of heat processing on carrot pectin was studied by extraction of Water Soluble Solids (WSS) and Chelating agent Soluble Solids (ChSS). Subsequently, a two-step enzymatic fingerprinting of the extracted pectin in WSS and ChSS was performed using pectin degrading enzymes. Oligosaccharides formed after the second digestion were analysed to localize acetyl groups and methyl esters in WSS and ChSS. 


\subsection{Materials and methods}

\subsubsection{Plant material}

Carrots (Daucus carota cv. Nantaise) were obtained in Spain and frozen at $-20^{\circ} \mathrm{C}$ directly after purchase to avoid enzymatic activity and microbial spoilage during storage. For the processed samples, carrots were cut into cubes and subsequently heat processed.

Three different processing conditions were performed: blanching at $90^{\circ} \mathrm{C}$ for 5 minutes followed by sterilisation at $110^{\circ} \mathrm{C}$ for 6 minutes; blanching at $100^{\circ} \mathrm{C}$ for 1 minute followed by sterilisation at $110^{\circ} \mathrm{C}$ for 22 minutes and blanching for 1 minute at $100^{\circ} \mathrm{C}$ followed by sterilisation at $120^{\circ} \mathrm{C}$ for 33 minutes.

\subsubsection{Extraction of pectin fractions}

Alcohol Insoluble Solids (AIS) were extracted using a procedure as described before with slight modifications [9]. AIS was extracted by blending frozen, peeled carrots or heat-treated carrot cubes in a 1:3 w/v ratio in $96 \%$ ethanol. The suspension was filtered using Whatman filter paper (pore size 12-25 $\mu \mathrm{m}$ ) and the retaining residue was resuspended in $70 \%$ ethanol. The suspension was filtered and the residue was washed with $70 \%$ ethanol until the filtrate gave a negative reaction in phenol-sulfuric acid test [10]. In the final washing step acetone was used. AIS was dried at $40^{\circ} \mathrm{C}$ and stored in a desiccator.

To extract the water soluble solids (WSS) $1 \mathrm{~g}$ AIS was suspended in $150 \mathrm{ml}$ distilled water and held for 10 minutes at $99^{\circ} \mathrm{C}$. The suspension was filtered using Whatman filter paper and the filtrate was freeze-dried, yielding Water Soluble Solids (WSS).

To extract the Chelating agent Soluble Solids (ChSS), the residue from WSS extraction was suspended in $150 \mathrm{ml} 0.05 \mathrm{M}$ EDTA in $0.1 \mathrm{M}$ potassium acetate for $6 \mathrm{~h}$ at room temperature. The suspension was filtered using Whatman filter paper, and the filtrate was extensively dialysed against potassium acetate followed by demineralised water, and freeze-dried to obtain the Chelating agent Soluble Solids (ChSS). Extraction was performed only one time. In general, the extraction procedure results in highly reproducible data with standard deviation $<3 \%$.

\subsubsection{Sugar composition}

To determine the pectin content of the extracted fractions, the uronic acid content was determined by the automated colorimetric m-hydroxydiphenyl method (Blumenkrantz \& Asboe-hansen, 1973). Neutral carbohydrate composition was analysed after pretreatment with $72 \%(w / w) \mathrm{H}_{2} \mathrm{SO}_{4}\left(1 \mathrm{~h}, 30^{\circ} \mathrm{C}\right)$ followed by hydrolysis with $1 \mathrm{M} \mathrm{H}_{2} \mathrm{SO}_{4}\left(3 \mathrm{~h}, 100^{\circ} \mathrm{C}\right)$. Sugars released were derivatised and analysed as their alditol acetates using gas chromatography [11], inositol was used as internal standard. 
The HG to RG-I ratio was calculated by: (GalA-Rha)/(2*Rha) in mol \%. The average side chain length of RG-I was calculated by: (Ara+Gal)/Rha [12].

\subsubsection{Determination of methyl-esterification and acetylation}

Samples were saponified at $\approx 3 \mathrm{mg} / \mathrm{ml}$ in $0.25 \mathrm{M} \mathrm{NaOH}\left(3 \mathrm{~h}, 4^{\circ} \mathrm{C}\right)$ to determine the degree of methyl-esterification (DM) using a colorimetric method as previously described [13]. The same saponification procedure was used to determine the degree of acetylation (DA), by measuring released acetic acid by a Megazyme acetic acid kit (Megazyme, Wicklow, Ireland). The DM and DA were calculated as the moles of methyl esters and acetyl groups per 100 moles of GalA, respectively.

\subsubsection{Digestion by $P G / P L$}

In order to study the fine chemical structure of pectin, controlled degradation by pectolytic enzymes was performed. WSS and ChSS were degraded by polygalacturonase (endo-PG) from $A$. aculeatus and pectin lyase (PL) from A. niger, both pure and well characterised [14, 15]. Degradation was done at $5 \mathrm{mg} / \mathrm{ml}$ WSS or ChSS in $50 \mathrm{mM}$ sodium citrate buffer $\mathrm{pH} 5$ at $40^{\circ} \mathrm{C}$ by head-over-tail rotation for $24 \mathrm{~h}$. Enzymes were dosed to theoretically degrade all substrate to monomers in $6 \mathrm{~h}$.

\subsubsection{Fractionation into size-based pools}

The small oligosaccharides formed by $P G$ and $P L$ were separated from the high $\mathrm{Mw}$ fragments by gel filtration according to the protocol previously described by Remoroza et al (2014) [8]. The PD-10 column with packed bed size of $1.45 \times 5.0 \mathrm{~cm}(8.3 \mathrm{ml})$ containing Sephadex G-25 Medium (GE Healthcare Bio-sciences Uppsala, Sweden) was equilibrated using $25 \mathrm{ml}$ of $50 \mathrm{mM}$ sodium citrate buffer ( $\mathrm{pH} \mathrm{5.0)}$ at room temperature. Freeze-dried PG+PL treated pectin (10 mg pectin) was dissolved into $300 \mu \mathrm{l} 50 \mathrm{mM}$ sodium citrate buffer ( $\mathrm{pH} 5.0$ ) and eluted with $4.70 \mathrm{ml}$ of $50 \mathrm{mM}$ sodium citrate buffer $(\mathrm{pH} \mathrm{5.0)}$ in fractions of 0.5 $\mathrm{ml}$. HPSEC was used to determine the Mw distribution of the fractions, and to pool the digest based on the Mw into a high Mw pool (Pool I) and low Mw pool (Pool II).

\subsubsection{Digestion of high $M w$ fraction by $P G / P M E / R G E$}

To degrade the PG- and PL-resistant polymeric material, a second enzymatic treatment was performed with high $\mathrm{Mw}$ material pool I obtained after the size-based separation. The second digestion was performed with pectin methyl esterase from either A. niger (f-PME) or Dickeya didantii (b-PME), endo-PG from A. aculeatus and RG-I degrading enzymes. The RG-I degrading enzymes (RGE) used were A. aculeatus endo-arabinanase [16], endo- 
galactanase [15] and RG-hydrolase, and exo-arabinase from Myceliophthora thermophila C1 [17].

Incubation was done in $50 \mathrm{mM}$ sodium citrate buffer $\mathrm{pH} 5$ at $40^{\circ} \mathrm{C}$ by head over tail rotation for $24 \mathrm{~h}$. Enzymes were dosed to theoretically degrade all substrate to monomers in $6 \mathrm{~h}$.

\subsubsection{High performance size exclusion chromatography (HPSEC)}

Extracted pectin fractions before and after enzymatic digestion were analysed for their molecular weight distribution using an Ultimate 3000 system (Dionex, Sunnyvale, CA, USA) coupled to a Shodex RI-101 detector (Showa Denko K.K., Tokyo, Japan). A set of TSK-Gel super AW columns 4000, 3000, 2000 ( $6 \mathrm{~mm} \times 150 \mathrm{~mm}$ ) preceded by a TSK-Gel super AW guard column ( $6 \mathrm{~mm}$ ID $\times 40 \mathrm{~mm}$ ) (Tosoh Bioscience, Tokyo, Japan) was used in series. The column temperature was set to $55^{\circ} \mathrm{C}$. Samples $(5 \mathrm{mg} / \mathrm{ml})$ were injected $(10 \mu \mathrm{l})$ and eluted with $0.2 \mathrm{M} \mathrm{NaNO} 3$ at a flow rate of $0.6 \mathrm{ml} / \mathrm{min}$. Pectin standards from 10-100 kDa were used to estimate the molecular weight distribution [18].

2.2.9 Matrix-assisted laser desorption/ionization time-of-flight mass spectrometry (MALDITOF MS)

MALDI-TOF and MALDI-TOF/TOF mass spectra were recorded using an Ultraflextreme workstation controlled by FlexControl 3.3 software (Bruker Daltonics, Bremen, Germany) equipped with a Smartbeam II laser of $355 \mathrm{~nm}$ and operated in positive mode.

Before analysis by MALDI-TOF MS, samples were desalted with Dowex 50W-X8 (Bio-Rad Laboratories, CA, USA) and $1 \mu \mathrm{L}$ of sample was co-crystallised with $1 \mu \mathrm{L}$ matrix $(25 \mathrm{mg} / \mathrm{mL}$ dihydroxy-benzoic acid in $50 \%(\mathrm{v} / \mathrm{v})$ acetonitrile). Samples were dried under a stream of air. For TOF/TOF mass analysis, parent and fragment ions were accelerated using a LIFT device located in the flight tube using the standard LIFT method optimized for the instrument. Maltodextrin MD 20 (Avebe, Foxhol, The Netherlands) was used for calibration.

Analysis of the uronic acid oligosaccharides in the PG/b-PME/RGE digest of the heat processed carrot samples improved after washing out the neutral oligosaccharides. This was done using centrifugal filter units with a cut-off of $3 \mathrm{kDa}$ (Millipore centrifugal filter units, Merck, Billerica, Massachusetts, United States). 


\subsection{Results and discussion}

\subsubsection{Yield and composition of different pectin populations}

In order to study the effect of heat treatment on carrot pectin, unprocessed and heat processed carrot cubes were subjected to analysis. AIS was isolated, and sequentially fractionated into WSS, ChSS and the residue. The effect of the different process conditions on the amount of AIS, WSS and ChSS extracted from carrots is presented in Table 2.1.

Table 2.1 Yield of AIS, WSS and ChSS isolated from unprocessed and heat processed carrot on dry matter basis.

\begin{tabular}{|l|c|c|c|}
\hline & $\%$ AIS(dry matter) & mg WSS/g AIS & mg ChSS/g AIS \\
\hline Unprocessed carrot & 31.4 & 213 & 145 \\
\hline $90^{\circ} \mathrm{C} / 5 \mathrm{~min}+110^{\circ} \mathrm{C} / 6 \mathrm{~min}$ & 51.0 & 321 & 201 \\
\hline $100^{\circ} \mathrm{C} / 1 \mathrm{~min}+110^{\circ} \mathrm{C} / 22 \mathrm{~min}$ & 44.5 & 273 & 166 \\
\hline $100^{\circ} \mathrm{C} / 1 \mathrm{~min}+120^{\circ} \mathrm{C} / 33.5 \mathrm{~min}$ & 45.1 & 321 & 181 \\
\hline
\end{tabular}

Comparison of the yield of alcohol insoluble solids (AIS) in the unprocessed and processed carrot samples shows that the yield increased by $\approx 50 \%$ after processing (Table 2.1 ). Although the yield increased, the GalA content decreased (see below, Table 2.2), and therefore about the same total amount of GalA was recovered by the AIS.

As well as AIS, the yield of water soluble solids (WSS) after processing increased by $\approx 50 \%$ compared to the unprocessed carrot sample. Next to an increased yield, the relative galacturonic acid content in the WSS fraction increased as an effect of processing (Table 2.2). This is assumed to be due to $\beta$-eliminative depolymerisation and subsequently enhanced extractability of pectins [19]. Analysis of the starch content in unprocessed WSS confirmed that up to $30 \%$ of glucose originates from starch and was not removed during AIS preparation.

The amount of ChSS, representing extracted calcium-bound pectin, increased after processing as well. Since the amount of calcium-bound pectin extracted into ChSS strongly depends on the DM, the yield of ChSS increased when the DM of cell wall pectin decreased upon processing due to the formation of calcium-sensitive pectin [3]. Endogenous PME might have been active during heating of the sample, decreasing the DM, since PME activity in carrots has been reported previously [20]. However, a decrease in methyl-esterification might be due to chemical lability of the methyl-ester as well.

It can be seen that the HG:RG-I ratio for pectin in WSS had a slightly higher relative RG-I content and pectin in ChSS a higher HG content for unprocessed when compared to processed carrot pectin

In order to ensure that all carrot pectin was included in the analysis of processed carrots, the covering liquid in the cans in which the carrot cubes were heat processed was freeze- 
dried and analysed for its sugar composition. The sugar composition of this fraction was similar to WSS with respect to the sugar composition and ratios of HG and RG-I isolated, but the covering liquid contained more glucose than WSS did. This is assumed to be free glucose. However, the yield of solids in the covering liquid compared to AIS was rather low and the covering liquid material was therefore not taken into account furthermore.

Table 2.2 Monosaccharide composition (mol\%) and degree of methyl-esterification (DM) and acetylation (DA) of AIS, WSS and ChSS of fractions isolated from unprocessed and heat processed carrots. Mean ( \pm absolute deviation), $n=2$ for monosaccharide composition, $n=3$ for DM and DA.

\begin{tabular}{|c|c|c|c|c|c|c|c|c|c|c|}
\hline & & \multicolumn{7}{|c|}{ Mol\% } & \multirow{2}{*}{$\begin{array}{l}\mathrm{DM} \\
(\%)\end{array}$} & \multirow{2}{*}{$\begin{array}{l}\text { DA } \\
(\%)\end{array}$} \\
\hline & & Ara & Rha & Gal & Glc & Xyl & Man & GalA & & \\
\hline \multirow{4}{*}{ AIS } & $\begin{array}{l}\text { Unprocessed } \\
\text { carrot }\end{array}$ & $\begin{array}{c}8 \\
(0.4)\end{array}$ & $\begin{array}{c}2 \\
(0.0)\end{array}$ & $\begin{array}{c}11 \\
(0.8)\end{array}$ & $\begin{array}{c}36 \\
(1.1)\end{array}$ & $\begin{array}{c}2 \\
(0.0)\end{array}$ & $\begin{array}{c}3 \\
(0.0)\end{array}$ & $\begin{array}{c}38 \\
(2.4)\end{array}$ & $\begin{array}{c}71 \\
(3.7)\end{array}$ & $\begin{array}{c}41 \\
(5.1)\end{array}$ \\
\hline & $\begin{array}{l}90^{\circ} \mathrm{C} / 5 \mathrm{~min}+ \\
110^{\circ} \mathrm{C} / 6 \mathrm{~min}\end{array}$ & $\begin{array}{c}7 \\
(0.2)\end{array}$ & $\begin{array}{c}2 \\
(0.0)\end{array}$ & $\begin{array}{c}9 \\
(0.3)\end{array}$ & $\begin{array}{c}43 \\
(1.3)\end{array}$ & $\begin{array}{c}3 \\
(0.1)\end{array}$ & $\begin{array}{c}4 \\
(0.1)\end{array}$ & $\begin{array}{c}32 \\
(0.9)\end{array}$ & $\begin{array}{c}40 \\
(2.2)\end{array}$ & $\begin{array}{c}42 \\
(3.4)\end{array}$ \\
\hline & $\begin{array}{l}100^{\circ} \mathrm{C} / 1 \mathrm{~min}+ \\
110^{\circ} \mathrm{C} / 22 \mathrm{~min}\end{array}$ & $\begin{array}{c}6 \\
(0.1)\end{array}$ & $\begin{array}{c}1 \\
(0.0)\end{array}$ & $\begin{array}{c}8 \\
(0.1)\end{array}$ & $\begin{array}{c}49 \\
(1.0)\end{array}$ & $\begin{array}{c}4 \\
(0.1)\end{array}$ & $\begin{array}{c}4 \\
(0.3)\end{array}$ & $\begin{array}{c}28 \\
(0.9)\end{array}$ & $\begin{array}{c}27 \\
(2.0)\end{array}$ & $\begin{array}{c}30 \\
(1.7)\end{array}$ \\
\hline & $\begin{array}{l}100^{\circ} \mathrm{C} / 1 \mathrm{~min}+ \\
120^{\circ} \mathrm{C} / 33.5 \mathrm{~min}\end{array}$ & $\begin{array}{c}7 \\
(0.2)\end{array}$ & $\begin{array}{c}2 \\
(0.0)\end{array}$ & $\begin{array}{c}9 \\
(0.4)\end{array}$ & $\begin{array}{c}48 \\
(0.3)\end{array}$ & $\begin{array}{c}3 \\
(0.0)\end{array}$ & $\begin{array}{c}4 \\
(0.2)\end{array}$ & $\begin{array}{c}27 \\
(0.6)\end{array}$ & $\begin{array}{c}29 \\
(0.8)\end{array}$ & $\begin{array}{c}30 \\
(1.8)\end{array}$ \\
\hline \multirow{4}{*}{ WSS } & $\begin{array}{l}\text { Unprocessed } \\
\text { carrot }\end{array}$ & $\begin{array}{c}4 \\
(0.1)\end{array}$ & $\begin{array}{c}1 \\
(0.0)\end{array}$ & $\begin{array}{c}7 \\
(0.2)\end{array}$ & $\begin{array}{c}16 \\
(0.3)\end{array}$ & $\begin{array}{c}0 \\
(0.4)\end{array}$ & $\begin{array}{c}13 \\
(0.1)\end{array}$ & $\begin{array}{c}58 \\
(0.3)\end{array}$ & $\begin{array}{c}68 \\
(5.8)\end{array}$ & $\begin{array}{c}18 \\
(1.3)\end{array}$ \\
\hline & $\begin{array}{l}90^{\circ} \mathrm{C} / 5 \mathrm{~min}+ \\
110^{\circ} \mathrm{C} / 6 \mathrm{~min}\end{array}$ & $\begin{array}{c}10 \\
(0.0)\end{array}$ & $\begin{array}{c}2 \\
(0.0)\end{array}$ & $\begin{array}{c}15 \\
(0.1)\end{array}$ & $\begin{array}{c}10 \\
(0.3)\end{array}$ & $\begin{array}{c}0 \\
(0.0)\end{array}$ & $\begin{array}{c}2 \\
(0.1)\end{array}$ & $\begin{array}{c}61 \\
(0.3)\end{array}$ & $\begin{array}{c}60 \\
(2.5)\end{array}$ & $\begin{array}{c}18 \\
(1.3)\end{array}$ \\
\hline & $\begin{array}{l}100^{\circ} \mathrm{C} / 1 \mathrm{~min}+ \\
110^{\circ} \mathrm{C} / 22 \mathrm{~min}\end{array}$ & $\begin{array}{c}11 \\
(0.6)\end{array}$ & $\begin{array}{c}2 \\
(0.1)\end{array}$ & $\begin{array}{c}18 \\
(0.8)\end{array}$ & $\begin{array}{c}10 \\
(0.3)\end{array}$ & $\begin{array}{c}0 \\
(0.0)\end{array}$ & $\begin{array}{c}2 \\
(0.1)\end{array}$ & $\begin{array}{c}57 \\
(1.2)\end{array}$ & $\begin{array}{c}52 \\
(1.1)\end{array}$ & $\begin{array}{c}18 \\
(0.7)\end{array}$ \\
\hline & $\begin{array}{l}100^{\circ} \mathrm{C} / 1 \mathrm{~min}+ \\
120^{\circ} \mathrm{C} / 33.5 \mathrm{~min}\end{array}$ & $\begin{array}{c}11 \\
(0.1)\end{array}$ & $\begin{array}{c}2 \\
(0.3)\end{array}$ & $\begin{array}{c}17 \\
(0.3)\end{array}$ & $\begin{array}{c}13 \\
(0.1)\end{array}$ & $\begin{array}{c}0 \\
(0.0)\end{array}$ & $\begin{array}{c}3 \\
(0.3)\end{array}$ & $\begin{array}{c}54 \\
(0.3)\end{array}$ & $\begin{array}{c}57 \\
(1.1)\end{array}$ & $\begin{array}{c}24 \\
(0.6)\end{array}$ \\
\hline \multirow{4}{*}{ ChSS } & $\begin{array}{l}\text { Unprocessed } \\
\text { carrot }\end{array}$ & $\begin{array}{c}5 \\
(0.4)\end{array}$ & $\begin{array}{c}0 \\
(0.4)\end{array}$ & $\begin{array}{c}4 \\
(0.2)\end{array}$ & $\begin{array}{c}0 \\
(0.0)\end{array}$ & $\begin{array}{c}0 \\
(0.0)\end{array}$ & $\begin{array}{c}0 \\
(0.0)\end{array}$ & $\begin{array}{c}91 \\
(0.2)\end{array}$ & $\begin{array}{c}47 \\
(5.4)\end{array}$ & $\begin{array}{c}3 \\
(0.2)\end{array}$ \\
\hline & $\begin{array}{l}90^{\circ} \mathrm{C} / 5 \mathrm{~min}+ \\
110^{\circ} \mathrm{C} / 6 \mathrm{~min}\end{array}$ & $\begin{array}{c}8 \\
(0.8)\end{array}$ & $\begin{array}{c}2 \\
(0.2)\end{array}$ & $\begin{array}{c}10 \\
(1.0)\end{array}$ & $\begin{array}{c}0 \\
(0.0)\end{array}$ & $\begin{array}{c}0 \\
(0.0)\end{array}$ & $\begin{array}{c}0 \\
(0.0)\end{array}$ & $\begin{array}{c}80 \\
(2.0)\end{array}$ & $\begin{array}{c}15 \\
(3.2)\end{array}$ & $\begin{array}{c}8 \\
(1.0)\end{array}$ \\
\hline & $\begin{array}{l}100^{\circ} \mathrm{C} / 1 \mathrm{~min}+ \\
110^{\circ} \mathrm{C} / 22 \mathrm{~min}\end{array}$ & $\begin{array}{c}6 \\
(0.1)\end{array}$ & $\begin{array}{c}2 \\
(0.0)\end{array}$ & $\begin{array}{c}7 \\
(0.1)\end{array}$ & $\begin{array}{c}2 \\
(2.3)\end{array}$ & $\begin{array}{c}1 \\
(0.5)\end{array}$ & $\begin{array}{c}0 \\
(0.0)\end{array}$ & $\begin{array}{c}82 \\
(3.0)\end{array}$ & $\begin{array}{c}5 \\
(2.1)\end{array}$ & $\begin{array}{c}5 \\
(1.0)\end{array}$ \\
\hline & $\begin{array}{l}100^{\circ} \mathrm{C} / 1 \mathrm{~min}+ \\
120^{\circ} \mathrm{C} / 33.5 \mathrm{~min}\end{array}$ & $\begin{array}{c}9 \\
(0.1)\end{array}$ & $\begin{array}{c}2 \\
(0.1)\end{array}$ & $\begin{array}{c}12 \\
(0.1)\end{array}$ & $\begin{array}{c}2 \\
(0.4)\end{array}$ & $\begin{array}{c}0 \\
(0.0)\end{array}$ & $\begin{array}{c}0 \\
(0.0)\end{array}$ & $\begin{array}{c}75 \\
(0.3)\end{array}$ & $\begin{array}{c}7 \\
(1.2)\end{array}$ & $\begin{array}{c}9 \\
(1.9)\end{array}$ \\
\hline
\end{tabular}


The degree of methyl-esterification (DM) and acetylation (DA) are of importance for the functional properties of pectin. Both DM and DA were determined for AIS, WSS and ChSS (Table 2.2). The DM of the WSS fraction for the unprocessed carrot was $68 \%$, and this corresponds with values reported previously $[3,21]$. The DM of the pectin present in AIS decreased $\approx 50 \%$ upon heat processing as a combined effect of PME activity and thermal instability, as mentioned before.

The effect of heat processing on the decrease of DM in the WSS fractions was less pronounced than found for AIS. This has been reported before and indicates the specific solubilisation of highly methyl-esterified pectin by water extraction of the cell wall material [22]. Acetylation levels of AIS were quite high, the DA was $30-40 \%$, but since AIS also contains hemicellulose the DA might be an overestimation since calculated on basis of GalA contents. Surprisingly, quite a high DA was found for WSS, while pectin acetylation of carrot pectin was only scarcely reported before [21]. The DA stayed rather stable upon heat processing.

Acetylation of pectin has so far mainly been related to the presence of acetylated GalA in the $R G-I$ region $[23,24]$. It can be calculated from the $H G: R G-I$ ratio that the $H G$ region had to be acetylated as well, since the percentage of acetyl groups was too high to be linked to the GalA residues in RG-I. Acetylation of pectin HG will be investigated and discussed below. Comparing the DM and DA of unprocessed with heat processed carrot samples showed that the DM and DA were lower in ChSS compared to WSS. Lower values were not surprising since the EDTA extracted ChSS pectin was typically bound by calcium, requiring long stretches of non-esterified GalA residues [25].

\subsubsection{Effect of heat treatment on pectin molecular weight}

The molecular weight distributions of the extracted fractions WSS and ChSS was determined by HPSEC and are presented in Figure 2.1. The molecular weight (Mw) distribution of both WSS and ChSS changed, indicating depolymerisation after processing. The increase in area in comparison to the unprocessed carrot sample indicates e.g. an improved solubility or an increased pectin content of the extract after processing.

Upon processing, pectin populations with a high Mw were solubilised. Surprisingly quite some high $\mathrm{Mw}$ material was not depolymerised, even after processing carrots for 33 minutes at $120^{\circ} \mathrm{C}$. Besides solubilisation of high $\mathrm{Mw}$ pectin populations, extensive depolymerisation into pectin with a lower Mw distribution is visible.

The extracted pectin populations as present in ChSS were less extensively depolymerised than WSS in comparison to the unprocessed carrot sample, and no additional high $\mathrm{Mw}$ pectin was released (Fig 2.1B). In carrot it is expected that an increase in temperature during processing increases the rate of $\beta$-elimination more than the rate of de-esterification [19]. However, the low DM (5-15\%, Table 2.2) clearly limited the rate of $\beta$-elimination in ChSS. 


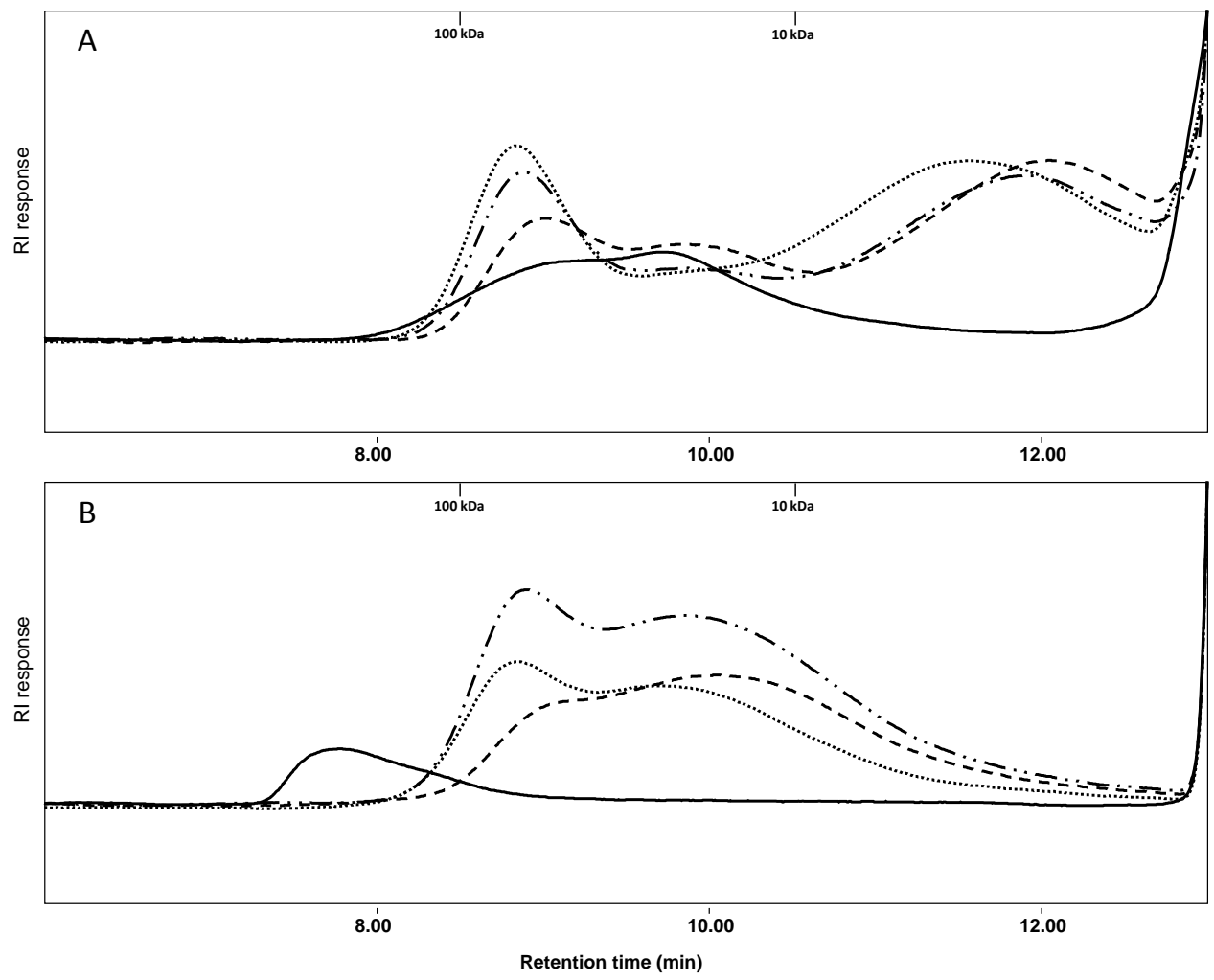

Figure 2.1 HPSEC elution pattern of (A) Water Soluble Solids (WSS) and (B) Chelating agent Soluble Solids (ChSS) of unprocessed and heat processed carrots. Unprocessed $(-) ; 90^{\circ} \mathrm{C} / 5 \mathrm{~min}+110^{\circ} \mathrm{C} / 6 \mathrm{~min}$ $(\cdots) ; 100^{\circ} \mathrm{C} / 1 \mathrm{~min}+110^{\circ} \mathrm{C} / 22 \mathrm{~min}(---) ; 100^{\circ} \mathrm{C} / 1 \mathrm{~min}+120^{\circ} \mathrm{C} / 33.5 \mathrm{~min}(-. \cdot)$. Molecular weights of pectin standards (in $\mathrm{kDa}$ ) are indicated.

\subsubsection{Degradation of WSS by PG/PL and fractionation into size-based pools}

In order to study the distribution of methyl esters and acetyl groups in pectin in WSS, an enzymatic degradation method was used [8].

Water soluble pectin was degraded with PG from A. Aculeatus and PL from A. Niger. The oligosaccharides in the digest were analysed by MALDI-TOF MS, showing the presence of unsaturated oligosaccharides in the unprocessed carrot WSS PG/PL digest (Fig. 2.2A). This was expected for pectin with $\mathrm{DM} \approx 60 \%$ digested by $P G$ and $P L$ since $P G$ releases saturated uronic acid oligomers from non-esterified pectin and PL releases unsaturated uronic acid oligomers from high methyl-esterified pectin. Pectic oligosaccharides were present having varying levels of esterification, e.g. from $U 4^{10}$ to $U 4^{40}$, meaning unsaturated GalA tetramer carrying 1 to 4 methyl-esters and no acetyl groups. It was shown that the heat processed carrot $\mathrm{PG} / \mathrm{PL}$ digests show mainly unsaturated oligosaccharides but saturated 
oligosaccharides are found as well (Fig. 2.2B). The decrease in DM when comparing the unprocessed to heat processed carrot pectins (Table 2.2) was reflected in the oligosaccharides found by MALDI-TOF MS. Oligosaccharides in the unprocessed carrot PG/PL digest were more methyl-esterified than oligosaccharides in the heat processed carrot PG/PL digest. For both the unprocessed and the heat processed carrot PG/PL digest, oligosaccharides from DP 3-9 showed the same pattern and DP 4 and 5 were selected to exemplify the oligosaccharides present.

It has to be noted that in mass spectrometry $U 4^{40}$ and $U 4^{11}$ could not be differentiated since the mass of 3 methyl esters equals 1 acetyl group. Since the pattern of oligosaccharides formed showed the presence of unsaturated oligosaccharides containing 1, 2 and 3 methyl esters, the presence of $\mathrm{U} 4^{40}$, carrying 4 methyl-esters, was more likely than $\mathrm{U} 4^{11}$, carrying 1 methyl-ester and 1 acetyl group. The same applied for $U 5^{50} / U 5^{21}$. The DA of all WSS fractions was relatively high, and therefore it was expected that acetylated oligosaccharides were formed after digestion with PG/PL. However, only methyl-esterified and no acetylated oligosaccharides were present in both the unprocessed and processed carrot PG/PL digests.
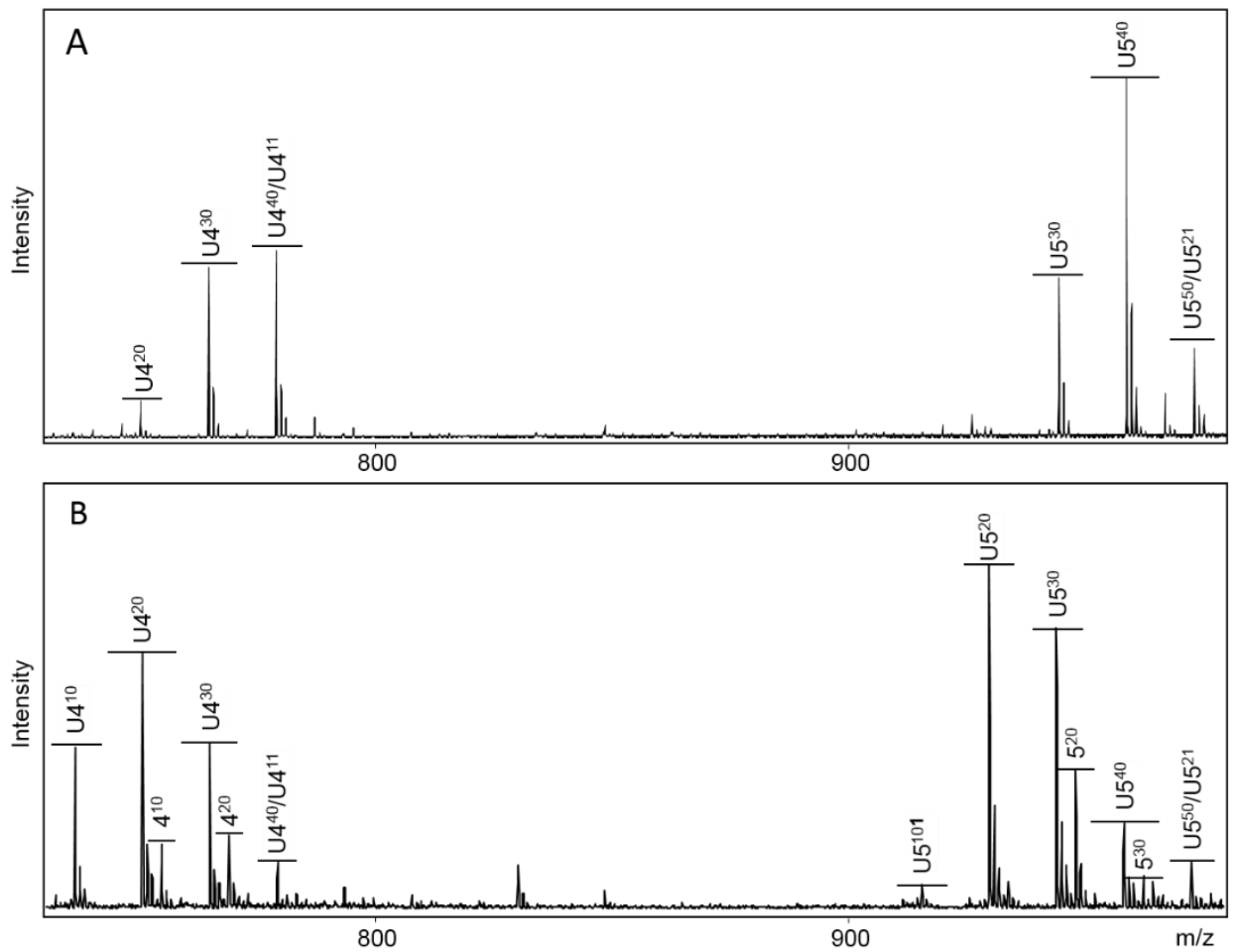

Figure 2.2 MALDI-TOF mass spectra of the PG/PL digest of (A) unprocessed carrot WSS and (B) WSS after heat treatment $\left(100^{\circ} \mathrm{C} / 1 \mathrm{~min}+120^{\circ} \mathrm{C} / 33.5 \mathrm{~min}\right)$. Peak annotation: $U 4^{20}$, unsaturated GalA DP 4, 2 methyl-esters, 0 acetyl groups. 
To confirm the presence of acetyl groups on HG and to get more structural information, the remaining polymeric pectin fragments had to be degraded to oligosaccharides. In order to perform a second, more efficient second enzymatic degradation step, the polymeric pectin was separated from the smaller oligosaccharides by fractionation of the PG/PL digest into a high Mw pool (pool I) and a low Mw pool (pool II) (data not shown). After fractionation of the PG/PL digest, $\approx 33 \%$ of all uronic acids present was recovered as oligosaccharides in the low Mw pool for both the unprocessed and heat processed WSS fraction. This indicates that the majority of the pectic material indeed was not degraded by PG/PL.

After isolation of the polymeric pectin, the DA of Pool I was determined. As shown in Table 2.3, the DA of pool I increased when compared to the DA of WSS. This confirms that acetylated polymeric pectin was separated from non-acetylated oligosaccharides. Taking the ratio HG:RG-I into account (Table 2.2), it also confirms that acetylation occurs in distinct $\mathrm{HG}$ regions. Highly acetylated HG is therefore a unique characteristic of carrot pectin since so far acetylation has only been described in detail for sugar beet pectin [26].

Table 2.3 Degree of acetylation of WSS and of Pool I after size-based fractionation of unprocessed and heat processed carrots. Mean ( \pm absolute deviation), $n=2$.

\begin{tabular}{|l|c|c|}
\hline & \multicolumn{2}{|c|}{ Water soluble solids } \\
\hline & DA WSS (\%) & DA WSS Pool I (\%) \\
\hline Unprocessed carrot & $18(1.3)$ & $38(1.5)$ \\
\hline $90^{\circ} \mathrm{C} / 5 \mathrm{~min}+110^{\circ} \mathrm{C} / 6 \mathrm{~min}$ & $18(1.3)$ & $28(1.9)$ \\
\hline $100^{\circ} \mathrm{C} / 1 \mathrm{~min}+110^{\circ} \mathrm{C} / 22 \mathrm{~min}$ & $18(0.7)$ & $23(3.1)$ \\
\hline $100^{\circ} \mathrm{C} / 1 \mathrm{~min}+120^{\circ} \mathrm{C} / 33.5 \mathrm{~min}$ & $24(0.6)$ & $27(2.0)$ \\
\hline
\end{tabular}

\subsubsection{Enzymatic degradation of high Mw WSS Pool I by PG/b-PME/RGE}

To confirm the presence of acetylation in the HG-region and to characterise the distribution of methyl esters and acetyl groups, a second enzymatic degradation step was performed on the acetylated polymeric pectin in high Mw Pool I originating from unprocessed carrot. This was done using polygalacturonase (PG), bacterial pectin methyl esterase (b-PME) and RG-I degrading enzymes (RGE). The effect of RG-I degrading enzymes on pectin degradation after heat processing will be discussed below in section 2.3.5.

A part of the methyl-esters was removed from the pectin by b-PME, enabling PG to better degrade the HG-region and to release partially methyl-esterified and acetylated oligosaccharides. It was calculated from the DM before and after b-PME treatment that roughly $40 \%$ of methyl-esters was still present after incubation of carrot pectin with b-PME from D. Dadantii. Although part of the information on the methyl-ester distribution is lost when using b-PME, still valuable information on the methyl-ester distribution in relation to acetyl groups can be obtained. RG-I degrading enzymes were used to degrade RG-I. Analysis of the RG-I oligosaccharides was done to check for acetylation in RG-I regions as well. 
Analysis of the PG/b-PME/RGE digest by MALDI-TOF-MS showed the presence of partially acetylated uronic acid oligomers of DP $\geq 6$ in the unprocessed carrot sample, confirming acetylation in the HG region (Fig. 2.3A). The distribution of acetyl groups must have been quite distinct, since hardly any oligosaccharides $\leq$ DP 5 were acetylated (data not shown). Although it is assumed that ionization efficiency decreases with increasing size and that the MS signal intensity can therefore not be used quantitatively, the MS intensity shows that the relative abundance of DP 3-5: 6-7: 8-10 is approximately 5:2:1 (data not shown). It can therefore be concluded that a quite substantial part of all pectin degraded to oligosaccharides is acetylated. As mentioned before, $40 \%$ of the methyl-esters was still present after incubation of unprocessed carrot pectin with b-PME. Partially methylesterified oligomers would therefore be expected after digestion with PG/b-PME/RGE. As can be observed in Figure 2.3, several oligosaccharides are tentatively suggested for one single $\mathrm{m} / \mathrm{z}$ value. The mode of action of $P G$ and the presence of partially methyl-esterified fragments indicate that, e.g., the hypothetical structures of fully methyl-esterified oligomer $6^{60}$ and the acetylated, non-methyl esterified oligomer $6^{02}$ as presented in Figure 2.3 as possible annotation of the oligomers are not likely to be dominant structures, whereas $6^{21}$ will be dominant. Following the same reasoning, also for DP 7-10, it can be concluded that both methyl-esterification and acetylation exist within the these oligomers. In order to differentiate between tentative structures, fragmentation spectra in section 2.3.5 will provide additional information. The oligosaccharides shown in fig. 2.3B confirm acetylation in the RG-I region after enzymatic digestion with PG/b-PME/RGE. It was shown before that digesting the pectins with PG/b-PME/RGE yielded partially acetylated RG-I oligosaccharides [27]. However, acetylation of the HG region is with certainty confirmed as well since the majority of the oligomers $\geq$ DP 6 are partially acetylated.

Determination of the degree of blockiness would be the most preferable way to quantitatively describe the distribution of acetyl groups. Remoroza et al (2014) successfully used HILIC-ELSD-MS to characterise and quantify GalA oligosaccharides since in sugar beet pectin also smaller oligosaccharides were acetylated [28]. The acetylated oligosaccharides in carrot pectin digests were larger ( $\geq$ DP 6 ) and not observed on HILIC-ELSD-MS, due to poor solubility under these chromatography conditions and/or due to poor ionisation. It was therefore only possible to describe the structures in a qualitative way by using MALDITOF MS. 

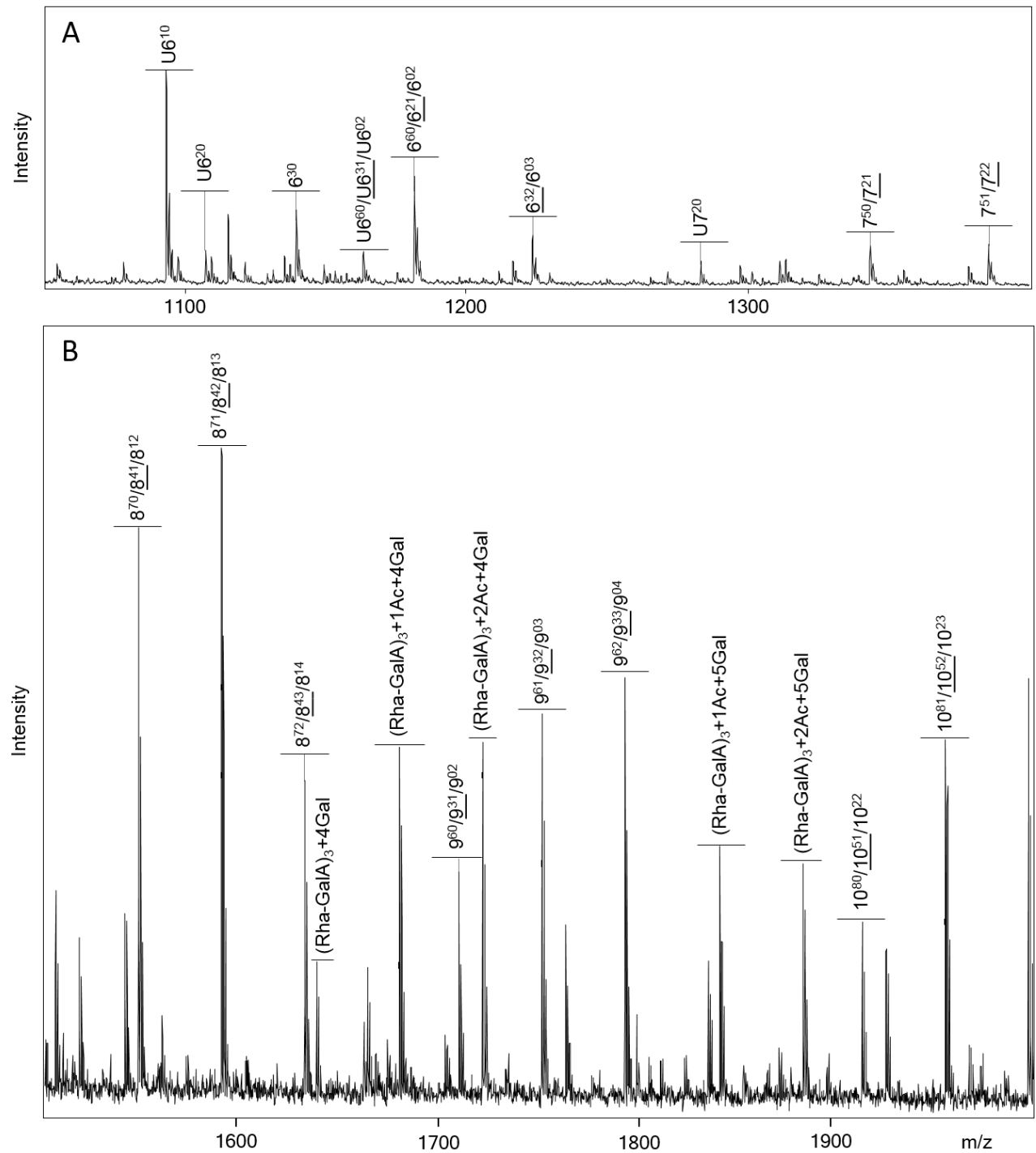

Figure 2.3 MALDI-TOF mass spectra of PG/b-PME/RGE digest of WSS from the unprocessed carrot, showing (A) DP 6-7 and (B) DP 8-10 oligomers. Peak annotation: 841, saturated GalA DP 8; 4 methylesters, 1 acetyl group. Gal, galactose; Rha, rhamnose; Ac, acetyl group. The most logical structure per isomer is underlined.

\subsubsection{Fragmentation of acetylated oligosaccharides}

In order to differentiate between tentative structures in the unprocessed pectin in WSS, acetylated oligomers were fragmented by MALDI-TOF/TOF mass spectrometry. 
Fragmentation of the parent ion $\mathrm{m} / \mathrm{z} 1751$ (961/932/903) is shown in figure 4. It can be seen that fragments from parent ion from both the reducing and the non-reducing end were found (mass difference of 18), e.g. $4^{20}$ and $4^{21}$. Most fragments formed from the parent were partially acetylated and partially methyl-esterified (Fig. 2.4). The fragments found, in combination with the mode of action of PG, showed that the major structures for $\mathrm{m} / \mathrm{z} 1751$ were 961 and 932. Fragmentation of other oligosaccharides $\geq$ DP 6 showed similar patterns with partially acetylated and partially methyl-esterified fragments. This confirmed that acetylation is present in distinct methyl-esterified regions. However, in order to more precisely describe these 2 major structures, additional separation prior to MS, or additional MS fragmentation is needed. This is also true for the other acetylated GalA oligomers present in the digest, since due to the structural variation in differently substituted pectin populations within WSS, the complexity was too high to reach complete sequencing of the oligosaccharides. Labelling of the reducing end to simplify interpretation of the fragmentation pattern, was not successful.

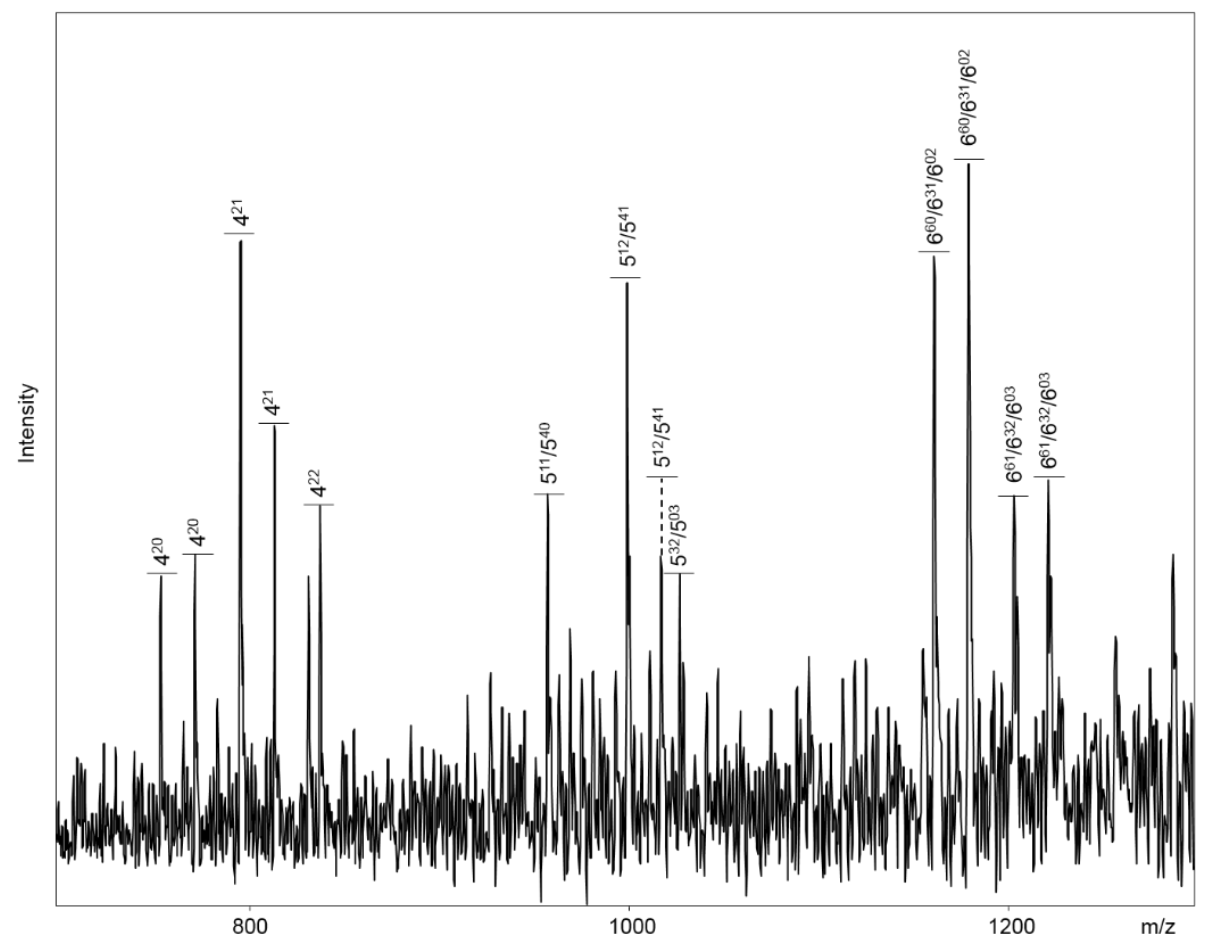

Figure 2.4 Selected zoom of MALDI-TOF/TOF mass spectrum of fragment oligosaccharides with parent $\mathrm{m} / \mathrm{z} 1751$ from the PG/b-PME/RGE digest of WSS from unprocessed carrot. Parent ions were tentatively annotated as $9^{61} / 9^{32}$. 
Degradation by PG and fungal PME ( $f$-PME) from A. niger did not lead to the formation of acetylated oligosaccharides visible by MALDI-TOF MS, whereas degradation by PG and bacterial PME (b-PME) from $D$. dadantii did. These degradation patterns give information about the distribution of the methyl-esters and acetyl groups. It was reported before that b-PME acts in a blockwise manner, whereas f-PME acts randomly [29]. Although a substantial part of the methyl-esters was removed by b-PME, it can be seen that most oligomers are still partially methyl-esterified. This indicates that acetylation is present in highly methyl-esterified regions since acetylated oligomers are only released after removing part of the methyl-esters from these regions. The fact that only a blockwise-acting b-PME allowed PG to release oligosaccharides therefore shows that the GalA residues in acetylated regions are highly methyl esterified, possibly even fully methyl-esterified. Furthermore, our results indicate a certain tolerance of b-PME towards acetylated GalA since b-PME was able to deesterify in acetylated regions whereas f-PME was not, which was previously observed for b-PME from other sources as well [30].

\subsubsection{Effect of heat treatment on HG in WSS}

Whereas the unprocessed carrot WSS after the second incubation with PG/b-PME/RGE showed highly acetylated oligomers, these were not observed in the heat processed carrot WSS PG/b-PME/RGE digest. As can be observed in Figure 2.5A, a mix of GalA and neutral oligomers was formed in the heat processed carrot PG/b-PME/RGE digest. The release of neutral oligosaccharides will be discussed below in section 2.3.8. Since higher DP uronides certainly were expected based on the DA of heat processed WSS but could not be recognized in the mass spectrum, it was assumed that neutral oligomers ionise more easily than acidic oligomers. To test this hypothesis, neutral oligomers were washed away by filtration using a $3 \mathrm{kDa}$ filter. Analysis of the retentate showed that the same acetylated oligosaccharides as found in the unprocessed carrot WSS PG/b-PME/RGE digest were indeed present in the heat processed carrot PG/b-PME/RGE digest (data not shown). This confirms that acetylation of GalA residues is not affected by heat processing.

\subsubsection{Characterisation of HG in ChSS after PG/b-PME/RGE digestion}

The same enzymatic degradation methods as described above were also used to characterise the effect of processing on detailed pectin structure in ChSS. Unprocessed and heat processed carrot ChSS were degraded by PG/PL to characterise the distribution of the methyl-esters and acetyl groups. Like in WSS, no acetylated oligosaccharides were found by MALDI-TOF MS in the PG/PL digest (data not shown). However, also the subsequent fractionation and degradation by PG/b-PME/RGE did not reveal the presence of acetylated oligosaccharides in unprocessed and heat processed carrot ChSS. With a DA of 3\% for the 
unprocessed carrot ChSS and 5-9\% for heat processed carrot ChSS, the acetyl groups are most probably exclusively present in RG-I and HG is not acetylated.

\subsubsection{Effect of heat treatment on RG-I in WSS and ChSS}

In section 2.3.4 it was demonstrated that acetylation was present on HG and RG-I.

As can be observed in figure $2.3 \mathrm{~A}$ and $2.3 \mathrm{~B}$, the digestion of unprocessed carrot WSS with PG/b-PME/RGE did not yield neutral oligosaccharides. Consequently, it was quite surprisingly that PG/b-PME/RGE digestion of heat processed carrot WSS and ChSS yielded neutral oligosaccharides originating from RG-I (Fig. 2.5). However, the oligosaccharides formed in both fractions were quite different, being enriched in pentose and hexose residues for WSS and ChSS respectively as will be discussed below.

Calculation of the ratio of RG-I to HG based on the sugar composition (Table 2.2) already showed that the ratio of RG-I to HG in WSS changed as an effect of processing, and the heat processed carrot WSS contained relatively more RG-I than the unprocessed carrot WSS. In order to understand the effect of heat processing and the enzyme accessibility of RG-I, it was of importance to identify all oligomers that were released. Based on the sugar composition in Table 2.2, the only pentose sugar present in WSS is arabinose. In the mass spectrum of heat processed carrot WSS digest, m/z 1229 (Fig 2.5A) corresponds with 9P or $5 \mathrm{Gal} A+1 \mathrm{DH}+1 \mathrm{H}$. Due to the presence of $8 \mathrm{P}, 10 \mathrm{P}, 11 \mathrm{P}$ and $12 \mathrm{P}$, it was assumed that $\mathrm{m} / \mathrm{z} 1229$ corresponds with 9P. This was confirmed by incubation with another set of arabinofuranosidases [31]. The presence of arabinose-based oligosaccharides after PG/b-PME/RGE digestion in heat processed WSS might indicate that arabinan was already partially modified by heat processing, and therefore more easily accessible for arabinanases. Partial modification of the pectic arabinan side chain by heat treatment might be explained by the fact that arabinose linkages are most labile amongst the glycosidic linkages in pectin [32].

Digestion of the heat processed carrot WSS with only endo-arabinanase did not degrade the oligomers, indicating that the arabinose oligomers are highly branched, as found for arabinans from most primary plant cell walls [33]. 

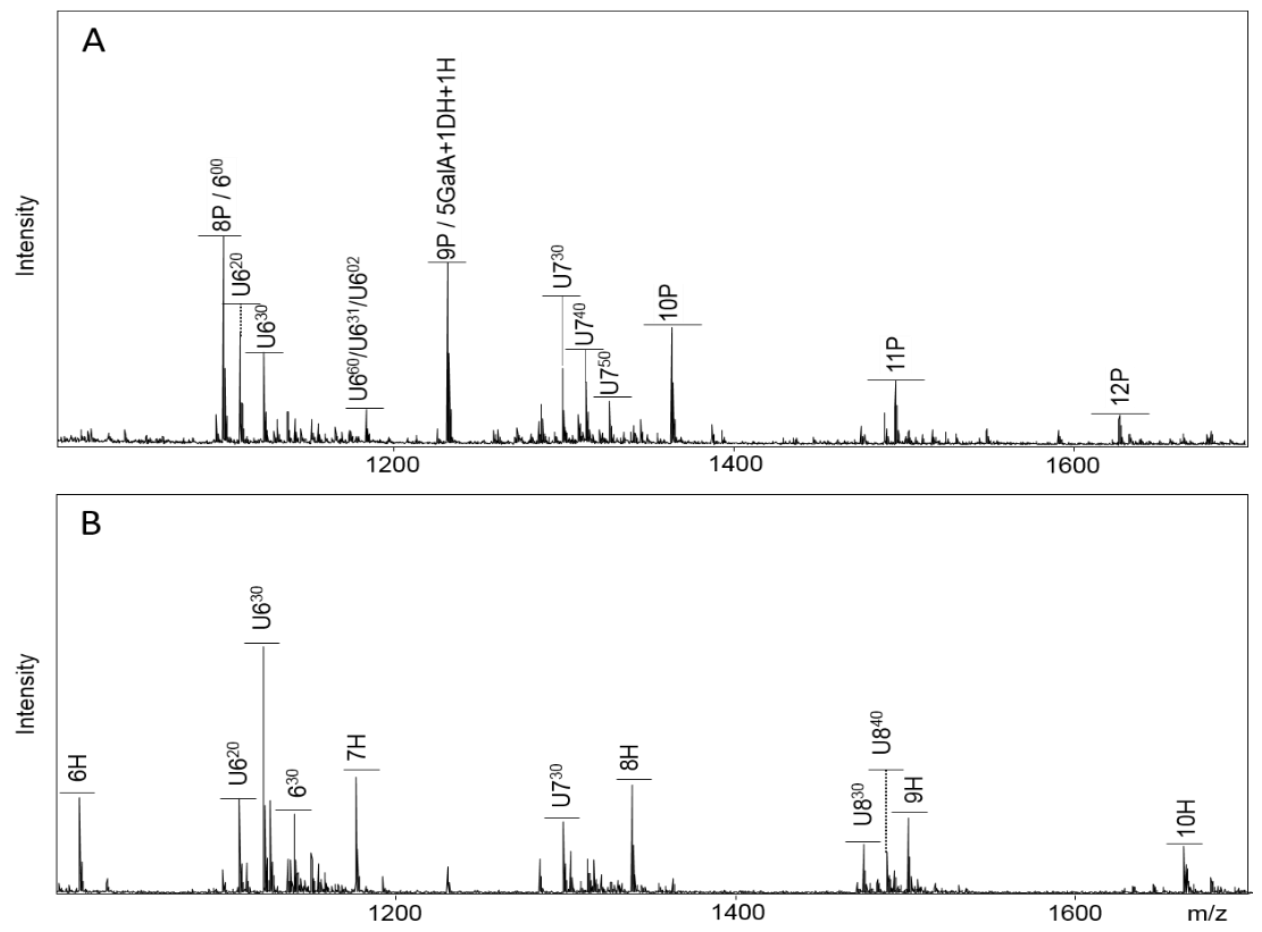

Figure 2.5 MALDI-TOF mass spectra of PG/b-PME/RGE digest of (A) WSS and (B) ChSS, both from heated carrot $\left(90^{\circ} \mathrm{C} / 5 \mathrm{~min}+110^{\circ} \mathrm{C} / 6 \mathrm{~min}\right)$. Peak annotation: $6^{00}$, saturated GalA DP 6; 0 methyl-esters, 0 acetyl group; $\mathrm{U}$ : Unsaturated GalA; $\mathrm{P}$, pentose; $\mathrm{DH}$, deoxy hexose; $\mathrm{H}$, hexose.

Like in WSS, the ratio of RG-I to HG in ChSS is higher in heat processed carrots than in unprocessed carrots (Table 2.2). Although ChSS contain both galactose (major) and glucose (minor) constituents, the hexose sugar present in the oligomers of the ChSS digest is most likely galactose, since released by galactanases present.

Comparison of the oligosaccharides formed by PG/b-PME/RGE digestion in unprocessed and heat processed carrots shows that the galactanase can be more active on ChSS in heat processed carrots. Galactan in ChSS from heat processed carrots is probably less branched with galactose or arabinose than galactan in WSS, and therefore more easily degradable by endo-galactanase. This shows that the galactan extracted into ChSS has a different structure from the galactan in WSS. Furthermore it also shows that not only the pectic arabinan side chains but also the galactan side chains are modified by heat processing. In unprocessed WSS and ChSS PG/b-PME/RGE digests no neutral oligosaccharides were formed. 


\subsection{Conclusions}

The study of the effects of processing on pectin structure revealed new characteristics of carrot pectin. Processing increases the yield of water soluble pectin by $\beta$-eliminative depolymerisation, and increased solubilisation of RG-I rich pectin. For the first time the presence of acetylated HG in unprocessed carrot tissue was shown evidently. The lower DM and higher DA in pectin from processed and non-processed carrots showed that acetyl groups are more stable during processing than methyl-esters.

After a controlled enzymatic degradation and fractionation procedure it was found that acetyl groups are present in both HG and RG-I. Acetylation in HG was found to be present in distinct, highly methyl-esterified regions. Depending on the type of pectin, heat processing partially modifies the arabinans and galactans found in RG-I, and enhances enzyme accessibility and subsequent degradability of the more linear structures.

These findings indicate the extended complexity of carrot cell wall pectins including acetylation on HG and RG-I. The findings also encourage studies to learn more about the functionality of acetylation within the carrot cell wall, and about the variability of structural elements in raw plant material and its processed equivalents.

\section{Acknowledgments}

This work received funding from the European Union's Seventh Framework Programme for Research, technological development and demonstration under Grant Agreement No. Kbbe-311754 (OPTIFEL). 


\section{References}

1. Sila, D., C. Smout, F. Elliot, A. Van Loey and M. Hendrickx, Non-enzymatic depolymerization of carrot pectin: Toward a better understanding of carrot texture during thermal processing. Journal of Food Science, 2006. 71(1): p. E1-E9.

2. Voragen, A.G., G.-J. Coenen, R.P. Verhoef and H.A. Schols, Pectin, a versatile polysaccharide present in plant cell walls. Structural Chemistry, 2009. 20(2): p. 263-275.

3. Sila, E. Doungla, C. Smout, A. Van Loey and M. Hendrickx, Pectin fraction interconversions: Insight into understanding texture evolution of thermally processed carrots. Journal of Agricultural and Food Chemistry, 2006. 54(22): p. 8471-8479.

4. Bemiller, J.N. and G.V. Kumari, Beta-Elimination in Uronic Acids - Evidence for an Elcb Mechanism. Carbohydrate Research, 1972. 25(2): p. 419-428.

5. Ramaswamy, U.R., M.A. Kabel, H.A. Schols and H. Gruppen, Structural features and water holding capacities of pressed potato fibre polysaccharides. Carbohydrate Polymers, 2013. 93(2): p. 589-596.

6. Ramasamy, U.S., H. Gruppen and H.A. Schols, Structural and water-holding characteristics of untreated and ensiled chicory root pulp. Journal of Agricultural and Food Chemistry, 2013. 61(25): p. 6077-6085.

7. Ralet, M.-C., M.-J. Crépeau and E. Bonnin, Evidence for a blockwise distribution of acetyl groups onto homogalacturonans from a commercial sugar beet (Beta vulgaris) pectin. Phytochemistry, 2008. 69(9): p. 1903-1909.

8. Remoroza, C., S. Broxterman, H. Gruppen and H.A. Schols, Two-step enzymatic fingerprinting of sugar beet pectin. Carbohydrate Polymers, 2014. 108: p. 338-347.

9. Houben, K., R.P. Jolie, I. Fraeye, A.M. Van Loey and M.E. Hendrickx, Comparative study of the cell wall composition of broccoli, carrot, and tomato: Structural characterization of the extractable pectins and hemicelluloses. Carbohydrate Research, 2011. 346(9): p. 1105-1111.

10. DuBois, M., K.A. Gilles, J.K. Hamilton, P.A. Rebers and F. Smith, Colorimetric method for determination of sugars and related substances. Analytical Chemistry, 1956. 28(3): p. 350-356.

11. Englyst, H.N. and J.H. Cummings, Simplified method for the measurement of total non-starch polysaccharides by gas-liquid chromatography of constituent sugars as alditol acetates. Analyst, 1984. 109(7): p. 937-942.

12. Huang, J.-H., A. Kortstee, D.C.T. Dees, L.M. Trindade, R.G.F. Visser, H. Gruppen, and H.A. Schols, Evaluation of both targeted and non-targeted cell wall polysaccharides in transgenic potatoes. Carbohydrate Polymers, 2017. 156: p. 312-321.

13. Klavons, J.A. and R.D. Bennett, Determination of methanol using alcohol oxidase and its application to methyl ester content of pectins. Journal of Agricultural and Food Chemistry, 1986. 34(4): p. 597-599.

14. Limberg, G., R. Körner, H.C. Buchholt, T.M.I.E. Christensen, P. Roepstorff, and J.D. Mikkelsen, Quantification of the amount of galacturonic acid residues in blocksequences in pectin homogalacturonan by enzymatic fingerprinting with exo- and endo-polygalacturonase II from Aspergillus niger. Carbohydrate Research, 2000. 327(3): p. 321-332.

15. Schols, H.A., M.A. Posthumus and A.G.J. Voragen, Structural features of hairy regions of pectins isolated from apple juice produced by the liquefaction process. Carbohydrate Research, 1990. 206(1): p. 117-129.

16. Beldman, G., M.J.F. Searle-van Leeuwen, G.A. De Ruiter, H.A. Siliha and A.G.J. Voragen, Degradation of arabinans by arabinanases from Aspergillus aculeatus and Aspergillus niger. Carbohydrate Polymers, 1993. 20(3): p. 159-168. 
17. Kühnel, S., S.W.A. Hinz, L. Pouvreau, J. Wery, H.A. Schols, and H. Gruppen, Chrysosporium lucknowense arabinohydrolases effectively degrade sugar beet arabinan. Bioresource Technology, 2010. 101(21): p. 8300-8307.

18. Voragen, A.G.J., H.A. Schols, J.A. De Vries and W. Pilnik, High-performance liquid chromatographic analysis of uronic acids and oligogalacturonic acids. Journal of Chromatography A, 1982. 244(2): p. 327-336.

19. Kravtchenko, T.P., I. Arnould, A.G.J. Voragen and W. Pilnik, Improvement of the selective depolymerization of pectic substances by chemical Beta-elimination in aqueous-solution. Carbohydrate Polymers, 1992. 19(4): p. 237-242.

20. Ly-Nguyen, B., A.M. Van Loey, C. Smout, S.E. Ozcan, D. Fachin, I. Verlent, S.V. Truong, T. Duvetter, and M.E. Hendrickx, Mild-heat and high-pressure inactivation of carrot pectin methylesterase: A kinetic study. Journal of Food Science, 2003. 68(4): p. 1377-1383.

21. Massiot, P., X. Rouau and J.F. Thibault, Structural Study of the Cell-Wall of Carrot (Daucus-Carota L) .2. Characterization of the Extractable Pectins and Hemicelluloses of the Cell-Wall of Carrot. Carbohydrate Research, 1988. 172(2): p. 229-242.

22. De Roeck, A., D.N. Sila, T. Duvetter, A. Van Loey and M. Hendrickx, Effect of high pressure/high temperature processing on cell wall pectic substances in relation to firmness of carrot tissue. Food Chemistry, 2008. 107(3): p. 1225-1235.

23. Santiago, J.S.J., S. Christiaens, A.M. Van Loey and M.E. Hendrickx, Deliberate processing of carrot purées entails tailored serum pectin structures. Innovative Food Science \& Emerging Technologies, 2016. 33: p. 515-523.

24. Schols, H.A. and A.G.J. Voragen, Occurrence of pectic hairy regions in various plant cell wall materials and their degradability by rhamnogalacturonase. Carbohydrate Research, 1994. 256(1): p. 83-95.

25. Braccini, I. and S. Pérez, Molecular Basis of Ca2+-Induced Gelation in Alginates and Pectins: The Egg-Box Model Revisited. Biomacromolecules, 2001. 2(4): p. 1089-1096.

26. Ralet, M.-C., J.C. Cabrera, E. Bonnin, B. Quéméner, P. Hellin, and J.-F. Thibault, Mapping sugar beet pectin acetylation pattern. Phytochemistry, 2005. 66(15): p. 1832-1843.

27. Remoroza, C., S. Cord-Landwehr, A.G.M. Leijdekkers, B.M. Moerschbacher, H.A. Schols, and H. Gruppen, Combined HILIC-ELSD/ESI-MSn enables the separation, identification and quantification of sugar beet pectin derived oligomers. Carbohydrate Polymers, 2012. 90(1): p. 41-48.

28. Remoroza, C., H.C. Buchholt, H. Gruppen and H.A. Schols, Descriptive parameters for revealing substitution patterns of sugar beet pectins using pectolytic enzymes. Carbohydrate Polymers, 2014. 101: p. 1205-1215.

29. Benen, J.A.E., J.-P. Vincken and G.-J.W.M. Van Alebeek, Microbial pectinases, in Pectins and Their Manipulation, G.B. Seymour and J.P. Knox, Eds. 2002, Blackwell Publising Ltd: Oxford, UK. p. 174221.

30. Remoroza, C., M. Wagenknecht, H.C. Buchholt, B.M. Moerschbacher, H. Gruppen, and H.A. Schols, Mode of action of Bacillus licheniformis pectin methylesterase on highly methylesterified and acetylated pectins. Carbohydrate Polymers, 2015. 115: p. 540-550.

31. Rombouts, F.M., A.G.J. Voragen, M.F. Searle-van Leeuwen, C.C.J.M. Geraeds, H.A. Schols, and W. Pilnik, The arabinanases of Aspergillus niger - Purification and characterisation of two $\alpha-I-$ arabinofuranosidases and an endo-1,5- $\alpha$-l-arabinanase. Carbohydrate Polymers, 1988. 9(1): p. 25-47.

32. Thibault, J.-F., C.M.G.C. Renard, M.A.V. Axelos, P. Roger and M.-J. Crépeau, Studies of the length of homogalacturonic regions in pectins by acid hydrolysis. Carbohydrate Research, 1993. 238: $p$. 271-286. 
33. Grant Reid, J.S., Carbohydrate metabolism: Structural carbohydrates, in Plant Biochemistry, P.M. Dey and J.B. Harborne, Eds. 1997, Academic Press: London. p. 205-236. 




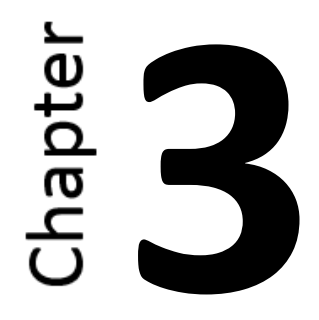

\section{Interactions between pectin and cellulose in carrot primary plant cell walls}

Published as: S.E. Broxterman, H.A. Schols, Interactions between pectin and cellulose in primary plant cell walls. Carbohydrate Polymers 2018, 192, 263-272 


\section{Abstract}

To understand the architecture of the plant cell wall, it is of importance to understand both structural characteristics of cell wall polysaccharides and interactions between these polysaccharides. Interactions between polysaccharides were studied in the residue after water and chelating agent extraction by sequential extractions with $\mathrm{H}_{2} \mathrm{O}$ and alkali. The $6 \mathrm{M}$ alkali residue still represented $31 \%, 11 \%$ and $5 \%$ of all GalA present in carrot, tomato and strawberry, respectively, and these pectin populations were assumed to strongly interact with cellulose. Digestion of the carrot $6 \mathrm{M}$ alkali residue by glucanases released $\sim 27 \%$ of the $6 \mathrm{M}$ residue, mainly representing pectin. In tomato and strawberry alkali residues, glucanases were not able to release pectin populations. The ability of glucanases to release pectin populations suggests that the carrot cell wall contains unique, covalent interactions between pectin and cellulose. 


\subsection{Introduction}

The primary plant cell wall is essential for strength, growth and development of the plant [1]. In edible tissue it is also of major importance for texture. The plant cell wall predominantly consists of pectin, hemicellulose and cellulose. Pectin consists of galacturonic acid as the most prevailing building block, mostly present in the homogalacturonan (HG) and in the rhamnogalacturonan I (RG-I) structural elements. Whereas the HG backbone is only composed of galacturonic acid residues, the RG-I backbone is composed of alternating rhamnose and galacturonic acid residues. The rhamnose residues in RG-I can be substituted with neutral sugar side chains, composed of arabinose and galactose [2]. Hemicelluloses are composed of xylans, xyloglucans and mannans [3]. Xyloglucan is the major hemicellulosic polysaccharide in primary plant cell walls of fruits and vegetables, and is composed of a cellulose-like backbone branched at 0-6 by xylosyl residues. The xylose units can be substituted by several other monosaccharides such as galactose, fucose and arabinose [4]. Cellulose consists of a linear chain composed of $\beta$-(1 $\rightarrow 4)$-linked glucose residues [3].

The plant cell wall is long believed to be composed of two separate networks: a pectin network and a hemicellulose/cellulose network [5]. Although this model of the plant cell wall is still generally accepted, increasing evidence shows interactions between these two networks and a more dominant role for pectin as part of the load-bearing cell wall structures [6]. The cell wall components involved and the exact nature of the interactions are still unknown, although evidence is found for both covalent and for non-covalent interactions between both networks $[7,8]$. The most well-known and fully accepted interaction between cell wall polysaccharides is the adsorption of xyloglucan onto cellulose by $\mathrm{H}$-bonds, hereby coating cellulose [9]. Similarly, many other interactions are also suggested such as interactions between xyloglucan and RG-I side chains or between xylan and RG-I side chains $[10,11]$. Interactions between RG-I and cellulose were shown in vitro, by adsorption of RG-I side chains to cellulose [12]. Linkages between cellodextrins and HG have been described, but the precise annotation and allocation has not been presented [13]. Next to polysaccharide interactions, interactions involving cell wall proteins such as extensin and AGP have been found $[8,14]$. The nature of the potential interactions between cell wall polysaccharides and proteins remains unclear, although it is speculated that many of these covalent and non-covalent interactions are based on ester linkages and $\mathrm{H}$-bonds [15].

Most of the dicot primary plant cell models indicate a dominant role for hemicellulose within the network. Therefore it was chosen to study the cell wall architecture of carrot, tomato and strawberry, 3 sources with a different hemicellulose content and composition $[16,17]$. Since both ester linkages and $\mathrm{H}$-bonds are not stable under strong alkali conditions, sequential alkali extraction was used as a method to degrade possible ester cross-links and 
characterise solubilised polysaccharide populations from the cell wall of carrot, tomato and strawberry. Pectinase and glucanase digestions were performed to release strongly interacting pectin populations from the alkali residues.

\subsection{Materials and methods}

\subsubsection{Plant material}

Carrots (Daucus carota cv. Romance) and strawberries (Fragaria ananassa cv. Elsanta) were purchased from a local vegetable store. Tomatoes (Solanum lycopersicum cv. H2401) were kindly donated by Heinz (Heinz, Nijmegen, The Netherlands).

\subsubsection{Extraction of cell wall polysaccharides}

Cell wall polysaccharides were extracted using the procedure as described before $[16,18]$. Shortly, Alcohol Insoluble Solids (AIS) were extracted by blending carrots, tomatoes and strawberries in a $1: 3 \mathrm{w} / \mathrm{v}$ ratio in $96 \%$ ethanol. Prior to blending, only for peeled tomatoes, microwave pretreatment was performed to inactivate pectinases (10 $\mathrm{min}, 900 \mathrm{~W})$. The suspension was filtered and the residue was washed with $70 \%$ ethanol until the filtrate gave a negative reaction in the phenol-sulfuric acid test [19]. The water soluble solids (WSS) and chelating agent soluble solids (ChSS) were subsequently extracted from AIS according to the references mentioned above. The residue after WSS and ChSS was extensively dialysed, first against potassium acetate, followed by distilled water. After freeze-drying the Chelating agent Unextractable Solids (ChUS) were obtained. This fraction was used to identify potential interactions between pectin, hemicellulose and cellulose. All fractions were milled for 30s in a Retsch Cryomill MM440 at a frequency of $20 \mathrm{~Hz}$ to obtain homogeneous material (Retsch $\mathrm{GmbH}$, Haan, Germany). Dry matter content of starting materials was determined in triplicate by drying $\sim 500 \mathrm{mg}$ of sample at $105^{\circ} \mathrm{C}$ for 3 hours.

\subsubsection{Sequential water-alkali extraction to yield $6 \mathrm{M} \mathrm{NaOH}$ and $0.1 \mathrm{M} \mathrm{NaOH}$ residues}

In order to selectively degrade alkali-labile interactions in the primary plant cell wall, sequential water-alkali extraction was performed according to the extraction diagram shown in Supporting Information Figure S-3.1. $30 \mathrm{ml}$ water was added to $300 \mathrm{mg}$ ChUS from carrot, tomato or strawberry. Extraction was done overnight at $40^{\circ} \mathrm{C}$, the suspension centrifuged $\left(20 \mathrm{~min}, 20^{\circ} \mathrm{C}, 30.000 \mathrm{xg}\right.$ ) and the supernatant was freeze-dried. $30 \mathrm{ml} 0.1 \mathrm{M}$ $\mathrm{NaOH}$ containing $25 \mathrm{mM} \mathrm{NaBH}_{4}$ was added to the residue and extraction was done for $6 \mathrm{~h}$ at $4^{\circ} \mathrm{C}$. After centrifugation $\left(20 \mathrm{~min}, 4^{\circ} \mathrm{C}, 30.000 \mathrm{xg}\right)$, the residue was washed with $30 \mathrm{ml}$ $0.1 \mathrm{M} \mathrm{NaOH}$ containing $25 \mathrm{mM} \mathrm{NaBH}_{4}$ for 30 minutes at $4^{\circ} \mathrm{C}$ and centrifuged again $(20 \mathrm{~min}$, $4^{\circ} \mathrm{C}, 30.000 \mathrm{xg}$ ). Supernatants were pooled. 
Both supernatant and residue were neutralized to $\mathrm{pH}$ 6. The supernatant was ultrafiltered by using a $10 \mathrm{kDa}$ filter (Millipore centrifugal filter units, Merck, Billerica, Massachusetts, United States) and subsequently freeze-dried. $30 \mathrm{ml} \mathrm{H}_{2} \mathrm{O}$ was added to the residue and water extraction was performed at $40^{\circ} \mathrm{C}$ overnight. The suspension was centrifuged $(20 \mathrm{~min}$, $20^{\circ} \mathrm{C}, 30.000 \mathrm{xg}$ ) and the supernatant was freeze-dried after ultrafiltration with a $10 \mathrm{kDa}$ filter.

The same procedure was repeated with $1 \mathrm{M} \mathrm{NaOH}$ containing $0.25 \mathrm{M} \mathrm{NaBH}$ followed by water, and $6 \mathrm{M} \mathrm{NaOH}$ with $0.25 \mathrm{M} \mathrm{NaBH}_{4}$ followed by water. All alkali extractions were done at $4^{\circ} \mathrm{C}$ for $6 \mathrm{~h}$, water extractions overnight at $40^{\circ} \mathrm{C}$, and all with head-over-tail rotation.

To obtain the $0.1 \mathrm{M}$ alkali residue, the same procedure was followed as described above. However, after water extraction following the $0.1 \mathrm{M} \mathrm{NaOH}$ extraction, the residue was neutralised, ultrafiltrated and freeze-dried to obtain the $0.1 \mathrm{M}$ alkali Residue.

\subsubsection{Sugar composition of the extracts}

To determine the pectin content of the extracted fractions, the uronic acid content was determined by the automated colorimetric m-hydroxydiphenyl method [20]. Neutral carbohydrate composition was analysed after pretreatment with $72 \%$ (w/w) $\mathrm{H}_{2} \mathrm{SO}_{4}(1 \mathrm{~h}$, $30^{\circ} \mathrm{C}$ ) followed by hydrolysis with $1 \mathrm{M} \mathrm{H}_{2} \mathrm{SO}_{4}\left(3 \mathrm{~h}, 100^{\circ} \mathrm{C}\right)$. Sugars released were derivatised and analysed as their alditol acetates using gas chromatography [21], inositol was used as internal standard.

\subsubsection{Starch digestion}

The presence of starch in AIS, WSS, ChSS and ChUS was analysed by using the Megazyme total starch assay procedure for resistant starch (Megazyme, Wicklow, Ireland). After digestion of the sample with amylase and amyloglucosidase, samples were filtered using a $10 \mathrm{kDa}$ filter to remove glucose originating from starch and freeze-dried. Starch was not removed prior to the fractionation of AIS into WSS, ChSS and ChUS. Starch levels were determined in isolated fractions, and all monosaccharide compositions given represent destarched fractions.

\subsubsection{Enzymatic digestion of pectin populations in the $0.1 \mathrm{M}$ and $6 \mathrm{M}$ alkali residue}

In order to test the accessibility of pectin in the $0.1 \mathrm{M}$ and $6 \mathrm{M}$ alkali residues, incubations with pectinases and glucanases were performed. The pectinases used were rhamnogalacturonan hydrolase (RG-H) from Aspergillus aculeatus, endo-polygalacturonase (PG) from Aspergillus aculeates [22], endo- $\beta$-(1,4)-galactanase from Aspergillus niger [23], $\beta$-galactosidase from Aspergillus niger, and endo-arabinanase from Aspergillus aculeates and exo-arabinanase from Chrysosporium lucknowense [24]. The glucanases used were 
endo-glucanase from Trichoderma viride and exoglucanase/CBH from Trichoderma viride [25]. Digestion was done at $5 \mathrm{mg} / \mathrm{ml}$ in $50 \mathrm{mM}$ sodium citrate buffer $\mathrm{pH} 5$ at $40^{\circ} \mathrm{C}$ (pectinases) or at $50^{\circ} \mathrm{C}$ (glucanases) by head-over-tail rotation for $24 \mathrm{~h}$. Enzymes were dosed to fully degrade the specific substrate in $6 \mathrm{~h}$. Isolation of solubilised polysaccharides $>10 \mathrm{kDa}$ was done using centrifugal filter units with a cut-off of $10 \mathrm{kDa}$.

All enzymes used were well characterised and extensively tested for their purity including the different pectin structure elements (HG, RG-I backbone and side chains), and did not show side activity.

\subsubsection{Structural characterisation of the extracts}

\subsubsection{High Performance Size Exclusion Chromatography (HPSEC)}

Extracted pectin fractions before and after enzymatic digestion were analysed for their molecular weight distribution using an Ultimate 3000 system (Dionex, Sunnyvale, CA, USA) coupled to a Shodex RI-101 detector (Showa Denko K.K., Tokyo, Japan). A set of TSK-Gel super AW columns 4000, 3000, $2000(6 \mathrm{~mm} \times 150 \mathrm{~mm}$ ) preceded by a TSK-Gel super AW guard column ( $6 \mathrm{~mm}$ ID $\times 40 \mathrm{~mm}$ ) (Tosoh Bioscience, Tokyo, Japan) was used in series. The column temperature was set to $55^{\circ} \mathrm{C}$. Samples $(5 \mathrm{mg} / \mathrm{ml})$ were injected $(10 \mu \mathrm{l})$ and eluted with $0.2 \mathrm{M} \mathrm{NaNO}_{3}$ at a flow rate of $0.6 \mathrm{ml} / \mathrm{min}$. Pectin standards from 10-100 kDa were used to estimate the molecular weight distribution [26].

\subsubsection{Matrix-Assisted Laser Desorption/Ionization Time-Of-Flight Mass Spectrometry (MALDI-TOF MS)}

The oligosaccharides in the glucanase digests of the $6 \mathrm{M}$ and $0.1 \mathrm{M}$ alkali residues were analysed by MALDI-TOF MS. MALDI-TOF mass spectra were recorded using an Ultraflextreme workstation controlled by FlexControl 3.3 software (Bruker Daltonics, Bremen, Germany) equipped with a Smartbeam II laser of $355 \mathrm{~nm}$ and operated in positive mode.

Before analysis by MALDI-TOF MS, samples were desalted with Dowex 50W-X8 (Bio-Rad Laboratories, CA, USA) and $1 \mu \mathrm{L}$ of sample was co-crystallised with $1 \mu \mathrm{L}$ matrix $(25 \mathrm{mg} / \mathrm{mL}$ dihydroxy-benzoic acid in $50 \%(\mathrm{v} / \mathrm{v})$ acetonitrile). Samples were dried under a stream of air. Maltodextrin MD 20 (Avebe, Foxhol, The Netherlands) was used for calibration.

\subsubsection{High performance anion exchange chromatography (HPAEC)}

Cellodextrins DP 1-6 in the glucanase digests were analysed and quantified using an ICS5000 High Performance Anion Exchange Chromatography system with Pulsed Amperometric detection (ICS5000 ED) (Dionex Corporation, Sunnyvale, CA, USA) equipped with a CarboPac PA-1 column ( $250 \mathrm{~mm} \times 2 \mathrm{~mm}$ i.d.) and a CarboPac PA guard column 
(25 $\mathrm{mm} \times 2 \mathrm{~mm}$ i.d.). The two mobile phases were (A) $0.1 \mathrm{M} \mathrm{NaOH}$ and (B) $1 \mathrm{M} \mathrm{NaOAc}$ in $0.1 \mathrm{M} \mathrm{NaOH}$ and the column temperature was $20^{\circ} \mathrm{C}$.

The elution profiles were as follows: 0-51 min 0-34\% B, 51-56 min 100\% B, and column reequilibration by $0 \%$ B from $56-71 \mathrm{~min}$. Samples $(0.5 \mathrm{mg} / \mathrm{ml})$ were injected $(10 \mu \mathrm{l})$ and eluted at a flow rate of $0.3 \mathrm{ml} / \mathrm{min}$. Cellodextrins DP 1-6 (Megazyme, Wicklow, Ireland) were used as standards for quantification.

\subsection{Results and discussion}

\subsubsection{Yield and composition of different pectin populations}

In order to study the interactions between cell wall polysaccharides, the cell wall polysaccharides of carrots, tomatoes and strawberries were isolated as Alcohol insoluble solids (AIS). Subsequently AIS was fractionated into Water Soluble Solids (WSS), Chelating agent Soluble Solids (ChSS), and the residue Chelating agent Unextractable Solids (ChUS). The dry matter content and yield of each fraction is shown in Table 3.1.

Table 3.1 Dry matter content of carrot, tomato and strawberry. Percentage of AIS isolated from fruit and vegetables are given on dry matter basis. Yield of WSS, ChSS and ChUS are expressed as percentage of AIS. Mean ( \pm absolute deviation), $n=2$ for extractions, $n=3$ for dry matter content.

\begin{tabular}{|l|c|c|c|c|c|}
\hline \multirow{2}{*}{} & \multirow{2}{*}{$\begin{array}{c}\text { Dry matter } \\
\text { content (\%) }\end{array}$} & \multirow{2}{*}{$\begin{array}{c}\text { \% AIS/ } \\
\text { Dry matter }\end{array}$} & \multicolumn{3}{|c|}{ Percentage of AIS (\%) } \\
\cline { 4 - 6 } & & WSS & ChSS & ChUS \\
\hline Carrot & $9.9(0.7)$ & $35(3.0)$ & $8(1.2)$ & $16(1.7)$ & $82(2.1)$ \\
\hline Tomato & $6.1(0.3)$ & $22(0.8)$ & $9(0.7)$ & $21(0.7)$ & $73(2.1)$ \\
\hline Strawberry & $7.4(0.8)$ & 19 & 15 (n.d.)* & 30 (n.d.)* & 68 (n.d.)* \\
\hline
\end{tabular}

*Isolation of strawberry AIS, WSS, ChSS and the residue ChUS was not performed in duplicate.

Differences in dry matter content and \% AIS/dry matter for different sources are apparent (Table 3.1).

The amount of extracted WSS and ChSS from AIS (\%) is highest for strawberry, indicating that strawberry contains the highest percentage of water soluble and calcium-bound pectin of the three sources studied, respectively. However, for all sources the majority of cell wall polysaccharides is not extracted by water or EDTA and is recovered in the ChUS fraction. 
Table 3.2 Monosaccharide composition (mol\%) of extracted AIS, WSS, ChSS and ChUS fractions isolated from carrot, tomato and strawberry. Percentage of GalA solubilised in WSS, ChSS and ChUS as percentage of GalA in AIS. Mean ( \pm absolute deviation), $n=2$.

\begin{tabular}{|c|c|c|c|c|c|c|c|c|c|}
\hline & \multicolumn{7}{|c|}{ Mol \% } & \multirow{2}{*}{$\begin{array}{l}\% \text { UA } \\
\text { of AIS }\end{array}$} \\
\hline & & Ara & Rha & Gal & Glc & Xyl & Man & UA & \\
\hline \multirow{4}{*}{ Carrot } & AIS & $\begin{array}{c}8 \\
(0.0)\end{array}$ & $\begin{array}{c}1 \\
(0.1)\end{array}$ & $\begin{array}{c}20 \\
(0.1)\end{array}$ & $\begin{array}{c}31 \\
(0.1)\end{array}$ & $\begin{array}{c}2 \\
(0.1)\end{array}$ & $\begin{array}{c}5 \\
(0.0)\end{array}$ & $\begin{array}{c}33 \\
(0.2)\end{array}$ & \\
\hline & WSS & $\begin{array}{c}8 \\
(0.1) \\
\end{array}$ & $\begin{array}{c}1 \\
(0.0) \\
\end{array}$ & $\begin{array}{c}19 \\
(0.4) \\
\end{array}$ & $\begin{array}{c}11 \\
(0.2) \\
\end{array}$ & $\begin{array}{c}1 \\
(0.0) \\
\end{array}$ & $\begin{array}{c}7 \\
(0.4) \\
\end{array}$ & $\begin{array}{c}53 \\
(0.7) \\
\end{array}$ & $8(0.1)$ \\
\hline & ChSS & $\begin{array}{c}4 \\
(0.0)\end{array}$ & $\begin{array}{c}1 \\
(0.0)\end{array}$ & $\begin{array}{c}7 \\
(0.2)\end{array}$ & $\begin{array}{c}3 \\
(0.3)\end{array}$ & $\begin{array}{c}0 \\
(0.0)\end{array}$ & $\begin{array}{c}5 \\
(0.1)\end{array}$ & $\begin{array}{c}80 \\
(0.5)\end{array}$ & $\begin{array}{c}15 \\
(1.0)\end{array}$ \\
\hline & ChUS & $\begin{array}{c}8 \\
(0.0)\end{array}$ & $\begin{array}{c}1 \\
(0.1)\end{array}$ & $\begin{array}{c}21 \\
(0.2)\end{array}$ & $\begin{array}{c}36 \\
(0.1)\end{array}$ & $\begin{array}{c}2 \\
(0.0)\end{array}$ & $\begin{array}{c}5 \\
(0.0)\end{array}$ & $\begin{array}{c}27 \\
(0.1)\end{array}$ & $\begin{array}{c}69 \\
(3.5)\end{array}$ \\
\hline \multirow{4}{*}{ Tomato } & AIS & $\begin{array}{c}6 \\
(0.1)\end{array}$ & $\begin{array}{c}1 \\
(0.0)\end{array}$ & $\begin{array}{c}7 \\
(0.2)\end{array}$ & $\begin{array}{c}42 \\
(0.1)\end{array}$ & $\begin{array}{c}7 \\
(0.2)\end{array}$ & $\begin{array}{c}6 \\
(0.1)\end{array}$ & $\begin{array}{c}31 \\
(0.7)\end{array}$ & \\
\hline & WSS & $\begin{array}{c}10 \\
(0.2)\end{array}$ & $\begin{array}{c}2 \\
(0.1)\end{array}$ & $\begin{array}{c}14 \\
(0.2) \\
\end{array}$ & $\begin{array}{c}5 \\
(0.1) \\
\end{array}$ & $\begin{array}{c}6 \\
(0.1) \\
\end{array}$ & $\begin{array}{c}1 \\
(0.1)\end{array}$ & $\begin{array}{c}62 \\
(0.4) \\
\end{array}$ & $\begin{array}{c}16 \\
(4.7) \\
\end{array}$ \\
\hline & ChSS & $\begin{array}{c}8 \\
(0.1) \\
\end{array}$ & $\begin{array}{c}1 \\
(0.3)\end{array}$ & $\begin{array}{c}8 \\
(0.4) \\
\end{array}$ & $\begin{array}{c}0 \\
(0.2) \\
\end{array}$ & $\begin{array}{c}0 \\
(0.0)\end{array}$ & $\begin{array}{c}0 \\
(0.0) \\
\end{array}$ & $\begin{array}{c}83 \\
(1.0) \\
\end{array}$ & $\begin{array}{c}28 \\
(0.7) \\
\end{array}$ \\
\hline & ChUS & $\begin{array}{c}5 \\
(0.1)\end{array}$ & $\begin{array}{c}1 \\
(0.1)\end{array}$ & $\begin{array}{c}6 \\
(0.0)\end{array}$ & $\begin{array}{c}55 \\
(0.8)\end{array}$ & $\begin{array}{c}8 \\
(0.1)\end{array}$ & $\begin{array}{c}6 \\
(0.1)\end{array}$ & $\begin{array}{c}19 \\
(0.5)\end{array}$ & $\begin{array}{c}50 \\
(2.3)\end{array}$ \\
\hline \multirow{4}{*}{ Strawberry } & AIS & $\begin{array}{c}8 \\
(0.1)\end{array}$ & $\begin{array}{c}1 \\
(0.2)\end{array}$ & $\begin{array}{c}8 \\
(0.1)\end{array}$ & $\begin{array}{c}25 \\
(2.1)\end{array}$ & $\begin{array}{c}8 \\
(0.2)\end{array}$ & $\begin{array}{c}3 \\
(0.1)\end{array}$ & $\begin{array}{c}47 \\
(2.4)\end{array}$ & \\
\hline & WSS & $\begin{array}{c}9 \\
(0.1) \\
\end{array}$ & $\begin{array}{c}1 \\
(0.2) \\
\end{array}$ & $\begin{array}{c}7 \\
(0.2) \\
\end{array}$ & $\begin{array}{c}2 \\
(0.2) \\
\end{array}$ & $\begin{array}{c}1 \\
(0.0) \\
\end{array}$ & $\begin{array}{c}0 \\
(0.0) \\
\end{array}$ & $\begin{array}{c}80 \\
(0.7) \\
\end{array}$ & $\begin{array}{c}33 \\
\text { (n.d.) }\end{array}$ \\
\hline & ChSS & $\begin{array}{c}7 \\
(0.2) \\
\end{array}$ & $\begin{array}{c}1 \\
(0.1)\end{array}$ & $\begin{array}{c}4 \\
(0.0) \\
\end{array}$ & $\begin{array}{c}0 \\
(0.1)\end{array}$ & $\begin{array}{c}0 \\
(0.0) \\
\end{array}$ & $\begin{array}{c}0 \\
(0.1)\end{array}$ & $\begin{array}{c}88 \\
(0.2) \\
\end{array}$ & $\begin{array}{c}36 \\
\text { (n.d.)* }\end{array}$ \\
\hline & ChUS & $\begin{array}{c}8 \\
(0.3)\end{array}$ & $\begin{array}{c}1 \\
(0.2)\end{array}$ & $\begin{array}{c}9 \\
(0.3)\end{array}$ & $\begin{array}{c}39 \\
(2.2)\end{array}$ & $\begin{array}{c}9 \\
(0.2)\end{array}$ & $\begin{array}{c}3 \\
(0.1)\end{array}$ & $\begin{array}{c}30 \\
(2.1)\end{array}$ & $\begin{array}{c}37 \\
\text { (n.d.)* }\end{array}$ \\
\hline
\end{tabular}

*Since strawberry AIS, WSS, ChSS and the residue ChUS were not determined (n.d.) in duplicate, the GalA recovery could not be expressed in duplicate. Starch contents have been measured separately and glc levels represent non-starch glucans.

The monosaccharide composition of the fractions obtained after isolation of AIS into WSS, ChSS and the residue ChUS was determined to characterise the different cell wall polysaccharides and is presented in Table 3.2. Starch was only present in carrot and absent in tomato and strawberry. Analysis of the starch content of isolated AIS, WSS, ChSS and ChUS showed the presence of 15, 30, 8 and $3 \mathrm{w} / \mathrm{w} \%$ starch, respectively. Comparison of the monosaccharide composition of carrot, tomato and strawberry ChUS showed that Glc and UA were the predominant monosaccharides. Especially in carrot, but also in tomato and strawberry xylose levels were rather low, and therefore GalA rather than GlcA was assumed to be the predominant UA. The level of Glc present is due to the insolubility of hemicellulose and cellulose in water and EDTA. It has been shown before that not all pectin is extracted by water and EDTA, explaining the presence of GalA in ChUS [27]. The percentages of GalA 
found in WSS and ChSS were rather similar to values found previously for tomato, while the amounts of GalA ending up in carrot WSS and ChSS were much lower even though similar extraction protocols were used [16]. Although the isolation of strawberry cell wall material was only done once, similar extraction yields for isolation of cell wall polysaccharides ( 1.5 $\mathrm{g}$ cell wall polysaccharides/100 g fresh product) and soluble pectins from strawberry ( $~ 30 \%$ of all UA in water soluble fractions) were reported previously [28, 29]. Furthermore water soluble pectins from strawberry were very high in uronic acid [30], similar to the results reported in Table 3.2.

It is assumed that the water insoluble or chelating agent insoluble pectin in ChUS is present due to interactions with the other cell wall polysaccharides. Characterisation of these pectin populations will be further studied below.

\subsubsection{Sequential alkali extraction}

A major challenge in studying interactions between polysaccharides is the insolubility of the pectin populations that remain in the cell wall after extraction of water soluble and $\mathrm{Ca}$ bound pectins by water and EDTA. Therefore the approach was chosen to selectively degrade cross-links by increasing alkali strength. Sequential alkali extractions of ChUS were performed since it is known that by increasing alkali concentrations pectin and hemicellulose can be gradually extracted [31], due to degradation of all ester linkages and $\mathrm{H}$-bonds between polysaccharides [32]. Furthermore $6 \mathrm{M} \mathrm{NaOH}$ is known to cause swelling of the cellulose and is therefore supposed to release polysaccharide populations which are physically entrapped in cellulose [33].

For the fractionation of ChUS a first extraction step using $\mathrm{H} 2 \mathrm{O}$ (fraction $\mathrm{H} 2 \mathrm{O}$ ) was performed since a pilot extract showed that despite the preceding chelating agent extraction, still some pectin was water soluble. Although mechanisms were unknown, it was hypothesized that freeze-drying alters the cell wall polysaccharides in such a way that new water soluble populations are formed.

The yield and monosaccharide composition of the extracted fractions are shown in Table 3.3. The recovery of the sum of all fractions based on ChUS was respectively $81 \%, 78 \%$ and $79 \%$ for carrot, tomato and strawberry on dry matter basis, respectively. 
Table 3.3 Monosaccharide composition (mol\%) and yield of each fraction, based on ChUS (\%), of the fractions extracted by sequential water and alkali extraction. Mean ( \pm absolute deviation), $n=2$.

\begin{tabular}{|c|c|c|c|c|c|c|c|c|c|}
\hline \multirow[b]{2}{*}{ Carrot } & \multicolumn{8}{|c|}{ Mol \% } & \multirow{2}{*}{$\begin{array}{l}\text { Yield (\% } \\
\text { of ChUS)* }\end{array}$} \\
\hline & & Ara & Rha & Gal & Glc & Xyl & Man & UA & \\
\hline $\mathrm{H} 2 \mathrm{O}$ & $\mathrm{H} 2 \mathrm{O}$ & $9(0.2)$ & $1(0.5)$ & $11(0.2)$ & $31(1.9)$ & $1(0.5)$ & $1(0.5)$ & $46(0.9)$ & 4 \\
\hline $0.1 \mathrm{M} \mathrm{NaOH}$ & $0.1 \mathrm{M}$ & $18(0.2)$ & $2(0.5)$ & $25(1.3)$ & $1(0.2)$ & $0(0.2)$ & $2(0.2)$ & $52(0.8)$ & 21 \\
\hline $\mathrm{H} 2 \mathrm{O}$ after $0.1 \mathrm{M}$ & $0.1 \mathrm{M}-\mathrm{H} 2 \mathrm{O}$ & $21(1.1)$ & $3(0.4)$ & $33(3.8)$ & $1(0.5)$ & $0(0.1)$ & $0(0.1)$ & $42(3.4)$ & 10 \\
\hline $1 \mathrm{M} \mathrm{NaOH}$ & $1 \mathrm{M}$ & $7(0.1)$ & $1(0.2)$ & $9(0.1)$ & $61(0.1)$ & $8(0.2)$ & $3(0.4)$ & $11(0.2)$ & 5 \\
\hline $\mathrm{H} 2 \mathrm{O}$ after $1 \mathrm{M} \mathrm{NaOH}^{*}$ & $1 \mathrm{M}-\mathrm{H} 2 \mathrm{O}$ & 20 & 1 & 33 & 8 & 0 & 0 & 38 & 3 \\
\hline $6 \mathrm{M} \mathrm{NaOH}$ & $6 \mathrm{M}$ & $7(2.0)$ & $1(0.1)$ & $8(0.6)$ & $40(5.7)$ & $17(1.5)$ & $18(0.3)$ & $9(3.1)$ & 3 \\
\hline $\mathrm{H} 2 \mathrm{O}$ after $6 \mathrm{M} \mathrm{NaOH} *$ & $6 \mathrm{M}-\mathrm{H} 2 \mathrm{O}$ & 18 & 1 & 19 & 38 & 7 & 5 & 12 & 2 \\
\hline Residue** & Res & $9(0.5)$ & $1(0.2)$ & $15(2.5)$ & $51(0.5)$ & $1(0.2)$ & $1(0.7)$ & $22(4.2)$ & 52 \\
\hline \multicolumn{10}{|l|}{ Tomato } \\
\hline $\mathrm{H} 2 \mathrm{O}$ & $\mathrm{H} 2 \mathrm{O}$ & $7(0.6)$ & $1(0.4)$ & $9(0.4)$ & $5(0.3)$ & $4(0.5)$ & $1(0.7)$ & $73(0.3)$ & 9 \\
\hline $0.1 \mathrm{M} \mathrm{NaOH}$ & $0.1 \mathrm{M}$ & $10(0.0)$ & $1(0.7)$ & $10(0.0)$ & $1(0.2)$ & $4(0.8)$ & $0(0.0)$ & $74(1.7)$ & 18 \\
\hline $\mathrm{H} 2 \mathrm{O}$ after $0.1 \mathrm{M}$ & $0.1 \mathrm{M}-\mathrm{H} 2 \mathrm{O}$ & $16(0.3)$ & $2(0.2)$ & $26(0.7)$ & $1(0.7)$ & $1(0.5)$ & $0(0.0)$ & $54(0.3)$ & 3 \\
\hline $1 \mathrm{M} \mathrm{NaOH}$ & $1 \mathrm{M}$ & $5(0.1)$ & $0(0.1)$ & $8(0.1)$ & $33(1.5)$ & $34(2.3)$ & $11(2.3)$ & $9(1.6)$ & 9 \\
\hline $\mathrm{H} 2 \mathrm{O}$ after $1 \mathrm{M} \mathrm{NaOH} *$ & $1 \mathrm{M}-\mathrm{H} 2 \mathrm{O}$ & 17 & 1 & 16 & 26 & 3 & 3 & 34 & 1 \\
\hline $6 \mathrm{M} \mathrm{NaOH}$ & $6 \mathrm{M}$ & $4(0.9)$ & $0(0.3)$ & $10(0.2)$ & $44(0.2)$ & $17(1.8)$ & $21(1.8)$ & $4(2.9)$ & 7 \\
\hline $\mathrm{H} 2 \mathrm{O}$ after $6 \mathrm{M} \mathrm{NaOH} *$ & $6 \mathrm{M}-\mathrm{H} 2 \mathrm{O}$ & 13 & 0 & 10 & 41 & 23 & 4 & 9 & 2 \\
\hline Residue** & Res & $2(0.1)$ & $0(0.1)$ & $4(0.1)$ & $79(2.3)$ & $2(0.0)$ & $4(0.1)$ & $9(2.2)$ & 51 \\
\hline \multicolumn{10}{|l|}{ Strawberry } \\
\hline $\mathrm{H} 2 \mathrm{O}$ & $\mathrm{H} 2 \mathrm{O}$ & $9(0.7)$ & $1(0.2)$ & $9(0.5)$ & $10(0.5)$ & $6(0.9)$ & $2(1.4)$ & $63(1.8)$ & 4 \\
\hline $0.1 \mathrm{M} \mathrm{NaOH}$ & $0.1 \mathrm{M}$ & $15(0.1)$ & $1(0.7)$ & $15(0.5)$ & $1(0.1)$ & $1(0.5)$ & $0(0.0)$ & $67(0.5)$ & 32 \\
\hline $\mathrm{H} 2 \mathrm{O}$ after $0.1 \mathrm{M}$ & $0.1 \mathrm{M}-\mathrm{H} 2 \mathrm{O}$ & $26(0.5)$ & $2(0.7)$ & $25(3.2)$ & $1(0.4)$ & $1(0.5)$ & $0(0.0)$ & $45(4.2)$ & 7 \\
\hline $1 \mathrm{M} \mathrm{NaOH}^{*}$ & $1 \mathrm{M}$ & 7 & 0 & 9 & 34 & 41 & 2 & 7 & 5 \\
\hline $\mathrm{H} 2 \mathrm{O}$ after $1 \mathrm{M} \mathrm{NaOH}^{*}$ & $1 \mathrm{M}-\mathrm{H} 2 \mathrm{O}$ & 22 & 2 & 23 & 11 & 3 & 2 & 37 & 1 \\
\hline $6 \mathrm{M} \mathrm{NaOH} *$ & $6 \mathrm{M}$ & 2 & 0 & 8 & 45 & 23 & 19 & 3 & 7 \\
\hline $\mathrm{H} 2 \mathrm{O}$ after $6 \mathrm{M} \mathrm{NaOH} *$ & $6 \mathrm{M}-\mathrm{H} 2 \mathrm{O}$ & 22 & 1 & 15 & 24 & 23 & 2 & 13 & 1 \\
\hline Residue** & Res & $7(0.2)$ & $0(0.1)$ & $9(0.4)$ & $66(2.3)$ & $6(0.4)$ & $1(0.0)$ & $11(3.3)$ & 43 \\
\hline
\end{tabular}

* Due to limited sample availability values were not determined in duplicate.

** Values represent means of triplicates.

The fractions $0.1 \mathrm{M}$, extracted by $0.1 \mathrm{M} \mathrm{NaOH}$, are composed of pectin. The fractions isolated by $1 \mathrm{M} \mathrm{NaOH}$ and $6 \mathrm{M} \mathrm{NaOH}$ consist predominantly of hemicellulose and a minor part is pectin. The extractability of predominantly hemicelluloses in strong alkali conditions is wellknown [16, 34]. However, the yields were not the same for all sources; the lowest yield of hemicellulose fractions was found in carrot and the highest yield in strawberry (Table 3.3). It was found that fractions $\mathrm{H} 2 \mathrm{O}, 0.1 \mathrm{M}-\mathrm{H} 2 \mathrm{O}, 1 \mathrm{M}-\mathrm{H} 2 \mathrm{O}$ and $6 \mathrm{M}-\mathrm{H} 2 \mathrm{O}$ contained predominantly pectin, and structurally different types of pectin populations were found compared to the preceding alkali fraction. Renard et al. [31] reported the presence of pectin in a water wash step after 4M alkali extraction, confirming limited solubility of pectin in strong alkali conditions. However, as can be seen in this study, not only after strong alkali extraction 
water soluble material was observed in the successive water fractions, but also after mild alkali extraction water soluble material remained present in the residue.

The $6 \mathrm{M}$ alkali residue was composed for $50-80 \%$ of cellulose but still contained pectin. Relative to the GalA content in ChUS, 39\%, 21\% and 14\% of GalA remains in the $6 \mathrm{M}$ alkali residue of carrot, tomato and strawberry, respectively. These pectin populations were supposed to strongly interact with cellulose since these pectin populations remain insoluble after degradation of $\mathrm{H}$-bonds and swelling of cellulose microfibrils.

\subsubsection{Structural characterisation of pectin in the 6M alkali residue by digestion with} pectinases

In order to understand the interactions between pectin and cellulose in the $6 \mathrm{M}$ alkali residue, it was of importance to determine which part of pectin is interacting with the (hemi)cellulose network, and via which mechanism. Although digestion of the $6 \mathrm{M}$ alkali residue with different HG and RG-I degrading enzymes does not necessarily solubilise the cross-linked regions, more structural information about cross-linked pectin populations can be obtained from these digestions. 


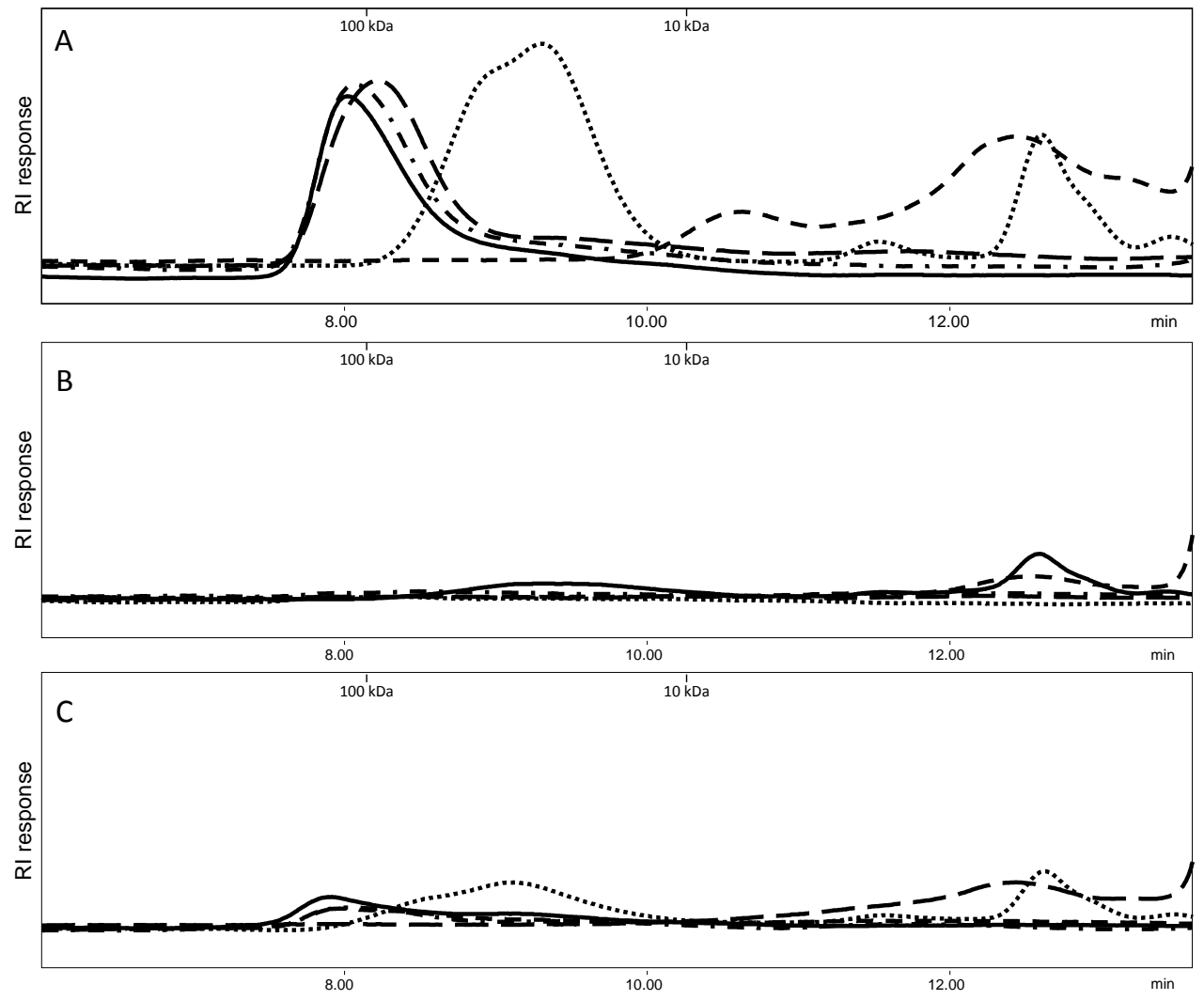

Figure 3.1 HPSEC elution pattern of the digest after enzymatic treatment of the $6 \mathrm{M}$ alkali residue with pectinases in Carrot (A), Tomato (B) and Strawberry (C). Blank (-); PG (...); RG-H (---); endo- \& exogalactanase (-.); endo- \& exo-arabinanase (-- ). All samples were analysed at $5 \mathrm{mg} / \mathrm{ml} 6 \mathrm{M}$ alkali residue concentration and the same scale for RI response was used. Molecular weights of pectin standards (in $\mathrm{kDa}$ ) are indicated.

First of all it can be seen from Fig 3.1 that in carrot 6M alkali residue a HMw (high molecular weight) peak is present in the blank. Analysis of the HMW population $>10 \mathrm{kDa}$ showed that it is predominantly composed of pectin (Table 3.4), although different in composition from fraction $6 \mathrm{M}-\mathrm{H} 2 \mathrm{O}$. The Gluc-HMw population reported in Table 3.4, representing a $\mathrm{HMw}$ fraction solubilised by glucanases, will be discussed in section 3.3.4. 
Table 3.4 Monosaccharide composition (mol\%) of water soluble HMw population (WS-HMw) and the population released with glucanases (Gluc-HMw). Both populations were released from the carrot $6 \mathrm{M}$ alkali residue and having $\mathrm{Mw}>10 \mathrm{kDa}$. Mean ( \pm absolute deviation), $\mathrm{n}=2$.

\begin{tabular}{|l|c|c|c|c|c|c|c|}
\hline & \multicolumn{7}{|c|}{ Mol \% } \\
\cline { 2 - 9 } & Ara & Rha & Gal & Glc & Xyl & Man & UA \\
\hline WS-HMw population & $23(0.2)$ & $2(0.7)$ & $42(0.7)$ & $3(0.6)$ & $1(0.1)$ & $0(0.0)$ & $29(0.5)$ \\
\hline Gluc-HMw population & $23(2.7)$ & $3(0.9)$ & $50(2.3)$ & $5(0.7)$ & $0(0.2)$ & $0(0.1)$ & $19(4.4)$ \\
\hline
\end{tabular}

PG was able to degrade the already water-soluble carrot pectin slightly, while hardly any additional pectin was solubilised from the $6 \mathrm{M}$ alkali residue (fig 3.1A). Also in tomato and strawberry, hardly any additional pectin was solubilised and pectin levels were rather similar to the blank.

RG-hydrolase was able to degrade the water soluble material in carrot but did not solubilise additional populations. Similar to PG, RG-H was also not able to solubilise additional pectin from the tomato and strawberry $6 \mathrm{M}$ residues. Digestion with a combination of endo- and exo-acting arabinanases and galactanases did not solubilise additional pectin in all sources. The amount, type and frequency of branching of RG-I remaining in the $6 \mathrm{M}$ residue is unknown. It is therefore possible that side chains are highly branched, or that side chains are too short to be accessed by arabinanases and galactanases.

3.3.4 Structural characterisation of pectin in the $6 \mathrm{M}$ alkali residue by digestion with glucanases

Since pectinases did not solubilise pectin from the $6 \mathrm{M}$ alkali residues, the effect of enzymatic cellulose digestion on solubility of cell wall polysaccharides was studied by using a combination of purified endo- \& exo-glucanase. 


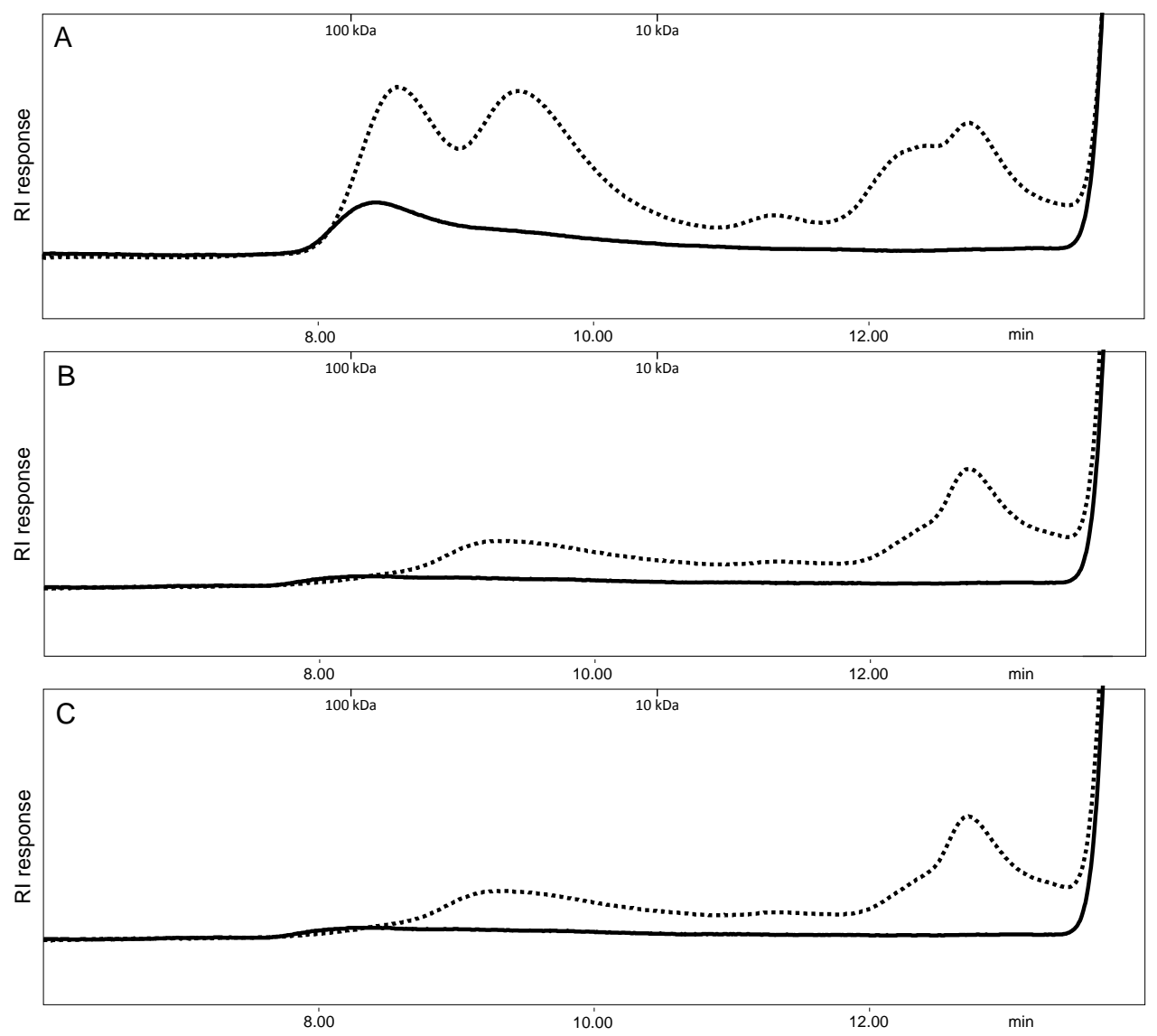

Figure 3.2 HPSEC elution pattern of the digest after enzymatic degradation of the $6 \mathrm{M}$ alkali residue with glucanases in Carrot (A), Tomato (B) and Strawberry (C). Blank (-); endo- \& exo-glucanase ( $\cdots$ ). All samples were analysed at $5 \mathrm{mg} / \mathrm{ml} 6 \mathrm{M}$ alkali residue concentration and the same scale for $\mathrm{RI}$ response was used. Molecular weights of pectin standards (in kDa) are indicated.

As can be seen in Figure 3.2A, glucanases were able to release both oligomeric and polymeric products from the carrot $6 \mathrm{M}$ alkali residue. Detailed analysis of cellodextrins (HPSEC eluting times $12-14 \mathrm{~min}$ ) by HPAEC showed that for carrot, approximately $30 \%$ of all glucose present in ChUS 6M alkali residue was degraded to cellodextrin DP 1-6 by glucanases. For tomato and strawberry, around $35 \%$ and $40 \%$ of all polymeric glucose was degraded to cellodextrins DP 1-6, respectively. Comparison of Figure 3.1A and 3.2A shows that the amount of polymeric material released by glucanases was substantially higher than the water soluble pectin as described above. In contrast, the yields of water extraction and glucanase digestion for the tomato and strawberry $6 \mathrm{M}$ alkali residue were $<5 \%$ insufficient to allow further characterisation. 
Cellulosic fragments DP $\geq 7$ cannot be present in the isolated soluble material due to their insolubility. To analyse only polymeric populations and no cellodextrins formed by glucanases, the Gluc-HMw population was isolated from the digest using a 10kDa cut-off filter. Characterisation of the population $>10 \mathrm{kDa}$ showed that it was predominantly composed of pectin, with only a minor percentage of glucose (Table 3.4). Especially RG-I was present, with galactose as the main sugar in the RG-I side chains. Surprisingly, the composition is very similar to the WS-HMw population from 6M Residue (Table 3.4). However, based on the yield the Gluc-HMw population represented $\sim 27 \%$ of the carrot $6 \mathrm{M}$ alkali residue, a substantially higher amount than WS-HMw ( 9\%). Since the $6 \mathrm{M}$ alkali residue was composed of cellulose for $51 \%$, the Gluc-HMW population composed $\sim 50-55 \%$ of all pectin present in the $6 \mathrm{M}$ residue.

Digestion of the Gluc-HMw fraction with PG and RG-H showed that only RG-H was able to substantially degrade the high molecular weight material and PG was not, confirming that a substantial part of the Gluc-HMw population was RG-I.

\subsubsection{Pectin is not physically entrapped in cellulose microfibrils}

Recently it was suggested that pectin might have a more dominant load-bearing role than often thought, based on the observation that only a small proportion of all xyloglucan is bound to cellulose $[6,35]$. Carrot, tomato and strawberry ChUS contained $2 \%, 8 \%$ and $9 \%$ xylose, respectively. It seems therefore likely that the difference in xyloglucan content has an effect on the cell wall architecture, and that pectin might have a load-bearing role in cell walls low in xyloglucan.

The release of pectin by glucanases may lead to several hypotheses. First of all, it might indicate that pectin is physically trapped in the cellulose matrix, and by degrading part of the cellulose matrix by glucanases, pectin was released. The inability of $6 \mathrm{M}$ alkali to extract these pectins from swollen cellulose microfibrils might be explained by the observation that $\mathrm{HG}$ is not soluble at alkali concentrations $\geq 4 \mathrm{M}$ [31]. However, it would be expected that such pectin would solubilise in the subsequent water extraction step. However, the absence of pectin populations in $6 \mathrm{M}-\mathrm{H} 2 \mathrm{O}$ confirms the absence of pectin physically entrapped in cellulose microfibrils.

The nature of the entrapment might have changed due to alterations in cellulose orientation as an effect of $6 \mathrm{M}$ alkali treatment, hereby releasing pectin [36], but also in this case the solubilised population would be expected in fraction $6 \mathrm{M}$ or $6 \mathrm{M}-\mathrm{H} 2 \mathrm{O}$.

Pauly et al. [32] showed that strong alkali treatments solubilised part of the XG populations, being closely and non-covalently associated with the cellulose surface. This indicated that certainly non-covalent, hydrogen-bond based interactions are targeted by sequential alkali 
extractions. Pectins adsorbed to the surface of cellulose microfibrils were therefore expected to be released during harsh sequential alkali extractions.

\subsubsection{Pectin is covalently linked to cellulose}

Enzymatic digestion of cellulose showed the release of RG-I rich pectin (Table 3.4, Figure 3.2A).

This observation was explained by the presence of covalently cross-linked pectin and cellulose, and the $5 \%$ glucose present in the HMw population $>10 \mathrm{kDa}$ was expected to be involved in this cross-link. Based on literature, it might indeed be expected that the linkage between pectin and cellulose is found in RG-I rather than HG [10, 37]. Further details of the proposed cross-link between RG-I and cellulose will be discussed in section 3.3.6.

\subsubsection{Characterisation of oligosaccharides formed by glucanase digestion}

For all 3 sources, cellodextrin oligomers were dominantly present in the glucanase digests. However, analysis of oligosaccharides $\geq$ DP 5 by MALDI-TOF MS showed differences in the oligosaccharides formed by glucanases in carrot, tomato and strawberry.

As can be seen in the MALDI-TOF mass spectra in Figure 3.3, hexoses $\geq$ DP 6 are present for all sources and based on glucanase activity assumed to be cellodextrins. Analysis of cellodextrins by HPAEC showed that DP 1-3 were present in much higher amount than cellodextrins $\geq$ DP 4 . As can be observed in Figure 3.3B and 3.3C, glucanase digestion of the tomato and strawberry $6 \mathrm{M}$ alkali residue results in xyloglucan-based oligosaccharides, next to cellodextrins.

The ability of Trichoderma viride glucanases to show activity towards xyloglucan is wellknown $[25,38]$. Xyloglucan is known to be present in three different domains: a xyloglucanspecific accessible domain, an alkali-accessible domain and a domain accessible by cellulase after treatment with concentrated alkali and xyloglucan-specific glucanases [32]. The formation of xyloglucan oligosaccharides by cellulose degradation in tomato and strawberry fits with the well-accepted ideas concerning xyloglucan interactions with cellulose. No xyloglucan oligosaccharides were formed in the carrot 6M alkali residue by the glucanases. Analysis of the oligosaccharides formed by digestion of the carrot $6 \mathrm{M}$ alkali residue showed next to hexoses also pentoses and RG-I oligosaccharides from pectin origin. Based on the sugar composition in Table 3.3, the pentose sugar involved is arabinose. Despite the low levels, $<0.1 \%$ of the pectin, the presence of oligosaccharides originating from pectin was unexpected. Since fraction $6 \mathrm{M} \mathrm{NaOH}$ contained a minor amount of xyloglucan, the alkaliextractable domain of XG seems to be present in small amounts. However, the strongly connected XG domain that can be released by cellulases [32] is absent in the carrot cell wall. 


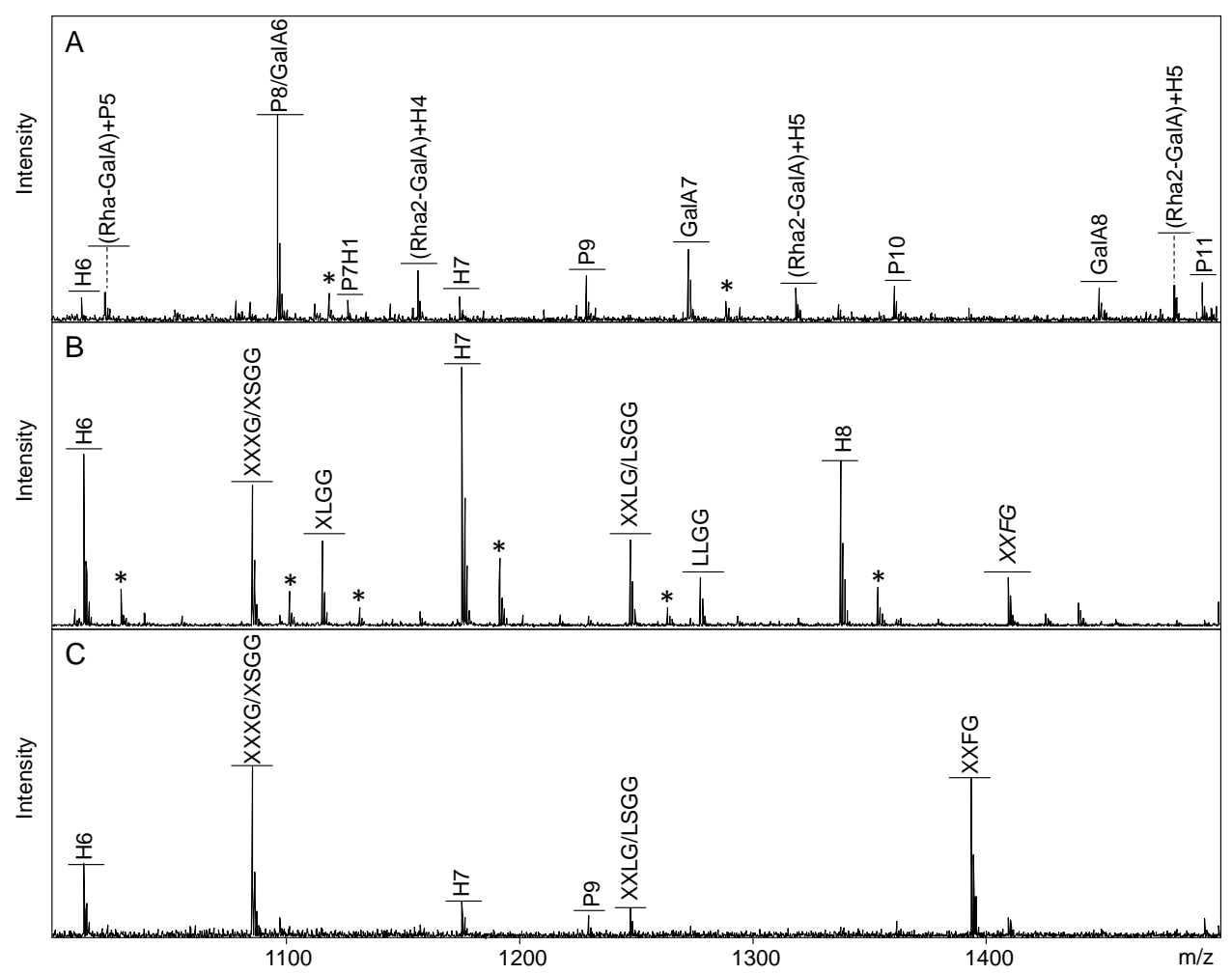

Figure 3.3 MALDI-TOF mass spectra of the $6 \mathrm{M}$ residue digested with endo- \& exo-glucanase for carrot (A), tomato (B) and Strawberry (C). Peak annotation: P, pentose; Rha, rhamnose; GalA, galacturonic acid; H, hexose; G, glucose; X, glucose - xylose; S, glucose - xylose - arabinose; L, glucose - xylose galactose; $F$, glucose - xylose - galactose - fucose. Structures with * represent the $\mathrm{K}^{+}$-adduct.

\subsubsection{Comparison of the residues obtained after $0.1 \mathrm{M}$ and $6 \mathrm{M}$ alkali extraction}

It was investigated whether the disruption of the pectin-cellulose interactions by glucanases was affected when hemicelluloses were still present in the network, since it is often suggested that hemicelluloses are involved in cell wall interactions.

In a distinct experiment, the sequential extraction was only performed until $0.1 \mathrm{M}$ alkali extraction and the $0.1 \mathrm{M}$ alkali residue was analysed for carrot, tomato and strawberry. The composition of the $0.1 \mathrm{M}$ alkali residue is given in Table 3.5. 
Table 3.5 Monosaccharide composition (mol\%) of the $0.1 \mathrm{M}$ alkali residue from carrot, tomato and strawberry. Mean ( \pm absolute deviation), $n=2$.

\begin{tabular}{|l|c|c|c|c|c|c|c|}
\hline & \multicolumn{7}{|c|}{ Mol \% } \\
\hline & Ara & Rha & Gal & Glc & Xyl & Man & UA \\
\hline Carrot & $7(0.1)$ & $1(0.4)$ & $13(0.6)$ & $60(1.8)$ & $4(1.2)$ & $6(1.3)$ & $9(3.2)$ \\
\hline Tomato & $3(0.6)$ & $1(0.2)$ & $5(0.4)$ & $69(4.0)$ & $8(2.8)$ & $6(2.4)$ & $8(1.9)$ \\
\hline Strawberry & $5(1.9)$ & $1(0.1)$ & $7(2.1)$ & $64(8.0)$ & $11(3.5)$ & $5(0.8)$ & $7(0.3)$ \\
\hline
\end{tabular}

Similar to the $6 \mathrm{M}$ alkali residue (Table 3.3), glucose is the most abundant monosaccharide in the $0.1 \mathrm{M}$ alkali residue. The main difference with the $6 \mathrm{M}$ alkali residue was the level of xylose and mannose next to glucose in the $0.1 \mathrm{M}$ alkali residue, representing hemicellulose, possibly coating or competing the pectin in its interaction with cellulose.

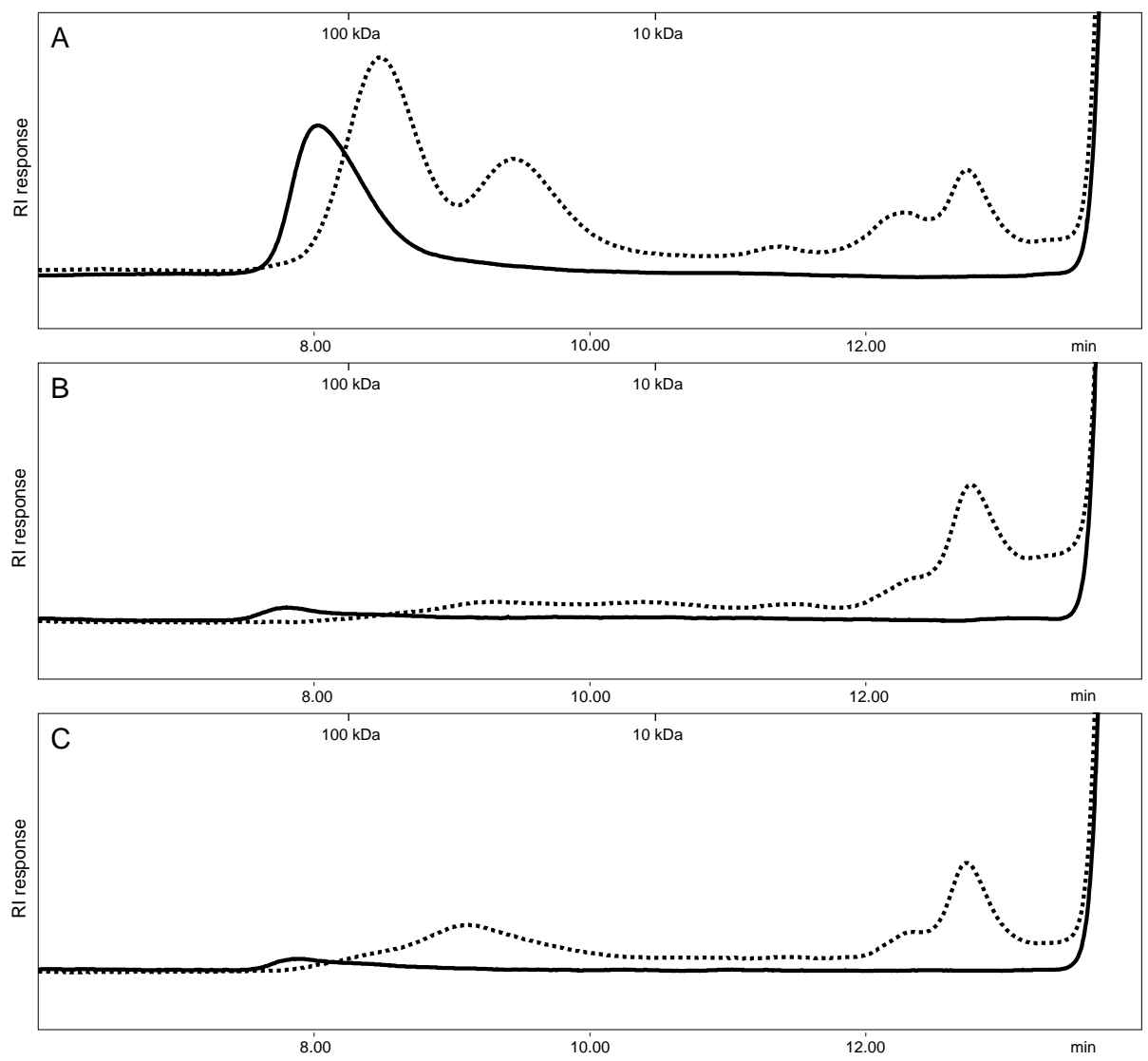

Figure 3.4 HPSEC elution pattern of the digest after enzymatic degradation of the $0.1 \mathrm{M}$ alkali residue with glucanases in Carrot (A), Tomato (B) and Strawberry (C). Blank (-); endo- \& exo-glucanase ( $\cdots$ ). All samples were analysed at $5 \mathrm{mg} / \mathrm{ml} 0.1 \mathrm{M}$ alkali residue concentration and the same scale for $\mathrm{RI}$ response was used. Molecular weights of pectin standards (in kDa) are indicated. 
For carrot, digestion of the $0.1 \mathrm{M}$ alkali residues with glucanases showed similarities to the $6 \mathrm{M}$ alkali residues (Fig 3.2, Fig 3.4) since for both residues glucanases were able to release a water soluble, high $\mathrm{Mw}$ population. The cellulose present in carrot $0.1 \mathrm{M}$ alkali residue was also similarly digested to cellodextrin DP 1-6 when compared to the $6 \mathrm{M}$ alkali residue; $25 \%$ versus $30 \%$ degradation respectively. In contrast, for tomato and strawberry, the hemicelluloses present in the $0.1 \mathrm{M}$ alkali residue limit cellulose digestion since only $20 \%$ of cellulose was degraded to cellodextrin DP 1-6 in both $0.1 \mathrm{M}$ alkali residues, compared to $35 \%$ and $40 \%$ for the $6 \mathrm{M}$ alkali residues, respectively.

The ability of xyloglucan to coat cellulose, by both cross-linking cellulose microfibrils while spatially separating them at the same time has been known for a long time [9, 38]. However, more recent research also showed pectin-cellulose interactions, suggesting a load-bearing role for pectin in the primary cell wall [35].

It was shown in vitro that not only xyloglucan, but also pectin was able to interact with cellulose [39, 40]. This information corresponds with our findings that the presence of hemicellulose did not substantially change the accessibility of the residue for glucanases to release pectin, and it suggests that hemicellulose is not coating cellulose in the region where pectin and cellulose interact.

\subsubsection{Isolation and concentration of the cross-link between RG-I and cellulose}

PG was not able to solubilise substantial amounts of pectin from the carrot $0.1 \mathrm{M}$ and $6 \mathrm{M}$ alkali residues. Since extraction with alkali removed all methyl-esters and acetyl groups, it was hypothesized that PG should not be hindered by any substitution of HG regions. If pectin would be bound to cellulose by its homogalacturonan region, digestion with PG should solubilise more pectin from the $6 \mathrm{M}$ alkali residue. Therefore the limited activity of $P G$ indicates that pectin is not bound to cellulose by its homogalacturonan region.

$\mathrm{RG}-\mathrm{H}$, arabinanases and galactanases were also not able to solubilise substantial amounts of pectin from the residues. The fine-structure of arabinan, galactan and arabinogalactan structures are not exactly known and might be heavily branched and potentially also rather short, it is suggested that enzymes are hindered in their action by structural properties of RG-I side chains. Most probably the glucan part originating from cellulose in the pectincellulose cross-link is rather short since this would explain why it is not any further degradable by endo-glucanase. It is proposed that in the RG-I side chains, galactose or arabinose units are covalently linked to cellulose.

The extent of side chain branching studied by AFM in strawberry pectin showed the potential of studying side chains in alkali extracted pectins [41], but so far detailed knowledge is not available about RG-I side chains in carrot alkali residues.

One of the main challenges in isolating cell wall cross-links is its potentially low abundance. As explained in Cosgrove's biomechanical hotspot hypothesis, only a minor part of cell wall 
polysaccharides and proteins might be involved in interactions holding networks together but still have a major influence of plant cell wall functionality [42].

In order to further isolate the cross-linked regions, the carrot $0.1 \mathrm{M}$ and $6 \mathrm{M}$ alkali residues were first digested with RG-H to degrade and subsequently the RG-I backbone present was washed out by ultrafiltration over a $10 \mathrm{kDa}$ filter. Subsequently the residues were digested with glucanases to isolate and concentrate the possibly present cross-linked region, predominantly consisting of RG-I side chains with cellodextrins attached.

Table 3.6 Monosaccharide composition (mol\%) of the soluble fractions < and > 10kDa isolated after treatment with RG-H and glucanases from the carrot $0.1 \mathrm{M}$ and $6 \mathrm{M}$ alkali residues. Mean ( \pm absolute deviation), $\mathrm{n}=2$.

\begin{tabular}{|c|c|c|c|c|c|c|c|}
\hline & \multicolumn{7}{|c|}{ Mol\% } \\
\hline & Ara & Rha & Gal & Glc & Xyl & Man & UA \\
\hline $0.1 \mathrm{M}$ res. $+\mathrm{RG}-\mathrm{H}<10 \mathrm{kDa} *$ & 3 & 8 & 57 & 6 & 0 & 0 & 26 \\
\hline $0.1 \mathrm{M}$ res. $+\mathrm{RG}-\mathrm{H}>10 \mathrm{kDa}$ & $\begin{array}{c}35 \\
(1.5)\end{array}$ & $\begin{array}{c}3 \\
(1.1)\end{array}$ & $\begin{array}{c}36 \\
(0.4)\end{array}$ & $\begin{array}{c}11 \\
(2.5)\end{array}$ & $\begin{array}{c}0 \\
(0.0)\end{array}$ & $\begin{array}{c}0 \\
(0.0)\end{array}$ & $\begin{array}{c}15 \\
(3.4)\end{array}$ \\
\hline $0.1 \mathrm{M}$ res. + RG-H. Res + Gluc $<10 \mathrm{kDa} *$ & 1 & 1 & 4 & 81 & 1 & 5 & 7 \\
\hline $0.1 \mathrm{M}$ res. + RG-H. Res + Gluc $>10 \mathrm{kDa}$ & $\begin{array}{c}19 \\
(0.5)\end{array}$ & $\begin{array}{c}3 \\
(0.5)\end{array}$ & $\begin{array}{c}25 \\
(0.5)\end{array}$ & $\begin{array}{c}22 \\
(3.8)\end{array}$ & $\begin{array}{c}1 \\
(0.1)\end{array}$ & $\begin{array}{c}1 \\
(0.1)\end{array}$ & $\begin{array}{c}29 \\
(2.3)\end{array}$ \\
\hline $0.1 \mathrm{M}$ final res. ${ }^{*}$ & 1 & 0 & 1 & 85 & 4 & 5 & 4 \\
\hline $6 \mathrm{M}$ res. + RG-H $<10 \mathrm{kDa} *$ & 5 & 8 & 53 & 4 & 0 & 0 & 30 \\
\hline $6 \mathrm{M}$ res. $+\mathrm{RG}-\mathrm{H}>10 \mathrm{kDa}$ & $\begin{array}{c}35 \\
(4.1) \\
\end{array}$ & $\begin{array}{c}3 \\
(0.7) \\
\end{array}$ & $\begin{array}{c}37 \\
(0.9) \\
\end{array}$ & $\begin{array}{c}7 \\
(1.7) \\
\end{array}$ & $\begin{array}{c}1 \\
(0.6) \\
\end{array}$ & $\begin{array}{c}0 \\
(0.0) \\
\end{array}$ & $\begin{array}{c}17 \\
(2.1) \\
\end{array}$ \\
\hline $6 \mathrm{M}$ res. + RG-H. Res + Gluc $<10 \mathrm{kDa} *$ & 0 & 0 & 2 & 87 & 1 & 4 & 6 \\
\hline $6 \mathrm{M}$ res. + RG-H. Res + Gluc $>10 \mathrm{kDa}$ & $\begin{array}{c}8 \\
(2.1)\end{array}$ & $\begin{array}{c}2 \\
(0.5)\end{array}$ & $\begin{array}{c}12 \\
(2.5)\end{array}$ & $\begin{array}{c}45 \\
(4.1)\end{array}$ & $\begin{array}{c}1 \\
(1.0)\end{array}$ & $\begin{array}{c}0 \\
(0.3)\end{array}$ & $\begin{array}{c}32 \\
(7.1)\end{array}$ \\
\hline $6 \mathrm{M}$ final res.* & 0 & 0 & 1 & 90 & 3 & 2 & 4 \\
\hline
\end{tabular}

*Due to low sample amounts compositions were not determined in duplicate

As already shown in Figure 3.1A, RG-H digestion did not solubilise substantial levels of pectin from the $0.1 \mathrm{M}$ and $6 \mathrm{M}$ alkali residues. The populations $<10 \mathrm{kDa}$ and $>10 \mathrm{kDa}$ (Table 3.6) were therefore expected to originate from the water soluble material rich in RG-I (WSHMw), shown in Table 3.4.

Digestion of the RG-H treated $6 \mathrm{M}$ residue with glucanases released a low Mw fraction dominated by glucose. Despite low yields, in the fractions $>10 \mathrm{kDa}$ populations composed of both glucose and pectic sugars were found for both the $0.1 \mathrm{M}$ alkali residue and the $6 \mathrm{M}$ 
alkali residue. Glucose levels highly increased up to $22 \%$ and $46 \%$ in the fractions $>10 \mathrm{kDa}$ compared to $5 \%$ for the Gluc-HMw population (Table 3.4).

Glucose cannot originate from polymeric, insoluble cellulose and was therefore made soluble by a connection to soluble polysaccharides. Furthermore glucose was not present in long linear glucose chains since endo-glucanase did not degrade the glucan chains any further. Taking all results into account, the most logical structure resisting endo-glucanase digestion is composed of a regular RG-I backbone with short and highly branched side chains of galactose and arabinose, and these side chains are cross-linked to the glucan part originating from cellulose. The hypothesis of rather short side chains would also explain the observations that arabinanases and galactanases were not able to solubilise additional pectin populations from the carrot $6 \mathrm{M}$ alkali residue (fig 3.1A). Cellulose is covalently linked to these side chains, most likely as polymer which is digested to cellodextrin oligomers by glucanases. It is speculated that in distinct parts of cell walls low in xyloglucan, pectin might take over the tethering role of xyloglucan holding microfibrils together. 


\subsection{Conclusions}

The study of the primary plant cell wall of carrot, tomato and strawberry revealed differences in the architecture. For all sources, extraction with water and chelating agent released pectin populations but also in the Chelating agent Unextractable Solids (ChUS) a substantial amount of pectin was present in all sources.

Sequential alkali extraction was performed to release pectin from ChUS. Substantial amounts of pectin were present in the final residue after $6 \mathrm{M}$ alkali extraction and these pectin populations were assumed to be strongly interacting with cellulose.

Only in the carrot cell wall, digestion with endo- \& exo-glucanase solubilised $27 \%$ of the $6 \mathrm{M}$ residue, composed of RG-I enriched pectin populations. Further studies of this population suggested that RG-I is directly linked to cellulosic glucan through its side chains. The presence or absence of hemicellulose hardly altered the solubilisation of pectin by glucanases.

These findings indicate the differences in cell wall architecture between different sources. Whereas the cell wall of tomato and strawberry is in line with the current cell wall models, the proposed interactions between RG-I and cellulose seem to be a unique property of the carrot cell wall within the three sources studied.

\section{Acknowledgments}

This work received funding from the European Union's Seventh Framework Programme for Research, technological development and demonstration under Grant Agreement No. Kbbe-311754 (OPTIFEL). 


\section{References}

1. Caffall, K.H. and D. Mohnen, The structure, function, and biosynthesis of plant cell wall pectic polysaccharides. Carbohydrate Research, 2009. 344(14): p. 1879-1900.

2. Voragen, A.G., G.-J. Coenen, R.P. Verhoef and H.A. Schols, Pectin, a versatile polysaccharide present in plant cell walls. Structural Chemistry, 2009. 20(2): p. 263-275.

3. Scheller, H.V. and P. Ulvskov, Hemicelluloses. Plant Biology, 2010. 61(1): p. 263-289.

4. Fry, S.C., The structure and functions of xyloglucan. Journal of Experimental Botany, 1989. 40(1): p. 1-11.

5. Cosgrove, D.J., Growth of the plant cell wall. Nature Reviews Molecular Cell Biology, 2005. 6(11): p. 850-861.

6. Höfte, H., A. Peaucelle and S. Braybrook, Cell wall mechanics and growth control in plants: the role of pectins revisited. Frontiers in Plant Science, 2012. 3(121): p. 1-6.

7. Cosgrove, D.J., Wall structure and wall loosening. A look backwards and forwards. Plant Physiology, 2001. 125(1): p. 131-134.

8. Mort, A.J., Interactions between pectins and other polymers, in Pectins and their manipulation, G.B. Seymour and J.P. Knox, Eds. 2002, Blackwell Publishing. p. 30-51.

9. Hayashi, T., Xyloglucans in the primary cell wall. Annual Review of Plant Biology, 1989. 40(1): p. 139-168.

10. Popper, Z.A. and S.C. Fry, Widespread occurrence of a covalent linkage between xyloglucan and acidic polysaccharides in suspension-cultured angiosperm cells. Annals of Botany, 2005. 96(1): p. 91-99.

11. Ralet, M.-C., M.-J. Crépeau, J. Vigouroux, J. Tran, A. Berger, C. Sallé, F. Granier, L. Botran, and H.M. North, Xylans provide the structural driving force for mucilage adhesion to the Arabidopsis seed coat. Plant Physiology, 2016. 171(1): p. 165-178.

12. Zykwinska, A.W., M.C.J. Ralet, C.D. Garnier and J.F.J. Thibault, Evidence for in vitro binding of pectin side chains to cellulose. Plant Physiology, 2005. 139(1): p. 397-407.

13. Nunes, C., L. Silva, A.P. Fernandes, R.P. Guiné, M.R.M. Domingues, and M.A. Coimbra, Occurrence of cellobiose residues directly linked to galacturonic acid in pectic polysaccharides. Carbohydrate Polymers, 2012. 87(1): p. 620-626.

14. Tan, L., S. Eberhard, S. Pattathil, C. Warder, J. Glushka, C.H. Yuan, Z.Y. Hao, X. Zhu, U. Avci, J.S. Miller, D. Baldwin, C. Pham, R. Orlando, A. Darvill, M.G. Hahn, M.J. Kieliszewski, and D. Mohnen, An Arabidopsis cell wall proteoglycan consists of pectin and arabinoxylan covalently linked to an arabinogalactan protein. Plant Cell, 2013. 25(1): p. 270-287.

15. Jarvis, M., S. Briggs and J. Knox, Intercellular adhesion and cell separation in plants. Plant, Cell \& Environment, 2003. 26(7): p. 977-989.

16. Houben, K., R.P. Jolie, I. Fraeye, A.M. Van Loey and M.E. Hendrickx, Comparative study of the cell wall composition of broccoli, carrot, and tomato: Structural characterization of the extractable pectins and hemicelluloses. Carbohydrate Research, 2011. 346(9): p. 1105-1111.

17. Voragen, F.G., J.P. Timmers, J.P. Linssen, H.A. Schols and W. Pilnik, Methods of analysis for cellwall polysaccharides of fruit and vegetables. Zeitschrift für Lebensmittel-Untersuchung und Forschung, 1983. 177(4): p. 251-256.

18. Broxterman, S.E., P. Picouet and H.A. Schols, Acetylated pectins in raw and heat processed carrots. Carbohydrate Polymers, 2017. 177: p. 58-66.

19. DuBois, M., K.A. Gilles, J.K. Hamilton, P.A. Rebers and F. Smith, Colorimetric method for determination of sugars and related substances. Analytical Chemistry, 1956. 28(3): p. 350-356.

20. Blumenkrantz, N. and G. Asboe-hansen, New method for quantitative-determination of uronic acids. Analytical Biochemistry, 1973. 54(2): p. 484-489. 
21. Englyst, H.N. and J.H. Cummings, Simplified method for the measurement of total non-starch polysaccharides by gas-liquid chromatography of constituent sugars as alditol acetates. Analyst, 1984. 109(7): p. 937-942.

22. Limberg, G., R. Körner, H.C. Buchholt, T.M.I.E. Christensen, P. Roepstorff, and J.D. Mikkelsen, Quantification of the amount of galacturonic acid residues in blocksequences in pectin homogalacturonan by enzymatic fingerprinting with exo- and endo-polygalacturonase II from Aspergillus niger. Carbohydrate Research, 2000. 327(3): p. 321-332.

23. Schols, H.A., M.A. Posthumus and A.G.J. Voragen, Structural features of hairy regions of pectins isolated from apple juice produced by the liquefaction process. Carbohydrate Research, 1990. 206(1): p. 117-129.

24. Kühnel, S., S.W.A. Hinz, L. Pouvreau, J. Wery, H.A. Schols, and H. Gruppen, Chrysosporium lucknowense arabinohydrolases effectively degrade sugar beet arabinan. Bioresource Technology, 2010. 101(21): p. 8300-8307.

25. Vincken, J.-P., G. Beldman and A.G.J. Voragen, Substrate specificity of endoglucanases: what determines xyloglucanase activity? Carbohydrate Research, 1997. 298(4): p. 299-310.

26. Voragen, A.G.J., H.A. Schols, J.A. De Vries and W. Pilnik, High-performance liquid chromatographic analysis of uronic acids and oligogalacturonic acids. Journal of Chromatography A, 1982. 244(2): p. 327-336.

27. Sila, E. Doungla, C. Smout, A. Van Loey and M. Hendrickx, Pectin fraction interconversions: Insight into understanding texture evolution of thermally processed carrots. Journal of Agricultural and Food Chemistry, 2006. 54(22): p. 8471-8479.

28. Heng Koh, T. and L.D. Melton, Ripening-related changes in cell wall polysaccharides of strawberry cortical and pith tissues. Postharvest Biology and Technology, 2002. 26(1): p. 23-33.

29. Kumpoun, W. and Y. Motomura, Comparison of cell wall pectic polysaccharides in flesh extracted with water and hot water from various fruits. 2002, AGRIS FAO. Hirosaki Univ., Aomori (Japan). Faculty of Agriculture and Life Science.

30. Fraeye, I., T. Duvetter, I. Verlent, D.N. Sila, M. Hendrickx, and A. Van Loey, Comparison of enzymatic de-esterification of strawberry and apple pectin at elevated pressure by fungal pectinmethylesterase. Innovative Food Science \& Emerging Technologies, 2007. 8(1): p. 93-101.

31. Renard, C.M.G.C. and C. Ginies, Comparison of the cell wall composition for flesh and skin from five different plums. Food Chemistry, 2009. 114(3): p. 1042-1049.

32. Pauly, M., P. Albersheim, A. Darvill and W.S. York, Molecular domains of the cellulose/xyloglucan network in the cell walls of higher plants. The Plant Journal, 1999. 20(6): p. 629-639.

33. Das, M. and D. Chakraborty, Influence of alkali treatment on the fine structure and morphology of bamboo fibers. Journal of Applied Polymer Science, 2006. 102(5): p. 5050-5056.

34. Huisman, M.M.H., H.A. Schols and A.G.J. Voragen, Changes in cell wall polysaccharides from ripening olive fruits. Carbohydrate Polymers, 1996. 31(3): p. 123-133.

35. Dick-Pérez, M., Y. Zhang, J. Hayes, A. Salazar, O.A. Zabotina, and M. Hong, Structure and interactions of plant cell-wall polysaccharides by two-and three-dimensional magic-anglespinning solid-state NMR. Biochemistry, 2011. 50(6): p. 989-1000.

36. Van de Weyenberg, I., T.C. Truong, B. Vangrimde and I. Verpoest, Improving the properties of UD flax fibre reinforced composites by applying an alkaline fibre treatment. Composites Part A: Applied Science and Manufacturing, 2006. 37(9): p. 1368-1376.

37. Zykwinska, A., J.-F. Thibault and M.-C. Ralet, Organization of pectic arabinan and galactan side chains in association with cellulose microfibrils in primary cell walls and related models envisaged. Journal of Experimental Botany, 2007. 58(7): p. 1795-1802.

38. Fry, S.C., Cellulases, hemicelluloses and auxin - stimulated growth: a possible relationship. Physiologia Plantarum, 1989. 75(4): p. 532-536. 
39. Chanliaud, E., K.M. Burrows, G. Jeronimidis and M.J. Gidley, Mechanical properties of primary plant cell wall analogues. Planta, 2002. 215(6): p. 989-996.

40. Zykwinska, A., J.-F. Thibault and M.-C. Ralet, Competitive binding of pectin and xyloglucan with primary cell wall cellulose. Carbohydrate Polymers, 2008. 74(4): p. 957-961.

41. Posé, S., A.R. Kirby, C. Paniagua, K.W. Waldron, V.J. Morris, M.A. Quesada, and J.A. Mercado, The nanostructural characterization of strawberry pectins in pectate lyase or polygalacturonase silenced fruits elucidates their role in softening. Carbohydrate Polymers, 2015. 132: p. 134-145.

42. Cosgrove, D.J., Re-constructing our models of cellulose and primary cell wall assembly. Current Opinion in Plant Biology, 2014. 22: p. 122-131. 


\section{Supporting information}

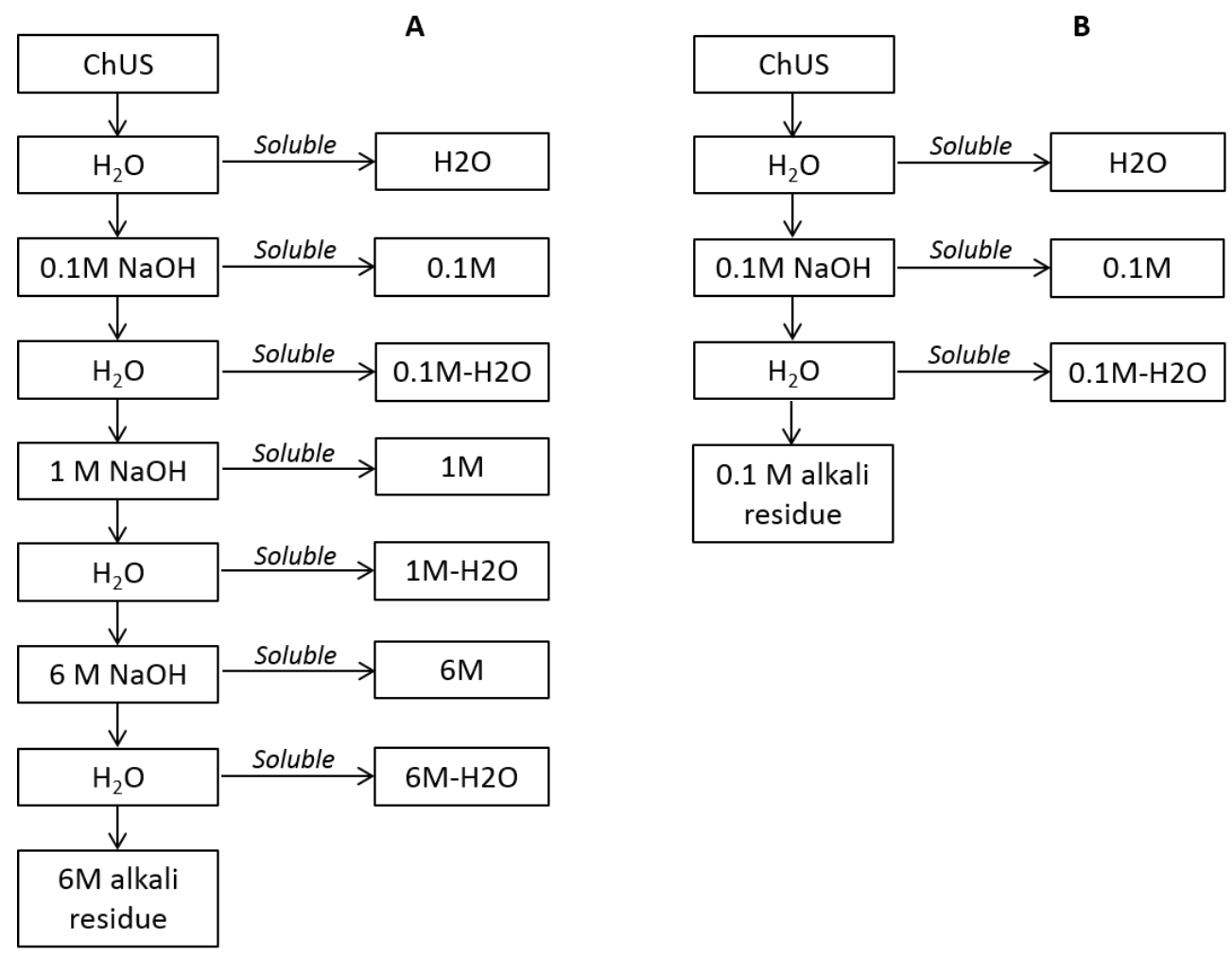

Figure S-3.1 Sequential extraction protocol described in section 3.2.3 for (A) Sequential extraction up to $6 \mathrm{M} \mathrm{NaOH}$ and (B) sequential extraction up to $0.1 \mathrm{M} \mathrm{NaOH}$. 




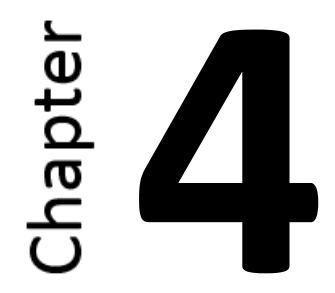

\section{Characterisation of pectin-xylan complexes in tomato primary plant cell walls}

Published as: S.E. Broxterman, H.A. Schols, Characterisation of pectin-xylan complexes in tomato primary plant cell walls. Carbohydrate Polymers 2018, 197, 269-276 


\section{Abstract}

The primary plant cell wall is composed of a complex network of pectin, hemicellulose and cellulose. Potential interactions between these polysaccharides were studied for carrot, tomato and strawberry, with focus on the role of pectin. The Chelating agent Unextractable Solids (ChUS), the residue after water- and EDTA extraction, was ball milled and subsequently water extracted. For tomato and strawberry, pectin and substantial amounts of hemicellulose were solubilised. Anion exchange chromatography (AEC) showed coelution of pectin and acetylated glucuronoxylan in tomato, representing $18 \%$ of solubilised uronic acid (75\%) and $48 \%$ of solubilised xylose $(60 \%)$ by ball milling from chUS. The existence of a covalently linked pectin-xylan complex was shown since xylan co-precipitated with pectin under mild alkali conditions. It was proposed that pectin links with xylan through the RG-I region since degradation of HG did not alter AEC elution patterns for RG-I and xylan, suggesting RG-I - xylan interactions. 


\subsection{Introduction}

The primary plant cell wall of fruits and vegetables is composed of the polysaccharides pectin, hemicellulose and cellulose. Pectin consists of galacturonic acid as the most prevailing building block, mostly present in homogalacturonan (HG) and rhamnogalacturonan I (RG-I) structural elements. The HG backbone is composed of galacturonic acid (GalA) residues and can be methyl-esterified and/or acetylated. The rhamnose residues in RG-I can be substituted with side chains, composed of arabinose and galactose [1].

Xyloglucan is the major hemicellulosic polysaccharide in primary plant cell walls of fruits and vegetables, and is composed of a cellulose-like backbone branched by xylosyl residues [2]. The xylose units can be substituted by several other monosaccharides such as galactose, fucose and arabinose [3]. Xylans have a backbone of xylose residues and depending on origin xylans can be substituted with GlcA, its 4-O-methylated derivative, arabinose and acetyl groups. In fruits and vegetables, glucuronoxylans are the most dominant xylans [4, 5]. Mannans are categorised into gluco- and galactomannans, composed of a mixed glucose-mannose backbone or a mannose backbone substituted with galactose, respectively [6]. Cellulose is composed of an unsubstituted linear backbone of glucose residues [6].

The load-bearing network of the cell wall was for a long time believed to be composed of cross-linked hemicellulose and cellulose, referred to as the tethered network model [7]. Increasing evidence suggests that pectin might interact with hemicellulose and/or cellulose and hereby has a larger load-bearing and cross-linking role than indicated before $[8,9]$. Amongst many interactions between pectin and (hemi)cellulose suggested, recent research in Arabidopsis suggested interactions between RG-I and xylan, indicating that xylans might act as covalent connection between pectin and the hemicellulose-cellulose network [10, 11]. Although the precise details of suggested cross-links between pectin and hemicellulose are in most cases not defined, RG-I is more often thought to be involved in cross-linking than HG $[12,13]$.

In order to study potential cross-links between cell wall polysaccharides, targeted disruption of the cell wall architecture might be useful. In this study, planetary ball milling and subsequent water extraction were used as a tool to mildly release and solubilise pectin and hemicellulose from the insoluble cell wall matrix. Subsequently, the solubilised populations for carrot, tomato and strawberry cell walls were studied by anion exchange chromatography (AEC) in combination with targeted enzymatic digestion to reveal potential interactions between these populations. 


\subsection{Materials and methods}

\subsubsection{Plant material}

Carrots (Daucus carota cv. Romance) and strawberries (Fragaria ananassa cv. Elsanta) were purchased from a local vegetable store. Tomatoes (Solanum lycopersicum cv. H2401) were kindly donated by Heinz (Heinz, Nijmegen, The Netherlands).

\subsubsection{Extraction of cell wall polysaccharides}

Cell wall polysaccharides were extracted using the procedure as described before $[14,15]$. Shortly, Alcohol Insoluble Solids (AIS) were extracted by blending $400 \mathrm{~g}$ carrots, tomatoes or strawberries in a $1: 3 \mathrm{w} / \mathrm{v}$ ratio in $96 \%$ ethanol. Prior to blending, only for peeled tomatoes, microwave pretreatment was performed to inactivate pectinases (10 min, $900 \mathrm{~W})$. The suspension was filtered and the residue was washed with $70 \%$ ethanol until the filtrate gave a negative reaction in the phenol-sulfuric acid test [16]. The water soluble solids (WSS) and chelating agent soluble solids (ChSS) were subsequently extracted from AIS according to the references mentioned above. The residue after WSS and ChSS was extensively dialysed, first against potassium acetate, followed by distilled water. After freeze-drying the Chelating agent Unextractable Solids (ChUS) were obtained. This fraction was used to identify potential interactions between pectin, hemicellulose and cellulose.

All fractions were milled for 30s in a Retsch Cryomill MM440 at a frequency of $20 \mathrm{~Hz}$ to obtain homogeneous material (Retsch $\mathrm{GmbH}$, Haan, Germany). Extractions were carried out in duplicate, unless stated otherwise.

\subsubsection{Planetary ball milling of ChUS}

ChUS was milled in a PM100 planetary ball mill (Retsch, Haan, Germany), particle sizes wre determined by laser diffraction (Mastersizer 3000; Malvern, Worcestershire, UK). A 12 ml stainless steel jar containing $40 \$ 5 \mathrm{~mm}$ stainless steel balls was used at a frequency of 600 rpm. After every $15 \mathrm{~min}$ of milling a pause of $10 \mathrm{~min}$ was set to prevent overheating. 500 mg of ChUS was milled per batch with net milling times of 15, 45 or $90 \mathrm{~min}$. In the remainder of the manuscript, milling refers to planetary ball milling, and not to the short homogenisation milling step described in section 4.2.2.

\subsubsection{Extraction of water soluble cell wall polysaccharides after planetary ball milling}

To study the effect of milling on the extractability of polysaccharides, $30 \mathrm{ml}$ water was added to $150 \mathrm{mg}$ milled and non-milled ChUS, and extraction was done for $1 \mathrm{hr}$ at $40^{\circ} \mathrm{C}$ with continuous head-over-tail rotation. Extractions were carried out in duplicate. Subsequently samples were centrifuged (15 min, $30.000 \mathrm{xg}$ ) and $30 \mathrm{ml}$ water was added once more to the residue, centrifuged (15 minutes, 30.000xg) and supernatants were collected and 
freeze-dried. Samples were coded according to substrate and milling time, e.g. C45 for carrot ChUS milled for 45 minutes.

\subsubsection{Sugar composition of the extracts}

To determine the uronic acid content of the extracted fractions, the uronic acid content was determined by the automated colorimetric m-hydroxydiphenyl method [17]. The neutral carbohydrate composition was analysed after pretreatment with $72 \%$ (w/w) $\mathrm{H}_{2} \mathrm{SO}_{4}(1 \mathrm{~h}$, $30^{\circ} \mathrm{C}$ ) followed by hydrolysis with $1 \mathrm{M} \mathrm{H}_{2} \mathrm{SO}_{4}\left(3 \mathrm{~h}, 100^{\circ} \mathrm{C}\right)$. Neutral monosaccharides were analysed after dilution (20x) using an ICS5000 High Performance Anion Exchange Chromatography system with Pulsed Amperometric detection (ICS5000 ED) (Dionex Corporation, Sunnyvale, CA, USA), equipped with a CarboPac PA-1 column ( $250 \mathrm{~mm} \times 2 \mathrm{~mm}$ i.d.) and a CarboPac PA guard column ( $25 \mathrm{~mm} \times 2 \mathrm{~mm}$ i.d.).

$10 \mu \mathrm{l}$ of sample was injected and eluted at a flow rate of $0.4 \mathrm{ml} / \mathrm{min}$ using a combination of three mobile phases: A) 0.1 M NaOH, B) $1 \mathrm{M} \mathrm{NaOAc}$ in $0.1 \mathrm{M} \mathrm{NaOH}$ and C) H2O. The gradient used was: 0-35 min isocratic $100 \%$ C; $35.1-50$ min linearly from $100 \%$ A to $40 \%$ B; $50.1-55$ min isocratic $100 \% \mathrm{~B}$; $55.1-63 \mathrm{~min}$ isocratic $100 \% \mathrm{~A}$; $63.1-78 \mathrm{~min}$ isocratic $100 \% \mathrm{C}$. Post column addition of $0.5 \mathrm{M} \mathrm{NaOH}$ at $0.1 \mathrm{ml} / \mathrm{min}$ was performed between 0-35 min and 63-78 min. Determination of the sugar composition by methanolysis using $3 \mathrm{~N} \mathrm{HCl}$ in dry $\mathrm{MeOH}$ $\left(16 \mathrm{~h}, 80^{\circ} \mathrm{C}\right)$ followed by $2 \mathrm{~N}$ TFA hydrolysis $\left(1 \mathrm{~h}, 121^{\circ} \mathrm{C}\right)$, was used to distinguish between glucuronic acid and galacturonic acid in T45 SN [18]. Analysis of the monosaccharide composition was performed in duplicate.

Although it is recognised that UA:Rha is the most common ratio for determination of HG:RG-I backbone ratios, rhamnose levels are often low and lead to less accurate HG:RG-I ratios. The HG to RG-I ratio in the extracts was therefore calculated by $\frac{U A}{A r a+G a l}$ in mol\%, leading to a HG to RG-I ratio including RG-I side chains. The ratio of hemicellulose to pectin was calculated by $\frac{M a n+X y l}{U A}$ in mol\%.

\subsubsection{Determination of methyl-esterification and acetylation}

Samples were saponified at $\approx 3 \mathrm{mg} / \mathrm{ml}$ in $0.25 \mathrm{M} \mathrm{NaOH}\left(3 \mathrm{~h}, 4^{\circ} \mathrm{C}\right)$ to determine the degree of methyl-esterification (DM) in duplicate using a colorimetric method as previously described [19]. The same saponification procedure was used to determine the degree of acetylation (DA), by measuring released acetic acid by a Megazyme acetic acid kit (Megazyme, Wicklow, Ireland). The DM and DA were calculated as the moles of methyl esters and acetyl groups per 100 moles of GalA, respectively. 


\subsubsection{Starch digestion}

The presence of starch in AIS, WSS, ChSS and ChUS was analysed in duplicate by using the Megazyme total starch assay procedure for resistant starch (Megazyme, Wicklow, Ireland). After digestion of $10 \mathrm{mg}$ sample with amylase and amyloglucosidase, samples were filtered using a 3kDa filter (Millipore centrifugal filter units, Merck, Billerica, Massachusetts, United States), to remove glucose originating from starch, and freeze-dried. Subsequently the sugar composition after $\mathrm{H}_{2} \mathrm{SO}_{4}$ hydrolysis was measured as indicated in 4.2.5.

\subsubsection{High Performance Size Exclusion Chromatography (HPSEC)}

Extracted polysaccharide populations and fractions obtained by AEC were analysed for their molecular weight distribution using an Ultimate 3000 system (Dionex, Sunnyvale, CA, USA) coupled to a Shodex RI-101 detector (Showa Denko K.K., Tokyo, Japan). A set of TSK-Gel super AW columns 4000, 3000, $2000(6 \mathrm{~mm} \times 150 \mathrm{~mm}$ ) preceded by a TSK-Gel super AW guard column ( $6 \mathrm{~mm}$ ID $\times 40 \mathrm{~mm}$ ) (Tosoh Bioscience, Tokyo, Japan) was used in series. The column temperature was set to $55^{\circ} \mathrm{C}$. Samples $(5 \mathrm{mg} / \mathrm{ml})$ were injected $(10 \mu \mathrm{l})$ and eluted with $0.2 \mathrm{M} \mathrm{NaNO}_{3}$ at a flow rate of $0.6 \mathrm{ml} / \mathrm{min}$. Pectin standards from 10-100 kDa were used to estimate the molecular weight distribution [20].

\subsubsection{Enzymatic degradation and alkali precipitation of solubilised populations}

In order to study the potential linkages between cell wall polysaccharides, several enzymatic digestions were performed. The polygalacturonase (PG) used was endo-polygalacturonase from Aspergillus aculeates [21, 22], and PME (pectin methyl esterase) was either from either Aspergillus niger (f-PME) or from Dickeya dadantii (b-PME) [15]. Xylan in tomato T45 SN was analysed after digestion with a well-characterised endo-xylanase from Aspergillus awamori [23]. All incubations were done in $50 \mathrm{mM}$ sodium citrate buffer $\mathrm{pH} 5$ at $40^{\circ} \mathrm{C}$ by head over tail rotation for $24 \mathrm{~h}$. Enzymes were dosed to fully degrade the substrate theoretically in $6 \mathrm{~h}$. Alkali solubility was determined by dissolving $10 \mathrm{mg}$ of both the populations solubilised by milling followed by water extraction, and pure polysaccharides in duplicate at $5 \mathrm{mg} / \mathrm{ml}$ in $0.1 \mathrm{M} \mathrm{NaOH}$ for $16 \mathrm{~h}$ at $4^{\circ} \mathrm{C}$ during continuous head-over-tail rotation. Samples were centrifuged (10min, 20.000xg) prior to neutralisation to $\mathrm{pH} 6$. Birch wood and beech wood xylans were from Sigma (St. Louis, USA), lemon pectin DM30 and DM70 from CP Kelco (Lille Skensved, Denmark), and soy and potato RG-I from Megazyme (Wicklow, Ireland).

\subsubsection{Fractionation of neutral and acidic polysaccharides by AEC}

The potential interactions between neutral and acidic cell wall polysaccharides were studied by anion exchange chromatography with an Akta Micro system equipped with a Resource Q-1 $\mathrm{ml}$ column (GE Healthcare, Uppsala, Sweden). Samples were manually injected (1.5 ml, $5 \mathrm{mg} / \mathrm{ml}$ ) and eluted with A) $50 \mathrm{mM}$ ammonium acetate buffer $\mathrm{pH} \mathrm{5,} \mathrm{B)} 1 \mathrm{M}$ ammonium 
acetate buffer $\mathrm{pH} 5, \mathrm{C}) 0.5 \mathrm{M} \mathrm{LiCl}$ in $50 \mathrm{mM}$ ammonium acetate buffer and D) $0.5 \mathrm{M} \mathrm{NaOH}$. The gradient programme applied was $100 \%$ A for $8 \mathrm{CV}$; $0-10 \% \mathrm{~B}$ and $100-90 \% \mathrm{~A}$ in $2 \mathrm{CV}$; 10-50\% $B$ and $90-50 \% A$ in $20 \mathrm{CV}$; $50-100 \% \mathrm{~B}$ and $50-0 \% \mathrm{~A}$ in $10 \mathrm{CV} ; 100 \% \mathrm{~B}$ for $8 \mathrm{CV}$, followed by $10 \mathrm{CV} C$ and $10 \mathrm{CV}$ D, and re-equilibration with $10 \mathrm{CV} \mathrm{A}$. Flowrate was set to $2 \mathrm{ml} / \mathrm{min}$. Experiments were performed in duplicate. Fractions of $1 \mathrm{ml}$ were collected, and pooled based on HPSEC results of populations showing RI-signal (Table 4.1). Pools were desalted using a $3 \mathrm{kDa}$ filter.

Table 4.1 Pools I-V, obtained by pooling all AEC fractions.

\begin{tabular}{|l|l|l|}
\hline & Fractions & Characteristics \\
\hline Pool I & $1-8$ & Unbound material \\
\hline Pool II & $9-21$ & Loosely bound material \\
\hline Pool III & $22-48$ & Strongly bound material \\
\hline Pool IV & $49-58$ & Strongly bound material \\
\hline Pool V & $59-68$ & Strongly bound material \\
\hline
\end{tabular}

4.2.11 Matrix-Assisted Laser Desorption/Ionization Time-Of-Flight Mass Spectrometry (MALDI-TOF MS)

The oligosaccharides in the xylanase digest of T45 SN were analysed by MALDI-TOF MS. MALDI-TOF mass spectra were recorded using an Ultraflextreme workstation controlled by FlexControl 3.3 software (Bruker Daltonics, Bremen, Germany) equipped with a Smartbeam II laser of $355 \mathrm{~nm}$ and operated in positive mode.

Before analysis by MALDI-TOF MS, samples were desalted with Dowex 50W-X8 (Bio-Rad Laboratories, CA, USA) and $1 \mu \mathrm{L}$ of sample was co-crystallised with $1 \mu \mathrm{L}$ matrix $(25 \mathrm{mg} / \mathrm{mL}$ dihydroxy-benzoic acid in $50 \%(\mathrm{v} / \mathrm{v})$ acetonitrile). Samples were dried under a stream of air. Maltodextrin MD 20 (Avebe, Foxhol, The Netherlands) was used for calibration. 


\subsection{Results and discussion}

\subsubsection{Yield and composition of different cell wall polysaccharides}

The potential linkages between pectin, hemicellulose and cellulose were studied in the Chelating agent Unextractable Solids (ChUS), the residue after solubilisation of easily extractable, non-bound pectin using water (WSS) and EDTA (ChSS) as extractants. Both WSS and ChSS were predominantly composed of pectin, the exact composition and yields are reported in Supporting information Table S-4.1 and are discussed elsewhere [24]. As can be seen from Table 4.2, xylose, mannose and glucose levels in ChUS differed between sources. As shown before for carrot, tomato and broccoli, not all pectin is extractable by water and EDTA [14]. It was assumed that the pectin populations remaining in ChUS were insoluble due to their interactions with the other cell wall polysaccharides. Differences in pectin and hemicellulose content and composition and increased attention for the role of xyloglucan in dicot plant cell walls [8] made carrot, tomato and strawberry good sources to study cell wall architecture.

Table 4.2 Monosaccharide composition (mol\%) of the Chelating agent Unextractable Solids (ChUS). Total yield and uronic acid (UA) solubilised in ChUS as percentage of AIS.

\begin{tabular}{|c|c|c|c|c|c|c|c|c|c|c|c|}
\hline & \multicolumn{7}{|c|}{ Mol \%* } & \multirow[t]{2}{*}{ DM* $^{*}$} & \multirow[t]{2}{*}{$\mathrm{DA}^{*}$} & \multirow[t]{2}{*}{$\%$ Yield } & \multirow[t]{2}{*}{$\%$ UA } \\
\hline & Ara & Rha & Gal & Glc & Xyl & Man & UA & & & & \\
\hline Carrot & 8 & 1 & 21 & 36 & 2 & 5 & 27 & 51 & 44 & 82 & 69 \\
\hline Tomato & 5 & 1 & 6 & 55 & 8 & 6 & 19 & 36 & 37 & 73 & 50 \\
\hline Strawberry & 8 & 1 & 9 & 40 & 9 & 3 & 30 & 53 & 37 & $68 * *$ & $37^{* *}$ \\
\hline
\end{tabular}

*Values are the average of two replicates. Absolute deviations were $<3 \%$.

**Isolation of strawberry AIS, WSS, ChSS and the residue ChUS was not performed in duplicate.

\subsubsection{Solubilisation of pectin and hemicellulose from ChUS as an effect of milling}

As suggested above, pectin populations present in ChUS might interact with the other cell wall polysaccharides present. In order to study these interactions and the structural characteristics of these pectin populations, selective disruption of the network and characterisation of subsequently solubilised populations was needed. In this study planetary ball milling (hereafter called milling) was used to disrupt interactions between cell wall polysaccharides and ChUS was milled to particle sizes of 30-60 $\mu \mathrm{m}$. To study the cell wall architecture with a minimal impact on polysaccharide structures, a series of rather short milling intervals was tested. The efficiency of milling to increase the solubility of cell wall polysaccharides in a subsequent extraction step with water was monitored by HPSEC to determine both amount and the Mw of the material solubilised (Figure 4.1). Milling has mainly been used to decrease the crystallinity of cellulose, as a pretreatment for enhanced enzyme digestibility or for enabling differently recrystallised cellulose $[25,26]$. Next to 
decreasing the crystallinity of cellulose, it was shown that extensive milling may degrade covalent linkages in pectin [27].
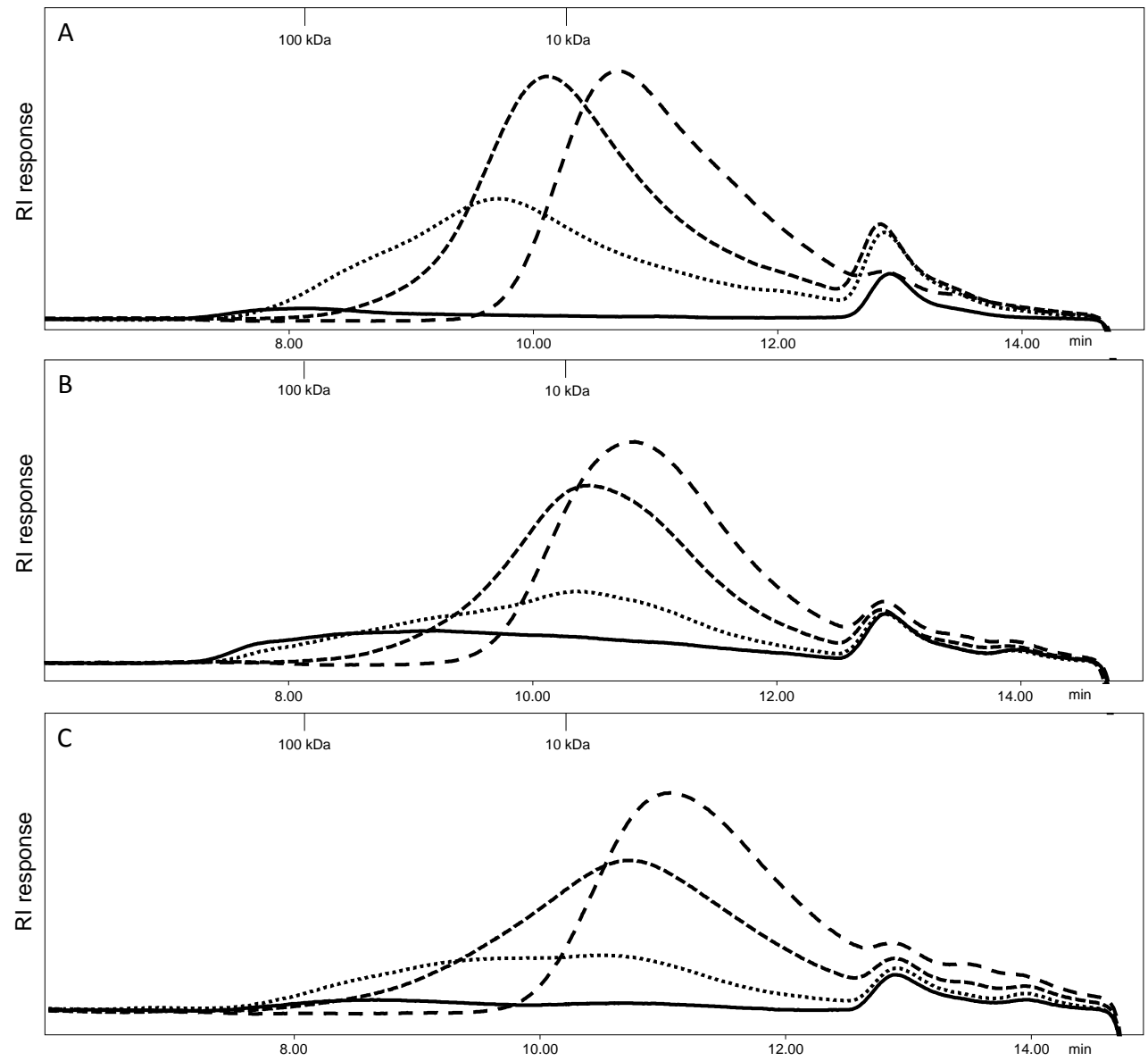

Figure 4.1 HPSEC elution pattern of (A) Carrot, (B) Tomato and (C) Strawberry ChUS before and after milling. Not milled (-); 15 minutes milled $(\cdots)$; 45 minutes milled (---); 90 minutes milled (-- - ). All samples were analysed at $5 \mathrm{mg} / \mathrm{ml}$ ChUS, RI responses were not similar for all samples and therefore $\mathrm{y}$-axis were auto scaled to the largest signal. Molecular weights of pectin standards (in $\mathrm{kDa}$ ) are indicated.

As can be seen, milling solubilised polysaccharides for all 3 sources studied. The average $\mathrm{Mw}$ reduced as milling time increased, indicating that insoluble polysaccharides were solubilised and/or depolymerised by milling. In time, also the level of solubilised material increased until a given plateau as can be seen from the yields reported in Table 4.3. The peak around 13 minutes seems to be a non-carbohydrate artefact since no oligosaccharides 
were detected by HPAEC analysis (data not shown). In order to obtain more information on the effect of milling on Mw distrubution, several pure polysaccharides were milled and analysed for their molecular weight $(\mathrm{Mw})$ distribution. The effects of milling on $\mathrm{Mw}$ distribution for pure polysaccharides are in Supporting information Figure S-4.1. In summary, milling for 15 minutes did not disrupt covalent linkages yet, but increasing milling times led to depolymerisation of polysaccharides to $\sim 10 \mathrm{kDa}$.

Table 4.3 Monosaccharide composition (mol\%), ratio of HG:RG-I (UA:Ara+Gal), Hemicellulose (HC): pectin (Man+Xyl:UA), and yield of water soluble material as percentage of ChUS after milling ChUS for $0,15,45$ and $90 \mathrm{~min}$.

\begin{tabular}{|c|c|c|c|c|c|c|c|c|c|c|}
\hline & \multicolumn{7}{|c|}{ Mol \% } & \multirow{2}{*}{$\begin{array}{c}\text { Ratio } \\
\text { HG:RG-I }\end{array}$} & \multirow{2}{*}{$\begin{array}{c}\text { Ratio } \\
\text { HC:Pectin }\end{array}$} & \multirow{2}{*}{$\begin{array}{c}\text { Yield (\% of } \\
\text { ChUS)* }\end{array}$} \\
\hline & Ara* & Rha* & Gal* & Glc* & $\left.X y\right|^{*}$ & Man* & UA* & & & \\
\hline CO SN & 7 & 3 & 10 & 4 & 0 & 0 & 76 & 4.4 & 0 & 4 \\
\hline C15 SN & 22 & 3 & 34 & 4 & 2 & 7 & 28 & 0.5 & 0.3 & 31 \\
\hline C45 SN & 17 & 3 & 30 & 3 & 1 & 3 & 43 & 0.9 & 0.1 & 42 \\
\hline C90 SN & 20 & 3 & 35 & 3 & 2 & 4 & 33 & 0.6 & 0.2 & 40 \\
\hline TO SN & 6 & 2 & 8 & 4 & 5 & 2 & 73 & 5.1 & 0.1 & 12 \\
\hline T15 SN & 8 & 2 & 12 & 11 & 10 & 6 & 51 & 2.6 & 0.3 & 19 \\
\hline T45 SN & 8 & 1 & 12 & 19 & 13 & 9 & 38 & 1.9 & 0.6 & 31 \\
\hline T90 SN & 8 & 2 & 12 & 19 & 13 & 9 & 37 & 1.8 & 0.6 & 36 \\
\hline SO SN & 8 & 1 & 8 & 11 & 8 & 5 & 59 & 3.7 & 0.2 & 4 \\
\hline S15 SN & 14 & 2 & 14 & 9 & 8 & 3 & 50 & 1.8 & 0.2 & 16 \\
\hline S45 SN & 14 & 2 & 16 & 13 & 10 & 4 & 41 & 1.4 & 0.3 & 28 \\
\hline S90 SN & 12 & 2 & 16 & 15 & 12 & 5 & 38 & 1.3 & 0.4 & 35 \\
\hline
\end{tabular}

*Values are the average of two replicates. Absolute deviations were $<2 \mathrm{~mol} \%$ in composition and $<5$ $\%$ for yield.

The monosaccharide compositions and yields of milled ChUS was reported in Table 4.3. For tomato and strawberry especially HG-rich pectins were solubilised after 15 min milling and relatively more RG-I rich pectin became water soluble as milling time increased. For all sources, the HG:RG-I ratio decreased as milling time increased, indicating that RG-I is less easily solubilised from the insoluble matrix compared to $H G$. The degree of methyl-esterification (DM) and degree of acetylation (DA) remained similar after milling (data not shown). In contrast to tomato and strawberry ChUS, milling and subsequent water extraction solubilised almost exclusively pectin from carrot ChUS. For the former two sources, the ratio hemicellulose:pectin increased as milling time increased, as observed by 
the ratio $M+X: U A$. Despite some exceptions, e.g. a water soluble xyloglucan population in tomato [28], hemicelluloses are typically water unextractable and only extracted at alkali concentrations $\geq 1 \mathrm{M}$. Hemicellulose strongly associated with cellulose, leading to insoluble hemicellulose in the cell wall matrix. Solubilisation of hemicelluloses indicated that the interactions between hemicellulose and cellulose were gradually disrupted as milling time increased, and that no substantial re-adsorption of the solubilised populations in ChUS occurred during water extraction.

The $X: G$ ratio of tomato and strawberry fractions (Table 4.3) pointed to the presence of xyloglucan. Substitution of xylose on 3 out of 4 glucose units has been reported for strawberry xyloglucan, with multiple substitution patterns present [29]. In contrast to strawberry XXXG type xyloglucan, tomato xyloglucans are known to appear as the XXGG-type [6]. The X:G ratio of the tomato extracts of 1.3, 0.9, 0.7 and 0.7 for T0 SN, T15 SN, T45 SN and T90 SN respectively, therefore points to the presence of xylans, next to xyloglucans.

It has been shown in Figure 4.1 that for all sources milling for 45 and 90 minutes resulted in solubilisation in $\mathrm{H}_{2} \mathrm{O}$ of heterogeneous populations with a similar molecular weight (Mw) distribution of $\sim 10 \mathrm{kDa}$. The effect of milling on the amount of water soluble material, released from the cell wall, reached a plateau after 45 minutes milling since milling ChUS for 8 hrs showed a rather similar yield, composition and Mw (data not shown). It was decided to study the polymeric populations solubilised by 45 minutes milling since this was considered as an optimal balance between solubilising a substantial amount of cell wall polysaccharides and minimising possible chain cleavage.

It is generally accepted that pectin molecules may consist of different regions including HG and RG-I, explaining the rather homogeneous $\mathrm{Mw}$ distribution for the carrot extract consisting mainly of pectin. For tomato and strawberry, the similarities in Mw distribution of the solubilised material could point to the presence of one complex composed of pectin and hemicellulose. Therefore potential interactions between the solubilised pectin and hemicellulose populations will only be further studied by AEC for tomato and strawberry.

\subsubsection{Anion exchange chromatography of T45 SN and S45 SN released by milling}

Anion exchange chromatography (AEC) has previously succesfully been used to study potential interactions between neutral and acidic polysaccharides $[12,30]$. Therefore the populations solubilised by milling were subjected to AEC and devided in 3 pools: an unbound pool I, a loosely bound pool II and a strongly bound pool III. Previous research showed the potential of recovering very strongly bound material with $\mathrm{LiCl} /$ buffer and $\mathrm{NaOH}$, and therefore pools IV and V were eluted using these solvents [31, 32].

The monosaccharide composition of the AEC pools from tomato and strawberry (Table 4) showed the presence of neutral polymers in pool I and RG-I in the subsequent pools, with 
an increasing HG:RG-I ratio for pools II, III and IV. For both tomato and strawberry, the nonbound pool I probably contained xyloglucans and mannans. Hardly any material was recovered in the pools $V$ and these pools were not further analysed. Since total recoveries were low but rather similar for all monosaccharides, it was concluded that losses were due to the various experimental steps.

The relative xylose content of $40 \%$ in the RG-I containing pool II was rather high and the recovery showed that approximately half of all xylose was recovered in pool II. The X:G ratio of 40:2 for pool II indicated the absence of xyloglucan and instead illustrated the dominant presence of xylan.

Table 4.4 Monosaccharide composition (mol\%) and recovery (\% of T45 SN and S45 SN) of AEC pools after fractionating T45 SN and S45 SN.

\begin{tabular}{|l|c|c|c|c|c|c|c|}
\hline & \multicolumn{7}{|c|}{ Mol \% } \\
\hline & Ara & Rha & Gal & Glc & Xyl & Man & UA \\
\hline T45 SN Blank pool I & 7 & 0 & 16 & 37 & 14 & 23 & 3 \\
\hline T45 SN Blank pool II & 6 & 1 & 9 & 2 & 40 & 0 & 42 \\
\hline T45 SN Blank pool III & 14 & 5 & 15 & 2 & 2 & 0 & 62 \\
\hline T45 SN Blank pool IV & 4 & 2 & 6 & 1 & 1 & 0 & 86 \\
\hline \multicolumn{7}{|c|}{} \\
\hline
\end{tabular}

Values are the average of two replicates. Absolute deviations were $<5 \mathrm{~mol} \%$. 


\subsubsection{Structural characterisation of tomato xylan}

Since it was not expected that such a substantial amount of xylose as reported in Table 4.4 originated from xylan rather than xyloglucan, it was of importance to confirm and characterise the solubilised xylan. This will enable further understanding of the behaviour of xylan in the hypothesized pectin-xylan complexes. To characterise pectin populations present in T45 SN, digestion with a well-characterised endo-xylanase I was performed [23]. The MALDI-TOF mass spectrum of the endo-xylanase digest is shown in Figure 4.2 and clearly demonstrates the presence of xylan oligomers.

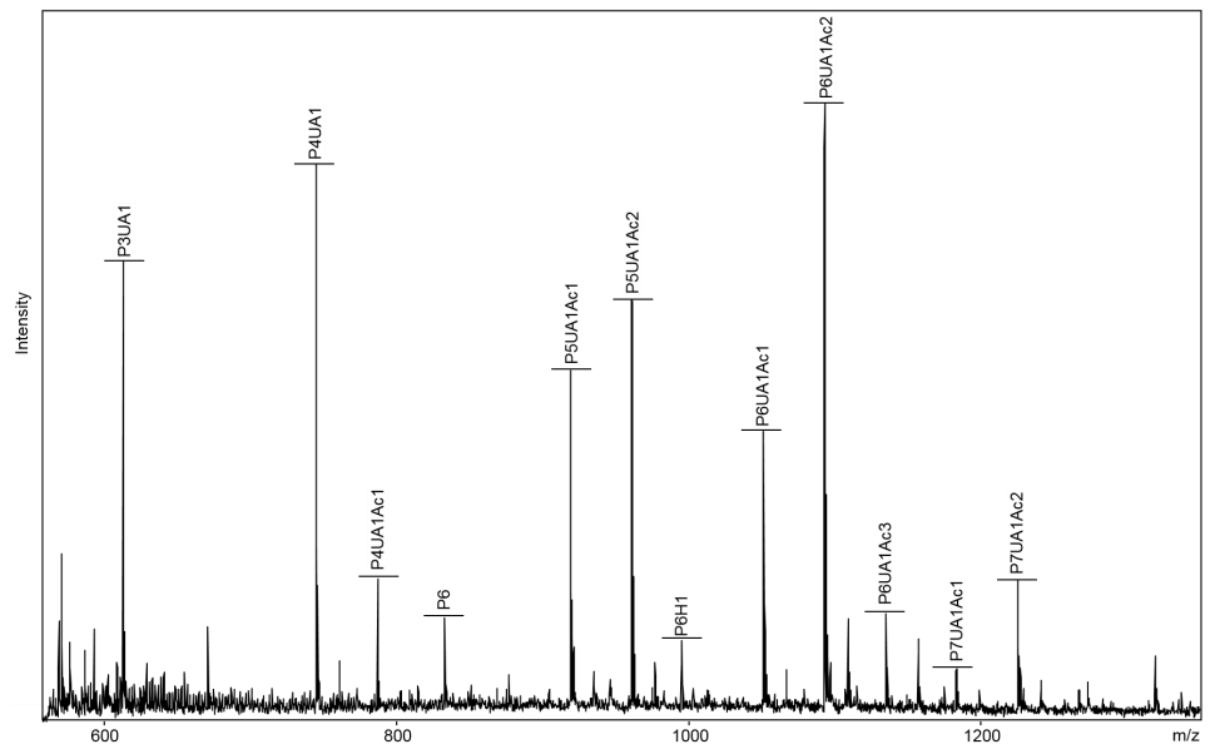

Figure 4.2 MALDI-TOF mass spectrum of T45 SN digested with endo-xylanase I. Peak annotation: P, pentose; UA, uronic acid; $\mathrm{H}$, hexose, Ac, acetyl group.

These xylan oligomers were mostly substituted with GIcA and substantially acetylated. It could not be established to what extent xylans were substituted with arabinose, but a low arabinose content was expected since only $6 \%$ arabinose was present in pool II. Furthermore the presence of galactose, rhamnose and uronic acid indicated the presence of RG-I, and at least part of the arabinose should be considered to be part of RG-I. Determination of the sugar composition by methanolysis revealed that $\sim 12 \%$ of all uronic acid in T45 SN was glucuronic acid, confirming the presence of glucuronoxylan. Previously, the presence of acetylated glucuronoxylans in tomato was reported after LiCl-DMSO extractaction and subsequent xylanase treatment [5]. However, solubilising highly acetylated glucuronoxylans from tomato by water extraction was not shown before. 
Substitution of xylan by GlcA residues explained xylan's acidic elution behaviour on AEC. The question remained whether xylan and pectin were present in pool II due to co-elution of two individual polymers as based on charged GalA in pectin and charged GlcA in xylan, or due to covalent interactions between both polymers. Interactions between pectin and xylan would be unexpected since previous research on the localisation of tomato cell wall polysaccharides by using specific antibodies pointed at close pectin-xyloglucan associations rather than pectin-xylan associations [28].

\subsubsection{Solubility of pectin and xylan in alkali conditions}

In order to further study potential interactions between xylan and pectin, the total charge of HG was changed by removal of the methyl-esters by mild alkali treatment and it was subsequently tested whether this action affected the elution behaviour of xylan. It was hypothesized that covalent cross-links between pectin and xylan would lead to a changed elution behaviour of xylan, since xylan would join pectin in its changed elution behaviour. To test whether alkaline conditions could affect polysaccharides, several pure polysaccharides were analysed for their molecular weight distribution by HPSEC before and after solubilisation in alkali. Surprisingly, solubilisation of several pure polysaccharides in $0.1 \mathrm{M} \mathrm{NaOH}$ for $16 \mathrm{~h}$ at $4^{\circ} \mathrm{C}$ showed that not all polysaccharides remained soluble under these conditions (Figure 4.3). As can be observed from the HPSEC elution patterns in Figure 4.3E and 4.3F, RG-I from both potato and soy solubilised well in $0.1 \mathrm{M} \mathrm{NaOH}$ without changes in their Mw distribution. Xylans from both birch wood and beech wood also solubilised well in $0.1 \mathrm{M} \mathrm{NaOH}$. However, both water soluble lemon pectin with a DM of 30 and 70 completely precipitated in $0.1 \mathrm{M} \mathrm{NaOH}$, as can be concluded from Figure $4.3 \mathrm{C}$ and $4.3 \mathrm{D}$. It is therefore clear that rather pure homogalacturonans become insoluble in alkali. For all polysaccharides, the $\mathrm{Mw}$ of soluble populations remained rather similar, indicating that polysacccharides did not depolymerise under the applied conditions. 

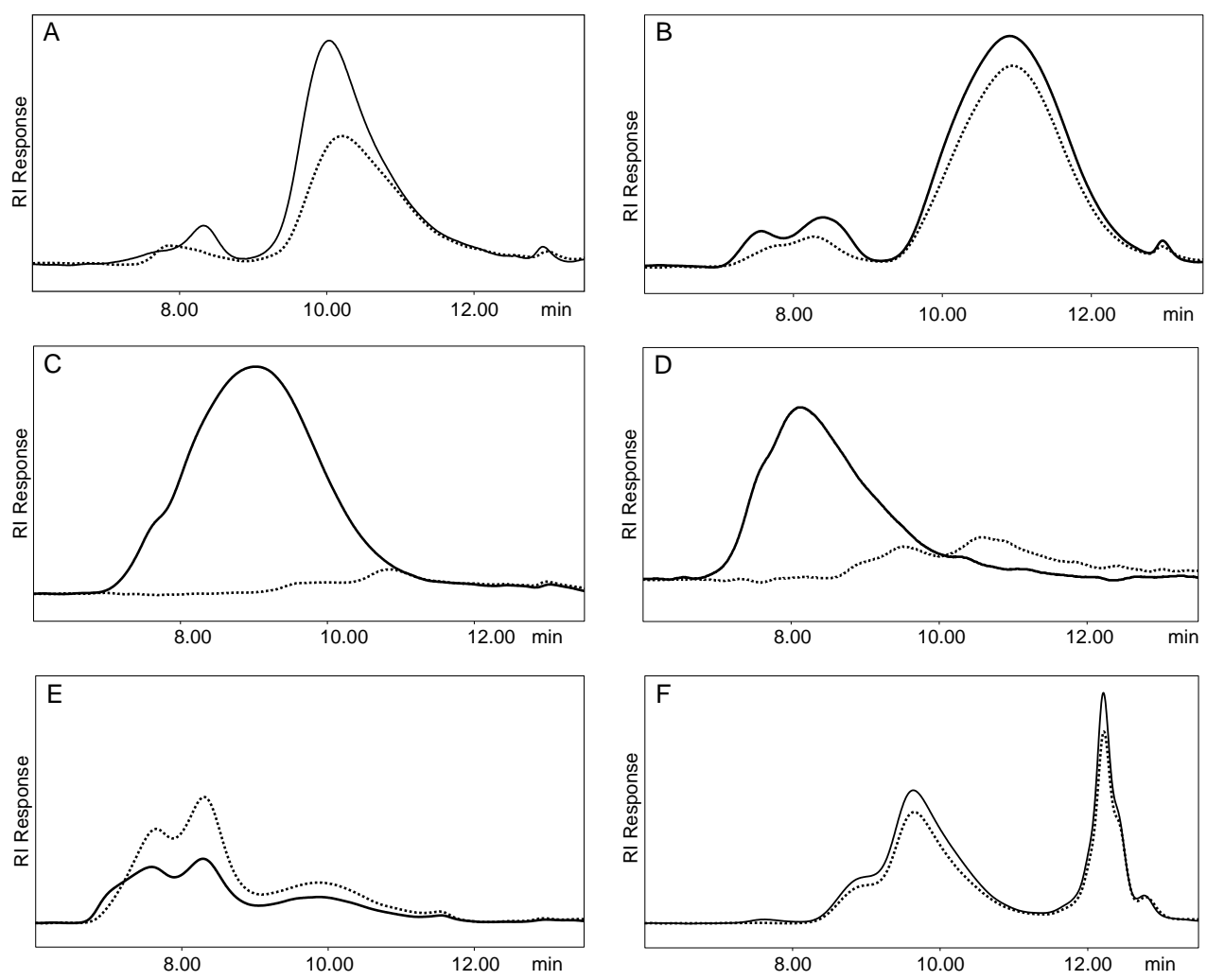

Figure 4.3 HPSEC elution patterns of different polysaccharides, solubilised in $0.1 \mathrm{M} \mathrm{NaOH}$. Solubilisation in water $(-)$ and $0.1 \mathrm{M} \mathrm{NaOH}(\cdots)$, for $16 \mathrm{~h}, 4^{\circ} \mathrm{C}$, and neutralisation was done after centrifugation ( $5 \mathrm{~min}, 15.000 \mathrm{xg}$ ). All samples analysed at $5 \mathrm{mg} / \mathrm{ml}$. Xylan birch wood $(A)$, xylan beech wood (B), citrus pectin DM30 (C), citrus pectin DM 70 (D), soy RG-I (E) and potato RG-I (F).

T45 SN was dissolved in $0.1 \mathrm{M} \mathrm{NaOH}, 4^{\circ} \mathrm{C}, 16 \mathrm{~h}$, to be fractionated by $\mathrm{AEC}$. Since it was visually observed that a substantial amount of material precipitated, in contrast to T45 SN Blank and S45 SN Blank, the pellet that was obtained prior to AEC fractionation was analysed together with the pools. 
Table 4.5 Monosaccharide composition (mol\%) and recovery (\% of T45 SN) of AEC pools after fractionating T45 SN solubilised in $0.1 \mathrm{M} \mathrm{NaOH}$. Pellet was composed of $0.1 \mathrm{M} \mathrm{NaOH}$ insoluble material.

\begin{tabular}{|l|c|c|c|c|c|c|c|}
\hline & \multicolumn{7}{|c|}{ Mol \% } \\
\hline & Ara & Rha & Gal & Glc & Xyl & Man & UA \\
\hline T45 SN NaOH pool I & 8 & 0 & 17 & 37 & 15 & 19 & 4 \\
\hline T45 SN NaOH pool II & - & - & - & - & - & - & - \\
\hline T45 SN NaOH pool III & 14 & 5 & 14 & 2 & 8 & 0 & 57 \\
\hline T45 SN NaOH pool IV & 6 & 3 & 8 & 1 & 3 & 0 & 79 \\
\hline T45 SN NaOH pellet & 5 & 1 & 6 & 13 & 30 & 4 & 41 \\
\hline & \multicolumn{7}{|c|}{ Recovery \% } \\
\hline & Ara & Rha & Gal & Glc & Xyl & Man & UA \\
\hline T45 SN NaOH pool I & 37 & 13 & 47 & 66 & 39 & 68 & 4 \\
\hline T45 SN NaOH pool II & 0 & 0 & 0 & 0 & 0 & 0 & 0 \\
\hline T45 SN NaOH pool III & 25 & 50 & 16 & 1 & 8 & 0 & 20 \\
\hline T45 SN NaOH pool IV & 3 & 9 & 2 & 0 & 1 & 0 & 8 \\
\hline T45 SN NaOH pellet & 7 & 11 & 6 & 8 & 28 & 5 & 14 \\
\hline Recovery pools I-IV + pellet & 73 & 82 & 72 & 77 & 77 & 74 & 46 \\
\hline
\end{tabular}

Values are the average of two replicates. Absolute deviations were $<5 \%$.

As can be observed from Table 4.5, no polysaccharides eluted under conditions from where pool II would be collected, indicating no loosely bound material was present. It was concluded from this observation that both RG-I and xylan were affected by HG precipitation and co-precipated with the homogalacturonan present. Although the DM of the solubilised pectin populations in the total T45 SN was only $\sim 38$, saponification had major effects on its solubility. Analysis of the pellet confirmed this since the pellet was composed of a mix of xylose and the common pectin monosaccharides (Ara, Gal, UA). Since xylan was soluble in $0.1 \mathrm{M} \mathrm{NaOH}$ (Fig $3 \mathrm{~A}+\mathrm{B}$ ), xylan co-precipitation with pectin confirmed that both polymers are covalently, non-ester linked to each other. Most cell wall models still indicate a dominant cross-linking role for xyloglucan. However, more recently pectin-xylan cross-links through the RG-I backbone were proposed for Arabidopsis thaliana [10, 11], suggesting that pectin-xylan cross-links are more apparent than previously believed. Furthermore it shows that other elements than xyloglucan might be involved in cross-links between cell wall polysaccharides.

\subsubsection{Digestion of T45 SN by PG + PME}

In order to further investigate the linkage between pectin and xylan, T45 SN was digested with polygalacturonase and pectin methyl esterase (PG+PME) to test the effect of $\mathrm{HG}$ digestion on AEC behaviour of xylan. AEC of T45 SN treated by PG+PME showed that 
enzymatic digestion of HG did not affect elution behaviour of xylan and RG-I (Table 4.6). While the total UA recovery decreased to $14 \%$ due to degradation of $H G$ and formation of GalA oligomers $<3 \mathrm{kDa}$ being removed by filtration, xylan and RG-I continued to be present at rather similar levels in pool II.

Table 4.6 Monosaccharide composition (mol\%) and recovery (\% of T45 SN) of AEC pools after fractionating Tomato T45 water soluble SN treated with PG+PME.

\begin{tabular}{|l|c|c|c|c|c|c|c|}
\hline & \multicolumn{7}{|c|}{ Mol \% } \\
\hline & Ara & Rha & Gal & Glc & Xyl & Man & UA \\
\hline T45 SN PG+PME pool I & 7 & 0 & 15 & 41 & 16 & 19 & 2 \\
\hline T45 SN PG+PME pool II & 10 & 1 & 16 & 6 & 51 & 1 & 15 \\
\hline T45 SN PG+PME pool III & 23 & 7 & 29 & 3 & 4 & 0 & 34 \\
\hline T45 SN PG+PME pool IV & 0 & 0 & 0 & 0 & 0 & 0 & 100 \\
\hline & \multicolumn{7}{|c|}{ Recovery \% } \\
\hline & Ara & Rha & Gal & Glc & Xyl & Man & UA \\
\hline T45 SN PG+PME pool I & 21 & 6 & 27 & 45 & 26 & 42 & 1 \\
\hline T45 SN PG+PME pool II & 11 & 10 & 12 & 3 & 34 & 1 & 3 \\
\hline T45 SN PG+PME pool III & 30 & 51 & 23 & 2 & 3 & 0 & 9 \\
\hline T45 SN PG+PME pool IV & 0 & 0 & 0 & 0 & 0 & 0 & 0 \\
\hline Total recovery & 62 & 66 & 62 & 50 & 63 & 43 & 14 \\
\hline
\end{tabular}

\subsubsection{Elution behaviour of pure RG-I}

In the proposed covalent interactions between RG-I and xylan in T45 SN PG+PME pool II, it was assumed that the elution behaviour of RG-I was governed by the elution behaviour of HG and xylan. From the substitution pattern of tomato xylans as visualised by MALDI-TOF MS (Fig 4.2), it can be estimated that $\sim 20 \%$ of all xylose residues was substituted with GlcA. Therefore the majority of uronic acid ( 10\%) found in pool II was present as GlcA substitution of xylan, next to ca $5 \%$ remaining GalA from pectic origin. It was deduced from the HG:RG-I ratio of the PG+PME digest and the low rhamnose levels that RG-I was substituted with long arabinose- and galactose-based side chains with limited HG regions attached. Since it is known that rhamnose levels are typically underestimated in the method used to determine the monosaccharide composition [18], a part of the remaining GalA is expected to be present in the RG-I backbone, leaving only very limited HG stretches. RG-I with such structural characteristics is typically expected to elute in the unbound fraction, similar to RG-I present in pool I. The presence of RG-I in pool II therefore points at a cross-link to xylan (Table 4.4). 
In order to confirm the elution behaviour of RG-I, it was attempted to obtain pure RG-I populations by digestion of T45 SN with endo-xylanase and PG+PME. However, the digest still contained a remaining percentage of UA in the absence of xylan, indicating that most probably PG+PME were not able to remove all HG due to steric hindrance caused by RG-I side chains. The presence of stretches of HG next to RG-I therefore neither confirmed or rejected the hypothesis on RG-I elution behaviour.

\subsubsection{The presence of xylan in strawberry cell walls}

Pectin-xylan complexes were only described for tomato, since xylan levels in pool II were much higher for tomato (40 mol\%) compared to strawberry (6 mol\%). Therefore the potential chance to recognise pectin-xylan interactions was much higher for tomato. S45 SN Blank pool II showed a Xyl:Glc ratio of 6:2, indicating the presence of xylan in strawberry pool II as well. Even though levels are lower, also in strawberry pectin-xylan complexes might be present although this should be confirmed by further studies.

\subsection{Conclusions}

The study on the solubilisation of cell wall polysaccharides showed new characteristics about the primary plant cell wall architecture. For carrot, tomato and strawberry, the amount of water soluble material increased with milling time. Whereas for carrot mainly pectin was solubilised, for tomato and strawberry both pectin and hemicellulose were solubilised. Solubilised populations showed a homogeneous $\mathrm{Mw}$ distribution, suggesting the presence of an interacting complex of pectin and hemicellulose in tomato and strawberry. Analysis of the solubilised populations revealed that for tomato ChUS, at least $\sim 30 \%$ of all xylose was present as acetylated glucuronoxylan. Xylan was proposed to be present in a covalently linked complex with pectin. It was proposed that the covalent cross-link is present between the RG-I region of pectin and xylan since removal of HG regions did not affect the complex between RG-I and xylan.

\section{Acknowledgments}

This work received funding from the European Union's Seventh Framework Programme for Research, technological development and demonstration under Grant Agreement No. Kbbe-311754 (OPTIFEL). 


\section{References}

1. Voragen, A.G., G.-J. Coenen, R.P. Verhoef and H.A. Schols, Pectin, a versatile polysaccharide present in plant cell walls. Structural Chemistry, 2009. 20(2): p. 263-275.

2. O'Neill, M.A. and W.S. York, The composition and structure of plant primary cell walls. The plant cell wall. Rose JCK, eds. Oxford, UK: Blackwell Publishing, 2003: p. 1-54.

3. Fry, S.C., The structure and functions of xyloglucan. Journal of Experimental Botany, 1989. 40(1): p. 1-11.

4. Coimbra, M.A., K.W. Waldron and R.R. Selvendran, Isolation and characterisation of cell wall polymers from the heavily lignified tissues of olive (Olea europaea) seed hull. Carbohydrate Polymers, 1995. 27(4): p. 285-294.

5. Assor, C., B. Quemener, J. Vigouroux and M. Lahaye, Fractionation and structural characterization of LiCl-DMSO soluble hemicelluloses from tomato. Carbohydrate Polymers, 2013. 94(1): p. 46-55.

6. Scheller, H.V. and P. Ulvskov, Hemicelluloses. Plant Biology, 2010. 61(1): p. 263-289.

7. Cosgrove, D.J., Growth of the plant cell wall. Nature Reviews Molecular Cell Biology, 2005. 6(11): p. 850-861.

8. Höfte, H., A. Peaucelle and S. Braybrook, Cell wall mechanics and growth control in plants: the role of pectins revisited. Frontiers in Plant Science, 2012. 3(121): p. 1-6.

9. Cosgrove, D.J., Re-constructing our models of cellulose and primary cell wall assembly. Current Opinion in Plant Biology, 2014. 22: p. 122-131.

10. Tan, L., S. Eberhard, S. Pattathil, C. Warder, J. Glushka, C.H. Yuan, Z.Y. Hao, X. Zhu, U. Avci, J.S. Miller, D. Baldwin, C. Pham, R. Orlando, A. Darvill, M.G. Hahn, M.J. Kieliszewski, and D. Mohnen, An Arabidopsis cell wall proteoglycan consists of pectin and arabinoxylan covalently linked to an arabinogalactan protein. Plant Cell, 2013. 25(1): p. 270-287.

11. Ralet, M.-C., M.-J. Crépeau, J. Vigouroux, J. Tran, A. Berger, C. Sallé, F. Granier, L. Botran, and H.M. North, Xylans provide the structural driving force for mucilage adhesion to the Arabidopsis seed coat. Plant Physiology, 2016. 171(1): p. 165-178.

12. Popper, Z.A. and S.C. Fry, Widespread occurrence of a covalent linkage between xyloglucan and acidic polysaccharides in suspension-cultured angiosperm cells. Annals of Botany, 2005. 96(1): p. 91-99.

13. Mort, A.J., Interactions between pectins and other polymers, in Pectins and their manipulation, G.B. Seymour and J.P. Knox, Eds. 2002, Blackwell Publishing: Oxford, UK. p. 30-51.

14. Houben, K., R.P. Jolie, I. Fraeye, A.M. Van Loey and M.E. Hendrickx, Comparative study of the cell wall composition of broccoli, carrot, and tomato: Structural characterization of the extractable pectins and hemicelluloses. Carbohydrate Research, 2011. 346(9): p. 1105-1111.

15. Broxterman, S.E., P. Picouet and H.A. Schols, Acetylated pectins in raw and heat processed carrots. Carbohydrate Polymers, 2017. 177: p. 58-66.

16. DuBois, M., K.A. Gilles, J.K. Hamilton, P.A. Rebers and F. Smith, Colorimetric method for determination of sugars and related substances. Analytical Chemistry, 1956. 28(3): p. 350-356.

17. Blumenkrantz, N. and G. Asboe-hansen, New method for quantitative-determination of uronic acids. Analytical Biochemistry, 1973. 54(2): p. 484-489.

18. De Ruiter, G.A., H.A. Schols, A.G. Voragen and F.M. Rombouts, Carbohydrate analysis of watersoluble uronic acid-containing polysaccharides with high-performance anion-exchange chromatography using methanolysis combined with TFA hydrolysis is superior to four other methods. Analytical Biochemistry, 1992. 207(1): p. 176-185.

19. Klavons, J.A. and R.D. Bennett, Determination of methanol using alcohol oxidase and its application to methyl ester content of pectins. Journal of Agricultural and Food Chemistry, 1986. 34(4): p. 597-599. 
20. Voragen, A.G.J., H.A. Schols, J.A. De Vries and W. Pilnik, High-performance liquid chromatographic analysis of uronic acids and oligogalacturonic acids. Journal of Chromatography A, 1982. 244(2): p. 327-336.

21. Limberg, G., R. Körner, H.C. Buchholt, T.M.I.E. Christensen, P. Roepstorff, and J.D. Mikkelsen, Quantification of the amount of galacturonic acid residues in blocksequences in pectin homogalacturonan by enzymatic fingerprinting with exo- and endo-polygalacturonase II from Aspergillus niger. Carbohydrate Research, 2000. 327(3): p. 321-332.

22. Schols, H.A., M.A. Posthumus and A.G.J. Voragen, Structural features of hairy regions of pectins isolated from apple juice produced by the liquefaction process. Carbohydrate Research, 1990. 206(1): p. 117-129.

23. Kormelink, F.J.M., H. Gruppen, R.J. Viëtor and A.G.J. Voragen, Mode of action of the xylandegrading enzymes from Aspergillus awamori on alkali-extractable cereal arabinoxylans. Carbohydrate Research, 1993. 249(2): p. 355-367.

24. Broxterman, S.E. and H.A. Schols, Interactions between pectin and cellulose in primary plant cell walls. Carbohydrate Polymers, 2018. 192: p. 263-272.

25. Paes, S.S., S. Sun, W. MacNaughtan, R. Ibbett, J. Ganster, T.J. Foster, and J.R. Mitchell, The glass transition and crystallization of ball milled cellulose. Cellulose, 2010. 17(4): p. 693-709.

26. Puri, V.P., Effect of crystallinity and degree of polymerization of cellulose on enzymatic saccharification. Biotechnology and Bioengineering, 1984. 26(10): p. 1219-1222.

27. Deventer-Schriemer, W.H.v. and W. Pilnik, Studies on pectin degradation. Acta Alimentaria, 1987. 16: p. 143-153.

28. Ordaz-Ortiz, J.J., S.E. Marcus and P.J. Knox, Cell wall microstructure analysis implicates hemicellulose polysaccharides in cell adhesion in tomato fruit pericarp parenchyma. Molecular Plant, 2009. 2(5): p. 910-921.

29. Ito, S. and Y. Kato, A study of the structures of xyloglucans from the fruit cell walls of strawberry, persimmon, prune and banana. Journal of Applied Glycoscience, 2002. 49(4): p. 501-504.

30. Thompson, J.E. and S.C. Fry, Evidence for covalent linkage between xyloglucan and acidic pectins in suspension-cultured rose cells. Planta, 2000. 211(2): p. 275-286.

31. Cheng, L. and P.K. Kindel, Effect of cations on the elution of pectic polysaccharides from anionexchange resins. Analytical Biochemistry, 1995. 228(1): p. 109-114.

32. Guillotin, S.E., E.J. Bakx, P. Boulenguer, J. Mazoyer, H.A. Schols, and A.G.J. Voragen, Populations having different GalA blocks characteristics are present in commercial pectins which are chemically similar but have different functionalities. Carbohydrate Polymers, 2005. 60(3): p. 391398. 


\section{Supporting information}

Table S-4.1 Dry matter content of carrot, tomato and strawberry. Percentage of AIS isolated from fruit and vegetables are given on dry matter basis. Yield of WSS, ChSS and ChUS are expressed as percentage of AIS. Mean ( \pm absolute deviation), $n=2$ for extractions, $n=3$ for dry matter content.

\begin{tabular}{|l|c|c|c|c|c|}
\hline \multirow{2}{*}{} & \multirow{2}{*}{$\begin{array}{c}\text { Dry matter } \\
\text { content (\%) }\end{array}$} & \multirow{2}{*}{ \% AIS/Dry matter } & \multicolumn{3}{|c|}{ Percentage of AIS (\%) } \\
\cline { 4 - 6 } & & & WSS & ChSS & ChUS \\
\hline Carrot & $9.9(0.7)$ & $35(3.0)$ & $8(1.2)$ & $16(1.7)$ & $82(2.1)$ \\
\hline Tomato & $6.1(0.3)$ & $22(0.8)$ & $9(0.7)$ & $21(0.7)$ & $73(2.1)$ \\
\hline Strawberry* & $7.4(0.8)$ & 19 & 15 (n.d.) & 30 (n.d.) & 68 (n.d.) \\
\hline
\end{tabular}

*Isolation of strawberry AIS, WSS, ChSS and the residue ChUS was not performed in duplicate. 

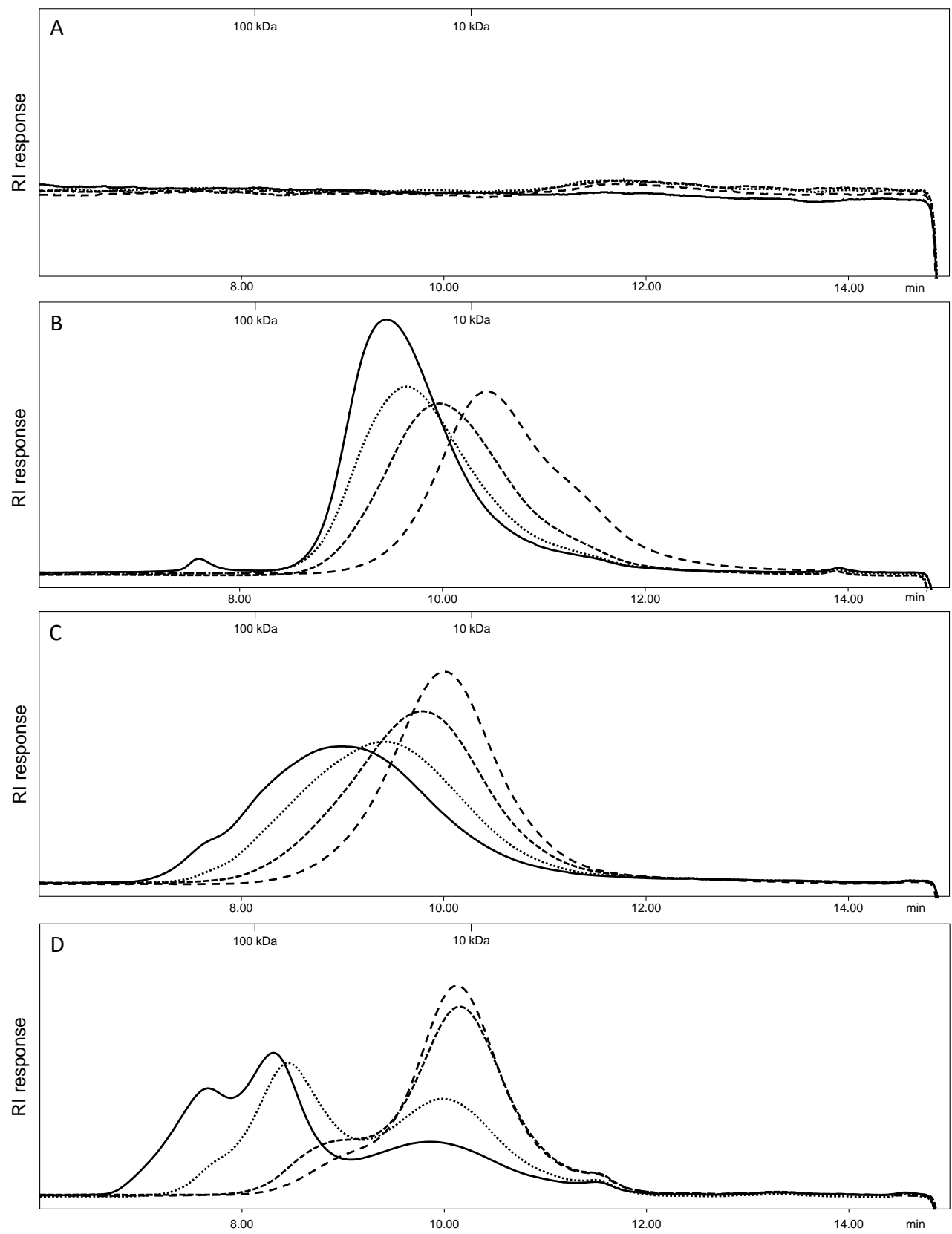

Figure S-4.1 HPSEC elution pattern of (A) Microcrystalline cellulose, (B) Arabinan, (C) Lemon pectin DM30 and (D) Rhamnogalacturonan-I. Not milled (-); 15 minutes milled ( $\cdots)$; 45 minutes milled (---); 90 minutes milled (-- -). All samples analysed at $5 \mathrm{mg} / \mathrm{ml}$. Pectin standards were used to estimate the molecular weight 




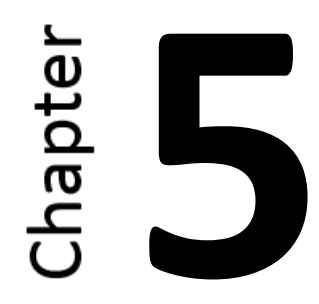

\section{The solubility of primary plant cell wall polysaccharides in LiCl-DMSO}

Accepted for publication in Carbohydrate Polymers as: S.E. Broxterman, G. van Erven, H.A. Schols, The solubility of primary plant cell wall polysaccharides in LiCl-DMSO. 


\begin{abstract}
In order to understand the architecture of the primary plant cell wall, knowledge on its polysaccharides and their interactions is of importance. In this study, further architectural insight was obtained by sequential LiCl-DMSO and buffer extractions after planetary ball milling. After milling, up to $50 \%$ of all polysaccharides in the Chelating agent Unextractable Solids (ChUS) from carrot, tomato and strawberry solubilised in LiCl-DMSO without loss of structural information. Approximately $30 \%$ of all pectin was LiCl-DMSO insoluble but solubilised in the subsequent buffer extraction, and these populations had higher HG:RG-I ratios than $\mathrm{LiCl}$-DMSO soluble populations. The degree of methyl-esterification (DM) of pure pectins highly determined its solubility in LiCl-DMSO. However, solubility of cell wall pectin was governed by more factors since both soluble and insoluble pectin were substantially methyl-esterified and acetylated. Digestion of LiCl-DMSO soluble and insoluble fractions by pectinases confirmed the presence of acetylated HG-regions for carrot and strawberry pectin.
\end{abstract}




\subsection{Introduction}

The primary plant cell wall of dicots is composed of the polysaccharides pectin, hemicellulose and cellulose. These polysaccharides are believed to be organised in the primary cell wall according to the tethered network model with xyloglucan-cellulose interactions [1], potentially with a more dominant role for pectin [2]. In addition to the structural details of the cross-linked polysaccharides, many questions remain on the nature of the interactions between cell wall polysaccharides. To overcome the insoluble nature of most cell wall polysaccharides, chemical, mechanical and/or enzymatic disruption of these interactions in the cell wall is essential.

Extraction with alkaline solvents is the most commonly used approach to solubilise part of the all pectin and hemicellulose. Whereas mild alkaline solvents solubilise pectin, strong alkaline solvents efficiently solubilise hemicellulose by disruption of the $\mathrm{H}$-bonds between hemicellulose and cellulose [3]. However, one of the major disadvantages is loss of structural information on alkali-labile substituents and cross-links. LiCl-DMSO has previously been presented as a promising alternative extractant for solubilising hemicellulose and cellulose. DMSO is known to swell cellulose microfibrils by disruption of inter- and intramolecular $\mathrm{H}$-bonds while the addition of $\mathrm{LiCl}$ prevents re-collapse of these microfibrils by forming $\mathrm{H}$-bonds with cellulose microfibrils [4]. The potential of characterising a large variety of acetylated xylan, xyloglucan and mannan from tomato and apple was shown previously using LiCl-DMSO extraction [5, 6]. However, the reported extraction yield were low ( $16 \%$ for tomato, $21 \%$ for apple), indicating the relevance of improving the extraction yield for a more representative characterisation. Pretreatment by ball milling was previously shown to be a suitable method to improve extractability of milled woods in LiCl-DMSO [7]. The improved extraction yields by ball milling were mainly explained by decreasing the crystallinity of cellulose and increasing the surface for the solvent [8]. Ball milling might thus improve the extraction of polysaccharides and allow more extended structural characterisation.

In the current study ball milling followed by sequential LiCl-DMSO and buffer extraction was used as a method to solubilise cell wall polysaccharides from carrot, tomato and strawberry. Furthermore the potential of extracting pectin and possible selectivity towards pectins structural characteristics was studied by structural characterisation of both soluble and insoluble polysaccharide fractions. 


\subsection{Materials and methods}

\subsubsection{Material}

Carrots (Daucus carota cv. Romance) and strawberries (Fragaria ananassa cv. Elsanta) were purchased from a local vegetable store. Tomatoes (Solanum lycopersicum cv. H2401) were kindly donated by Heinz (Heinz, Nijmegen, The Netherlands).

The lemon pectins DM30 and DM70 were obtained from CP Kelco (Lille Skensved, Denmark) and sugar beet pectin DM53, DA17 was obtained from Danisco (Brabrand, Denmark). Avicel was obtained from Sigma (St. Louis, USA), arabinan and RG-I from Megazyme (Wicklow, Ireland).

\subsubsection{Extraction of cell wall polysaccharides}

Cell wall polysaccharides were extracted using the procedure as described before $[9,10]$. In short, AIS was extracted by blending either carrots, tomatoes or strawberries in a 1:3 w/v ratio in $96 \%$ ethanol. Tomatoes and strawberries were both in their ripe stage. Prior to blending, only for peeled tomatoes, microwave pretreatment was performed to inactivate pectinases (10 $\mathrm{min}, 900 \mathrm{~W}$ ). The suspension was filtered and the residue was washed with $70 \%$ ethanol until the filtrate gave a negative reaction in the phenol-sulfuric acid test [11]. The water soluble solids (WSS) and chelating agent soluble solids (ChSS) were subsequently extracted from AIS according to the references mentioned above. The residue after WSS and ChSS extraction was extensively dialysed, first against potassium acetate, followed by distilled water. After freeze-drying the Chelating agent Unextractable Solids (ChUS) were obtained. This fraction was used to identify potential interactions between pectin, hemicellulose and cellulose. All fractions were milled for 30s in a Retsch Cryomill MM440 (Retsch $\mathrm{GmbH}$, Haan, Germany) at a frequency of $20 \mathrm{~Hz}$ to obtain homogeneous material. Extractions were carried out in duplicate.

\subsubsection{Planetary ball milling of ChUS}

ChUS was milled in a PM100 planetary ball mill (Retsch, Haan, Germany) using a $12 \mathrm{ml}$ stainless steel jar containing $40 \$ 5 \mathrm{~mm}$ stainless steel balls at a frequency of $600 \mathrm{rpm}$. After every $15 \mathrm{~min}$ of milling a pause of $10 \mathrm{~min}$ was set to prevent overheating. $500 \mathrm{mg}$ of ChUS was milled per batch with net milling times of 15 or $45 \mathrm{~min}$. Samples were coded according to substrate and milling time, e.g. C45 for carrot ChUS milled for $45 \mathrm{~min}$, T refers to tomato, and $\mathrm{S}$ refers to strawberry.

The lemon pectins DM30 and DM70 and sugar beet pectin DM53, DA17 were milled similarly. In the remainder of the manuscript, milling refers to planetary ball milling, and not to the short homogenisation milling step described in section 5.2.2. 


\subsubsection{Extraction of LiCl-DMSO soluble cell wall polysaccharides after ball milling}

$120 \mathrm{mg}$ non-milled or milled ChUS was suspended in $24 \mathrm{ml} 8.4 \%(\mathrm{w} / \mathrm{w}) \mathrm{LiCl}$ in DMSO and left for extraction for $48 \mathrm{~h}$ at $50^{\circ} \mathrm{C}$ in glass tubes with continuous head-over-tail rotation. Subsequently, samples were transferred to centrifuge tubes, centrifuged (15 min, 30.000xg, $20^{\circ} \mathrm{C}$ ) and separated in LiCl-DMSO soluble solids (Li/D-SS) and Residues. Prior to freeze-drying, LiCl-DMSO was removed from the supernatant by desalting over a 3kDa filter (Millipore centrifugal filter units, Merck, Billerica, Massachusetts, United States) after mixing LiCl-DMSO with Millipore water in a 1:7 ratio, to prevent dissolution of the filter. Not all polysaccharides remained in solution by addition of Millipore water.

The solubility of pure pectins in LiCl-DMSO was determined using the same conditions.

\section{Buffer extraction}

After removal of $\mathrm{LiCl}-\mathrm{DMSO}$ from the insoluble material through $3 \mathrm{kDa}$ filtration, the residue was extracted with $24 \mathrm{ml} 20 \mathrm{mM}$ Sodium Acetate buffer $\mathrm{pH} 5$ for $24 \mathrm{~h}$ at $40^{\circ} \mathrm{C}$ in centrifuge tubes with continuous head-over-tail rotation. Subsequently, the supernatant and final residue were separated by centrifugation $\left(15 \mathrm{~min}, 30.000 \mathrm{xg}, 20^{\circ} \mathrm{C}\right)$. Similarly, the buffer supernatant (B-SS) and the final residue were desalted by using $3 \mathrm{kDa}$ filters prior to freeze-drying. Extractions were performed in duplicate. The extraction diagram is shown in Figure 5.1.

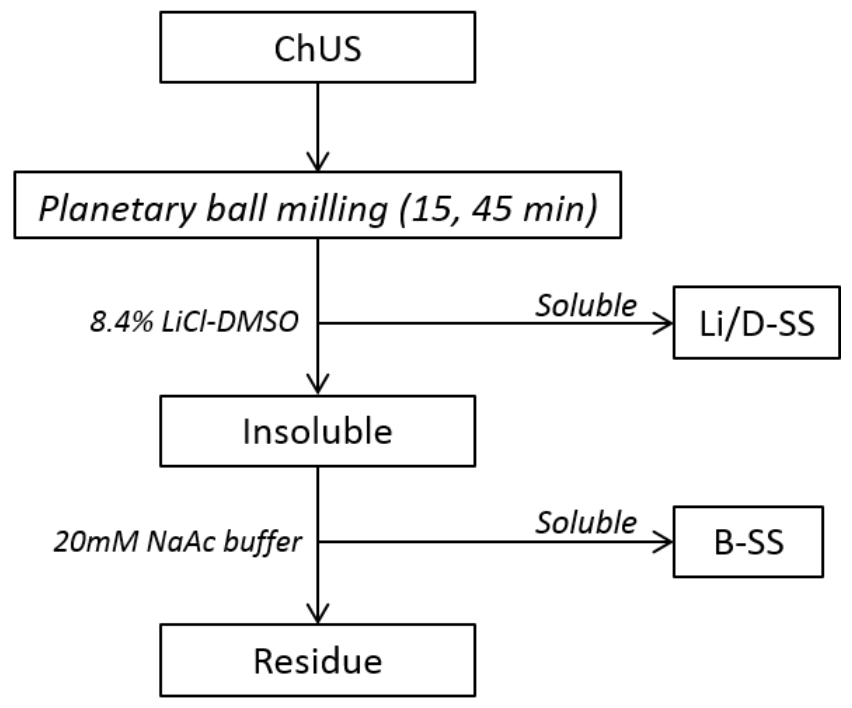

Figure 5.1 Extraction diagram of sequential LiCl-DMSO and buffer extractions on milled and non-milled ChUS. Li/D: LiCl-DMSO; B: buffer; SS: soluble solids.

\subsubsection{Sugar composition of the extracted fractions}

To determine the uronic acid content of the extracted fractions, the uronic acid content was determined by the automated colorimetric m-hydroxydiphenyl method [12]. The neutral 
carbohydrate composition was analysed after pretreatment with $72 \%$ (w/w) $\mathrm{H}_{2} \mathrm{SO}_{4}(1 \mathrm{~h}, 30$ ${ }^{\circ} \mathrm{C}$ ) followed by hydrolysis with $1 \mathrm{M} \mathrm{H}_{2} \mathrm{SO}_{4}\left(3 \mathrm{~h}, 100{ }^{\circ} \mathrm{C}\right)$. Neutral monosaccharides were analysed using an ICS5000 High Performance Anion Exchange Chromatography system with Pulsed Amperometric detection (ICS5000 ED) (Dionex Corporation, Sunnyvale, CA, USA), equipped with a CarboPac PA-1 column ( $250 \mathrm{~mm} \times 2 \mathrm{~mm}$ i.d.) and a CarboPac PA guard column ( $25 \mathrm{~mm} \times 2 \mathrm{~mm}$ i.d.).

$10 \mu \mathrm{l}$ of sample was injected and eluted at a flow rate of $0.4 \mathrm{ml} / \mathrm{min}$ using a combination of three mobile phases: A) 0.1 M NaOH, B) $1 \mathrm{M} \mathrm{NaOAc}$ in $0.1 \mathrm{M} \mathrm{NaOH}$ and C) H2O. The gradient used was: 0-35 min isocratic $100 \%$ C; $35.1-50$ min linearly from $100 \% A$ to $40 \%$ B; $50.1-55$ min isocratic $100 \% \mathrm{~B}$; $55.1-63 \mathrm{~min}$ isocratic $100 \% \mathrm{~A}$; $63.1-78 \mathrm{~min}$ isocratic $100 \% \mathrm{C}$. Post column addition of $0.5 \mathrm{M} \mathrm{NaOH}$ at $0.1 \mathrm{ml} / \mathrm{min}$ was performed between 0-35 min and 63-78 min. Analysis of the monosaccharide composition was performed in duplicate. Although it is recognised that UA:Rha is the most common ratio for determination of HG:RG-I backbone ratios, rhamnose levels are often low and lead to less accurate HG:RG-I ratios. The HG to RG-I ratio in the extracts was therefore calculated by $\frac{U A}{A r a+G a l}$ in mol\%, expressing the ratio HG: RG-I including RG-I side chains and assuming that Ara and Gal originated from RG-I.

\subsubsection{Starch digestion}

The presence of starch in ChUS and the fractions solubilised by LiCl-DMSO was analysed in duplicate by using the Megazyme total starch assay procedure for resistant starch (Megazyme, Wicklow, Ireland) using amylase and amyloglucosidase, as described previously [13].

\subsubsection{Determination of methyl-esterification and acetylation}

Samples were saponified at $\approx 5 \mathrm{mg} / \mathrm{ml}$ in $0.1 \mathrm{M} \mathrm{NaOH}$ for $24 \mathrm{~h}$ in head-space vials $(1 \mathrm{~h}$ at 4 ${ }^{\circ} \mathrm{C}$, followed by $23 \mathrm{~h}$ at $20{ }^{\circ} \mathrm{C}$ ) to determine the degree of methyl-esterification (DM) in duplicate using a GC method as previously described [14].

Gas chromatography was run on a HS-GC equipped with a flame ionisation detector and an automatic injection system. For GC, a Trace GC system (Thermo Scientific, Waltham, MA, USA) equipped with a DB-WAX $30 \mathrm{~m} \times 0.25 \mathrm{~mm} \times 0.25 \mu \mathrm{m}$ was used. The following conditions were used: helium as carrier gas with a flow rate of $20 \mathrm{ml} / \mathrm{min}$. Column temperature was set at $40{ }^{\circ} \mathrm{C}$ for $1,25 \mathrm{~min}$ and then programmed to $160^{\circ} \mathrm{C}$ at a rate of $20^{\circ} \mathrm{C} / \mathrm{min}$. The injector was set at $200^{\circ} \mathrm{C}$ and the detector performed at $225^{\circ} \mathrm{C}$. Samples were heated at $50{ }^{\circ} \mathrm{C}$ for $10 \mathrm{~min}$ in the head-space sampler prior to splitless injection. Two $\mathrm{ml}$ of the head-space volatiles was automatically injected in $10 \mathrm{~s}$ on the column. In order to determine the degree of acetylation (DA), samples were saponified as described for DM, and subsequently analysed for the degree of acetylation (DA) by HPLC [15]. An Ultimate 3000 system (Dionex, 
Sunnyvale, CA, USA) coupled to a Shodex RI-101 detector (Showa Denko K.K., Tokyo, Japan) was used, equipped with an Aminex HPX-87H ion exclusion column of $300 \mathrm{~mm} \times 7.8 \mathrm{~mm}$ preceded by a guard column (125-0131) (Bio-Rad Laboratories, Hercules, CA, USA). Column temperature was set at $40{ }^{\circ} \mathrm{C}$, samples were injected $(20 \mu \mathrm{l})$ and eluted with $0.05 \mathrm{M} \mathrm{H}_{2} \mathrm{SO}_{4}$ at $0.6 \mathrm{ml} / \mathrm{min}$. The DM and DA were calculated as moles of methyl esters and acetyl groups per 100 moles of UA, using methanol and acetic acid as standards.

\subsubsection{Enzymatic digestion of pectin populations in the Li/D-SS and Residues}

In order to characterise the pectin populations in the Li/D-SS and Residues, incubations with pectinases were performed. Enzymatic digestions were not performed on the buffersoluble fractions since even though fractions were high in pectin, yields of the buffer fractions were insufficient to allow further characterisation. To enhance the enzymatic accessibility of the HG region, RG-I side chains were first degraded with endo- $\beta$-( $1 \rightarrow 4)$-galactanase from Aspergillus niger [16], $\beta$-(1 $\rightarrow 4)$-galactosidase from Aspergillus niger, endo-arabinanase from Aspergillus aculeatus and exo-arabinanase from Chrysosporium lucknowense [17]. Both Li/D-SS and Residues were subsequently digested with endo-polygalacturonase (PG) from Aspergillus aculeatus and pectin lyase (PL) from Aspergillus niger [18]. Digestion was done at $5 \mathrm{mg} / \mathrm{ml}$ in $50 \mathrm{mM}$ sodium acetate buffer $\mathrm{pH} 5$ at $40^{\circ} \mathrm{C}$ by head-over-tail rotation for $24 \mathrm{~h}$. Enzymes were dosed to fully degrade the specific substrate in $6 \mathrm{~h}$.

\subsubsection{High Performance Size Exclusion Chromatography (HPSEC)}

Ball milled polysaccharides were analysed for their molecular weight distribution using an Ultimate 3000 system (Dionex, Sunnyvale, CA, USA) coupled to a Shodex RI-101 detector (Showa Denko K.K., Tokyo, Japan) as described previously, using pectin standards from 10-100 kDa to estimate the molecular weight distribution [13].

\subsubsection{Characterisation of oligosaccharides by High Performance Anion Exchange Chromatography (HPAEC)}

Oligosaccharides formed by digestion with PG, PL, arabinanases and galactanases were analysed using High Performance Anion Exchange Chromatography as described previously [13]. Galacturonic acid oligomers DP 1-3, galactose and arabinose (Sigma-Aldrich, Steinheim, Germany), galactobiose and arabinose oligomers DP 2-7 (Megazyme, Wicklow, Ireland) and previously purified unsaturated galacturonic acid DP 2-4 [19] were used as standards for annotation of pectin oligosaccharides in the enzyme digests. 
5.2.11 Characterisation of oligosaccharide structures by Matrix-Assisted Laser Desorption/Ionization Time-Of-Flight Mass Spectrometry (MALDI-TOF MS)

The oligosaccharides in the pectinase digests of the Li/D-SS and Residues were characterised by MALDI-TOF MS as described previously [10], using $25 \mathrm{mg} / \mathrm{mL}$ dihydroxybenzoic acid in $50 \%(\mathrm{v} / \mathrm{v})$ acetonitrile as a matrix.

\subsection{Results and discussion}

\subsubsection{Yield and composition of different cell wall polysaccharides}

Extraction of pectin by water and EDTA from the Alcohol Insoluble Solids (AIS) yielded the Water Soluble Solids (WSS) and Chelating agent Soluble Solids (ChSS). Both fractions were predominantly composed of pectin, and it was hypothesized that these pectin populations were easily extractable due to the absence of interactions with the hemicellulose-cellulose network. The exact yield and composition has been discussed elsewhere [13]. The characteristics of insoluble pectin, hemicellulose and cellulose were studied in the Chelating agent Unextractable Solids (ChUS), the residue after isolation of WSS and ChSS. It was assumed that pectin in ChUS was insoluble due to its interaction with the hemicellulosecellulose network. The composition of ChUS, yield of ChUS (based on AIS) and percentage of uronic acid (UA) in ChUS (based on AIS) is shown in Table 5.1.

Table 5.1 Monosaccharide composition (mol\%) of the Chelating agent Unextractable Solids (ChUS). Total yield and uronic acid (UA) solubilised in ChUS as percentage of AIS (\%w/w). Mean ( \pm absolute deviation), $n=2$.

\begin{tabular}{|c|c|c|c|c|c|c|c|c|c|}
\hline & \multicolumn{7}{|c|}{ Mol \% } & \multirow{2}{*}{$\begin{array}{c}\% \text { Yield } \\
\text { of AIS }\end{array}$} & \multirow{2}{*}{$\begin{array}{l}\% \text { UA } \\
\text { of AIS }\end{array}$} \\
\hline & Ara & Rha & Gal & Glc & Xyl & Man & UA & & \\
\hline Carrot & $\begin{array}{c}8 \\
(0.0)\end{array}$ & $\begin{array}{c}1 \\
(0.1)\end{array}$ & $\begin{array}{c}21 \\
(0.2)\end{array}$ & $\begin{array}{c}36 \\
(0.1)\end{array}$ & $\begin{array}{c}2 \\
(0.0)\end{array}$ & $\begin{array}{c}5 \\
(0.0)\end{array}$ & $\begin{array}{c}27 \\
(0.1)\end{array}$ & $\begin{array}{c}82 \\
(2.1)\end{array}$ & $\begin{array}{c}69 \\
(3.5)\end{array}$ \\
\hline Tomato & $\begin{array}{c}5 \\
(0.1)\end{array}$ & $\begin{array}{c}1 \\
(0.1)\end{array}$ & $\begin{array}{c}6 \\
(0.0)\end{array}$ & $\begin{array}{c}55 \\
(0.8)\end{array}$ & $\begin{array}{c}8 \\
(0.1)\end{array}$ & $\begin{array}{c}6 \\
(0.1)\end{array}$ & $\begin{array}{c}19 \\
(0.5)\end{array}$ & $\begin{array}{c}73 \\
(2.1)\end{array}$ & $\begin{array}{c}50 \\
(2.3)\end{array}$ \\
\hline Strawberry & $\begin{array}{c}8 \\
(0.3)\end{array}$ & $\begin{array}{c}1 \\
(0.2)\end{array}$ & $\begin{array}{c}9 \\
(0.3)\end{array}$ & $\begin{array}{c}39 \\
(2.2)\end{array}$ & $\begin{array}{c}9 \\
(0.2)\end{array}$ & $\begin{array}{c}3 \\
(0.1)\end{array}$ & $\begin{array}{c}30 \\
(2.1)\end{array}$ & 68 (n.d.)* & 37 (n.d.)* \\
\hline
\end{tabular}

*Isolation of strawberry AIS, WSS, ChSS and the residue ChUS was not performed in duplicate.

\subsubsection{Yield and composition of LiCl-DMSO soluble populations}

As can be seen from Table 5.1, the majority of the cell wall polysaccharides was insoluble in water and EDTA, and was recovered in ChUS. As can be observed, $69 \%, 50 \%$ and $37 \%$ of all uronic acid in AIS was recovered in ChUS for carrot, tomato and strawberry respectively. Prior to LiCl-DMSO extraction, ChUS was milled to particle sizes of 30-60 $\mu \mathrm{m}$. A previous study showed that 45 min milling was considered as an optimal balance between 
solubilising a substantial amount of cell wall polysaccharides and minimising possible chain cleavage [20].

The residue of LiCl-DMSO extractions was subjected to buffer extraction, as shown in the extraction diagram (Figure 5.1). The yield and monosaccharide composition of LiCl-DMSO (Li/D-SS) and buffer soluble (B-SS) populations, and of the Residue are shown in Table 5.2. Yields were $7 \%, 17 \%$ and $11 \%$ for the carrot, tomato and strawberry Li/D-SS respectively, for non-milled ChUS.

The yield for Li/D-SS TO shown in Table 5.2 (17\%) was rather similar to the yield reported by previously for tomato (16\%) [5]. The increased yields reported in Table 5.2, 40-50\% of all cell wall polysaccharides for 45 minutes milling, showed the potential of milling as an additional treatment to solubilise a substantially higher amount of cell wall polysaccharides in LiCl-DMSO. 
Table 5.2 Monosaccharide composition (mol\%) of LiCl-DMSO soluble solids (Li/D-SS), subsequent buffer soluble solids (B-SS) and Residues after LiCl-DMSO and buffer extraction. Yield was for each fraction expressed as a percentage of ChUS, and UA as a percentage of all UA in ChUS. Ratio HG:RG-I, expressed by UA/Ara+Gal. Values represent means of two analytical replicates, deviations $<5 \%$.

\begin{tabular}{|c|c|c|c|c|c|c|c|c|c|c|}
\hline & \multicolumn{7}{|c|}{ Mol \% } & \multirow{2}{*}{$\begin{array}{l}\text { Yield (\% } \\
\text { of ChUS) }\end{array}$} & \multirow{2}{*}{$\begin{array}{c}\text { UA (\% of } \\
\text { ChUS) }\end{array}$} & \multirow{2}{*}{$\begin{array}{c}\text { UA/(Ara + } \\
\text { Gal) }\end{array}$} \\
\hline & Ara & Rha & Gal & Glc & xyl & Man & UA & & & \\
\hline Li/D-SS CO* & 18 & 2 & 20 & 19 & 2 & 3 & 36 & 7 & 1 & 0.8 \\
\hline Li/D-SS C15* & 17 & 2 & 30 & 16 & 3 & 5 & 27 & 25 & 42 & 0.7 \\
\hline Li/D-SS C45* & 16 & 2 & 27 & 22 & 2 & 6 & 25 & 50 & 39 & 0.7 \\
\hline Li/D-SS TO & 5 & 0 & 8 & 36 & 24 & 17 & 10 & 17 & 12 & 0.7 \\
\hline Li/D-SS T15 & 6 & 1 & 9 & 39 & 20 & 14 & 11 & 32 & 23 & 0.7 \\
\hline Li/D-SS T45 & 6 & 1 & 9 & 47 & 15 & 9 & 13 & 49 & 38 & 0.9 \\
\hline Li/D-SS SO & 7 & 1 & 11 & 31 & 19 & 9 & 22 & 11 & 6 & 1.2 \\
\hline Li/D-SS S15 & 8 & 1 & 10 & 39 & 13 & 6 & 23 & 49 & 49 & 1.3 \\
\hline Li/D-SS S45 & 6 & 1 & 7 & 30 & 7 & 3 & 46 & 40 & 43 & 3.6 \\
\hline B-SS CO** & 6 & 1 & 6 & 30 & 0 & 0 & 57 & 4 & 9 & 4.4 \\
\hline B-SS C15** & 12 & 2 & 18 & 11 & 0 & 0 & 57 & 5 & 15 & 1.8 \\
\hline B-SS C45** & 12 & 2 & 18 & 8 & 0 & 0 & 60 & 6 & 19 & 1.9 \\
\hline B-SS TO** & 7 & 2 & 8 & 7 & 2 & 1 & 73 & 5 & 33 & 4.8 \\
\hline B-SS T15** & 7 & 2 & 9 & 1 & 1 & 0 & 80 & 5 & 33 & 5.1 \\
\hline B-SS T45** & 6 & 2 & 8 & 1 & 1 & 0 & 82 & 6 & 42 & 5.6 \\
\hline B-SS SO** & 7 & 1 & 8 & 16 & 6 & 1 & 61 & 5 & 12 & 4 \\
\hline B-SS S15** & 14 & 3 & 11 & 2 & 1 & 0 & 69 & 2 & 8 & 2.8 \\
\hline B-SS S45** & 15 & 3 & 13 & 2 & 1 & 0 & 66 & 3 & 9 & 2.4 \\
\hline Residue CO & 13 & 2 & 23 & 36 & 2 & 3 & 21 & 75 & 88 & 0.7 \\
\hline \begin{tabular}{|l} 
Residue C15 \\
\end{tabular} & 11 & 1 & 19 & 46 & 2 & 2 & 19 & 42 & 47 & 0.7 \\
\hline Residue C45 & 9 & 1 & 16 & 48 & 2 & 4 & 20 & 30 & 27 & 0.7 \\
\hline \begin{tabular}{|l|} 
Residue T0 \\
\end{tabular} & 5 & 1 & 6 & 65 & 6 & 4 & 13 & 66 & 77 & 1.2 \\
\hline Residue T15 & 4 & 1 & 5 & 71 & 4 & 2 & 13 & 57 & 64 & 1.5 \\
\hline Residue T45 & 3 & 1 & 3 & 75 & 3 & 3 & 12 & 42 & 37 & 2.1 \\
\hline Residue SO & 10 & 1 & 11 & 46 & 6 & 2 & 24 & 69 & 82 & 1.1 \\
\hline Residue S15 & 8 & 1 & 8 & 52 & 9 & 1 & 21 & 51 & 48 & 1.2 \\
\hline Residue S45 & 7 & 1 & 7 & 54 & 11 & 1 & 19 & 36 & 26 & 1.4 \\
\hline
\end{tabular}

*Starch contents have been measured separately and glc levels represent non-starch glucans.

**Not analysed in duplicate due to insufficient sample quantities.

It can be observed from the monosaccharide composition in Table 5.2 that for all sources and all milling intervals LiCl-DMSO solubilised a mixture of pectin, hemicellulose and cellulose, and extraction yields increased with milling time. For carrot, all Li/D-SS samples were dominated by Ara, Gal, Glc and UA, indicating the presence of both pectin and cellulose. Although relative uronic acid levels (mol\%) were slightly decreased upon milling time, and galactose levels (mol\%) slightly increased, the HG:RG-I ratios remained rather similar at $0.7-0.8$. Increasing glucose levels with increasing milling times suggested gradual 
solubilisation of cellulose. For tomato, levels of Xyl and Man were higher than for carrot, indicating the presence of mannans, and potentially both xylans and/or xyloglucans. Upon increasing milling time, the relative ratio of glucose to xylose and mannose increased, suggesting that whereas hemicellulose solubilised more easily than cellulose, both hemicellulose and cellulose solubilisation increased upon increased milling time. Similar to carrot pectin, also for tomato pectin the HG:RG-I ratios for the different Li/D-SS fractions remained rather similar at 0.7-0.9. For strawberry, Li/D-SS SO and Li/D-SS S15 followed similar trends as described for tomato. However, Li/D-SS S45 showed different values with a highly increased HG:RG-I value.

\subsubsection{Effect of milling time on Mw distribution for pure polysaccharides}

The effect of milling on the molecular weight ( $\mathrm{Mw}$ ) distribution of pure polysaccharides was not known and therefore several polysaccharides were milled for 15 or 45 min. Both milling for short time intervals and DMSO were hypothesized to disrupt primarily $\mathrm{H}$-bonds between the insoluble cell wall polysaccharides in ChUS. The effect of milling time on the $\mathrm{Mw}$ distribution of several pure polysaccharides is presented in Figure 5.2 and showed that for arabinan and lemon pectin only limited depolymerisation occurred by the relatively short milling intervals reported here and no material < $10 \mathrm{kDa}$ was formed. Analysis by HPAEC and MALDI-TOF MS showed the absence of soluble oligosaccharides, indicating that the limited depolymerisation observed in Figure 5.2 did not lead to the formation of oligosaccharides. The limited depolymerisation reported for pure polysaccharides showed that ball milling might be a suitable technique to improve the solubility and further characterisation of plant cell wall polysaccharides. 

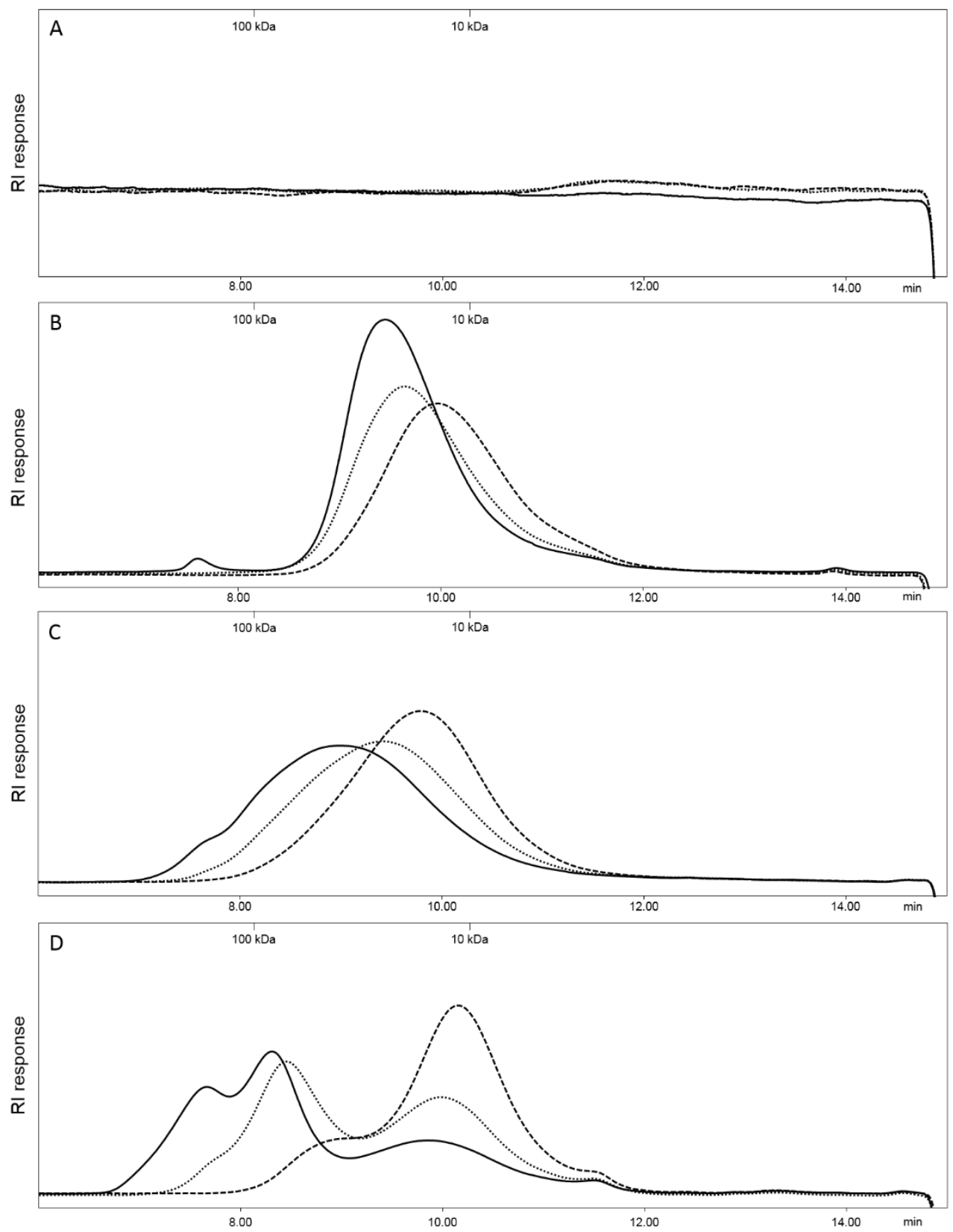

Figure 5.2 HPSEC elution patterns of (A) Microcrystalline cellulose, (B) Arabinan, (C) Lemon pectin DM30 and (D) Rhamnogalacturonan-I. Not milled (-); 15 minutes milled ( $\cdots)$; 45 minutes milled (---). All samples analysed at $5 \mathrm{mg} / \mathrm{ml}$, dissolved/suspended in Millipore $\mathrm{H}_{2} \mathrm{O}$. Pectin standards were used to estimate the molecular weight. 


\subsubsection{Extractability of pectin by LiCl-DMSO}

Whereas LiCl-DMSO is known as a suitable solvent for (hemi)cellulose, less is known about pectin extractability and solubility in this solvent. Pectin could be extracted due to three reasons. First, $\mathrm{H}$-bonds leading to pectins insolubility in ChUS were disrupted by LiCl-DMSO, leading to solubilisation of pectin populations independent from hemicellulose and cellulose. The potential of adsorption of pectin to (hemi)cellulose was shown in vitro, indicating the relevance of this mechanism [21]. Second, through ball milling the crystallinity of cellulose microfibrils is greatly reduced, leading to amorphous cellulose and hence cellulose is better accessible to the solvent [22]. Similarly, by disruption of the crystalline parts regions of cellulose, pectin populations that were entrapped but not covalently linked in these regions might be released and solubilised. Third, pectin populations that were solubilised by LiCl-DMSO extraction might have co-solubilised in complexes with hemicellulose and cellulose, with pectin only being soluble due to (hemi)cellulose solubility in LiCl-DMSO. Most likely polysaccharides in these complexes would be covalently linked.

Solubilisation and subsequent structural characterisation of a part of the hemicellulose and cellulose from tomato by LiCl-DMSO extraction was shown previously. Although a part of the pectin was shown to solubilise, structural characteristics of solubilised pectin populations were not studied [5].

Comparison of a previous study on milling followed by water extraction with the results presented above for LiCl-DMSO showed that water and LiCl-DMSO solubilised different cell wall polysaccharides [20]. Water extraction solubilised predominantly pectin, whereas LiClDMSO solubilised hemicellulose and cellulose as well. In general, yields of solubilised polysaccharides were higher for LiCl-DMSO than for water, probably due to the potential of LiCl-DMSO to solubilise cellulose.

\subsubsection{Yield and composition of buffer soluble populations}

As can be seen from the buffer soluble populations reported in Table 5.2, an additional 8$42 \%$ of all uronic acid was solubilised in the buffer extraction following LiCl-DMSO extraction. Although yields were not very high, most buffer fractions contained rather pure pectins with high HG:RG-I ratios. For all sources and milling intervals except Li/D-SS S45, the B-SS soluble pectins had 2-7x higher HG:RG-I ratios than Li/D-SS pectin populations. This indicates that either $\mathrm{LiCl}-\mathrm{DMSO}$ soluble pectin populations co-solubilised by their interaction with hemicellulose and cellulose, or that properties of LiCl-DMSO soluble pectin differed from buffer soluble pectin. The latter might indicate that entrapped pectin populations were released by disruption of the (hemi)cellulose network, but not LiCl-DMSO soluble. Comparison of buffer soluble populations with the water soluble populations discussed before in Table 4.3 showed that B-SS were relatively much higher in HG. These 
differences indicate that the composition of B-SS was affected by the preceding LiCl-DMSO extraction.

Finally, not all cell wall polysaccharides were LiCl-DMSO or buffer soluble, and although the yield of the residue decreased as milling time increased, still $30-42 \%$ of all ChUS remained insoluble. Since LiCl-DMSO is not commonly used for pectin extraction, it is of importance to further understand the solubility of pure pectin in LiCl-DMSO.

\subsubsection{Solubility of pure, HG-rich pectins in LiCl-DMSO}

Several parameters might influence pectin solubility in LiCl-DMSO. First of all, the HG:RG-I ratio might be of importance. LiCl-DMSO soluble pectin populations were relatively enriched in RG-I compared to buffer soluble populations (Table 5.2), indicating HG had a limited solubility in LiCl-DMSO. Therefore the absence of RG-I might limit the solubility of HG-rich pectins.

The functional properties of pectin are highly affected by the DM of the HG region [23]. To study the effect of the DM on pectin solubility in LiCl-DMSO, the solubility of several differently methyl-esterified pectins in LiCl-DMSO was determined. Whereas pectin with DM 30 did not solubilise in LiCl-DMSO at all, solubility increased for DM 53, while DM 70 had the highest solubility (Supporting information Table S-5.1), showing that high methyl-esterified pectins were more soluble than low methyl-esterified pectins in $\mathrm{LiCl}$ DMSO. For all pectins, solubility increased with milling time, potentially due to the reduced particle size leading to a higher solvent accessibility.

5.3.7 DM and DA of LiCl-DMSO soluble populations, buffer soluble populations and residues Since solubility of pectin seemed related to DM for pure pectins, the DM of the Li/D-SS, B-SS and Residues was determined (Table 5.3). The DM and DA were not affected by the milling intervals used in this study (data not shown). 
Table 5.3 DM and DA of LiCl-DMSO soluble fractions (Li/D-SS), buffer fractions (B-SS) and final Residues. Values represent means of two analytical replicates ( \pm absolute deviation).

\begin{tabular}{|l|c|c|c|c|c|c|}
\hline \multirow{2}{*}{} & \multicolumn{3}{|c|}{ DM } & \multicolumn{3}{|c|}{ DA } \\
\cline { 2 - 7 } & Li/D-SS & B-SS* & Residue & Li/D-SS & B-SS * & Residue** $^{*}$ \\
\hline C0 & n.d. & 37 & $40(0.7)$ & n.d. & 14 & $36(7.2)$ \\
\hline C15 & $41(4.2)$ & 42 & $38(0.8)$ & $49(3.4)$ & 19 & $41(0.7)$ \\
\hline C45 & $57(13.4)$ & 35 & $44(7.0)$ & $56(8.3)$ & 18 & $50(5.2)$ \\
\hline T0 & $22(2.9)$ & 19 & $30(0.3)$ & $122(15.1)$ & 7 & $34(9.9)$ \\
\hline T15 & $31(4.0)$ & 19 & $27(2.0)$ & $103(12.5)$ & 6 & $28(6.7)$ \\
\hline T45 & $38(5.8)$ & 16 & $28(0.4)$ & $79(3.4)$ & 6 & $34(13.1)$ \\
\hline S0 & $87(2.5)$ & 45 & $59(5.3)$ & $70(4.3)$ & 24 & $39(3.6)$ \\
\hline S15 & $48(0.5)$ & n.d. & $45(7.5)$ & $30(3.6)$ & n.d. & $45(3.4)$ \\
\hline S45 & $53(5.7)$ & n.d. & $40(0.9)$ & $34(3.1)$ & n.d. & $47(6.4)$ \\
\hline
\end{tabular}

GlcA:GalA ratio was not determined, all UA was assumed to be GalA.

*Not analysed in duplicate or not determined reliably (n.d.) due to insufficient sample quantities.

** Means of triplicates ( \pm absolute deviation).

Whereas the majority of studies on cell wall polysaccharides involves an alkaline extraction step, the method presented here allows characterisation of the DM and DA of both soluble and insoluble populations.

For tomato, pectin populations with a rather low DM were still LiCl-DMSO soluble. However, tomato Li/D-SS contained substantial levels of xylose and glucuronic acid (GlcA) and substitution of LiCl-DMSO soluble tomato xylan was shown previously [5]. Furthermore it was previously determined that $12 \%$ of all UA in the water soluble fractions after milling tomato ChUS was GIcA rather than GalA [20]. As can be seen from Table 5.2, xylose levels were highest for tomato Li/D-SS, compared to carrot and strawberry Li/D-SS, suggesting that the highest xylan levels might be found in tomato. Therefore it was assumed for all fractions that $\leq 12 \%$ of all UA might be GlcA originating from glucuronoxylan, and that the DM reported for tomato and strawberry might be higher. Although for several fractions the DM was $\geq 10 \%$ higher for the Li/D-SS compared to B-SS and Residues (C45, T45, S0 and S45), this trend was not consistently observed for all fractions, showing that the solubility of pectin populations cannot fully be explained by differences in DM.

Next to the DM, the degree of acetylation (DA) is of importance for pectin properties as acetylation will increase the hydrophobicity of pectin [24]. Since hydrophobicity might affect solubility, the degree of acetylation (DA) was also determined for all fractions (Table 5.3). Both Li/D-SS and Residues showed highly acetylated populations. It has to be taken into account that acetylation can be found in several different cell wall polysaccharides, including pectins HG and RG-I regions, xylan, mannan and xyloglucan [25, 26], indicating that the reported DA might be an overestimation. However, even if all hemicelluloses 
present in the Li/D-SS and Residues were highly acetylated, it can be deduced from the hemicellulose to pectin ratios that pectin was substantially acetylated as well.

With the exception of $6 \% \mathrm{Xyl}$ in B-SS SO, all B-SS fractions were nearly devoid of xylose and mannose, pointing to hemicellulose, and the DA was therefore solely attributed to pectin. Especially carrot and strawberry B-SS showed a relatively high DA (14-24\%), and based on the low Rha content also HG regions were substantially acetylated. Acetylation of the HG region was previously reported for water soluble carrot pectin [10]. Acetylation of tomato and strawberry HG regions was not reported before, but based on the UA:Rha ratio (Table 5.2 ) it could be deduced that especially the strawberry HG region is substantially acetylated. Although the high degrees of acetylation might affect solubility of pectin in LiCl-DMSO, the differences between Li/D-SS, B-SS and the Residues do not allow unambiguous conclusions about the effect of acetylation on solubility of pectin in LiCl-DMSO. Besides methylesterification and acetylation, other structural features of the polysaccharides are thus impacting their solubilisation behaviour.

\subsubsection{Digestibility of pectin in Li/D-SS and Residues by pectinases}

In order to characterise the structural properties of soluble and insoluble pectin populations in more detail, both the LiCl-DMSO soluble fractions and residues were digested with pectinases. A combination of polygalacturonase (PG) and pectin lyase (PL) was used. Furthermore endo- and exoarabinanase, and endo- and exogalactanase were used to digest the RG-I side chains and to enhance enzymatic accessibility of the HG region. In order to understand which pectin regions were degraded, oligosaccharide profiles were analysed by MALDI TOF MS (Figure 5.3). 

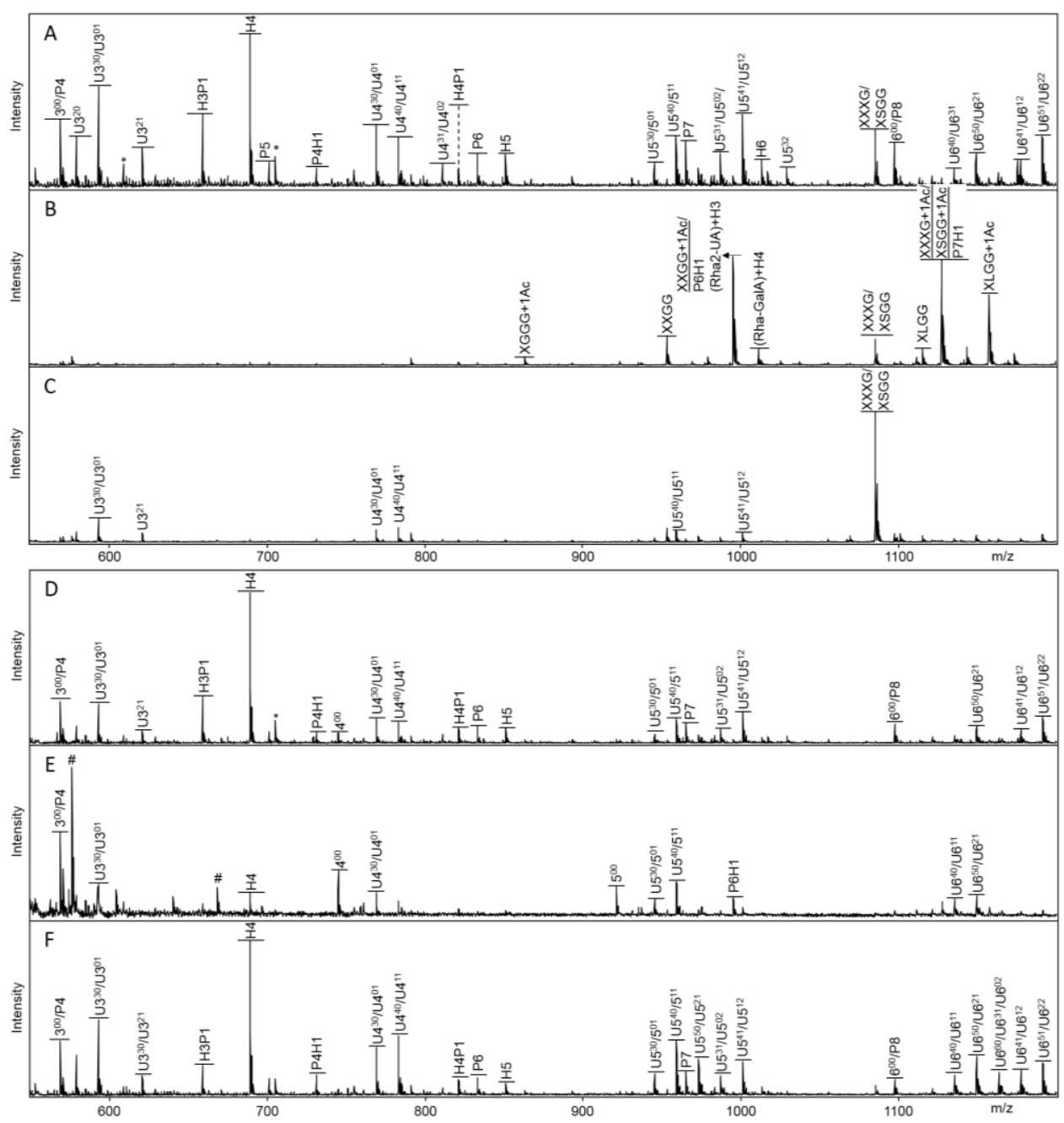

Figure 5.3 MALDI TOF mass spectra of LiCl-DMSO soluble solids (Li/D-SS) and Residues digested with PG + PL (A) Li/D-SS C15, (B) Li/D-SS T15, (C) Li/D-SS S15, (D) Residue C15, (E) Residue T15, (F) Residue S15. Peak annotation: U $4^{20}$, unsaturated GalA DP 4, 2 methyl-esters, 0 acetyl groups; P, pentose; $H$, hexose. Nomenclature for xyloglucan: G, glucose; X, glucose - xylose; S, glucose - xylose - arabinose; L, glucose - xylose - galactose; F, glucose - xylose - galactose - fucose. $\left({ }^{*}\right) \mathrm{K}+$-adduct; (\#) unidentified $\mathrm{m} / \mathrm{z}$ value.

\section{Pectin oligosaccharides}

Mass spectrometry analysis of the oligosaccharides showed differences between the oligosaccharides formed in the Li/D-SS and the Residues. As can be seen in Figure 5.3A and 5.3D for carrot, mass spectra for both Li/D-SS and Residues were dominated by unsaturated pectin oligosaccharides, next to pentoses and hexoses originating from digested RG-I side 
chains. Unsaturated oligosaccharides were both methyl-esterified and acetylated, showing that PL was able to release acetylated oligosaccharides in both the Li/D-SS and Residues. Surprisingly, previous research showed that $P G+P L$ did not release acetylated oligosaccharides from water soluble carrot pectin [10]. Consequently, it is concluded that milling followed by LiCl-DMSO solubilised different pectin populations than water did. It is suggested that the solubilisation of these pectin populations is related to the disruption of the hemicellulose/cellulose network by milling and LiCl-DMSO extraction.

The DM was $41 \%-57 \%$ for carrot, $22-38 \%$ for tomato and $48-87 \%$ for strawberry Li/D-SS. Based on these values both PG and PL would have been able to be active, releasing both saturated and unsaturated oligomers, as was confirmed by HPAEC (results not shown). The dominance of unsaturated oligosaccharides in MALDI TOF mass spectra was previously observed and expected to be related to differences in ionisation [10]. Similarly, it was expected that also the DM of $38 \%-44 \%$ for carrot, $27-30 \%$ for tomato and $40-59 \%$ for strawberry Residues would result in both saturated and unsaturated oligomers whereas the mass spectrum showed the dominance of unsaturated oligosaccharides.

\section{Xyloglucan oligosaccharides}

Contrasting to carrot, the mass spectrum for the tomato Li/D-SS T15 PG + PL digest (Figure 5.3B) was dominated by acetylated xyloglucan oligosaccharides. Pectin oligosaccharides were nearly absent in the mass spectrum, although analysis of pectin oligosaccharides by HPAEC showed digestion of $\leq 20 \%$ for HG regions (Supporting information Table S-5.2). Analysis of the purity of the pectinases on model substrates revealed slight activity towards xyloglucan. However, since in previous studies digesting $6 \mathrm{M}$ alkali residues with PG $+\mathrm{PL}$ did not result in xyloglucan oligosaccharides (data not shown), the presence of xyloglucan oligosaccharides rather than pectin oligosaccharides in the Li/D-SS T15 PG + PL digest was unexpected. Whereas GalA oligomers were observed by HPAEC, mass spectra were dominated by xyloglucan oligosaccharides. The underrepresentation of acidic oligosaccharides might be explained by more efficient ionisation of neutral oligosaccharide in MALDI-TOF MS [10].

\section{Xyloglucan domains}

Although the xyloglucanase activity was unexpected and not seen before in the PG and PL enzymes, results may provide valuable information on the accessibility of xyloglucans. As reported previously described to be present in 3 different domains in the cell wall, an XEGextractable domain, a concentrated alkali-extractable domain and a cellulase-extractable domain [27]. Whereas the XEG-extractable and alkali-extractable domains were related to adsorption to the cellulose surface, the cellulase-extractable domain was hypothesized to be firmly entrapped within cellulose microfibrils. Milling and LiCl-DMSO are able to disrupt $\mathrm{H}$-bonds between xyloglucan and cellulose. It might therefore be hypothesized that a rather 
similar division into accessible and inaccessible domains might explain the difference in enzyme activity towards XG in the Li/D-SS and the Residues.

In order to show the large variation of xyloglucan oligomers released, the mass spectra up to $\mathrm{m} / \mathrm{z} 1500$ were analysed (Supporting information Figure S-5.1). The large structural variety in substitution of xyloglucan oligosaccharides did not point to subpopulations with specific structural characteristics. In line with the mass spectra in Figure 5.3B, the majority of xyloglucan oligosaccharides were also reported by Assor et al [5].

The Residues contained 2, 4, and 9 mol\% xylose for carrot, tomato and strawberry respectively. Based on the absence of xyloglucan oligosaccharides in the mass spectra for the digested Residues it can be hypothesized that either all xylose in the Residue originated from xylan, or that xylose is present in enzymatically inaccessible xyloglucan domains.

The strawberry Li/D-SS showed a mix of xyloglucan oligomers and unsaturated GalA oligomers, showing that xyloglucan oligosaccharides were also formed in other sources next to tomato. Furthermore, also the strawberry Residues were devoid of xyloglucan oligosaccharides. Similar to the tomato Residues, xylose might originate from xylan or from xyloglucan found in an inaccessible domain.

\subsection{Conclusions}

The study on the potential of characterising cell wall polysaccharides by planetary ball milling and subsequent LiCl-DMSO extractions showed the potential of solubilising up to $50 \%$ of all polysaccharides from ChUS without loss of structural information. In a subsequent buffer extraction step, another $30 \%$ of all pectin from ChUS was solubilised. Whereas the DM seems of key importance in determining pectin solubility for pure HG-rich pectin, solubility of pectin from plant cell walls could not be ascribed to solely the DA or DM. The LiCl-DMSO- and buffer-insoluble pectin is believed to be insoluble due to interactions with the other insoluble plant cell wall polymers. Although the nature of the interactions was not determined, it can be concluded that these interactions were not based on $\mathrm{H}$-bonds, since both ball milling and LiCl-DMSO disrupt inter- and intramolecular $\mathrm{H}$-bonds. The higher HG:RG-I ratios observed for B-SS pectin populations compared to Li/D-SS suggested that RG-I enhanced pectin solubility in LiCl-DMSO

Analysis of the Li/D-SS showed that substantial percentages of all pectin and hemicelluloses solubilised by LiCl-DMSO were acetylated, and digestion with pectinases confirmed acetylated pectin and xyloglucans. Also in the Residues, highly acetylated pectin was found, showing the potential of using milling followed by LiCl-DMSO and buffer extraction to determine degrees of the methyl-esterification and acetylation of both soluble and insoluble cell wall polysaccharides. 


\section{References}

1. Cosgrove, D.J., Growth of the plant cell wall. Nature Reviews Molecular Cell Biology, 2005. 6(11): p. 850-861.

2. Höfte, H., A. Peaucelle and S. Braybrook, Cell wall mechanics and growth control in plants: the role of pectins revisited. Frontiers in Plant Science, 2012. 3(121): p. 1-6.

3. Renard, C.M.G.C. and C. Ginies, Comparison of the cell wall composition for flesh and skin from five different plums. Food Chemistry, 2009. 114(3): p. 1042-1049.

4. Petruš, L., D.G. Gray and J.N. BeMiller, Homogeneous alkylation of cellulose in lithium chloride/dimethyl sulfoxide solvent with dimsyl sodium activation. A proposal for the mechanism of cellulose dissolution in LiCl/Me ${ }_{2} \mathrm{SO}$. Carbohydrate Research, 1995. 268(2): p. 319-323.

5. Assor, C., B. Quemener, J. Vigouroux and M. Lahaye, Fractionation and structural characterization of LiCl-DMSO soluble hemicelluloses from tomato. Carbohydrate Polymers, 2013. 94(1): p. 46-55.

6. Ray, S., J. Vigouroux, B. Quémener, E. Bonnin and M. Lahaye, Novel and diverse fine structures in LiCl-DMSO extracted apple hemicelluloses. Carbohydrate Polymers, 2014. 108: p. 46-57.

7. Wang, Z., T. Yokoyama, H.-M. Chang and Y. Matsumoto, Dissolution of beech and spruce milled woods in LiCl/DMSO. Journal of Agricultural and Food Chemistry, 2009. 57(14): p. 6167-6170.

8. Abbaszadeh, A., W. MacNaughtan and T.J. Foster, The effect of ball milling and rehydration on powdered mixtures of hydrocolloids. Carbohydrate Polymers, 2014. 102: p. 978-985.

9. Houben, K., R.P. Jolie, I. Fraeye, A.M. Van Loey and M.E. Hendrickx, Comparative study of the cell wall composition of broccoli, carrot, and tomato: Structural characterization of the extractable pectins and hemicelluloses. Carbohydrate Research, 2011. 346(9): p. 1105-1111.

10. Broxterman, S.E., P. Picouet and H.A. Schols, Acetylated pectins in raw and heat processed carrots. Carbohydrate Polymers, 2017. 177: p. 58-66.

11. DuBois, M., K.A. Gilles, J.K. Hamilton, P.A. Rebers and F. Smith, Colorimetric method for determination of sugars and related substances. Analytical Chemistry, 1956. 28(3): p. 350-356.

12. Blumenkrantz, N. and G. Asboe-hansen, New method for quantitative-determination of uronic acids. Analytical Biochemistry, 1973. 54(2): p. 484-489.

13. Broxterman, S.E. and H.A. Schols, Interactions between pectin and cellulose in primary plant cell walls. Carbohydrate Polymers, 2018. 192: p. 263-272.

14. Huisman, M.M.H., A. Oosterveld and H.A. Schols, Fast determination of the degree of methyl esterification of pectins by head-space GC. Food Hydrocolloids, 2004. 18(4): p. 665-668.

15. Voragen, A., H. Schols and W. Pilnik, Determination of the degree of methylation and acetylation of pectins by HPLC. Food Hydrocolloids, 1986. 1(1): p. 65-70.

16. Schols, H.A., M.A. Posthumus and A.G.J. Voragen, Structural features of hairy regions of pectins isolated from apple juice produced by the liquefaction process. Carbohydrate Research, 1990. 206(1): p. 117-129.

17. Kühnel, S., S.W.A. Hinz, L. Pouvreau, J. Wery, H.A. Schols, and H. Gruppen, Chrysosporium lucknowense arabinohydrolases effectively degrade sugar beet arabinan. Bioresource Technology, 2010. 101(21): p. 8300-8307.

18. Limberg, G., R. Körner, H.C. Buchholt, T.M.I.E. Christensen, P. Roepstorff, and J.D. Mikkelsen, Quantification of the amount of galacturonic acid residues in blocksequences in pectin homogalacturonan by enzymatic fingerprinting with exo- and endo-polygalacturonase II from Aspergillus niger. Carbohydrate Research, 2000. 327(3): p. 321-332.

19. Van Alebeek, G.-J.W., T.M. Christensen, H.A. Schols, J.D. Mikkelsen and A.G. Voragen, Mode of action of pectin lyase $A$ of Aspergillus niger on differently C6-substituted oligogalacturonides. Journal of Biological Chemistry, 2002. 277(29): p. 25929-25936. 
20. Broxterman, S.E. and H.A. Schols, Characterisation of pectin-xylan complexes in tomato primary plant cell walls. Submitted for publication, 2018.

21. Zykwinska, A.W., M.C.J. Ralet, C.D. Garnier and J.F.J. Thibault, Evidence for in vitro binding of pectin side chains to cellulose. Plant Physiology, 2005. 139(1): p. 397-407.

22. Paes, S.S., S. Sun, W. MacNaughtan, R. Ibbett, J. Ganster, T.J. Foster, and J.R. Mitchell, The glass transition and crystallization of ball milled cellulose. Cellulose, 2010. 17(4): p. 693-709.

23. Bonnin, E., C. Garnier and M.C. Ralet, Pectin-modifying enzymes and pectin-derived materials: applications and impacts. Applied Microbiology and Biotechnology, 2014. 98(2): p. 519-532.

24. Dea, I. and J. Madden, Acetylated pectic polysaccharides of sugar beet. Food Hydrocolloids, 1986. 1(1): p. 71-88.

25. Scheller, H.V. and P. Ulvskov, Hemicelluloses. Plant Biology, 2010. 61(1): p. 263-289.

26. Voragen, A.G., G.-J. Coenen, R.P. Verhoef and H.A. Schols, Pectin, a versatile polysaccharide present in plant cell walls. Structural Chemistry, 2009. 20(2): p. 263-275.

27. Pauly, M., P. Albersheim, A. Darvill and W.S. York, Molecular domains of the cellulose/xyloglucan network in the cell walls of higher plants. The Plant Journal, 1999. 20(6): p. 629-639. 


\section{Supporting information}

Table S-5.1 Solubility of commercial HG-rich pectins in LiCl-DMSO (A) C30: Lemon pectin DM30, (B) SBP5317: Sugar beet pectin DM53 + DA17, (C) C70: Lemon pectin DM70.

\begin{tabular}{|c|c|c|}
\hline \multirow{4}{*}{ C30 } & Milling time $(\mathrm{min})$ & \% Soluble \\
\cline { 2 - 3 } & 0 & 0 \\
\cline { 2 - 3 } & 15 & 0 \\
\hline \multirow{4}{*}{5317} & 45 & 0 \\
\cline { 2 - 3 } & 0 & 1 \\
\cline { 2 - 3 } & 15 & 28 \\
\hline \multirow{3}{*}{ C70 } & 45 & 34 \\
\cline { 2 - 3 } & 0 & 53 \\
\cline { 2 - 3 } & 15 & 69 \\
\hline
\end{tabular}

Table S-5.2 Percentage of GalA in ChUS for carrot, tomato and strawberry digested to saturated and unsaturated oligosaccharides for both LiCl-DMSO supernatants and residues by polygalacturonase (PG) and pectin lyase (PL). Sat. GalA: saturated galacturonic acid oligosaccharides; Unsat. GalA: unsaturated galacturonic acid oligosaccharides.

\begin{tabular}{|c|c|c|c|c|c|}
\hline & \multicolumn{2}{|c|}{ Li/D-SS } & \multicolumn{3}{|c|}{ Residue } \\
\hline & C15 & $C 45$ & CO & C15 & $C 45$ \\
\hline Sat.GalA & 0 & 0 & 7 & 8 & 11 \\
\hline \multirow[t]{3}{*}{ Unsat.GalA } & 7 & 7 & 6 & 5 & 6 \\
\hline & \multicolumn{2}{|c|}{ Li/D-SS } & \multicolumn{3}{|c|}{ Residue } \\
\hline & TO & T45 & TO & $T 15$ & T45 \\
\hline Sat.GalA & 7 & 0 & 18 & 18 & 19 \\
\hline \multirow[t]{3}{*}{ Unsat.GalA } & 0 & 2 & 1 & 2 & 1 \\
\hline & \multicolumn{2}{|c|}{ Li/D-SS } & \multicolumn{3}{|c|}{ Residue } \\
\hline & S15 & $S 45$ & so & $S 15$ & $S 45$ \\
\hline Sat.GalA & 5 & 16 & 4 & 5 & 6 \\
\hline Unsat.GalA & 10 & 4 & 7 & 7 & 7 \\
\hline
\end{tabular}

Values are the average of two replicates. Absolute deviations were $<10 \%$. 

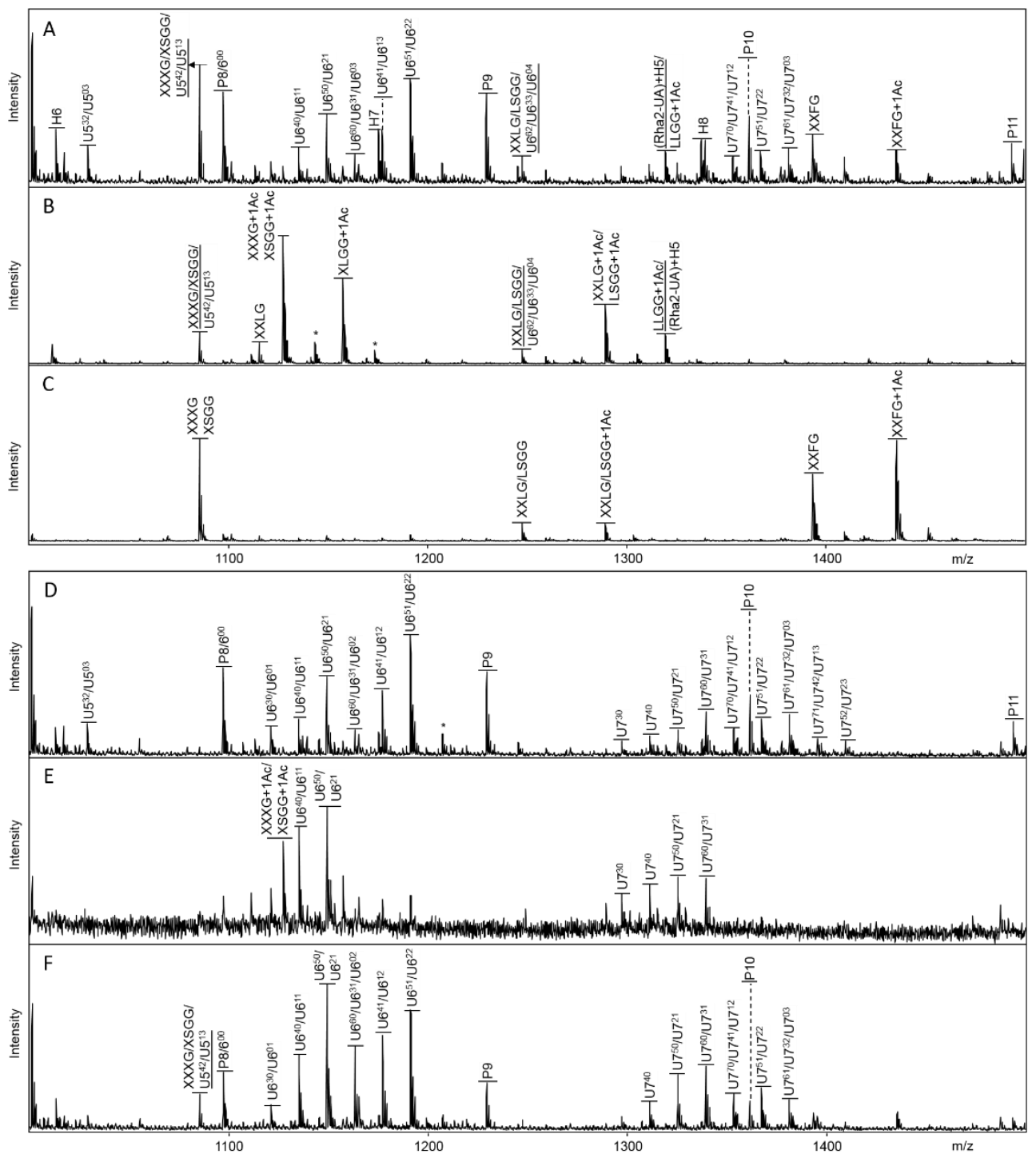

Figure S-5.1 MALDI TOF mass spectra of LiCl-DMSO supernatants and residues digested with PG + PL (A) Carrot Li/D-SS C15, (B) Tomato Li/D-SS T15, (C) Strawberry Li/D-SS S15, (D) Carrot Residue C15, (E) Tomato Residue T15, (F) Strawberry Residue S15. Peak annotation: U420, unsaturated GaIA DP 4, 2 methyl-esters, 0 acetyl groups; $P$, pentose. Nomenclature for xyloglucan: $G$, glucose; $X$, glucose xylose; S, glucose - xylose - arabinose; L, glucose - xylose - galactose; F, glucose - xylose - galactose fucose. Most logical structures are underlined. $\left({ }^{*}\right) \mathrm{K}^{+}$-adduct. 



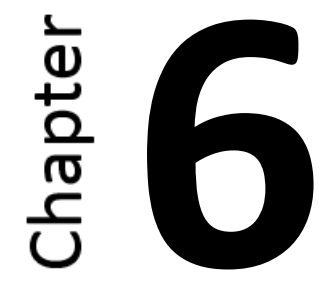




\subsection{Aim of the research}

The primary plant cell wall is essential for strength, growth and development of the plant [1]. The primary plant cell wall is composed of the polysaccharides pectin, hemicellulose and cellulose. Especially in fruits and vegetables pectin levels are high, and pectin structural properties largely determine texture and firmness during growth, ripening, storage and processing [2-4].

The aim of this research was to understand the cell wall architecture of carrot, tomato and strawberry, primarily focussed on pectin and its potential interactions with hemicellulose and cellulose. Although several models for the primary cell wall were proposed over time, many questions with respect to the precise architecture and potential interactions between cell wall polysaccharides remain unanswered. One of the main analytical difficulties in studying the architecture of the primary plant cell wall is found in the highly complex and insoluble nature of cell wall polysaccharides in muro. Therefore strategies for targeted disruption of interactions were needed in order to solubilise and further characterise specific populations and hereby recognise potential cross-links between cell wall polysaccharides. Furthermore, the effect of heat processing on pectin was studied and previously established enzymatic fingerprinting methods were optimised to understand the effect of heat processing on carrot pectin structural characteristics.

\subsection{Motivation for the sources studied}

In this research the cell wall architecture of carrot, tomato and strawberry was studied. Carrot was studied based on its inclusion in the EU project Optifel. The project aimed at using different processing techniques to develop protein-enriched and fibre-enriched products for elderly people based on commonly consumed European vegetable sources. Related hereto, chapter 2 describes the effect of heat processing on carrot pectin.

The second part of this research focussed on studying the primary plant cell wall architecture, and more specifically the role of pectin in the carrot cell wall. In most of the primary cell wall models, xyloglucan was considered to be highly involved in polysaccharide interactions, primarily due to interactions between xyloglucan and cellulose microfibrils [5, 6]. Additionally cross-links between xyloglucan and pectin were also described $[7,8]$. However, since xylose levels in carrot were low, tomato and strawberry were included in the study based on their higher xylan/xyloglucan levels. As can be seen from the composition of the cell wall material, represented by the Alcohol Insoluble Solids (AIS) in Table 6.1 , xylose levels ranged from $2 \%$ to $7 \%$ and $8 \%$ for carrot, tomato and strawberry, respectively. 
Table 6.1 Monosaccharide composition (mol\%) of the Alcohol Insoluble Solids (AIS) extracted from carrot, tomato and strawberry.

\begin{tabular}{|l|c|c|c|c|c|c|c|}
\hline & \multicolumn{7}{|c|}{ Mol \% } \\
\cline { 2 - 9 } & Ara & Rha & Gal & Glc & Xyl & Man & UA \\
\hline Carrot & 8 & 1 & 20 & 31 & 2 & 5 & 33 \\
\hline Tomato & 6 & 1 & 7 & 42 & 7 & 6 & 31 \\
\hline Strawberry & 8 & 1 & 8 & 25 & 8 & 3 & 47 \\
\hline
\end{tabular}

\subsection{Characteristics of different pectin extracts}

In chapters 3-5 we focussed on the potential interactions between cell wall polysaccharides in carrot, tomato and strawberry, 3 sources with different levels of pectin, hemicellulose and cellulose. In all sources studied, water and EDTA solubilised easily extractable pectin populations. The residue after water and EDTA extractions, the chelating agent unextractable solids (ChUS) contained substantial levels of pectin, and potential polysaccharide interactions were studied in ChUS.

In chapter 2, the presence of acetylated HG regions was shown for water soluble carrot pectin. Heat processing resulted in increased amounts of water soluble pectin, and also these water soluble populations were highly acetylated. Furthermore the RG-I: HG ratio for water soluble pectin increased after heat processing.

In chapter 3, sequential alkali and water extractions showed that roughly half of all pectin in ChUS did not solubilise during these extractions. Pectin levels were highest in the carrot $6 \mathrm{M}$ alkali residue and it was shown that half of the pectin remaining in the residue could be released by digestion with purified glucanases. It was deduced from all experimental evidence that the pectin populations released by glucanases are most likely linked to cellulose by a covalent glycosidic linkage since any other cross-link would have been degraded along the increasing severity of the sequential water-alkali extraction process.

In chapter 4 planetary ball milling was used as a pretreatment for subsequent water extractions, leading to highly increased extraction yields. A water soluble pectin-xylan complex was shown in tomato cell walls by co-elution of pectin and (glucurono)xylan on $A E C$, indicating a stable linkage in increasing ionic strength. Pectin and xylan co-precipitated in $0.1 \mathrm{M} \mathrm{NaOH}$, indicating an alkali-stable linkage. Similar to chapter 3 , it was therefore deduced that only a covalent glycosidic linkage between pectin and xylan would resist in these conditions.

In chapter 5, ball milling and subsequent LiCl-DMSO extraction solubilised substantial parts of all cell wall polysaccharides without losing information on alkali-labile structural characteristics. Studying the solubility of pure, commercial pectin in LiCl-DMSO revealed that a higher DM improved solubility. However, this trend was not observed for pectin in 
the cell wall, leading to the suggestion that interactions with other cell wall polymers affected pectin solubility. We showed that highly acetylated pectin and xyloglucan can be found in carrot and strawberry cell walls, and that a large variety of xyloglucan structures was present in tomato and strawberry.

\subsection{The presence of different pectin domains}

\subsubsection{Division of extracted pectin fractions in different domains}

The results presented in this thesis show that a high number of extraction steps is required to extract all pectin. Whereas a part of the pectin was solubilised rather easily by mild agents, other parts of pectin need more disruptive methods to be extracted. Additionally, part of the pectin was not extracted and remained present in the final, cellulose-rich residue after sequential alkali-water extractions. Based on these different extractabilities, it is proposed that the role of pectin in the cell wall can be best visualised in a multi-domain model, as presented in Figure 6.1. By proposing these domains, pectin populations are categorised based on the extent of interactions with other cell wall polymers.

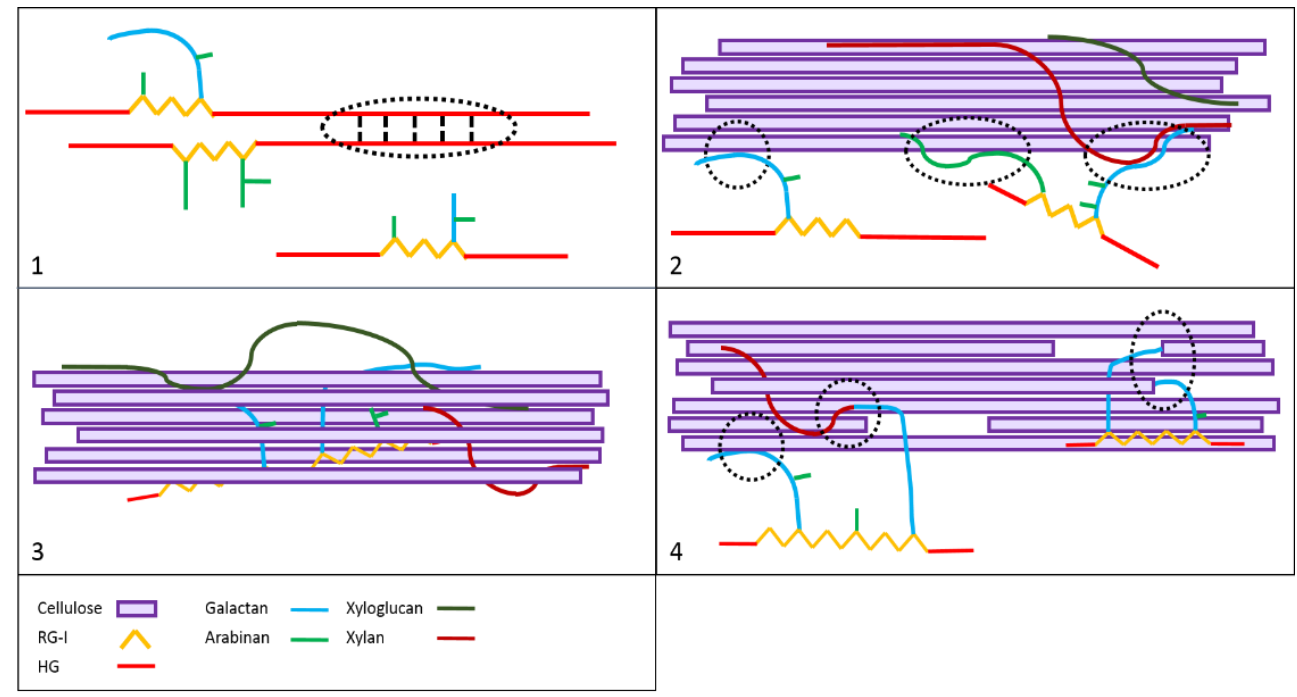

Figure 6.1 Proposed pectin domains. 1) Independent domain; 2) Surface-bound domain; 3) Entrapped domain; 4) Strongly connected domain. The dashed circles indicates spots of potential interactions. The size of the different polysaccharides and the extent of RG-I branching was not taken into account or meant to be represented in a quantitative way. 


\section{Domain 1 -Independent domain}

For all sources studied, pectin was first extracted from the Alcohol Insoluble Solids (AIS) into the water soluble solids (WSS) and the chelating agent soluble solids (ChSS). Both WSS and ChSS were highly pure pectin fractions, with a high HG:RG-I ratio. As depicted in Figure 6.1.1, both water and EDTA soluble pectin populations were assumed to be part of separate pectin networks since they are relatively easy extracted and not interacting with other cell wall polysaccharides $[6,9]$. Relating this domain to existing cell wall models, this part of pectin is believed to comply with the tethered network model [10] since pectin is present as a co-existing, non-interacting network.

After extraction of water and chelating agent soluble pectin, the chelating agent unextractable solids (ChUS) were obtained. It was assumed that all pectin found in ChUS was interacting with the insoluble cell wall network. By taking uronic acid levels as indicator for pectin, $69 \%, 50 \%$ and $37 \%$ of all pectin was found in the ChUS for carrot, tomato and strawberry, respectively.

\section{Domain 2 - Surface-bound domain}

The pectic polysaccharides found in domain 2 are proposed to be interacting with the surface of the insoluble (hemi)cellulose network and are extractable by $\leq 2 \mathrm{M}$ alkali.

As shown in chapter 3, 20-30\% of cell wall polysaccharides in ChUS was extracted by mild alkaline conditions $(0.1 \mathrm{M} \mathrm{NaOH})$, often referred to as the ester-bound pectins. Knowledge lacks in literature on the question to which cell wall elements these pectins are ester-linked, since it remains unanswered whether these pectin populations interact with other pectin populations or with (hemi)cellulose networks. Furthermore, it has never been fully determined which element of pectin is involved in the ester-linkage, and what type of ester is present. Based on the ability of different pectin structural elements to adsorb to cellulose in vitro [11], it might be suggested that these pectins are adsorbed to (hemi)cellulose rather than being ester-bound.

As long as the alkali strength is $\leq 2 \mathrm{M}$ to prevent swelling of cellulose microfibrils [12], pectin populations categorised in this domain are proposed to interact solely with the surface of the (hemi)cellulose network. Percentages of pectin extracted by sequential $1 \mathrm{M} \mathrm{NaOH}$ extractions were very low, and as expected primarily hemicellulose was extracted by $1 \mathrm{M}$ $\mathrm{NaOH}$.

\section{Domain 3-Entrapped domain}

Pectin populations that are not released until harsh alkaline solvents are used are believed to be entrapped within the cellulose microfibrils, and released by swelling of cellulose microfibrils (Figure 6.1.3) 
However, one of the difficulties in categorising this domain is that the effects of strong alkaline conditions on cellulose microfibrils are not fully understood. More specifically, it is not characterised whether $\mathrm{H}$-bonds are disrupted up to the level of individual glucan chains $[12,13]$. Typically, upon mercerisation, washing and recrystallization, the outer regions of cellulose microfibrils change structure and recrystallize onto the inner, less accessible cellulose regions that remained unaltered [12]. It is not fully clear whether all parts of cellulose microfibrils reorient or only the initially amorphous regions. Literature on this topic does not allow unambiguous conclusions. On the one hand $\mathrm{H}$-bond reorientation on the glucan chain level is suggested, based on analysing isolated microfibrils [14]. Contrasting hereto it is suggested that not all $\mathrm{H}$-bonds are disrupted and recrystallization occurs on top of organised cellulose microfibrils [12].

Alkaline extractions using $4 \mathrm{M} / 6 \mathrm{M} \mathrm{NaOH}$ or $\mathrm{KOH}$ are primarily aimed at solubilisation of hemicellulose [15]. As expected, roughly $20-30 \%$ of all xylose and mannose was found in the $6 \mathrm{M} \mathrm{NaOH}$ extracts, indicating the release of xyloglucan/xylan and mannan in strong alkaline conditions ( $\geq 4 \mathrm{M}$ alkali).

\section{Domain 4 - Strongly connected domain}

Pectin populations remaining in alkaline residues are believed to strongly associate with cellulose, either being firmly entrapped in inner, inaccessible cellulose regions, or potentially covalently cross-linked to these microfibrils, as depicted in Figure 6.1.4. Even after extensive sequential alkali and water extractions, 31\%, $11 \%$ and $5 \%$ of all GalA in AIS remained unextractable for carrot, tomato and strawberry, respectively.

\subsubsection{Quantification of the different domains}

By taking monosaccharide levels of uronic acid as indicator for pectin, and normalising all alkaline extraction yields to $100 \%$, the distribution of all pectin populations over the different domains was quantified and shown in Figure 6.2. Whereas all domains are found in all sources, variations from source to source are high, and especially the amounts of independent and strongly connected pectin show high variation between sources. This clearly indicates that the distribution of pectin in primary plant cell walls is sourcedependent. 


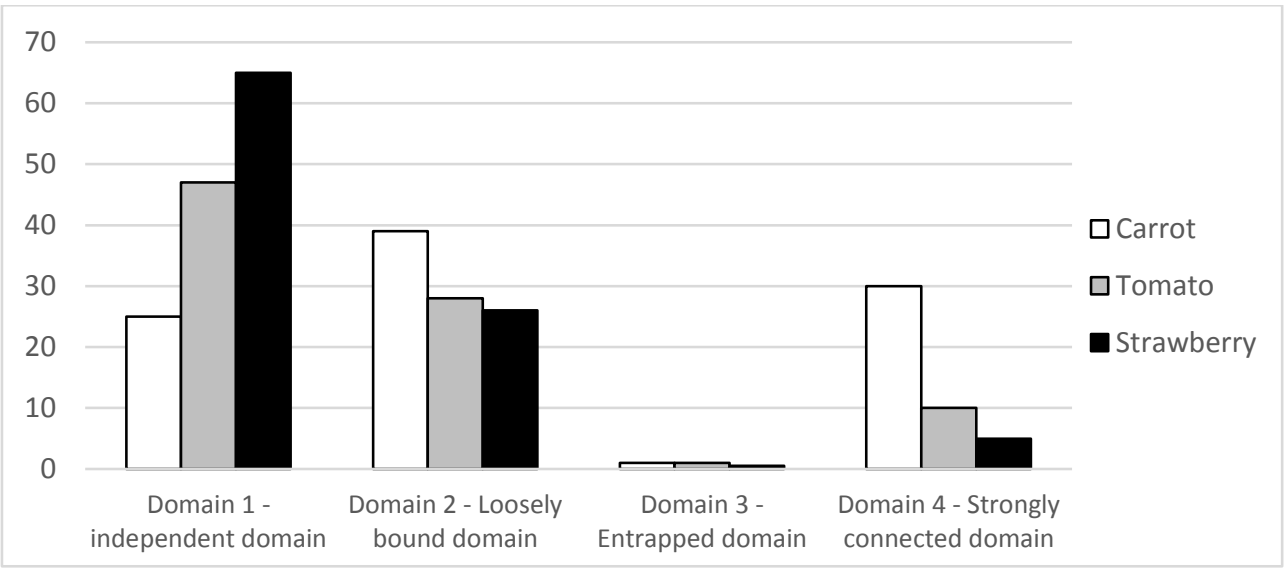

Figure 6.2 Distribution of pectin over the different domains for carrot, tomato and strawberry. Domains were quantified using uronic acid as indicator for pectin, and normalising all yields to $100 \%$.

\subsubsection{Difference in pectin characteristics for different domains}

For the domains described above, the HG:RG-I ratio decreased upon increasing the severity of the extraction solvent. Rhamnose levels are typically very low, and therefore using UA:Rha as HG:RG-I ratio results in very high variations for this ratio. The HG:RG-I ratio was therefore expressed as UA:Ara+Gal.

For all sources, comparison of HG:RG-I ratios of WSS and ChSS with $0.1 \mathrm{M} \mathrm{NaOH}$ extracts showed that pectin in WSS and ChSS contained relatively more HG regions, but differences were limited (data not shown). Furthermore, pectin in the $6 \mathrm{M}$ alkali residues had $\sim 2 \mathrm{x}$ lower HG:RG-I ratios than WSS and ChSS. These ratios show that in general, RG-I rich pectin more firmly associates with other cell wall polymers than HG rich pectin.

Similarly, it was shown in chapter $\mathbf{2}$ (Table 2.2) that the HG:RG-I ratio of water and chelating agent soluble pectin decreased upon increasing water soluble pectins yields after heat processing. This confirms that RG-I initially being less soluble and more integrated in the insoluble cell wall network becomes more soluble upon disrupting the cell wall through heat processing.

One of the characteristics of current cell wall models is that it has been attempted to fit all polysaccharides into 1 picture [10]. Similarly, it has been attempted to capture all pectin elements in one macromolecular structural picture [16-18]. However, one of the challenges in creating these models is fitting the excess of $H G$ to RG-I in a pectin model. Visualising pectin as domains with distinct HG:RG-I ratios rather than as one macromolecular populations could therefore aid in understanding the excess of HG to RG-I. 


\subsubsection{Relating methyl-esterification and acetylation to pectin domains}

One of the main conclusions of chapters $\mathbf{2}$ and $\mathbf{5}$ was that both carrot and strawberry pectin contain highly acetylated HG regions. It might be suggested that acetylation of pectins HG regions is more prevalent than currently believed. In general, methyl-esterification of pectin extracts is more frequently determined than acetylation of pectin. In order to confirm whether acetylation of HG regions is indeed more prevalent than currently believed, it would be necessary to include determination of the DA present in pectin characterisation in a similar way as the DM is determined. Furthermore it shows the need for avoiding alkaline extractions conditions and the added value of introducing extraction solvents such as LiCl-DMSO (chapter 5), which allow determination of the methyl-esterification and acetylation of both soluble and insoluble pectin populations.

By using alkaline extraction conditions as performed in chapter $\mathbf{3}$, all structural information on methyl-esters and acetyl groups was lost and therefore relating the DM and DA to the proposed pectin domains was not possible. However, the high DM and DA values reported for both soluble and insoluble pectin populations in chapter 5 suggest that the insoluble domains do not have an uncommonly low or high DM (27-59\%) and/or DA (28-50\%). Therefore methyl-esterification and acetylation do not seem to govern the presence of pectin in the domains $2-4$.

Functional properties of pectin are often predominantly related to methyl-esterification of the HG region [19], and this might perhaps be the reason why the DM of pectin extracts is much more frequently determined than the DA of pectin. Pectin is believed to be highly methyl-esterified during biosynthesis. The DM decreases over the course of ripening and the importance of PME for post-biosynthetic pectin modification has widely been recognized [4, 20]. In contrast, it is less clear why polysaccharides are acetylated. Acetylation is known to enhance the hydrophobic character of polysaccharides. For example, acetylated pectins show emulsifying properties when used as a food ingredient [21]. It might be speculated that through increased hydrophobicity, properties related to the charge of pectin (e.g. ion/solute transport) might be affected. Potentially, hydrophobic interactions with other cell wall polymers might be affected as well. For xyloglucan, it was reported that acetylation improves solubility and will prevent self-association and aggregation $[22,23]$. This might be of high relevance for XG in e.g. Solanaceous species such as tomato, which are characterised by a lower substitution than found in many other species. 


\subsection{Cross-links between cell wall polysaccharides}

In chapter $\mathbf{3}$ and $\mathbf{4}$, the presence of respectively cross-linked pectin-cellulose complexes and pectin-xylan complexes was discussed. The results show that substantial parts of all pectin seem closely associated or even covalently connected with hemicellulose or cellulose. Furthermore the results show that these complexes are source-dependent and not present in substantial levels in all sources.

\subsubsection{Pectin-cellulose}

In chapter 3, cross-linked pectin and cellulose populations in the carrot cell wall were described. After extensive sequential alkali-water extractions, 52\% of all GalA from carrot ChUS remained in the $6 \mathrm{M}$ alkali residue, and about half of all GalA in the $6 \mathrm{M}$ alkali residue was solubilised by glucanases. Further isolation of the pectin populations released by glucanases led to the proposal of covalently cross-linked pectin-cellulose populations. Relating this pectin-cellulose complex to the domains proposed in Figure 6.1, would categorise these cellulose-associated pectin populations in domain 4 since these pectin populations remained insoluble during the extraction procedures used to obtain domains 1-3.

Due to the inability of PG to release pectin from the $6 \mathrm{M}$ alkali residue, we hypothesized a cross-link through RG-I side chains. Although highly speculative, we hypothesized a crosslink involving galactan rather than arabinan, since the Gal level (50\%) was higher than the Ara level $(23 \%)$ in the isolated Glucanase-HMw population. It remained unanswered whether the cross-linked populations are present as branched populations, or whether the backbones are connected, in which galactan chains further continue in glucan chains. In order to further clarify the precise details of this connection, linkage analysis might be a useful tool. However, the main difficulty remains that entire pectin-cellulose populations might be cross-linked by a very small number of actual covalent cross-links present. It is therefore not guaranteed that linkage analysis will clarify the question of chain branching vs chain elongation, or the question on whether arabinan, galactan or another pectin element is connected to cellulose. The same challenge holds for NMR, since several attempts to proof the type of cross-link by NMR did not succeed.

\subsubsection{Pectin-xylan}

In chapter 4, a water soluble covalently cross-linked pectin-xylan complex was proposed to be present in the tomato cell wall. Whereas pure xylan and RG-I polysaccharides remained soluble in mild alkaline conditions, pure HG-rich pectins precipitated. It was shown that a complex of pectin and xylan, solubilised from the tomato cell wall, precipitated using the same mild alkaline conditions, suggesting that pectin and xylan were interacting by an 
alkali-stable linkage. Categorising pectin found in this proposed complex to the domains proposed in Figure 6.1 is not straightforward since the disrupting effect of planetary ball milling on the cell wall is not fully understood. The pectin-xylan complex might originate from the surface-bound domain 2 , being released by disruption of the $\mathrm{H}$-bonds responsible for the initial insolubility of these polysaccharides. The pectin-xylan complex might also be categorised in domain 3 , due to the ability of milling to disrupt the crystallinity of cellulose microfibrils. Due to its solubility in water, it is considered unlikely that the pectin-xylan complex is strongly associated with cellulose, as proposed for pectin populations in domain 4.

Since enzymatic removal of $\mathrm{HG}$ regions from the pectin-xylan complex did not alter the elution behaviour of RG-I and xylan on AEC, it was proposed that xylan links to pectin through its RG-I regions. The RG-I backbone might elongate into the xylan backbone, whereas it could also be hypothesized that xylan is cross-linked to pectin through RG-I side chains. In this fraction the galactose level (9\%) was slightly higher than the arabinose level (6\%), but this difference was less pronounced than for the pectin-cellulose complex in chapter 3 . The same challenge as described above was faced here for linkage analysis and NMR.

As shown by Tan et al. [24], complex covalently linked protein-polysaccharide complexes can be found in Arabidopsis cultured cells. Extensive isolation, purification and characterisation of the complex by NMR and amino acid sequencing showed unexpected covalent linkages, forming unknown levels of complexes in which AG Type II links the protein part of AGP through a Gal-GlcA-Rha element to RG-I. Furthermore arabinoxylan was crosslinked to both AG type II and to rhamnose in the RG-I backbone, showing that many unexpected covalent linkages in cell walls might be present.

\subsubsection{Relating proposed cross-links to biosynthetic events}

In order to further understand the nature of the proposed cross-linked complexes, it is of importance to discuss these complexes with respect to the required biosynthetic events. Plant cell wall polysaccharides are synthesized in different locations in the cell. Whereas pectin and hemicellulose are synthesized in the Golgi apparatus [1, 25], cellulose is synthesized in the plasma membrane [26]. After synthesis, polysaccharides are transported to, and deposited into the cell wall. Knowledge on biosynthetic processes for most individual polysaccharides emerged, and polysaccharide biosynthetic pathways are partially resolved [20, 22, 26, 27]. However, the process of deposition in the cell wall and the potential formation of interactions between wall polymers in the cell wall is poorly understood. Since it might be considered highly unlikely that the proposed pectin-cellulose complexes are already synthesized directly as one extended cross-linked polymer, it is 
assumed that these polysaccharides cross-link during or after their deposition in the cell wall.

It is believed that in the process of cellulose synthesis, all cellulosic glucan chains synthesized in the plasma membrane by 1 rosette spontaneously crystallise into microfibrils when released into the cell wall [26]. Adsorption of xyloglucan to cellulose is believed to be a spontaneous process as well [6]. The presence of firmly entrapped domains argues for the hypothesis that xyloglucan is trapped within these microfibrils during crystallisation [22, 28]. Perhaps pectin domains are entrapped in a similar way. Although less frequently mentioned, it was alternatively hypothesized that mature xyloglucans are assembled in the cell wall from small segments by XET. This assembly process might result in complex entanglements, potentially explaining why strong alkaline solvents are needed to release XG from cell walls $[22,29]$.

Cross-linking between xyloglucan and pectin has been proposed to occur in the Golgi system rather than after deposition in the cell wall $[22,30]$. The mechanism for enzymatic synthesis of this complex was not resolved, but in cultured cells the complex was formed much faster than the required transport time for polysaccharides to the cell wall. This led to the conclusion that cross-linking already happened prior to deposition in the wall. Taking this into account, the proposed pectin-xylan complex might either be cross-linked during synthesis in the Golgi system, or during subsequent deposition in the cell wall.

Hints for interacting polysaccharides were derived from the suggestion that pectin and xylan biosynthesis might be coupled [20]. Mutant studies showed that reduction in HG synthesis by HG:GalAT transferase activity was coupled to a reduction in xylan biosynthesis. These related activities were not expected since xylan was predominantly ascribed to the secondary cell wall, contrasting to pectin being solely present in the primary cell wall. However, the proposed covalent pectin-xylan complexes for tomato in chapter $\mathbf{4}$ align with the results for the described mutant studies.

Along the same line of circumstantial evidence, the GAUT1/GAUT7 (galacturonosyltransferase) complex, involved in pectin biosynthesis, was found to be associated with KOR1, an endo- $\beta$-glucanase that might be involved in cellulose biosynthesis. Although this might be considered as a hint for potentially connected pectin and cellulose biosynthesis, many questions still remain, including the precise role of KOR1 in the biosynthesis of cellulose $[20,31]$.

It is reported that $\geq 67$ transferases are involved in pectin biosynthesis $[20,32]$. The presence of potentially covalently linked complexes means that either unidentified transferase activites are present in the cell, or that (some) transferases show promiscuous behaviour towards their substrates. 


\subsection{Impact of planetary ball milling on cell wall polysaccharides}

Whereas the different pectin domains are framed based on well-known alkaline extraction procedures, new methods for polysaccharide extraction were incorporated in this thesis. In chapters 4 and 5, yields for both water and LiCl-DMSO extractions increased after planetary ball milling (further referred to as milling). Reduction of cellulose crystallinity by disruption of $\mathrm{H}$-bonds is believed to be the main effect of milling [33] and the milling intervals used were assumed to create amorphous cellulose. Furthermore the particle size will decrease by milling, increasing the accessibility of the substrate for the solvent.

In this thesis, milling intervals of 15, 45 and 90 minutes were used. As reported in chapters 4 and $\mathbf{5}$, limited depolymerisation of covalent linkages in pure polysaccharides was observed for the milling intervals applied. However, the disrupting effect of milling on other interactions and/or linkages is still poorly understood and not easily studied. Relating solubilised pectin populations to the proposed pectin domains suggested that by water extraction after milling 1) populations connected by adsorption were released and 2) populations entrapped within cellulose microfibrils were released, as depicted in Figure 6.1.2 and 6.1.3. The solubilised pectin populations would be categorised in domains 2 and 3. Although it requires more research to draw unambiguous conclusions on these domains, it clearly shows the potential of solubilising initially insoluble cell wall polysaccharides without loss of structural information.

As discussed before, one of the difficulties in characterising entrapped populations is the lack of a full understanding on cellulose swelling in alkali. Digestion of the alkali residues with endo- + exo-glucanases revealed that for carrot, tomato and strawberry, respectively only $\sim 30 \%, \sim 35 \%$ and $\sim 40 \%$ of all glucose in the $6 \mathrm{M}$ alkali residue was digestible to cellodextrins. This suggests that cellulose retained a part of its initial structure or that extraction by strong alkaline solvents altered cellulose in a way that led to partially inaccessible regions. Alternatively, the inaccessibility of cellulose might be enhanced by removal of pectin and hemicellulose, which might play a role in keeping microfibrils separated. For all explanations, the presence of entrapped populations and the subsequent release of these populations will be affected, releasing not all entrapped populations. Determination of the crystallinity index $(\mathrm{Cl})$ showed that whereas carrot ChUS initially had a $\mathrm{Cl}$ of $35 \%$, the $\mathrm{Cl}$ already decreased to $6 \%$ after milling for 15 minutes. This might suggest that all entrapped populations could be released from microfibrils during extraction. However, also in the residues of water extracted ball milled ChUS, only $\sim 40 \%$ of all cellulose was digested to cellodextrins by endo- and exo-glucanase, suggesting that also after milling cellulose retained some of its initial, inaccessible structure. 
Increasing the milling time decreased the HG:RG-I ratio of the solubilised pectin populations. Similar to previous observations, this confirms that solubilisation of RG-I-rich pectin requires more disruption of the cell wall network compared to HG-rich pectin.

\subsection{Relating LiCl-DMSO soluble pectin to pectin domains}

The combination of planetary ball milling and LiCl/DMSO described in chapter $\mathbf{5}$ was used to extract primary plant cell wall polysaccharides. LiCl-DMSO extractions solubilised up to $50 \%$ of all polysaccharides from ChUS. LiCl-DMSO is predominantly known as a solvent for solubilising cellulose from lignocellulosic biomass, since DMSO will swell cellulose and LiCl will interact with disrupted microfibrils, preventing their collapse [34]. Interestingly, for all sources LiCl-DMSO also solubilised $\sim 30-40$ of all pectin after milling. Furthermore, another $10-40 \%$ of all pectin solubilised in the subsequent buffer extraction, as a pure HG-rich fraction. By categorising LiCl-DMSO and buffer soluble pectin populations in the proposed domains, the same challenges are met as described in previous section. Pectin populations could originate from domains 2 and 3 . In addition, pectin populations extracted by $\mathrm{LiCl}$ DMSO could even originate from domain 4, being strongly connected to cellulose, since a part of the cellulose solubilised in LiCl-DMSO. In order to further understand the origin of these pectin populations, the $\mathrm{LiCl}-\mathrm{DMSO}$ soluble polysaccharides could be subjected to an extraction step using a solvent that would specifically solubilise pectin and yield insoluble cellulose. This would further help in understanding whether pectin and cellulose co-eluted or whether a complex of these polysaccharides was extracted. Similarly, the presence of monosaccharides other than glucose in the residue after milling + LiCl-DMSO extraction might point at interacting pectin, hemicellulose and cellulose populations. However, this requires more research, and more knowledge on the solubility of pectin in LiCl-DMSO.

\subsection{Common features of pectin and xyloglucan domains}

Whereas pectin is not commonly quantified in domains, this approach was previously used for xyloglucan. Pauly et al [28] characterised 3 different hemicellulose domains based on sequential extractions: 1) the xyloglucan-specific (XEG)-extractable domain, 2) the concentrated alkali-extractable domain and 3) the cellulase-extractable domain. The residue was nearly devoid of xylose, indicating that all xyloglucan was extracted in domains 1-3.

Similar to the XG domains described by Pauly et al [28], the pectin domains were also categorised based on accessibility, and extent of interactions with other cell wall polymers. Similar to XG, a part of all pectin is rather accessible, whereas another part is not easily accessible and potentially entrapped or even covalently connected. 
Contrasting to the extractability of xyloglucan, 25\%-65\% (depending on the source) of pectin is easily extracted with water and chelating agent, as discussed for domain 1 in Figure 6.1. With respect to more strongly bound populations, strong alkaline extractions solubilise large parts of xyloglucan. However, the percentage of pectin solubilised by strong alkali solvents as categorised in domain 3 was limited.

Furthermore, contrasting to XG, not all pectin was removed by alkaline and enzymatic extractions. Only half of all pectin was removed from the carrot $6 \mathrm{M}$ alkali residue by digestion with glucanases, and the residue after glucanase digestion was not devoid of pectin. This difference might be partially explained by the different sources of cellulosedegrading enzymes since the commercial cellulases used by Pauly et al [28] might contain several different enzyme activities compared to the purified glucanases used in chapter 3 . However, the differences might also be caused by differences in the type of interactions with cellulose between $X G$ domain 3 and pectin domain 4 .

Finally, the XG domains extracted by XEG and cellulase were not extracted as polymeric XG populations. Extracting polysaccharide populations would allow a more extended characterisation, of e.g. the Mw distribution.

\subsection{Implications of our findings for interactions involved in cell wall models}

The interactions and polysaccharide structures described in chapters 3-5 have implications for the cell wall models of the sources described. Therefore the following section will discuss our findings related to all potential interactions suggested in chapter $\mathbf{1}$, and the findings presented in chapter 2-5.

Covalent glycosidic linkages. Covalent glycosidic interactions were proposed between pectin-cellulose in chapter 3 and pectin-xylan in chapter 4 . This was proposed based on circumstantial evidence that only covalent linkages between cell wall polysaccharides would resist under the experimental conditions tested. It should be mentioned that the involvement of a pectin-xylan cross-link involving ferulic acid was not further studied since the characteristic bathochromic shift linked to ferulic acid [35] was absent upon solubilisation of the tomato water soluble fraction in $0.1 \mathrm{M} \mathrm{NaOH}$.

Adsorption by $\mathrm{H}$-bonds: Analysis of the Mw distribution of several pure polysaccharides showed that after ball milling for 15 minutes, no covalent linkages were degraded yet. The water and LiCl-DMSO extracted populations after planetary ball milling were therefore hypothesized to be primarily solubilised due to disruption of the $\mathrm{H}$-bonds. It was hypothesized that these initially insoluble populations solubilised by both LiCl-DMSO and ball milling due to disruption of these cross-linking $\mathrm{H}$-bonds. 
The most established cross-link in the primary plant cell wall is the adsorption of xyloglucan onto cellulose microfibrils by $\mathrm{H}$-bond based adsorption. Adsorption of pectin and hemicellulose to cellulose is quite extensively studied in vitro [36-38]. Several pectic elements such as arabinan and galactan showed cellulose adsorption, but xyloglucan always showed a much higher adsorption affinity for cellulose than pectic RG-I side chains. Whereas in vitro adsorption experiments using pure substrates are useful to understand potential mechanisms, extrapolating these results to plant cell walls has some drawbacks since in muro more mechanisms are playing a role than in vitro [9]. It was shown that adsorption rates differ significant for the different systems, and that e.g. xylan/xyloglucan to cellulose adsorption rates are different for microcrystalline cellulose (Avicel), bacterial cellulose and isolated plant cell wall cellulose $[11,36]$. Building further on this, it might be hypothesized that using isolated plant cell wall cellulose is the most suitable substrate. However, even in that case it can be questioned how cellulose morphology is affected by the extraction conditions used since obtaining pure, isolated plant cell wall cellulose requires rather harsh (heat, acid, alkali) extractions conditions [11, 12, 39]. Furthermore it was also shown that adsorption rates for xylans were negatively correlated to the degree of substitution [36], indicating the importance of using structurally similar plant cell wall polysaccharides in vitro to understand the cell wall interactions in muro.

Ester linkages: By extraction of pectin using mild alkali, the released pectin populations are suggested to be ester-bound $[4,15]$. As indicated already in 6.4.2, many suggestions on ester-bound pectins lack proof and it is never discussed what type of ester was degraded, e.g. methyl-esterified or acetylated cross-links, uronyl esters [40] or perhaps RG-II boratediol esters [41, 42]. Substantial amounts of cell wall proteins were extracted in mild alkaline conditions (data not shown). Similar to polysaccharides extracted by mild alkali, these proteins might be either adsorbed or ester-linked as well.

Physical entrapment: Physical entrapment is often used in explaining cell wall phenomena, and it indicates that pectin and hemicelluloses become entrapped within cellulose microfibrils during deposition in the cell wall $[28,43]$. Upon swelling of cellulose microfibrils in strong alkaline solvents, physically entrapped populations can be released from microfibrils. It might be speculated that something similar occurs during ball milling, and that entrapped populations were released from crystalline regions by disruption of the $\mathrm{H}$ bonds in these crystalline regions. In this research, it was determined by X-ray diffraction (XRD) that the crystallinity of isolated carrot ChUS was $36 \%$, compared to $75 \%$ for Avicel microcrystalline cellulose. After ball milling for only 15 minutes, the crystallinity of carrot ChUS already decreased to $6 \%$. This indicates the large effect of ball milling on cellulose crystallinity, and enhances the suggestion that entrapped populations might be accessible for solvents after ball milling. 
Molecular crowding: The concept molecular crowding is not that often discussed in relation to cell wall biosynthesis. It indicates that cell wall polysaccharides are present in close vicinity due to molecular crowding, but not necessarily interacting. The importance of molecular crowding effects was studied in Arabidopsis by solid-state NMR [9]. It was shown that $\sim 40 \%$ of all HG was extractable by CDTA and sodium carbonate, indicating that the other $60 \%$ involved in strong pectin-cellulose associations was not involved in molecular crowding. Therefore this partially fits with the model of the co-existing pectin network. Similar hereto, it was discussed by Park \& Cosgrove [22] that the cell wall matrix is a crowded space and the large amounts of pectin may kinetically limit xyloglucan access to cellulose.

\subsection{Challenges in alternative cell wall models}

It was proposed from chapters $\mathbf{3}$ and $\mathbf{4}$ that substantial amounts of pectin in primary plant cell walls are involved in interconnecting polymer networks. These findings correspond with increasing literature of the last 10 years stating that the tethered network model is not the only interconnecting polymer network in the primary plant cell wall $[9,44,45]$. However, a large part of the research was carried out using 7-14-day old Arabidopsis seedlings rather than fully grown plants. Furthermore, percentages of cross-linked populations are rarely quantified, making it more difficult to judge the amount of polysaccharides involved and the relevance of the cross-link indicated. In contrast hereto, we proposed different cross-linked populations in carrot and tomato in chapters $\mathbf{3}$ and $\mathbf{4}$, including quantifications of the percentage of cell wall polysaccharides involved. Both complexes described argue for differentiation in the precise cell wall architecture from source to source, but both also argue for similarities in load-bearing structures other than xyloglucan-cellulose cross-links. Cell walls are divided in Type I and II based on the role of xyloglucan and xylan [46]. In Type I cell walls xyloglucan has a cross-linking role, contrasting to the cross-linking role of xylans in Type II cell walls. Surprisingly, xylan was involved in cross-links in the tomato cell wall. However, dicots are stated to have a Type I cell wall and therefore the proposed pectin-xylan complexes indicate that the classification in Type I or II is perhaps not complete and not yet fully understood.

It is obvious that a large source-to-source variation exists, since the cross-linked complexes described were in both chapter 3 and chapter 4 clearly were present in only 1 of the 3 sources studied. This indicates that it is not so easy to extrapolate our findings, or findings for Arabidopsis thaliana, to an alternative, general model for the entire primary plant cell wall architecture and it shows that source-specific models might be needed. 


\subsubsection{Differences in plant functionality of carrot, tomato and strawberry}

As indicated before, sources were selected based on differences in hemicellulose content. Based on the monosaccharide compositions of the Alcohol Insoluble Solids (AIS) and the Chelating agent Unextractable Solids (ChUS), carrot had lower hemicellulose levels than tomato and strawberry. The cross-link between pectin and cellulose in chapter $\mathbf{3}$ led us to suggest that when pectin takes over the cross-linking, perhaps load-bearing role in the cell wall, the presence of hemicellulose is not necessary. From the perspective of building and maintaining plant strength and functional properties, it is understandable why different polysaccharides and/or cross-links are being formed in the absence of other, more regular polysaccharides. As an example of modified plant cell wall polysaccharides, it was shown that mutations oriented towards $\beta$-galactosidase or rhamnogalacturonan lyase activity in potato pectin led to alterations, or side effects, in the biosynthesis leading to changes in the levels of methyl-esterification and acetylation of pectin [47]. However, the question still remains why each plant synthesizes such different levels of all cell wall polysaccharides. From a plant physiological perspective the difference between the chosen sources is that carrots are roots, whereas tomato and strawberry are the fruits of the plant, containing the seeds. These differences raise the question whether polysaccharide compositions and cross-links are unique for a certain source or type of tissue.

Another source that is high in pectin and grows as root is sugar beet. Similar to carrot, also sugar beets show low xylose levels and have highly acetylated HG pectins [48-50]. However, attempts to show close pectin-cellulose association by solid-state NMR in sugar beet did not succeed [50]. For potato, hemicellulose levels were low as well and HG regions were acetylated, although potato is a tuber rather than a root [47].

A large number of studies on polysaccharide interactions used Arabidopsis thaliana as a model organism. Attempts to relate findings in Arabidopsis to the proposal to study cell wall architecture based on functionality face some difficulties since functionality is difficult to judge from cultured cell lines [24]. Some examples using different sources can be found, although studies are limited. Studies comparing different tissue types are limited, but comparison of 30-d old Arabidopsis root and shoot extracts showed that in both root and shoot extracts xyloglucans with acidic elution behaviour pointed towards pectin-xyloglucan complexes. The complexes were present in different levels and not all sub-populations eluted completely similar, showing differences between the root and shoot extracts studied [51]. 


\subsection{Future perspectives}

Pectin is a major component of the primary plant cell wall, and changes in texture of fruits and vegetables during processing are related to changes in pectin structure. Structural characteristics of pectin are important for both pectins role in the complex primary cell wall architecture and textural changes induced by processing.

In this study planetary ball milling followed by water or LiCl-DMSO extractions was shown as a valuable method for characterising polysaccharide structures without loss of important structural information, while limiting modification. Therefore using milling combined with either water or LiCl-DMSO extraction could aid in a further understanding of the acetylation levels of pectin and hemicellulose from different sources. By choosing rather short milling intervals, milling might also be used as a mild pretreatment to solubilise potentially crosslinked polymer complexes.

Looking at the large differences between sources with respect to the extractability of pectin populations shows that future cell wall models would benefit from source-dependent adaptation, including potential source-dependent structures and interacting polymers. To further determine whether cross-linked polysaccharides are depending on source, functionality of a source, or polysaccharide composition, more sources should be included in similar studies. Alternatively, more complicated, general models including all domains might be created in a qualitative way. This might benefit from avoiding the difficulty of large variations of pectin found in the different domains while still addressing the different levels of association with other cell wall polysaccharides. 


\section{References}

1. Caffall, K.H. and D. Mohnen, The structure, function, and biosynthesis of plant cell wall pectic polysaccharides. Carbohydrate Research, 2009. 344(14): p. 1879-1900.

2. Sila, D., S. Van Buggenhout, T. Duvetter, I. Fraeye, A. De Roeck, A. Van Loey, and M. Hendrickx, Pectins in processed fruits and vegetables: Part II-Structure-function relationships. Comprehensive Reviews in Food Science and Food Safety, 2009. 8(2): p. 86-104.

3. Thakur, B.R., R.K. Singh and A.K. Handa, Chemistry and uses of pectin - A review. Critical Reviews in Food Science and Nutrition, 1997. 37(1): p. 47-73.

4. Brummell, D.A., Cell wall disassembly in ripening fruit. Functional Plant Biology, 2006. 33(2): p. 103119.

5. Hayashi, T., Xyloglucans in the primary cell wall. Annual Review of Plant Biology, 1989. 40(1): p. 139168.

6. Cosgrove, D.J., Growth of the plant cell wall. Nature Reviews Molecular Cell Biology, 2005. 6(11): p. 850-861.

7. Popper, Z.A. and S.C. Fry, Widespread occurrence of a covalent linkage between xyloglucan and acidic polysaccharides in suspension-cultured angiosperm cells. Annals of Botany, 2005. 96(1): p. 91-99.

8. Thompson, J.E. and S.C. Fry, Evidence for covalent linkage between xyloglucan and acidic pectins in suspension-cultured rose cells. Planta, 2000. 211(2): p. 275-286.

9. Wang, T., Y. Park, D.J. Cosgrove and M. Hong, Cellulose-pectin spatial contacts are inherent to neverdried Arabidopsis thaliana primary cell walls: evidence from solid-state NMR. Plant Physiology, 2015. 168: p. 871-884.

10. McCann, M.C. and K. Roberts, Architecture of the primary cell wall, in The Cytoskeletal Basis of Plant Growth and Form C.W. Lloyd, Editor. 1992, Academic Press: London. p. 109-129.

11. Zykwinska, A.W., M.C.J. Ralet, C.D. Garnier and J.F.J. Thibault, Evidence for in vitro binding of pectin side chains to cellulose. Plant Physiology, 2005. 139(1): p. 397-407.

12. Dinand, E., M. Vignon, H. Chanzy and L. Heux, Mercerization of primary wall cellulose and its implication for the conversion of cellulose I $\rightarrow$ cellulose II. Cellulose, 2002. 9(1): p. 7-18.

13. Kalia, S., B. Kaith and I. Kaur, Pretreatments of natural fibers and their application as reinforcing material in polymer composites - a review. Polymer Engineering \& Science, 2009. 49(7): p. 1253-1272.

14. Oh, S.Y., D.I. Yoo, Y. Shin, H.C. Kim, H.Y. Kim, Y.S. Chung, W.H. Park, and J.H. Youk, Crystalline structure analysis of cellulose treated with sodium hydroxide and carbon dioxide by means of $X$-ray diffraction and FTIR spectroscopy. Carbohydrate Research, 2005. 340(15): p. 2376-2391.

15. Renard, C.M.G.C. and C. Ginies, Comparison of the cell wall composition for flesh and skin from five different plums. Food Chemistry, 2009. 114(3): p. 1042-1049.

16. Ralet, M. and J. Thibault, Hydrodynamic properties of isolated pectin domains: a way to figure out pectin macromolecular structure, in Pectins and pectinases, H.A. Schols, R.G.F. Visser, and A.G.J. Voragen, Eds. 2009, Wageningen Academic Publishers: Wageningen. p. 35-48.

17. Vincken, J.P., H.A. Schols, R.J.F.J. Oomen, M.C. McCann, P. Ulvskov, A.G.J. Voragen, and R.G.F. Visser, If homogalacturonan were a side chain of rhamnogalacturonan I. Implications for cell wall architecture. Plant Physiology, 2003. 132(4): p. 1781-1789.

18. De Vries, J., F. Rombouts, A. Voragen and W. Pilnik, Enzymic degradation of apple pectins. Carbohydrate Polymers, 1982. 2(1): p. 25-33.

19. Bonnin, E., C. Garnier and M.C. Ralet, Pectin-modifying enzymes and pectin-derived materials: applications and impacts. Applied Microbiology and Biotechnology, 2014. 98(2): p. 519-532.

20. Atmodjo, M.A., Z. Hao and D. Mohnen, Evolving views of pectin biosynthesis. Annual Review of Plant Biology, 2013. 64: p. 747-779. 
21. Dea, I. and J. Madden, Acetylated pectic polysaccharides of sugar beet. Food Hydrocolloids, 1986. 1(1): p. 71-88.

22. Park, Y.B. and D.J. Cosgrove, Xyloglucan and its interactions with other components of the growing cell wall. Plant and Cell Physiology, 2015: p. 180-194.

23. Sims, I.M., A.M. Gane, D. Dunstan, G.C. Allan, D.V. Boger, L.D. Melton, and A. Bacic, Rheological properties of xyloglucans from different plant species. Carbohydrate Polymers, 1998. 37(1): p. 61-69.

24. Tan, L., S. Eberhard, S. Pattathil, C. Warder, J. Glushka, C.H. Yuan, Z.Y. Hao, X. Zhu, U. Avci, J.S. Miller, D. Baldwin, C. Pham, R. Orlando, A. Darvill, M.G. Hahn, M.J. Kieliszewski, and D. Mohnen, An Arabidopsis cell wall proteoglycan consists of pectin and arabinoxylan covalently linked to an arabinogalactan protein. Plant Cell, 2013. 25(1): p. 270-287.

25. Scheller, H.V. and P. Ulvskov, Hemicelluloses. Plant Biology, 2010. 61(1): p. 263-289.

26. Guerriero, G., J. Fugelstad and V. Bulone, What do we really know about cellulose biosynthesis in higher plants? Journal of Integrative Plant Biology, 2010. 52(2): p. 161-175.

27. Brett, C.T., Cellulose microfibrils in plants: biosynthesis, deposition, and integration into the cell wall. International Review of Cytology, 2000. 199: p. 161-199.

28. Pauly, M., P. Albersheim, A. Darvill and W.S. York, Molecular domains of the cellulose/xyloglucan network in the cell walls of higher plants. The Plant Journal, 1999. 20(6): p. 629-639.

29. Thompson, J.E. and S.C. Fry, Restructuring of wall - bound xyloglucan by transglycosylation in living plant cells. The Plant Journal, 2001. 26(1): p. 23-34.

30. Popper, Z.A. and S.C. Fry, Xyloglucan-pectin linkages are formed intra-protoplasmically, contribute to wall-assembly, and remain stable in the cell wall. Planta, 2008. 227(4): p. 781-794.

31. Endler, A. and S. Persson, Cellulose Synthases and Synthesis in Arabidopsis. Molecular Plant, 2011. 4(2): p. 199-211.

32. Mohnen, D., Pectin structure and biosynthesis. Current Opinion in Plant Biology, 2008. 11(3): p. 266277.

33. Paes, S.S., S. Sun, W. MacNaughtan, R. Ibbett, J. Ganster, T.J. Foster, and J.R. Mitchell, The glass transition and crystallization of ball milled cellulose. Cellulose, 2010. 17(4): p. 693-709.

34. Petruš, L., D.G. Gray and J.N. BeMiller, Homogeneous alkylation of cellulose in lithium chloride/dimethyl sulfoxide solvent with dimsyl sodium activation. A proposal for the mechanism of cellulose dissolution in $\mathrm{LiCl} / \mathrm{Me}_{2} \mathrm{SO}$. Carbohydrate Research, 1995. 268(2): p. 319-323.

35. Rombouts, F.M. and J.-F. Thibault, Feruloylated pectic substances from sugar-beet pulp. Carbohydrate Research, 1986. 154(1): p. 177-187.

36. Kabel, M.A., H. van den Borne, J.-P. Vincken, A.G. Voragen and H.A. Schols, Structural differences of xylans affect their interaction with cellulose. Carbohydrate Polymers, 2007. 69(1): p. 94-105.

37. Vincken, J.-P., A. de Keizer, G. Beldman and A.G.J. Voragen, Fractionation of xyloglucan fragments and their interaction with cellulose. Plant Physiology, 1995. 108(4): p. 1579-1585.

38. Zykwinska, A., J.-F. Thibault and M.-C. Ralet, Competitive binding of pectin and xyloglucan with primary cell wall cellulose. Carbohydrate Polymers, 2008. 74(4): p. 957-961.

39. Dinand, E., H. Chanzy and R.M. Vignon, Suspensions of cellulose microfibrils from sugar beet pulp. Food Hydrocolloids, 1999. 13(3): p. 275-283.

40. Brown, J.A. and S.C. Fry, Novel O-D-Galacturonoyl Esters in the Pectic Polysaccharides of SuspensionCultured Plant Cells. Plant Physiology, 1993. 103(3): p. 993-999.

41. Ishii, T., T. Matsunaga and N. Hayashi, Formation of rhamnogalacturonan II-borate dimer in pectin determines cell wall thickness of pumpkin tissue. Plant Physiology, 2001. 126(4): p. 1698-1705.

42. O'Neill, M.A., S. Eberhard, P. Albersheim and A.G. Darvill, Requirement of borate cross-linking of cell wall rhamnogalacturonan II for Arabidopsis growth. Science, 2001. 294(5543): p. 846-849.

43. Cosgrove, D.J., Expansive growth of plant cell walls. Plant Physiology and Biochemistry, 2000. 38(1): p. 109-124. 
44. Höfte, H., A. Peaucelle and S. Braybrook, Cell wall mechanics and growth control in plants: the role of pectins revisited. Frontiers in Plant Science, 2012. 3(121): p. 1-6.

45. Dick-Pérez, M., Y. Zhang, J. Hayes, A. Salazar, O.A. Zabotina, and M. Hong, Structure and interactions of plant cell-wall polysaccharides by two-and three-dimensional magic-angle-spinning solid-state NMR. Biochemistry, 2011. 50(6): p. 989-1000.

46. Carpita, N.C. and M.C. McCann, Maize and sorghum: genetic resources for bioenergy grasses. Trends in Plant Science, 2008. 13(8): p. 415-420.

47. Huang, J.-H., A. Kortstee, D.C.T. Dees, L.M. Trindade, H.A. Schols, and H. Gruppen, Modification of potato cell wall pectin by the introduction of rhamnogalacturonan lyase and B-galactosidase transgenes and their side effects. Carbohydrate Polymers, 2016. 144: p. 9-16.

48. Oosterveld, A., G. Beldman, H.A. Schols and A.G. Voragen, Arabinose and ferulic acid rich pectic polysaccharides extracted from sugar beet pulp. Carbohydrate Research, 1996. 288: p. 143-153.

49. Renard, C.M.G.C. and J.-F. Thibault, Structure and properties of apple and sugar-beet pectins extracted by chelating agents. Carbohydrate Research, 1993. 244(1): p. 99-114.

50. Renard, C.M. and M.C. Jarvis, A cross-polarization, magic-angle-spinning, 13C-nuclear-magneticresonance study of polysaccharides in sugar beet cell walls. Plant Physiology, 1999. 119(4): p. 13151322.

51. Cornuault, V., I.W. Manfield, M.C. Ralet and J.P. Knox, Epitope detection chromatography: a method to dissect the structural heterogeneity and inter - connections of plant cell - wall matrix glycans. The Plant Journal, 2014. 78(4): p. 715-722. 


\section{Summary}

The aim of this research was to understand the cell wall architecture of carrot, tomato and strawberry, primarily focussed on pectin and its potential interactions with hemicellulose and cellulose. By disrupting potential interactions between cell wall polysaccharides in a targeted way, we aimed at solubilisation of specific polysaccharides and/or complexes of several polysaccharides. Several extractions methods were developed, varying from alternating water-alkali extractions to ball milling followed by water or LiCl-DMSO extractions.

In chapter 1 of this thesis, we introduced the background of this topic. The structural characteristics of plant cell wall polysaccharides are presented, together with an overview of their functional role in the cell wall. Together with a small amount of structural proteins, these polysaccharide build up the primary cell wall. The history and development of cell wall models is discussed. Additionally, literature on cross-links between cell wall polysaccharides and proteins was described. We shortly described the processes related to biosynthesis of the cell wall. Changes occurring during the ripening process are discussed, next to the activity of endogenous pectinases. Finally, the effect of different (enzymatic) modifications on pectin structure is introduced.

Heat processing results in changes in pectin structure, causing softening of carrots. In chapter 2, the effect of heat processing on pectin was studied, showing that the amount of pectin in water soluble solids (WSS) and chelating agent soluble solids (ChSS) increased substantially upon heat processing of the carrots. Pectin in WSS from both unprocessed and heat processed carrot had a degree of methyl-esterification (DM) of $\approx 60 \%$ and a degree of acetylation $(D A)$ of $\approx 20 \%$. Enzymatic degradation with polygalacturonase $(P G)$ and pectin lyase $(\mathrm{PL})$ digested $\approx 33 \%$ of all GalA in the water soluble pectin fractions, but did not release acetylated oligosaccharides. Additional size-based fractionation and digestion of the high Mw material with PG, PL and pectin methyl esterase (PME) released methyl-esterified galacturonic acid oligomers of degree of polymerisation $\geq 6$ carrying acetyl groups.

A randomly de-esterifying fungal PME was not able to allow PG + PL to release acetylated oligosaccharides, whereas a blockwise de-esterifying bacterial PME, potentially more tolerant towards acetylation, allowed PG + PL to be active in highly methyl-esterified, acetylated regions. Mass spectrometry confirmed acetylation in highly methyl-esterified homogalacturonan (HG) regions, next to acetylation in rhamnogalacturonan (RG-I) regions. ChSS HG regions were not acetylated. RG-I levels of both heat processed carrot WSS and ChSS increased compared to unprocessed carrot WSS and ChSS. Digestion of WSS with RG- 
I degrading enzymes showed that WSS arabinan became more accessible upon heat processing resulting in the release of oligosaccharides, while in ChSS galactan became more accessible.

Interactions between plant cell wall polysaccharides were studied in the chelating agent unextractable solids (ChUS), the residue after extraction of water and chelating agent soluble pectin. It was hypothesized that pectin in ChUS was insoluble due to interactions with other cell wall polymers, and these interactions were studied for carrot, tomato and strawberry. In chapter 3 , ChUS was subjected to sequential extractions with $\mathrm{H}_{2} \mathrm{O}$ and alkali. It was shown that water extractions following alkali extractions solubilised small amounts of cell wall polysaccharides as well, suggesting that a small amount of cell wall polysaccharides was released by increasing alkali extraction but not soluble in these alkaline conditions. The $6 \mathrm{M}$ alkali residue still represented $31 \%, 11 \%$ and $5 \%$ of all GalA present in carrot, tomato and strawberry, respectively, and these pectin populations were assumed to strongly interact with cellulose. Digestion of the carrot $6 \mathrm{M}$ alkali residue by glucanases released $\approx 27 \%$ of the $6 \mathrm{M}$ residue, mainly representing pectin. In the presence of hemicellulose, in the $0.1 \mathrm{M}$ alkali residue, glucanases were also able to release high $\mathrm{Mw}$ pectin-cellulose complexes from the carrot cell wall. This showed that hemicellulose was not involved in pectin-cellulose interactions in the carrot cell wall. In tomato and strawberry $0.1 \mathrm{M}$ and $6 \mathrm{M}$ alkali residues, glucanases were not able to release pectin populations. The ability of glucanases to release pectin populations therefore suggests that the carrot cell wall contains unique, covalent interactions between pectin and cellulose.

In chapter 4, ChUS was milled in a planetary ball milling and subsequently water extractions were performed. Using different, rather short milling intervals $(15,45,90 \mathrm{~min})$, for carrot, water soluble pectin yields increased from $4 \%$ to $31-42 \%$ of all insoluble cell wall polysaccharides. For tomato and strawberry, both pectin and hemicellulose were solubilised, and yields based on insoluble cell wall polysaccharides increased from $12 \%$ to $36 \%$ for tomato and from $4 \%$ to $35 \%$ for strawberry. Determination of the molecular weight (Mw) distribution of the solubilised polysaccharides showed homogeneous $\mathrm{Mw}$ distributions for all sources, which was remarkable since for tomato and strawberry both pectins and hemicelluloses were solubilised. In order to study whether the solubilised pectin and hemicellulose populations were interacting, anion exchange chromatography (AEC) was performed. Analysis of AEC fractions showed co-elution of pectin and acetylated glucuronoxylan in tomato, representing $18 \%$ of solubilised uronic acid (75\%) and $48 \%$ of solubilised xylose $(60 \%)$ by ball milling from ChUS. The existence of a covalently linked pectin-xylan complex was proposed since xylan co-precipitated with pectin under mild alkaline conditions. Pectin was composed of both HG and RG-I regions, and it was proposed 
that pectin links with xylan through the RG-I region since degradation of HG did not alter AEC elution patterns for RG-I and xylan, suggesting RG-I - xylan interactions.

In chapter $\mathbf{5}$ we showed the potential of planetary ball milling and subsequent LiCl-DMSO extraction to solubilise up to $50 \%$ of all insoluble cell wall polysaccharides from ChUS without loss of structural information. Approximately $30 \%$ of all pectin was not LiCl-DMSO soluble but solubilised during the subsequent buffer extraction, and these populations were characterised by a higher HG:RG-I ratio than LiCl-DMSO soluble populations. The solubility of pectin in LiCl-DMSO was not studied before, and testing pure, commercial pectins showed that increasing the DM increased the solubility for HG-rich pectin. However, in the fractions extracted from carrot, tomato and strawberry, values reported for DM and DA could not solely explain pectin solubility, suggesting that interactions with other cell wall polymers also determined pectin solubility. Both soluble and insoluble pectin and hemicellulose was highly acetylated, showing the potential of this method to determine the DM and DA of both soluble and insoluble polysaccharides. Digestion of LiCl-DMSO soluble and insoluble fractions by pectinases confirmed the presence of acetylated HG-regions for carrot and strawberry pectin. Furthermore highly acetylated xyloglucan polysaccharides were present in the tomato and strawberry LiCl-DMSO supernatants.

Finally, in chapter 6, we discussed the presented data in relation to existing cell wall models. The disrupting effect of alkaline solvents, ball milling and LiCl-DMSO on polysaccharide interactions was discussed, and based on the extractability of pectin in previous chapters, a division of pectin populations in more and less easily accessible domains was proposed. The findings from chapter $3+4$ suggested that substantial parts of pectin were cross-linked with either cellulose or xylan. However, the presence and levels of these complexes were depending on the source studied, showing the challenge in proposing one, general cell wall model based on the findings in this research. 


\section{Samenvatting}

Het doel van dit onderzoek was om de architectuur van de plantcelwand van wortel, tomaat en aardbei te begrijpen. Hierbij lag de focus voornamelijk op de rol van pectine en potentiele interacties met hemicellulose en cellulose. Door potentiele interacties tussen celwand polysacchariden in een doelgerichte manier te verbreken, hebben we geprobeerd om specifieke polysacchariden en/of complexen van verschillende polysacchariden oplosbaar te maken. Verschillende extractie methoden zijn ontwikkeld, varierend van opeenvolgende water-loog extracties tot malen gevolgd door water of LiCl-DMSO extractie.

In hoofdstuk 1 van dit proefschrift introduceerden we de achtergrond van het onderwerp. De structuur eigenschappen van celwand polysacchariden worden beschreven, naast een overzicht van de functionele rol van deze polysacchariden in de plantencelwand. De celwand bestaat, naast een klein percentage eiwitten, uit deze polysacchariden. De geschiedenis en ontwikkeling van celwandmodellen is bediscussieerd. Daarnaast is de literatuur over potentiele interacties tussen celwand polysacchariden en eiwitten besproken. Het biosynthese proces van de celwand is in het kort beschreven. De veranderingen die plaats vinden tijdens rijping zijn beschreven, en zijn gerelateerd aan de activiteit van natieve pectinases. Tot slot is het effect van verschillende (enzymatische) modificaties op pectine structuren bediscussieerd.

Hittebehandeling resulteert in veranderingen van de pectine structuur. Dit resulteert in het zacht worden van wortels. In hoofdstuk 2 wordt het effect van hittebehandeling beschreven, waarbij gedemonstreerd wordt dat de hoeveelheid water oplosbaar pectine (WSS) en cheleringsmiddel oplosbaar pectine (ChSS) aanzienlijk toeneemt door hittebehandeling van wortels.

Zowel hittebehandeld als onbehandeld pectine had een methyl veresteringsgraad (DM) van $\approx 60 \%$ en een acetyleringsgraad (DA) van $\approx 20 \%$. Enzymatische afbraak met polygalacturonase $(P G)$ en pectine lyase $(P L)$ braken $\approx 33 \%$ van alle galacturonzuur af uit de water oplosbare pectines, maar er werden geen geacetyleerde oligosacchariden vrij gemaakt. Een toegevoegde, op grootte gebaseerde scheidingsstap was voorafgaand aan enzymatische afbraak van het materiaal met een hoog molecuulgewicht met PG, PL en een bacteriele pectine methyl esterase (PME) gedaan. Dit maakte methyl-veresterde galacturonzuur oligosacchariden met een polymerisatiegraad $\geq 6 \mathrm{vrij}$, die geacetyleerd waren. PG + PL afbraak na een willekeurig werkende PME maakte geen geacetyleerde oligosacchariden vrij. Een bloksgewijs werkende PME was echter wel in staat om PG + PL afbraak in hoog methyl-veresterde, geacetyleerde regionen te faciliteren, mogelijk vanwege 
grotere tolerantie richting acetylering. Massa spectrometrie bevestigde acetylering in hoog methyl-veresterde homogalacturonaan (HG) regionen, naast acetylering van rhamnogalacturonaan I (RG-I) regionen. ChSS regionen waren niet geacetyleerd. RG-I gehaltes van zowel hitte behandelde wortel WSS en ChSS stegen ten opzichte van onbehandelde wortel WSS en ChSS. Afbraak van WSS met RG-I afbrekende enzymen demonsteerde dat WSS arabaan toegankelijker wordt door hittebehandeling. Dit resulteert in het vrij maken van oligosacchariden, waar dat voor ChSS voor galactaan geldt.

Interacties tussen celwand polysacchariden waren bestudeerd in de cheleringsmiddel onoplosbare fractie (ChUS). Dit is het residu na extractie van water en cheleringsmiddel oplosbaar pectine. De hypothese was dat pectine in ChUS onoplosbaar was door interacties met andere celwand polysacchariden. Deze interacties zijn bestudeerd in wortel, tomaat en aardbei. In hoofdstuk 3 is ChUS onderworpen aan opeenvolgende extracties met loog en water. Water extracties na loog extracties losten ook kleine hoeveelheden celwand polysacchariden op. Dit suggereert dat een een kleine hoeveelheid celwand polysacchariden wel was vrij gemaakt door loog maar niet oploste in loog condities. Het $6 \mathrm{M}$ loog residu bevatte nog $31 \%, 11 \%$ en $5 \%$ van alle GalA aanwezig in wortel, tomaat en aardbei respectievelijk. De aanname was dat deze pectine populaties sterke interacties met cellulose hebben. Afbraak van het wortel $6 \mathrm{M}$ loog residu door glucanases maakte $27 \%$ van het $6 \mathrm{M}$ residu vrij en dit bestond voornamelijk uit pectine. Glucanases waren ook in staat om pectine-cellulose complexen met hoog molecuulgewicht vrij te maken uit het wortel $0.1 \mathrm{M}$ loog residu, waar hemicellulose nog aanwezig is. Dit laat zien dat hemicellulose niet betrokken is bij pectine-cellulose interacties in de wortel celwand. Glucanases waren niet in staat om pectine populaties vrij te maken uit tomaat en aardbei $0.1 \mathrm{M}$ en $6 \mathrm{M}$ loog residuen. Het vermogen van glucanases om pectine vrij te maken suggereert daarom dat de wortel celwand unieke, covalente interacties tussen pectine en cellulose bevat.

In hoofdstuk 4 is ChUS gemalen in een planetaire kogelmolen (PBM) en vervolgens onderworpen aan waterextracties. Met verschillende korte maalintervallen (15, 45, 90 min) stegen water oplosbare pectine gehaltes van $4 \%$ naar $31-42 \%$ van alle onoplosbare celwand polysacchariden. Zowel pectine als hemicellulose losten op in tomaat en aardbei en de oplosbare pectine gehalten stegen van $12 \%$ tot $36 \%$ voor tomaat en van $4 \%$ tot $35 \%$ voor aardbei. De verdeling van het molecuulgewicht was homogeen voor alle bronnen, en dit was opmerkelijk omdat in tomaat en aardbei zowel pectine als hemicellulose opgelost waren. Mogelijke interacties tussen pectine en hemicellulose populaties zijn bestudeerd met anionen uitwisseling chromatografie (AEC). Analyse van de AEC fracties liet co-elutie van pectine en geacetyleerd glucuronoxylaan zien in tomaat, voor $18 \%$ van al het door malen opgeloste uronzuur (75\%) en $48 \%$ van al het door malen opgeloste xylaan (60\%). De 
aanwezigheid van een covalent gebonden pectine-xylaan complex is gesuggereerd omdat xylaan mee neersloeg met pectine onder milde loog condities. Pectine bestond uit zowel HG als RG-I regionen. Het is mogelijk dat pectine met xylaan linkt door RG-I regionen omdat afbraak van HG de AEC elutiepatronen van RG-I en xylaan niet verandert. Dit suggereert dat er RG-I - xylaan interacties zijn.

In hoofdstuk 5 laten we het potentieel van planetair kogel malen gevolgd door LiCl-DMSO interacties zien door $50 \%$ van alle onoplosbare polysacchariden uit ChUS op te lossen zonder verlies van structuur informatie. Ongeveer $30 \%$ van alle pectine was onoplosbaar in LiCl-DMSO, maar loste wel op in de opvolgende buffer extractie. De HG:RG-I ratio van deze pectine populaties was voor buffer oplosbaar pectine hoger dan voor LiCl-DMSO oplosbaar pectine. De oplosbaarheid van puur, commercieel pectine was niet eerder getest en liet zien dat een hogere DM de oplosbaarheid vergrootte voor HG-rijk pectine. De DM en DA waarden van de geëxtraheerde wortel, tomaat en aardbei fracties konden de oplosbaarheid echter niet verklaren, suggererend dat oplosbaarheid ook door interacties met andere celwand polymers werd bepaald. Zowel oplosbaar als onoplosbaar pectine en hemicellulose waren sterk geacetyleerd en dit demonstreert het potentieel van deze methode om de DM en de DA van zowel oplosbare als onoplosbare polysacchariden te bepalen. De aanwezigheid van geacetyleerde HG regionen in wortel en aardbei is bevestigd na enzymatische afbraak van zowel LiCl-DMSO oplosbare als onoplosbare fracties. Daarnaast waren er sterk geacetyleerde xyloglucanen aanwezig in de LiCl-DMSO supernatanten van tomaat en aardbei.

Uiteindelijk bespraken we in hoofdstuk 6 de gepresenteerde data in relatie met bestaande celwand modellen. Het verstorende effect van loogextracties, kogelmalen en LiCl-DMSO op polysaccharide interacties is besproken. Een verdeling van meer en minder toegankelijke pectine domeinen in de celwand is voorgesteld op basis van de extraheerbaarheid van pectine in eerdere hoofdstukken. De bevindingen uit hoofdstuk $3+4$ impliceerden dat aanzienlijke hoeveelheden pectine in cross-links met cellulose en xylaan betrokken zijn. De aanwezigheid en gehalten van deze complexen waren echter afhankelijk van de bestudeerde bron en dit laat de uitdagingen zien in het opstellen van één overkoepelend celwandmodel gebaseerd op de bevindingen in dit proefschrift. 

Na ruim 4 jaar is het dan zover, tijd om het dankwoord te schrijven, in de wetenschap dat dit het meest gelezen stuk tekst wordt in dit hele boekje. Het is ook het moment waarop je je realiseert dat het nu toch echt bijna klaar is, én het moment waarop je je realiseert dat je dit in je eentje nooit had gered. Bij deze wil ik dan ook de kans grijpen om een hoop mensen te bedanken voor hun bijdrage aan het tot stand komen van dit boekje of voor hun bijdrage aan ontspanning buiten het PhD leven om.

Henk, uiteraard gaat mijn dank allereerst uit naar jou! Allereerst bedankt voor de kans die ik eind 2013 kreeg om na een kort avontuur buiten Wageningen terug te mogen keren. Het startte redelijk soepel met het werk aan alleen pectine, maar het deel van alle celwand interacties ging zeker niet gelijk zo soepel. Het duurde een tijdje voor ik er echt goed in zat en we leerden om kansen te herkennen in de soms onduidelijke bergen resultaten. Jij hield er vertrouwen in dat al dit werk echt wel een keer mooie resultaten op zou gaan leveren. Gelukkig ging het uiteindelijk ook lopen en hadden we een hoop mooie discussies over alle gekke resultaten :-) Vooral op de momenten dat mijn eigen enthousiasme even wat minder was heeft jouw oneindige enthousiasme voor alles wat aan pectine gerelateerd is me enorm geholpen!

Jean-Paul, van xyloglucaan structuren tot mooie fietsroutes, en van enzymen tot restaurantjes rond de veluwe, dank voor al jouw adviezen op werk- en privégebied. In het bijzonder bedankt voor je hulp bij het structureren van het laatste discussie hoofdstuk! Harry, hoewel je niet zozeer betrokken was bij mijn project, heb ik wel een hoop van je kunnen leren en met name de AIO reis naar Japan was een mooie en leerzame ervaring.

Being part of the $\mathrm{FCH}$ family has always been a pleasure! Allereerst natuurlijk dank aan Jolanda voor al je hulp bij praktische zaken, voor de gezelligheid, en voor de altijd goed gevulde snoeppot.

Dank voor de gezellige rondjes aan lunchwandelmaatjes Roy, Emma, Anne \& Renske.

Margaret, René, Peter, Mark \& Edwin, bedankt voor al jullie hulp bij de apparatuur. Margaret, natuurlijk ook bedankt voor alle gezelligheid in Lab 1.04.

Hugo, Matthias, my apologies for my (and my students..) poor sing-along skills. Although our preferences for Qmusic foute uur vs Scooter were somewhat different, I enjoyed our times in the lab and all of your crazy jokes (ghostbuster!).

Yuxi, Renske, Wouter \& Bianca: Thanks for the fun experience of organising a 'perfect' PhD trip!

Gijs, bedankt voor het meedenken en je bijdrage aan het laatste artikel!

Office 1.03 , I started in a ladies office, and it always remained a nice ladies office. Especially the last years it was truly a pleasure to be part of 1.03, where we shared both positive and difficult moments. Sylvia (Junior!), please take care of the future of this wonderful office! 
During my PhD I had the opportunity to supervise several students. Floor, Judith, Vian, Maloe, Renan, Martine and Gijs-Piet, thanks for your contribution. I learned a lot from supervising all of you, and wish you all the best for the future.

Renske, vlak na elkaar gestart, vlak na elkaar klaar, heel veel lunchwandelingen samen en nu allebei gestart met een mooie nieuwe uitdaging. Ik ben blij dat ik dit traject met jou als paranimf afsluit!

Bianca, vanaf het eerste moment hadden we een goede klik en ik ben heel blij dat we de afgelopen jaren zo'n goede vriendschap hebben opgebouwd. Heel fijn dat ik dit traject met jou als paranimf afsluit!

Dat het leven uit meer dan alleen werk bestaat hoefde men mij nooit te vertellen... Het voelt een beetje gek om hier nu een hoop vrienden $\&$ familie te gaan bedanken, maar dat ga ik toch gewoon doen!

Naast het schrijven van dit proefschrift heb ik de afgelopen jaren zo'n $10.000 \mathrm{~km}$ gelopen. Heren en dame van Pallas, dank voor het goede gezelschap tijdens rondjes op de blauwe baan of in de prachtige bossen rond Wageningen. Speciale dank aan JZ voor alle schema's, adviezen \& betrokkenheid.

S.N.O.T.'ers, dank voor de supertoffe Traika weekenden in de Ardennen, Limburg \& Drenthe en de gave trips naar Zurich en Tenerife. Ik kijk alweer uit naar het volgende S.N.O.T. Traika, voor de mooie loopkilometers en de té fanatieke spelletjes met z'n allen!

Dorien \& Heleen, dank voor een hele waardevolle vriendschap die al bijna 20 jaar duurt, en wat mij betreft voortduurt tot in het bejaardentehuis!

Suuz, soms op de racefiets en soms in de kroeg, soms $3 x$ per week en soms 3 weken niet; altijd super gezellig samen, met of zonder onze leuke mannen erbij ;-)

Lies, laten we de oud-Kasjé etentjes \& Lebo-lunches erin houden!

Marlou, de onderschatte kunst van het bijkletsen onder zware intervallen train ik niet meer genoeg nu we niet meer zo heel vaak samen lopen, maar ik ben blij dat we onze loop+koffie bijklets dates wel in stand houden.

Cluppies, Jes in het bijzonder, ik zie jullie toch echt te weinig maar wat is het altijd weer tof om jullie te zien, het is dan gelijk weer zo leuk met $z$ 'n allen!

Kasjé, of de volgende date nu Spice Girls \& GT is, of wat braver lunchen \& bijkletsen, ik kijk er naar uit! 
Pap \& mam, Martin \& Anne, het is nog altijd goed 'thuis' komen in Limburg, en gezellig met $z$ 'n allen! Jullie voorzichtige vragen over hoe het ging en 'of het nog leuk is' hoeven nu niet meer voorzichtig: het is af! Lia, dank voor jouw interesse in de voortgang van het onderzoek $\&$ het enthousiaste meeleven, ook in Apeldoorn is het altijd fijn 'thuis' komen!

Lieve Rob, dank voor je steun de afgelopen jaren, zowel wanneer dingen lukten, maar vooral ook wanneer dingen niet lukten! Ik ben je vooral dankbaar voor de momenten waarop je me kalmeerde, motiveerde, en me vervolgens naar buiten schopte om een rondje te gaan hardlopen... Het leven met jou samen is zo goed, en ik kijk uit naar wat de toekomst ons gaat brengen! 

Suzanne Ester Broxterman was born on February 23 $3^{\text {rd }}, 1988$ in Naarden, The Netherlands. After graduating from secondary school (VWO, Trevianum, Sittard) in 2006, she started her bachelor Food Technology at Wageningen University. Her bachelor study was completed with a thesis on protein-rich particles, encapsulated in water/oil/water emulsions, within the Laboratory of Food Physics. In 2009, she continued with the master Food technology at Wageningen University, with the specialization Ingredient Functionality. After following half a year of courses in Copenhagen,

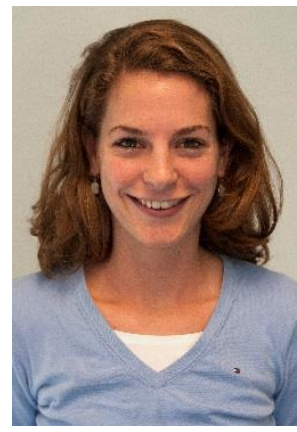
Denmark, she moved to Braband (Arhus), Denmark, to do an internship on the effect of lactase treatment on ice cream properties. After her internship, she did her master thesis at the Laboratory of Food Chemistry on characterisation of the acetylation pattern of sugar beet pectin. In 2012, she obtained her MSc degree. In 2013, she spent one year working as a Product Technologist at Ausnutria Hyproca. From 2014 onwards, she worked as PhD candidate at the Laboratory of Food Chemistry under supervision of Prof. Dr H.A Schols. Part of this research was carried out within the EU-project OPTIFEL: Optimised Food Products for Elderly People. The results of her $\mathrm{PhD}$ research are presented in this thesis. Curently, Suzanne is working as product developer at FrieslandCampina in Wageningen.

Contact: suzanne.broxterman@gmail.com 


\section{List of publications}

Broxterman, S.E., van Erven, G., Schols, H.A. The solubility of primary plant cell wall polysaccharides in LiCl-DMSO. Accepted for publication in Carbohydrate Polymers

Broxterman, S.E., Schols, H.A. Characterisation of pectin-xylan complexes in tomato primary plant cell walls. Carbohydrate Polymers (2018); 197, p269-276

Broxterman, S.E., Schols, H.A. Interactions between pectin and cellulose in primary plant cell walls. Carbohydrate Polymers (2018); 192, p263-272

Broxterman, S.E., Picouet, P., Schols, H.A. Acetylated pectins in raw and heat processed carrots. Carbohydrate Polymers (2017); 177, p58-66

Remoroza C., Broxterman, S.E., Gruppen, H., Schols, H.A. Two-step enzymatic fingerprinting of sugar beet pectin. Carbohydrate Polymers (2014); 108, p338-347 


\section{Overview of completed training activities}

\section{Discipline specific activities}

\section{Courses}

Summer course Glycosciences

VLAG, Wageningen

2014

Advanced Food Analysis

VLAG, Wageningen

$2015^{\mathrm{a}}$

Food and Biorefinery Enzymology

VLAG, Wageningen

2015

\section{Conferences}

$18^{\text {th }}$ Gums and Stabilisers for the

Food Hydrocolloids Trust,

$2015^{a, b}$

Food Industry Conference

Wrexham, UK

$14^{\text {th }}$ Cell wall meeting

Chania, Crete

$2016^{b}$

$5^{\text {th }}$ European Polysaccharide Network

Jena, Germany

$2017^{a}$

of Excellence (EPNOE) meeting

\section{General courses}

Techniques for writing and

WGS, Wageningen

2015

Presenting Scientific Papers

Voice Matters - Voice and Presentation

WGS, Wageningen

2015

Skills Training

Mobilising your Scientific Network

WGS, Wageningen

2015

Philosophy and Ethics of Food

WGS, Wageningen

2016

Science and Technology

Scientific Writing

WGS, Wageningen

2016

Career Perspectives

WGS, Wageningen

2017

\section{Additional activities}

PhD research proposal

$\mathrm{FCH}$, Wageningen

2014

Food Chemistry PhD study trip

FCH, Germany, Denmark,

Sweden, Finland

Food Chemistry PhD study trip

FCH, Japan

$2016^{a, b, c}$

PhD Presentations

$\mathrm{FCH}$, Wageningen

2014-2017

BSc and MSc Thesis Student Supervision

$\mathrm{FCH}$, Wageningen

\footnotetext{
a Poster presentation, ${ }^{b}$ Oral presentation, ${ }^{\mathrm{c}}$ Organizing commitee. Abbreviations: $\mathrm{FCH}$, Laboratory of Food Chemistry; VLAG, The Graduate School VLAG (Advanced Studies in Food Technology, Agrobiotechnology, Nutrition and Health Sciences); WGS, Wageningen Graduate Schools
} 
The work presented in this thesis received funding from the European Union's Seventh Framework Programme for Research, Technological Development and Demonstration under Grant Agreement No. Kbbe-311754 (OPTIFEL) and the Laboratory of Food Chemistry, Wageningen University.

Financial support from Wageningen University for printing this thesis is gratefully acknowledged.

This thesis was printed by Digiforce || ProefschriftMaken

Edition: 250 copies

Cover design by Lia van Tiggelen

Suzanne E. Broxterman, 2018 